\title{
3 Rhetorische Designanalyse
}

\section{Auslegeordnung und Detailanalysen des Untersuchungsmaterials}

\subsection{Ordnungsprinzipien und Elaborationskriterien}

Eine der zentralen Fragen an die Auslegeordnung ist es, nach welchen Kriterien sich das gesammelte Material kategorisieren, gruppieren und bewerten lässt. Die offene Anlage der explorativen Methode führte zu einem unterschiedlichen Vorgehen der beiden Experten, dem teilweise auch andere Bewertungsmaßstäbe und Gewichtungen zugrunde lagen. Obschon die Ausgangspunkte unterschiedlich waren und die Ordnungen während des Auslegeprozesses organisch entstanden, lässt sich am Ende bei beiden Experten und in beiden Gestaltungsbereichen ein vergleichbares Grundordnungsraster erkennen, das folgende fünf Kriterien berücksichtigt (für eine Übersicht der entstandenen Auslegeordnungen siehe Grafiken 1-4 im folgenden Abschnitt):

- Professionalität und Know-how

- Graduelle Aspekte der technischen Ausarbeitung

- Angemessenheit

- Originalität und Konzepthaftigkeit

- Gestalterische Qualität

Professionalität und Know-how: Die Artefakte wurden erstens kategorisiert nach der eingeschätzten Professionalität, also danach, ob es sich bei diesen um «professionell» oder «unprofessionell» bzw. «laienhaft» gestaltete Arbeiten handelt. ${ }^{1}$ Diese erste Klassifizierung bedeutet nicht zwingend eine wertende Unterteilung in «gute» oder «schlechte» Gestaltung, sondern äußert primär die angesichts des Artefakts getroffene Vermutung, dass dieses durch einen Gestaltungsprofi oder durch einen gestalterischen Laien produziert wurde. $\mathrm{Zu}$ den Profis werden dabei Personen gerechnet, die eine gestalterische Ausbildung absolviert haben, d.h. einen Hochschulabschluss in Visueller Kommunikation, Grafikdesign, Kommunikationsdesign oder dergleichen erworben oder eine Polygrafen-, Mediengestalter- oder Grafikerlehre abgeschlossen haben, bzw. die gewerblich als visuelle Gestalterinnen oder Gestalter arbeiten und die ein hohes Know-how im Gestalten offenbaren. Auf dieses vorhandene oder fehlende Fach- und Erfahrungswissen des Urhebers weisen auch Urteile wie «gekonnt», «meisterhaft», «versiert» oder

1 In diesem Kapitel verweisen doppelte Anführungszeichen auf wörtliche Aussagen bzw. Formulierungen der Gestaltungsexpertinnen und -experten. 
im Gegensatz dazu «stümperhaft» oder «dilettantisch» hin - wobei hier durchaus bereits eine Bewertung der gestalterischen Qualität mitschwingen kann.

Technische Ausarbeitung: Eng verbunden mit der Einschätzung von Professionalität und Können sowie ausschlaggebend für die Unterscheidung von Graden der Professionalität und Laienhaftigkeit innerhalb der beiden Hauptgruppen sind zweitens unterschiedliche Grade der technischen Ausarbeitung. Ob die Urheber der Artefakte einen professionellen Hintergrund haben oder nicht, lässt sich für die Experten einzig anhand der wahrnehmbaren Eigenschaften des Kommunikationsmaterials ableiten. Für diese Zuordnung erweisen sich Aspekte der technischen Ausführung als zentral: Wie gut oder mangelhaft ist der Umgang mit Typografie, Satz, Layout? Wie hoch oder niedrig ist die Bildqualität? Wurde das Artefakt aufwändig oder billig produziert? Sind Papier- und Druckqualität hoch- oder minderwertig? Wirkt die Gestaltung «souverän», «solide», «schlicht» und «sauber» oder «simpel», «billig», «handgestrickt», «selbstgebastelt», «lowtech», «rudimentär»? Innerhalb der beiden Hauptkategorien «professionell» und «unprofessionell» wurden Artefakte mit ähnlichen elaborativen Ausprägungen oft zusammen gruppiert oder übereinandergelegt. Diese Gruppen enthalten Hinweise auf typische Elaborationsformen in den jeweiligen Einsatzbereichen.

Trotz des heuristischen Zusammenhangs zwischen einem hohen Elaborationsgrad und der Zuordnung zum professionellen Bereich ist dieser jedoch nicht notwendig. So kann der professionelle Gesamteindruck bestehen bleiben, wenn einzelne Aspekte der Elaboration als niedrig eingestuft werden - oder umgekehrt ein auf einzelnen Ebenen technisch elaboriertes oder hochwertiges Produkt als Laienarbeit eingestuft wird. Professionelle und zugleich handgestrickt oder billig wirkende Beispiele kommen im Untersuchungskorpus verschiedentlich vor. Eine Besonderheit innerhalb dieses Ordnungssystems ist die wahrgenommene «Einfachheit» der Gestaltung, da sie der Tendenz «je elaborierter desto professioneller〉 $\mathrm{zu}$ widersprechen scheint. «Einfachheit» oder «Schlichtheit» wird sowohl auf Laiengestaltung appliziert als auch im Sinne von Schlichtheit als Elaborationsmerkmal professioneller Gestaltung gewertet. Umgekehrt kann gestalterische Komplexität Ausdruck von professionellem Grafikdesign, aber auch von Laiengrafik sein. Hier gilt es genau hinzusehen, ob die Begriffe in unterschiedlichen Bedeutungen verwendet werden oder ob tatsächlich dieselben Formen von Einfachheit bzw. Komplexität für beide Bereiche charakteristisch sein können.

Wo sich Aspekte der hohen und niedrigen Elaboration stark vermischen, wird für die Experten eine klare Zuordnung zur Profi- oder Laiengestaltung unmöglich. Es bildet sich deshalb eine dritte Gruppe der gestalterischen Grenzphänomene oder Mischformen, die sich unter dem Begriff der semiprofessionellen Gestaltung zusammenfassen lässt. Vermutet werden hinter solchen Artefakten ungenügend 
ausgebildete oder zu wenig geübte Grafikdesignerinnen oder Polygrafen, aber auch grafische Autodidakten, die hin und wieder kommerziell oder ehrenamtlich als Gestalter tätig sind. Auch Laien mit einem überdurchschnittlichen gestalterischen Know-how, die mit Profisoftware arbeiten oder moderne Gestaltungssoftware mit vorgefertigten Layouts verwenden, die ihre Arbeiten hochwertig (z.B. im Digitaldruck) produzieren lassen oder professionell gestaltete Elemente (z.B. Profifotos oder -illustrationen) einbinden, fallen in diesen Grenzbereich. Außerdem gilt dies auch für Artefakte, deren Gestaltung - wenn auch erkennbar von Profis gestaltet - in der Ausführung simpel gehalten oder nur wenig elaboriert wurden.

Angemessenheit: Neben der Zuordnung nach Professionalität und technischem Elaborationsgrad wurden die Arbeiten drittens unterschieden nach ihrer Angemessenheit (vgl. Grafik 2). Die Experten gruppierten die Beispiele nach in ihren Augen «gelungener», «stimmiger», «funktionierender», «adäquater», «passender» und somit «angemessener» Gestaltung sowie «ihren Zweck verfehlender», «misslungener» und somit «unangemessener» Gestaltung - manchmal auch lakonisch ausgedrückt durch Wertungen wie «Kann man so machen» oder «Geht so nicht». Ganz im Sinn der Designrhetorik wird die Angemessenheit stets relativ zum jeweils vermuteten Verwendungskontext, Zielpublikum, Thema und Absender bemessen: Das Design ist «passend für das, was es sein will». In dieser Logik ist es möglich, dass nicht nur Profidesign und technisch elaborierte Gestaltung als gelungen und angemessen betrachtet werden kann, sondern auch Laiengestaltung. Umgekehrt kann auch Profigestaltung als unangemessen bewertet werden.

Originalität und Konzepthaftigkeit: Bei der Taxierung der Artefakte spielt viertens eine ganze Gruppe wertender Attribute aus dem Gestalterwortschatz und der Kreativbranche eine Rolle, die teils stärker, teils weniger stark mit der eingeschätzten Angemessenheit korrelieren. Die Palette reicht von positiven Einschätzungen wie «herausragend», «originell», «anregend», «mit einer Idee», «mit Konzept», «durchdacht», über neutrale bis abwertende wie «durchschnittlich», «konventionell», «mittelmäßig», «regelkonform» bis zu klar negativ konnotierten Beschreibungen wie «langweilig», «uninspiriert», «ideenlos» und «konzeptlos». In den Augen des Experten zeichnet sich angemessene Gestaltung auch durch einen höheren Grad an Originalität, Ideenreichtum und Konzepthaftigkeit aus, während aus Sicht der Expertin die Angemessenheit nicht zwingend an diese Bewertungsebenen gebunden ist. Durch die grundsätzliche Entkoppelung der Kriterien wird die Möglichkeit zugelassen, dass ein durchschnittliches oder konventionelles Design als angemessen beurteilt wird, oder der Fall, dass ein originell gestalte- 
tes Artefakt seinen Zweck verfehlt. Je nach Einsatzgebiet und Verwendungszweck kann so mitunter sogar mittelmäßiges Grafikdesign am passendsten sein.

Gestalterische Qualität: Alle verwendeten Kategorisierungsbegriffe stehen schließlich implizit in Zusammenhang mit der gestalterischen Qualität - oder mit 〈Professionalität» in einem umfassenden Sinn. Die Bestimmung «guter», qualitativ hochwertiger (oder «schlechter», qualitativ minderwertiger) Gestaltung umfasst alle vier bisher genannten Kategorisierungsebenen: die Professionalität, den technischen Elaborationsgrad, die Angemessenheit sowie die Originalität und Konzeption eines grafischen Artefakts. Ein Fazit aus der Auslegeordnung ist jedoch, dass die Frage nach gestalterischer Qualität nur bedingt Aufschluss gibt über das untersuchte Material. Denn die Beispiele aus der Lokalpolitik zeigen vor allem den professionellen gestalterischen Durchschnitt, während die Gemeinwesenarbeit stark von Laiengestaltung geprägt ist. Beide Gestaltungsgebiete können deshalb nicht primär an ihrer gestalterischen Exzellenz gemessen werden. Ja, in beiden Bereichen werden gestalterische Höchstleistungen vielleicht sogar mit gutem Grund umgangen. Zwar fiel bei der Betrachtung der Beispiele mitunter das Urteil: «Das ist schlecht gestaltet.» Dennoch wurde die Frage nach Güte, Wert oder Qualität der Gestaltung von den Experten sekundär behandelt und - sozusagen als Gegenbegriff zum gestalterischen Wert - der «Gebrauchswert» in den Vordergrund gerückt. Diese Sicht entspricht einer rhetorischen Perspektive, welche das Resultat im Sinne des Aptum immer relativ zur verfolgten Wirkungsintention, zum Thema, Publikum, Absender und zu weiteren Kontextfaktoren bemisst.

Bei der zum Abschluss der Auslegeordnung getroffenen Auswahl von Artefakten für die Detailanalyse wurde versucht, für die Gesamtheit und Vielfalt des Materials repräsentative und typische Beispiele, aber auch auffällige und eigenständige Arbeiten zu berücksichtigen und aus jeder der drei Hauptgruppen (professionelles Grafikdesign, semiprofessionelle Gestaltung, Amateurgestaltung) jeweils unterschiedlich gelungene Artefakte $\mathrm{zu}$ finden (siehe Grafiken 1-4 im folgenden Abschnitt). Die getroffene Auswahl sollte die unterschiedlichen Elaborationstypen spiegeln, die in den verschiedenen Bereichen vorgefunden wurden und die später gesondert vorgestellt werden (Kap. 4). 



\section{2 Übersicht Auslegeordnungen und Auswahl}

\section{Lokalpolitik}

Fertige Auslegeordnung und Auswahl Experte 1
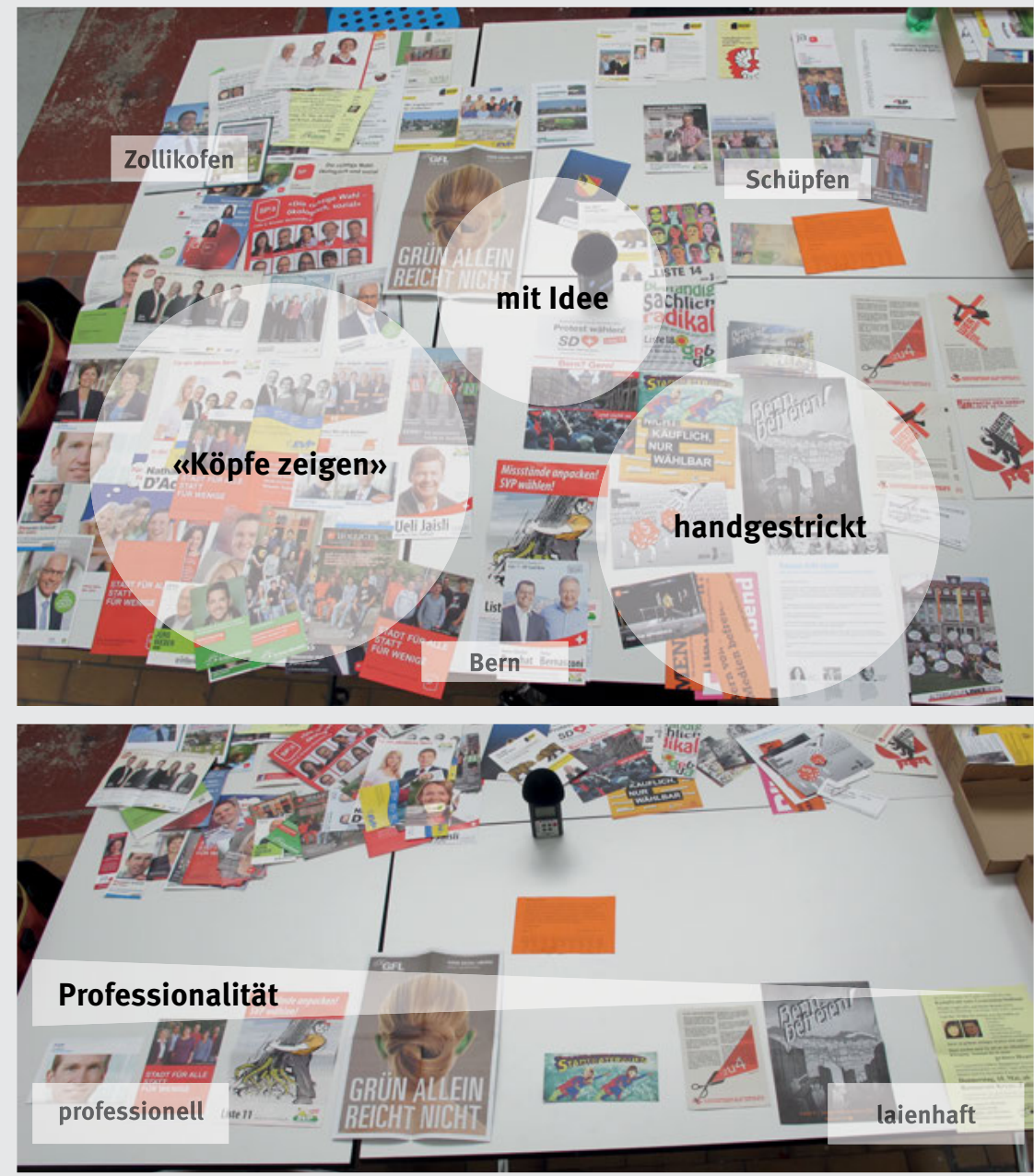

Grafik 1: Übersicht Auslegeordnung und Auswahl Lokalpolitik, Experte 1 


\section{Lokalpolitik}

Fertige Auslegeordnung und Auswahl Experte 2
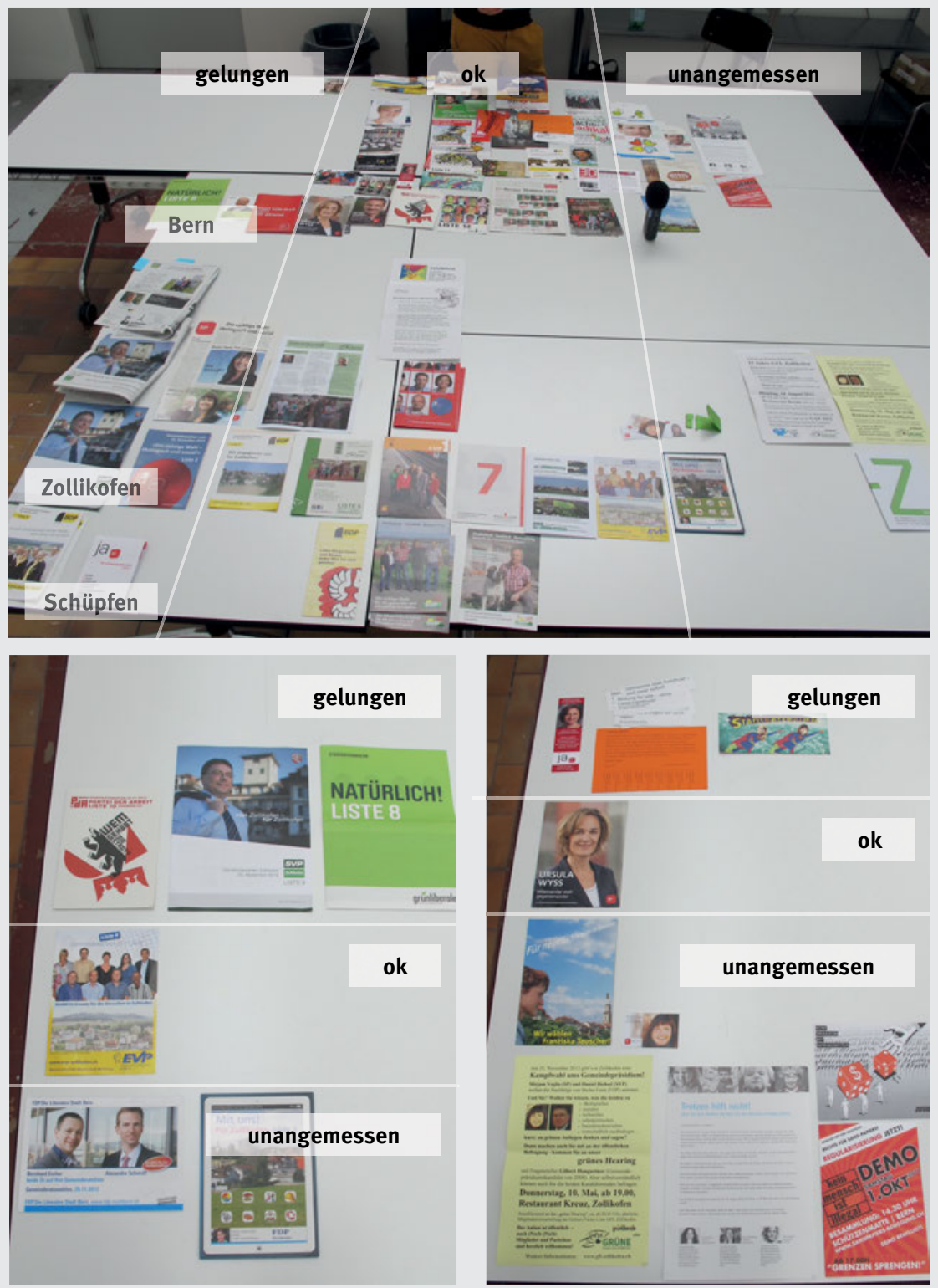

Grafik 2: Übersicht Auslegeordnung und Auswahl Lokalpolitik, Experte 2 


\section{Gemeinwesenarbeit}

Fertige Auslegeordnung und Auswahl Experte 1
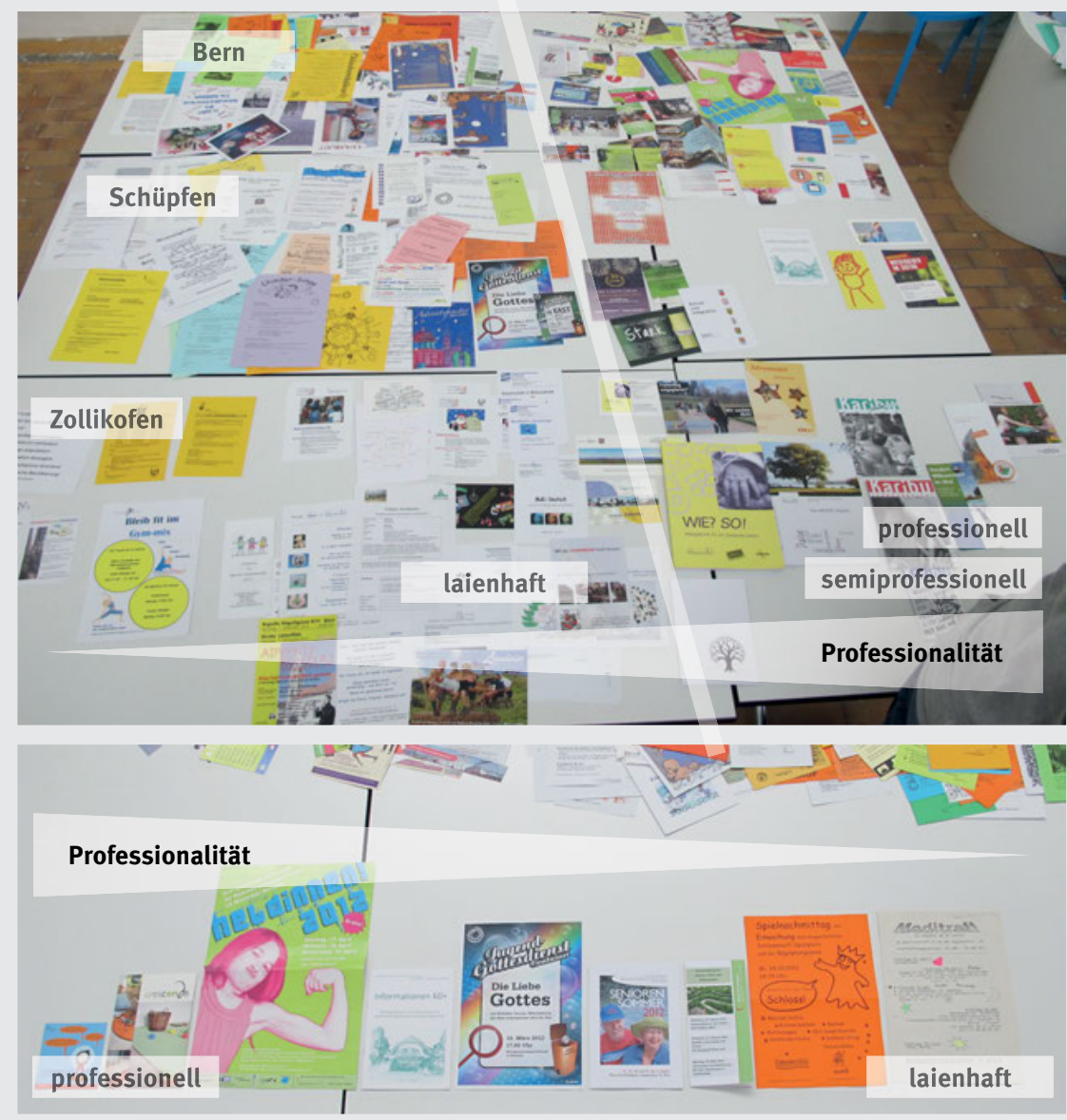

Grafik 3: Übersicht Auslegeordnung und Auswahl Gemeinwesenarbeit, Experte 1 


\section{Gemeinwesenarbeit}

\section{Fertige Auslegeordnung und Auswahl Experte 2}
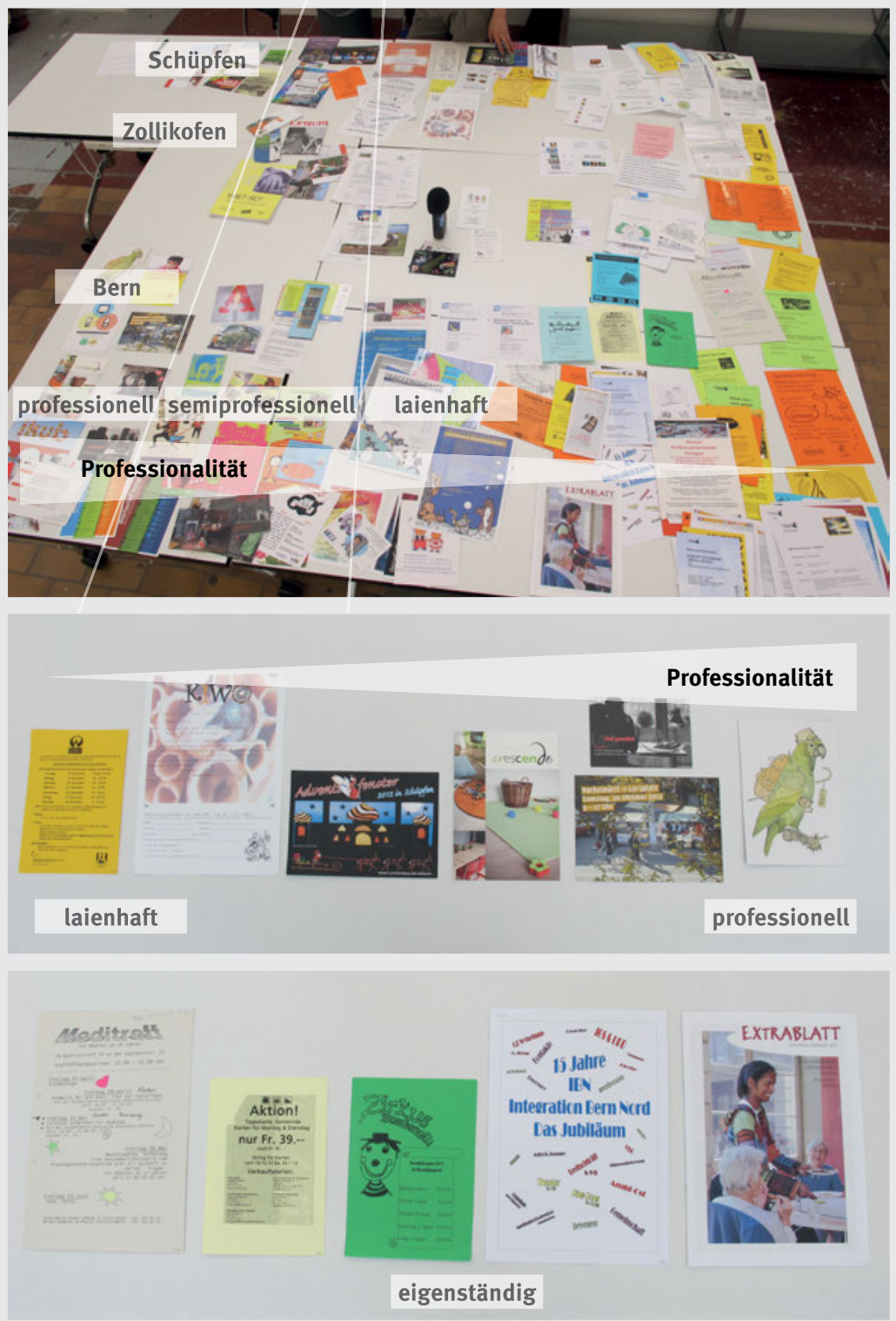

Grafik 4: Übersicht Auslegeordnung und Auswahl Gemeinwesenarbeit, Experte 2 


\subsection{Grafische Gesamtübersicht}

\section{Lokalpolitik}

Übersicht geordnet nach Professionalität
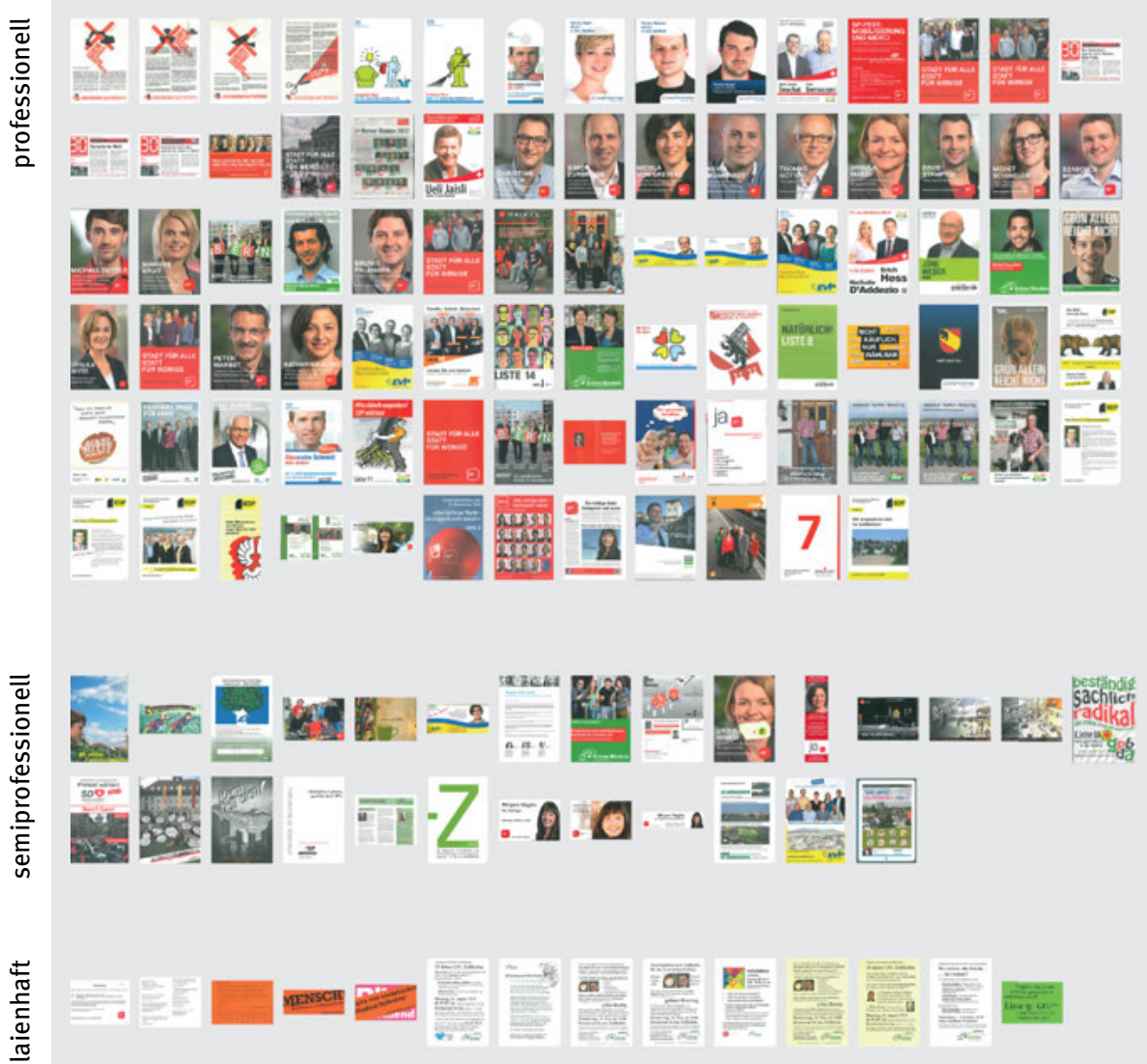

Grafik 5: Grafische Gesamtübersicht Lokalpolitik 


\section{Gemeinwesenarbeit}

Übersicht geordnet nach Professionalität

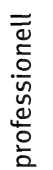

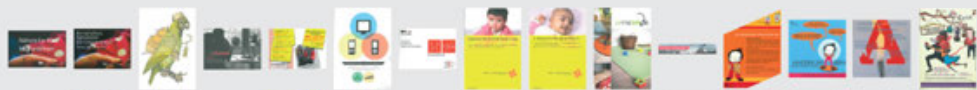

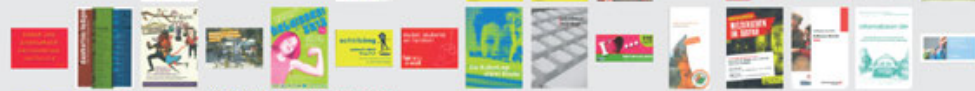
iiin

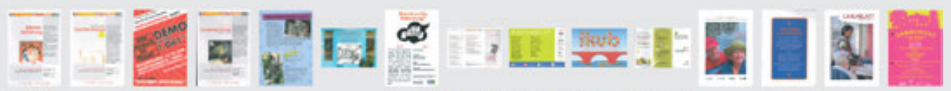

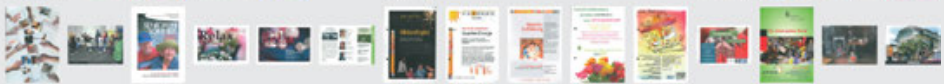

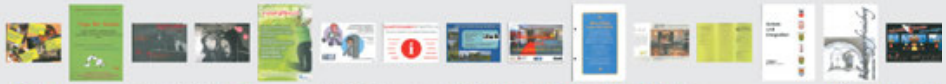

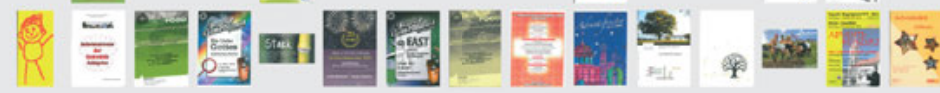
$\rightarrow \quad$ and

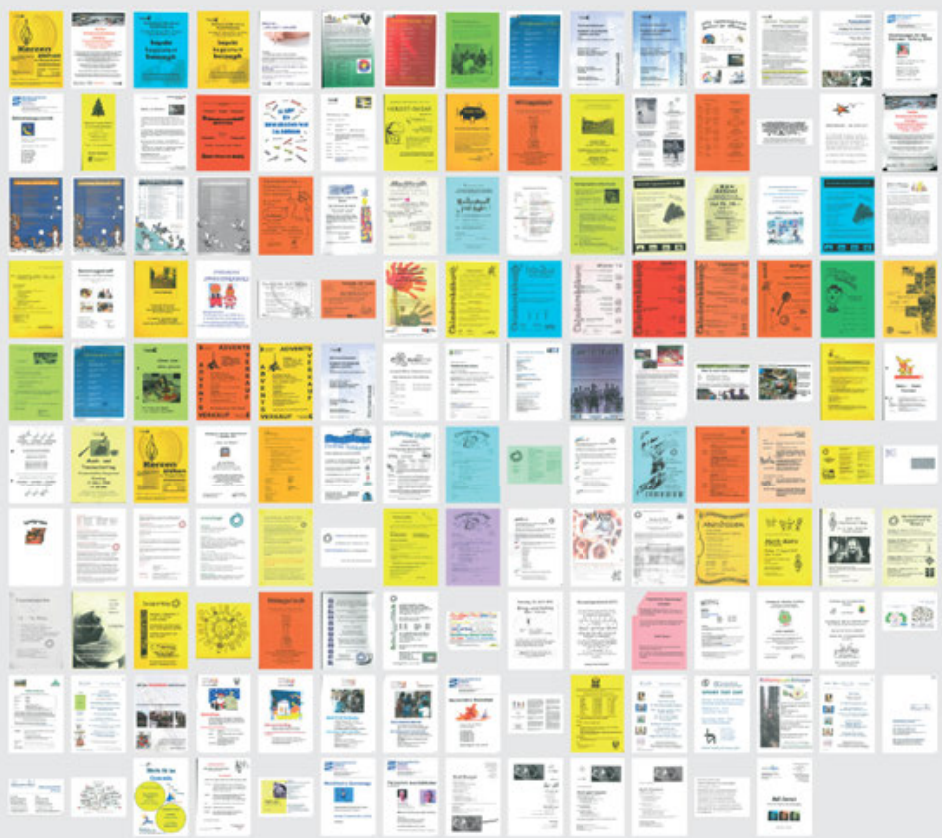

Grafik 6: Grafische Gesamtübersicht Gemeinwesenarbeit 


\subsection{Auslegeordnung Lokalpolitik}

\subsection{1 Überblick über das Material: «Köpfe zeigen` von links bis rechts}

Das gesammelte lokalpolitische Material besteht aus Faltprospekten, Flugblättern und Postkarten mehrheitlich professioneller Herkunft, die für den Wahlkampf zu den lokalen Wahlen in der jeweiligen Gemeinde eingesetzt wurden. Neben den offiziellen Wahlprospekten ist die persönliche Wahlwerbung für einzelne Kandidierende am häufigsten, vereinzelt wurden auch Wahlzeitungen, Veranstaltungshinweise oder Informationszettel zu politischen Sachthemen in Umlauf gebracht. In der Gesamtschau zeigt sich das untersuchte Material aus allen drei politischen Gemeinden erstaunlich homogen. In Aufmachung, Anmutung und Tonalität sind die gesammelten Beispiele oft austauschbar. Besonders die offiziellen Wahlprospekte, welche jeweils den per Post versandten Wahlunterlagen beigelegt werden, gleichen sich stark. Das in ihnen erkennbare Gestaltungsprinzip ist das «Zeigen von Köpfen» - Porträtaufnahmen der Kandidierenden -, welches das Gesamtbild dominiert (siehe Abb. 26-28). Ein Großteil der Wahlkampfkommunikation wurde ganz in der Weise des «klassischen Wahlprospekts» gestaltet, wie er in einer gesamtschweizerischen gestalterischen Tradition seit den 1970er, spätestens 1980er Jahren vorkommt: Neben Porträtfotos mit Kurzinformationen zu allen zur Wahl stehenden Personen findet sich auf dem Prospekt ein Gruppenbild der Kandidierenden, das vor einer zum Parteiprogramm passenden Kulisse aufgenommen wird, sowie ein Wahlslogan oder getexteter Aufhänger.

Eingebettet werden diese Elemente in das jeweilige Corporate Design der Partei und oftmals wird auf Hochglanzpapier gedruckt. Zwischen Stadt, Agglomeration und Land lassen sich dabei keine markanten Unterschiede feststellen. Obgleich mehrheitlich von Profis gestaltet, wirken die Artefakte in der Regel «mittelmäßig», «durchschnittlich», «uninspiriert» bis «dilettantisch». Konzeptlosigkeit überwiegt. Wo originellere Gestaltungsformen gewählt werden, wirken diese oft «gesucht», «hilflos», «unpassend» bis «misslungen». Kleinere Parteien weichen eher von der Norm ab und greifen öfter $z u$ «handgestrickten» Gestaltungsmitteln. In allen drei Gemeinden leistet sich die lokalpolitische Kommunikation auch immer wieder gestalterische Fehler und Unsauberkeiten. Am häufigsten bemerkt werden von den Experten kleinere bis grobe Abweichungen von den Gestaltungsvorgaben (Corporate Design) der kantonalen oder nationalen Parteien. Mängel in der Ausarbeitung wie etwa in der Farb- und Bildqualität, typografischen Ausführung oder Materialität kommen bei Laien- wie auch Profigestaltung vor. Typische Laienfehler, z.B. fehlendes Raster oder mangelhafte Tonwertangleichung bei Fotos, finden sich in den gestalterischen Eigenleistungen einzelner Kandidaten oder in selbst gemachten Veranstaltungshinweisen. 

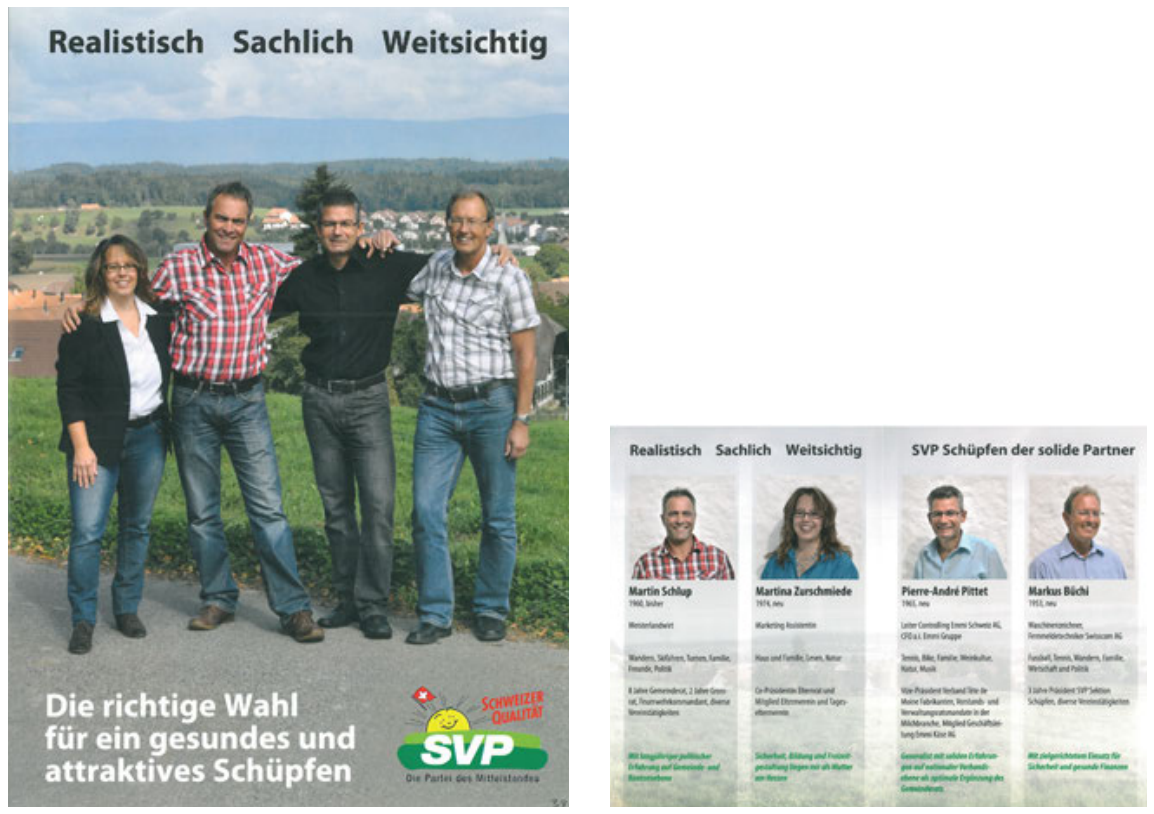

Abb. 26: Wahlprospekt SVP Schüpfen.
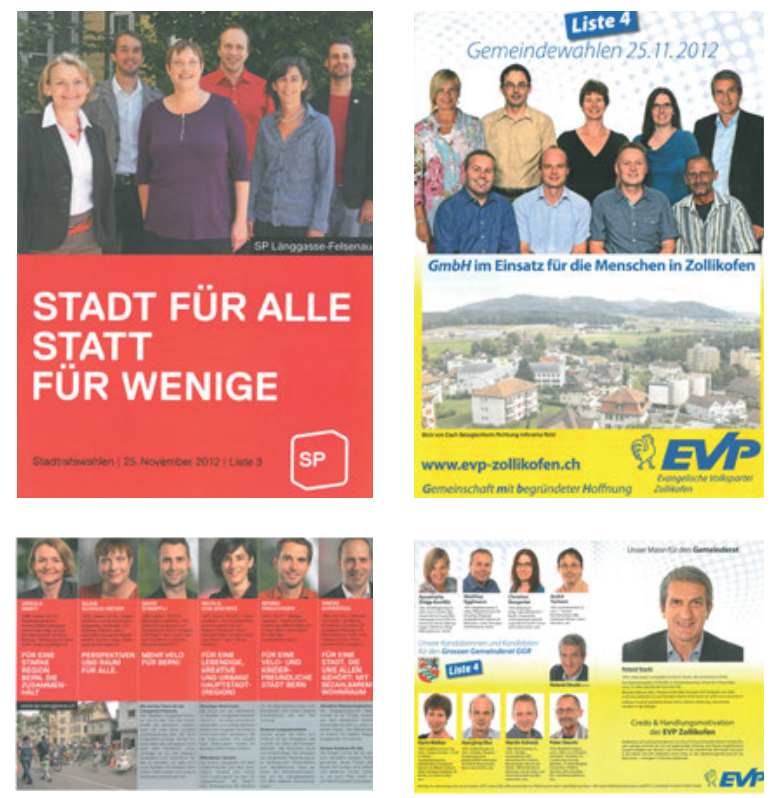

Abb. 27: Wahlprospekt SP Länggasse- Felsenau.

Abb. 28: Wahlprospekt EVP Zollikofen. 


\section{Gemeindewahlen 2012 \\ FdU Forum der Unabhängigen}

Einsatz für ein wohnliches Zollikofen

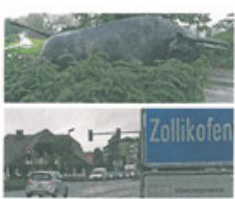

Seit 44 Jahren sozial-liberales Wirken mit besonderer Berücksichtigung der Umwelt

Wir werden uns für den Erhalt dieser grünen Lungen einsetzen

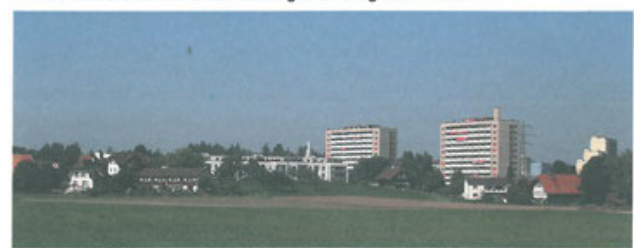

Der ūberregional historisch wertvolle Landstuhl muss erhalten bleiben. Die Grünen haben im GGR bereits eine Motion zur Einzonung eingereicht.

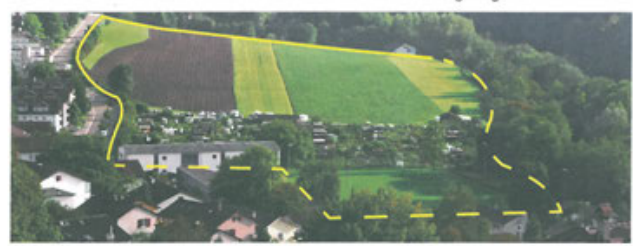

Die Steinibachmatte wurde 1991 dank unserer Volksinitiative ausgezont,

mit Schaffung einer Zone für Familiengärten und Sport (Fussballfeld).

Der Gemeinderat und die Grünen haben ihre Absichten zur Einzonung kundgetan.

Listen Nr.1 Gemeinderat und Grosser Gemeinderat

FdU Forum der Unabhängigen Vereinigung der Parteilosen

Abb. 29: Wahlprospekt Forum der Unabhängigen Zollikofen.

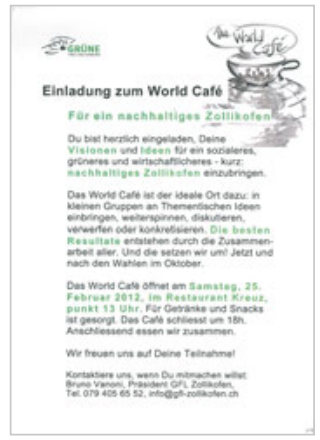

Abb. 30: Veranstaltungseinladung Grüne Freie Liste Zollikofen.

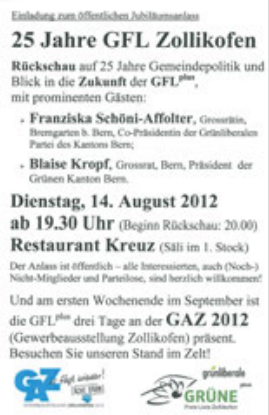

Abb. 31: Jubiläums-

einladung Grüne Freie Liste Zollikofen. 


\subsubsection{Zum Verhältnis von Amateur- und Profigestaltung: Das professionelle Mittelmass}

Rund zwei Drittel der insgesamt rund 130 Artefakte aus der lokalpolitischen Kommunikation - insbesondere die offiziellen Wahlprospekte - wurden von den Experten als Profiarbeiten identifiziert. In der Stadt sind für die Straßen- und Briefkastenwerbung der einzelnen Kandidierenden auch professionell, einheitlich und gemäß Corporate Design-Vorgaben gestaltete persönliche Postkarten beliebt (z.B. SP B 214, GFL B 210, GB B 208, GLP B 207, JFDP B 131). ${ }^{2}$ Selbst auf Gemeindeebene scheint sich die Meinung durchgesetzt $\mathrm{zu}$ haben, dass professionelle Gestaltung eher zum Wahlerfolg führt als selbstgemachte. Auffallend ist jedoch, wie wenige der Arbeiten als hochprofessionell eingeschätzt werden, weder in Bezug auf Originalität, Besonderheit oder Konzeption noch auf die gestalterische Qualität insgesamt. Es überwiegt der professionelle Durchschnitt, das gestalterische Mittelmaß, manifestiert in Form des klassischen Wahlprospekts (z.B. SVP S 387, Abb. 26; EVP Z, 364, Abb. 28, siehe auch Detailanalyse, SP B 213, Abb. 27), an den sich auch die individuelle Kandidatenwerbung anlehnt (z.B. SVP S 389, Abb. 32; SP Z 118, EVP B 201). Diese Gestaltungsform erfreut sich im ganzen politischen Spektrum und in allen drei Gemeinden großer Beliebtheit. Konzeptionell durchdachte Beispiele und grafische Arbeiten, die auf einer inhaltlichen oder formalen Idee aufbauen, bilden die - tendenziell eher städtische - Ausnahme (z.B. GFL B 238, Abb. 42; BERN4 B 248). Die Art und Weise der Gestaltung deutet darauf hin, dass die Wahlmaterialien nicht durch Agenturen, sondern eher durch kleinere, lokal angesiedelte Grafikbüros gestaltet wurden. Besonders in der Agglomeration werden verschiedentlich Polygrafen bzw. Druckereien als Urheber vermutet (z.B. EVP Z 364, Abb. 28, siehe auch Detailanalyse, BDP Z 365, FDP Z 366, Abb. 40).

Verschiedene Beispiele reichen in den Grenzbereich der semiprofessionellen Gestaltung hinein. Diverse Spezialanfertigungen einzelner Kandidierender für die Straßenkommunikation enthalten gestalterische Unsauberkeiten (Typografie, Layout, Tonwerte, Druckqualität), die in einer Profiarbeit nicht vorkommen sollten. Zu nennen sind hier etwa der Flyer von Franziska Teuscher (GB B, 127, Abb. 46), die als Buchzeichen originell und zum Portfolio der Kandidatin passend gestaltete Wahlwerbung von Katharina Altas (SP B, 217, Abb. 47) oder ein eben-

\footnotetext{
2 Das Untersuchungskorpus wurde zur eindeutigen Identifizierung fortlaufend durchnummeriert. Die in Klammern genannten Zahlen stehen für einzelne Beispiele aus dem Untersuchungsmaterial, die Parteikürzel benennen die jeweilige Absenderpartei bzw. das Wahlbündnis. Im Anhang befindet sich eine Auflistung mit einer Miniaturansicht aller Artefakte aus dem Korpus, geordnet nach Herkunftsort (B - Bern, Z - Zollikofen, S - Schüpfen), Bereich (LP - Lokalpolitik, GWA - Gemeinwesenarbeit) und Identifikationsnummer.
} 
falls als Lesezeichen konzipiertes sowie zwei in Form von Visitenkarten gestaltete Kommunikationsmittel von Mirjam Veglio (SP Z, 115-117, Abb. 48). Ein Mischphänomen ergibt sich auch dort, wo die professionell vorgefertigten Postkarten von den Kandidierenden wiederum mit einer individuellen Note versehen werden, bevor sie auf der Straße oder in Briefkästen handverteilt werden (z.B. durch eine angeheftete Minischokolade, SP B 215 oder eine handgeschriebene Ergänzung, EVP B 166). Sowohl die genannten semiprofessionellen Spezialanfertigungen als auch die Beispiele mit persönlicher Note wurden zur Bewerbung von weiblichen Kandidierenden eingesetzt. Dies könnte ein Hinweis darauf sein, dass Frauen mehr Wert auf eine individuelle Ansprache legen als auf die Professionalität der Kommunikationsmittel. In der Stadt finden sich zudem diverse Wahlprospekte stärker links oder rechts orientierter Kleinparteien, die mit Amateurelementen arbeiten, bei denen der Anteil echter Laienarbeit jedoch nicht abschließend bestimmbar ist. Beispiele sind etwa die dilettantisch wirkenden Illustrationen und Schriftzüge, die den Wahlprospekt und die Postkarten der Jungen Alternative zieren (oder verunzieren) (JA! B 250, siehe auch Detailanalyse, 221, Abb. 44; 222), oder die nachträglich unfachmännisch ins Gruppenbild collagierten Sprechblasen, gesetzt in der bei Laien beliebten Schrift «Comic Sans〉, auf dem Prospekt der Alternativen Linken (AL B 240, Abb. 43). Zu nennen ist hier aber auch der sehr krude gelayoutete Prospekt der Schweizer Demokraten (SD B 228). Bei diesen Beispielen ist allein aufgrund der Erscheinung, also aufgrund ihrer designrhetorischen Qualitäten, nicht zu erkennen, ob die «handgestrickte» Anmutung gezielt eingesetzt wurde oder mangels finanzieller Mittel oder gestalterischen Knowhows ohne Absicht entstanden ist.

Offensichtliche Amateurgestaltung («Wordgestaltung») kommt nur vereinzelt, jedoch verteilt auf alle drei Gemeinden vor, so etwa die allgemeinen Informationen der SP Schüpfen (SP S 394), verschiedene Guerilla-Aktionen der Jungen Alternative Bern (JA! B 219, 223, siehe auch Detailanalyse, 225, 226) sowie die selbst für den Laienbereich auffallend dilettantisch gestalteten Veranstaltungshinweise der Grünen Freien Liste Zollikofen (GFL Z 103-110, Abb. 30 und 31, zu 108 siehe Detailanalyse). Der einzige offizielle Wahlprospekt, der laut Expertenmeinung ganz aus Laienarbeit resultiert (wenn auch im Offsetdruck hergestellt), ist jener des Forums der Unabhängigen Zollikofen (FdU Z 362, Abb. 29).

\subsubsection{Vergleich Stadt, Agglomeration und Land: Ländlicher Konformismus und urbane Originalitätssuche}

Die Unterschiede in der Gestaltungsweise der untersuchten lokalpolitischen Kommunikation zwischen Stadt, Land und Agglomeration sind nicht auffallend. 
In der Gesamtschau ist ihre visuelle Erscheinung durchaus vergleichbar. Ein deutlicher Unterschied ist in Bezug auf die Menge erkennbar, was jedoch auf die variierende Anzahl involvierter Parteien und Kandidierender in den drei Gemeinden zurückzuführen ist. Während sich in der ländlichen Gemeinde Schüpfen im Wahljahr 2012 nur gerade drei Parteien am Wahlkampf beteiligten, waren es in der Agglomerationsgemeinde Zollikofen immerhin neun und in der Stadt Bern sechzehn Parteien. In den kleineren Gemeinden stellten sich außerdem weniger Kandidatinnen und Kandidaten pro Partei zur Wahl. Durch die besondere «Kampfwahl» zwischen rechts und links (SVP versus SP) um das Gemeindepräsidium in Zollikofen war die kommunikative Aktivität neben der offiziellen Wahlkommunikation in dieser Gemeinde - insbesondere von Seiten der Herausforderin SP - außergewöhnlich groß. In Schüpfen, wo die Konkurrenzsituation weniger virulent war (BDP versus SVP), blieb die Menge an außeroffiziellem Material überschaubar. In der Stadt scheint die Ergänzung der offiziellen Parteiprospekte durch Kandidatenwerbung am geläufigsten zu sein. Auch Parteibündnisse oder Listenverbindungen und Quartiersektionen sorgen mit eigenen Wahlzeitungen, Prospekten und Flyern in der Stadt für zusätzliches visuelles Kommunikationsmaterial (z.B. Bern4 B 162, Bürgerliches Bündnis B 243, Abb. 33; Mitte-Liste B 242, SP Holligen B 168, 169, 218). Durch die schiere Anzahl der Akteure und die größere Bandbreite der Parteienlandschaft ist in der Stadt auch eine größere Vielfalt in der visuellen Gestaltung auszumachen. Diese geht mit häufigeren Abweichungen vom Standardwahlprospekt einher und mit einer größeren Anzahl von Prospekten, die eine eigene gestalterische Idee umzusetzen versuchen. Aus den genannten Gründen wirkt das Angebot in der Stadt heterogener, lauter und «wilder». In seiner Gesamtheit jedoch wird das Material von den Experten auch im Stadtgebiet als auffallend konventionell bezeichnet. Jene Beispiele, die vom gewohnten Bild abweichen, sind untereinander oft wieder vergleichbar. So ähnelt etwa der «selbstgebastelt» wirkende Prospekt der Exotenpartei Forum der Unabhängigen in Zollikofen (FdU Z 362, Abb. 29) jenem der Randpartei Junge Alternative Bern (JA! B 250, Abb. 45, siehe Detailanalyse).

Von Stadt bis Land wird gerne das klassische visuelle Schema angewendet, sich im angestammten Umfeld zu präsentieren - je nach Partei eher in der Natur, vor einem öffentlichen Verkehrsmittel oder einem Geschäftshaus. Auf der Ebene der Abbildungen machen die Kommunikationsmaterialien so auch deutlich, ob man sich auf dem Land, in der Stadt oder der Agglomeration befindet. Sind in Schüpfen etwa Bauernhaus und Hofhund (SVP S 389, Abb. 32), Wald und Wiese (SVP S 387, Abb. 26; BDP S 392) oder Holzstapel (SP S 385, Innenseite) zu sehen, zeigen sich die Kandidierenden in Bern beispielsweise vor einem modern verglasten Bürohaus (Bürgerliches Bündnis B 243, Abb. 33) oder am S-Bahnhof (SP $B$ 218). In der Vorortsgemeinde Zollikofen ist die auf der Wahlwerbung gezeigte 


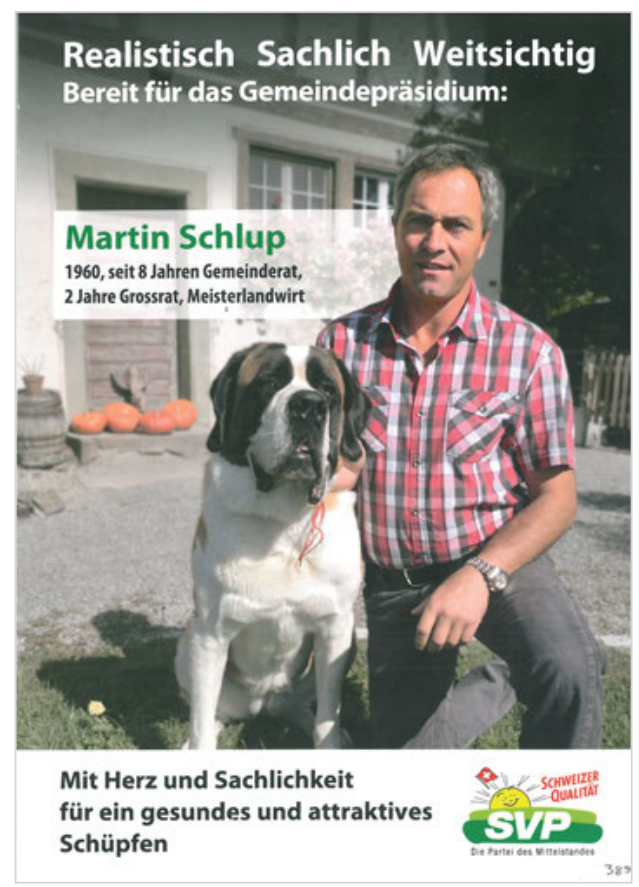

Abb. 32: Wahlprospekt SVP Schüpfen.

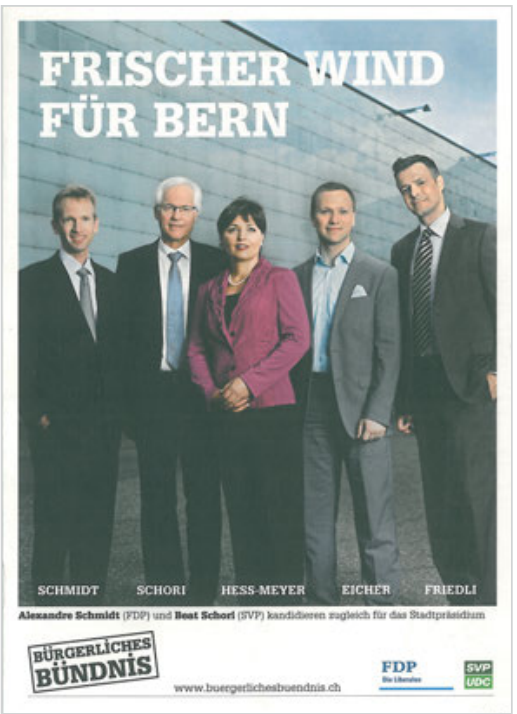

Abb. 33: Wahlprospekt Bürgerliches Bündnis Bern. 
Umgebung aus einer Mischung von Einfamilienhäusern, Hochhäusern, Wiesen und Bäumen zusammengesetzt (BDP Z 365, FdU Z 362, FDP Z 366, Abb. 40; EVP Z 364, Abb. 28). Erstaunlich war für die Experten zu sehen, welch unterschiedliche Handschriften die Wahlmaterialien derselben Partei in den drei Gemeinden teilweise tragen. Dies deutet darauf hin, dass jeweils unterschiedliche Gestaltungsbüros am Werk waren. Im Direktvergleich zwischen jenen Parteien, die in Stadt und Umgebung vertreten sind, lässt sich erkennen, dass die Gestaltungsrichtlinien der Partei in der Agglomeration weniger konsequent umgesetzt sind (z.B. FDP B 245 und FDP Z 366, Abb. 40; SP B 247 und SP Z 120). In puncto Formate sind in der Stadt neben Prospekt, Faltblatt und Flyer der Postkartenflyer und die Wahlzeitung sehr beliebt, welche beide außerhalb der Stadt nicht vorkommen. Außerdem wurden neben der Papierform zahlreiche bedruckte «Give-Aways` wie Taschentücher, Pins, Kugelschreiber, Haftnotizzettel, Schleckstängel oder Kekse verteilt (außerhalb des Korpus). In der Agglomeration kommen nur wenige Spezialdrucksachen wie Visitenkarte, Los oder Buchzeichen vor, auf dem Land fehlen solche Sonderformen gänzlich. Überhaupt beschränkt sich die politische Kommunikation in der Landgemeinde fast vollständig auf die klassisch gestalteten offiziellen Wahlprospekte und die im selben Stil und Format gestalteten Kandidatenflyer für das Gemeindepräsidium.

Auf eine Formel gebracht lässt sich festhalten: Auf dem Land wird am häufigsten und ohne gröbere Fehler die gestalterisch risikoarme Form des klassischen Wahlprospekts gewählt. In der Stadt kommen die meisten von der Standardform abweichenden, aber auch die meisten «gesucht» originellen Aktionen vor. Gleichzeitig werden hier die gestalterischen Vorgaben der Mutterparteien generell am besten umgesetzt. In der Agglomeration wirken die Wahlmaterialien am wenigsten inspiriert und finden sich die stärksten Abweichungen von den Gestaltungsvorgaben der Partei. Laiengestaltung kommt in Stadt, Land und Agglomeration nur vereinzelt vor. Die vorgefundenen Laienartefakte wiederum lassen eher Rückschlüsse auf die Aktivität einzelner Akteure zu als auf ihre städtische oder ländliche Herkunft. 


\subsubsection{Elaboration und Angemessenheit: Hohe Anforderungen an etablierte Parteien, «Narrenfreiheit` für Parteien am Rand}

Der Anteil der Artefakte, die als professionell eingestuft werden, überwiegt in der untersuchten lokalpolitischen Kommunikation deutlich. Worin unterscheiden sich die vorgefundenen Profiarbeiten jedoch in ihrem Elaborationsgrad und in ihrer Angemessenheit? Wie sich in der Analyse zeigte, sind Beispiele für rundum gelungene, hochprofessionelle lokalpolitische Kommunikation dünn gesät, und zwar sowohl auf Stadt-, Agglomerations- als auch ländlicher Ebene. Als überzeugende Beispiele ragen die Wahlprospekte der SVP Zollikofen (SVP Z 361, Abb. 35) und der Grünliberalen der Stadt Bern (GLP B 235, Abb. 34) heraus. Nicht durch eine spektakuläre, sondern eine solide, seriöse und schlichte Gestaltung hebt sich der SVP-Prospekt von der ansonsten «wenig engagierten» Gestaltung in der Agglomerationsgemeinde ab. Der Prospekt repräsentiert die bürgerliche Bodenständigkeit der Partei und verzichtet auf die gewohnt populistische Aufmachung. Der Kandidat, der für das Gemeindepräsidium zur Wahl steht, wird großformatig und gekonnt in Szene gesetzt: Weitblick, selbstbewusstes Lächeln, das Sakko locker zum Aufbruch über die Schulter gelegt; im Hintergrund wird der lokale Bezug sichtbar, lenkt aber dank verringerter Tiefenschärfe nicht vom Hauptmotiv $\mathrm{ab}$ - dies alles sorgt dafür, dass der Kandidat siegessicher und gelassen daherkommt. Ob der tatsächliche Erfolg der Kandidatur auf diese positiven Merkmale des Wahlprospekts zurückgeht, muss hier dahingestellt bleiben. Dem GLP-Prospekt wiederum gelingt es, durch formale Reduktion inmitten der mit Bildern und Parolen überladenen städtischen Flut von Wahlmaterialien aufzufallen. Der Prospekt kommt ruhig und zugleich erfrischend daher. Auf der Vorderseite wird konsequent auf ein Bildmotiv verzichtet und ganz auf die Wirkung von Farbe und Schrift sowie die Aussagekraft des knappen Slogans «Natürlich» gesetzt. Auch innen bleibt formale Reduktion Programm. Die Professionalität wird von den Experten insgesamt bei jenen Arbeiten am höchsten eingestuft, die «einfach», geradlinig («straight») und mit einer gewissen Zurückhaltung gestaltet wurden.

Auch etliche der nach klassischem Vorbild gestalteten Wahlunterlagen, wie etwa der Wahlprospekt der BDP Schüpfen (BDP S 392, siehe Detailanalyse) oder die Flugblätter der Quartiersektionen SP Bern (SP B 213, Abb. 27; 167), erfüllen ihren Zweck in den Augen der Experten gut, obschon - oder vielleicht auch gerade weil - sie die altbekannten formalen Merkmale aufweisen und die Seherwartungen des Publikums bedienen. Als wichtiges Kriterium in der Beurteilung der Angemessenheit der Artefakte gilt nämlich auch, dass diese klar und deutlich als Wahlmaterialien bzw. als politische Kommunikationsmittel erkennbar sind. Dieses 〈Erkennen als〉 wird dem Betrachter bei jenen Beispielen, die sich an der 


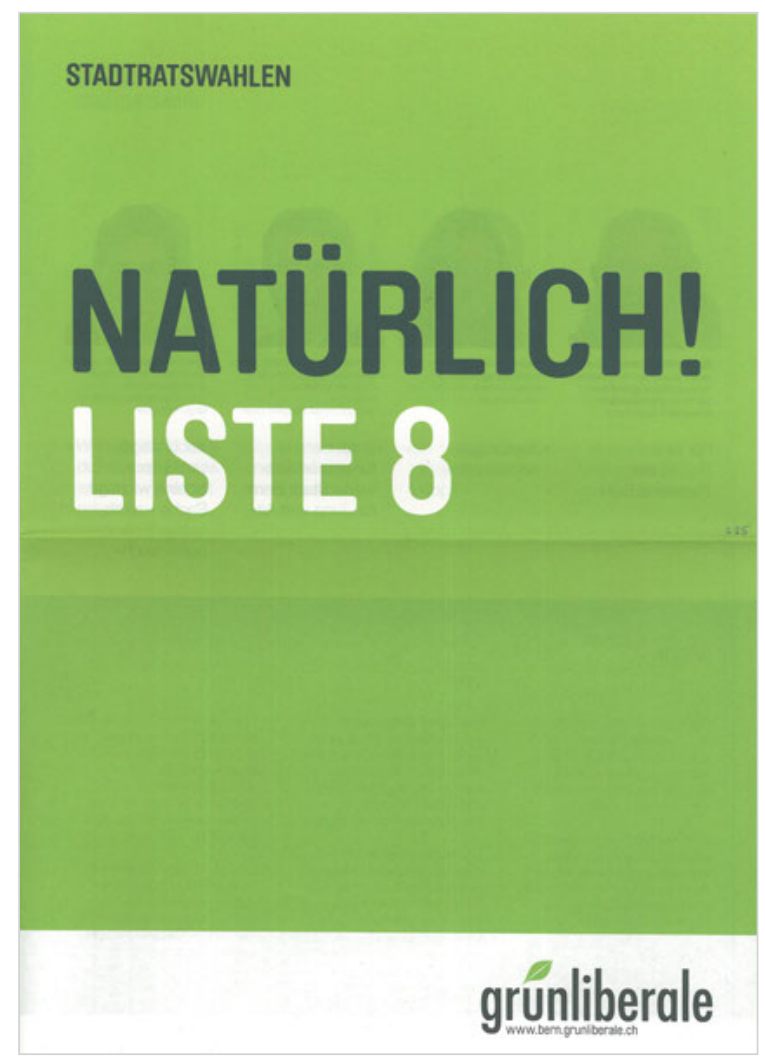

Abb. 34: Wahlprospekt Grünliberale Bern GLP.

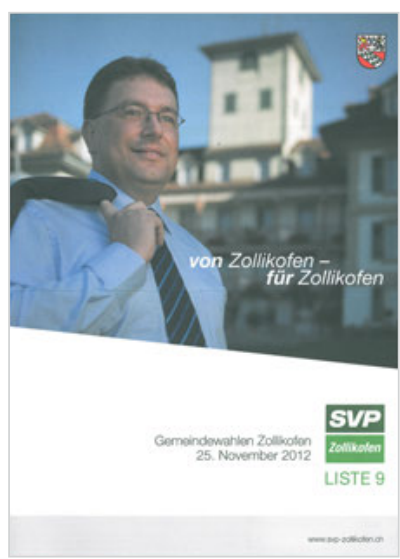

Abb. 35: Wahlprospekt SVP Zollikofen. 
klassischen Wahlprospektgestaltung orientieren, deutlich erleichtert. Gleichzeitig soll die beworbene Partei und deren politische Gesinnung rasch erkennbar sein - was gerade bei größeren Parteien mit der Verwendung des parteiinternen Corporate Design verbunden ist: Neben den explizit festgeschriebenen Vorgaben zu Schrift, Farbe und Logo trägt die gesamte visuelle und materielle Erscheinung und Bildsprache zur Konturierung eines spezifischen Partei-Images bei. Zudem sollte das Material auch über verschiedene Werbemittel hinaus einheitlich gestaltet sein, damit es rasch wiedererkennbar ist. Dies umfasst die gewählten Formate sowie die Papier- und Druckqualität. Je origineller und ausgefallener die Gestaltung wirken will und je stärker eine eigenständige gestalterische Idee verfolgt wird, desto eher verschwindet dahinter jedoch die Corporate Identity des Absenders.

Der Großteil der professionellen lokalpolitischen Kommunikation jeder politischen Couleur wird immerhin noch als gestalterisch «korrekt», «ok», «durchschnittlich» oder «passabel» beurteilt. Grundkriterien sind hier einerseits verschiedene Standards der technischen Ausarbeitung wie Übersichtlichkeit, Klarheit, saubere Typografie und Hierarchisierung der Textelemente sowie eine ausreichende Qualität der Fotografie und Reproduktion. Von Bedeutung für die Angemessenheit ist andererseits die Übereinstimmung der Gestaltung mit der Partei, ihrer politischen Botschaft und Zielgruppe. Diese Grundanforderungen erfüllen aus Expertensicht eine Mehrheit der klassisch gestalteten Wahlprospekte aus der Agglomeration (z.B. BDP Z 365, CVP Z 363), vom Land (SP S 385, SVP S 387, Abb. 26) und aus der Stadt (EVP B 203, CVP B 230) sowie verschiedene Wahlbroschüren aus der Stadt, die vom klassischen Prospekt abweichen (z.B. JFDP B 237, Abb. 38; SVP 246, Piratenpartei B 236, Abb. 39).

In der Gesamtschau fällt auf, dass sich selbst bei professionellen Umsetzungen erstaunlich viele Abweichungen von den Corporate-Vorgaben der Mutterpartei finden lassen. Es ist nicht immer zu erkennen, ob die eigentlich verbindlichen gestalterischen Richtlinien zu wenig ernst genommen wurden, ob das gestalterische Know-how für ihre Umsetzung fehlte oder ob sie bewusst umgangen wurden, weil sie den Bedürfnissen der Lokalparteien oder dem Selbstbild von Einzelmitgliedern zu wenig entsprachen. Auf einen bewusst «hemdsärmeligen» Umgang mit den Parteivorgaben deuten diverse Abweichungen von den Gestaltungsvorgaben der Sozialdemokratischen Partei in den Wahlmaterialien der SP Zollikofen hin (SP Z 115-121): Vielfach fehlen die vorgegebenen großen Rotflächen, die Hausschrift mit den eingängigen, in Versalien gesetzten 〈Headlines〉 wird ganz weggelassen und das Material kommt über die verschiedenen Wahlmaterialien hinweg uneinheitlich daher. Im offiziellen Wahlprospekt (SP Z 119) dominiert auf der Vorderseite ein blauer Himmel und im Innern sind zahlreiche stilfremde Elemente 


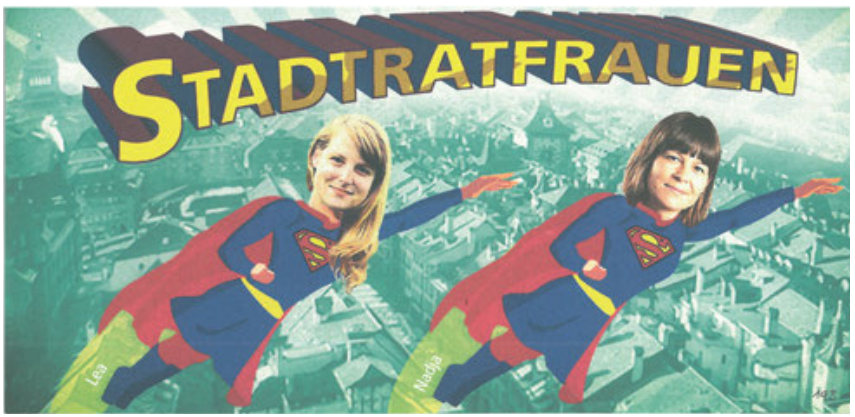

Abb. 36: Wahlflyer «Stadtratfrauen», SP Bern.
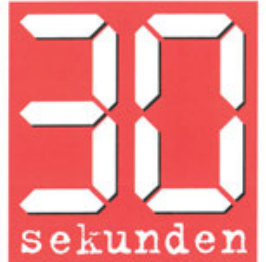

WoCit 44 12. NovemeER 2012

Bern

Thema

Wo wohnen in der Stadt Bern?

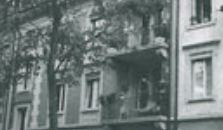

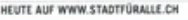

\begin{tabular}{|c|}
\hline Gemeinderatswahlen: Liste Bern' - \\
\hline für konstruktive Politik im Gemeinderat! \\
\hline
\end{tabular}

\section{Suchst du noch oder} wohnst du schon in Bern?

BERN. Im Lindenhof geboren, in der Länggasse gross geworden. WG in der Lorraine. Loge im Breitenrain. Verliebt, verlobt verheiratet. Zusammen gezogen. in die Agglo gezogen, Kinder erzogen. Job in der Stadt, Shoppen in der Stadt, Kultur in der Stad. Pendeln satt, zurück in die Stadt. Wohnungsinserat. Altstadt - etwas zu gewagt. Ostring - wollen kein Kind. Kirchenfeld - dafur hast du kein Geld Weissenstein wirklich fein, aber zu klein Gute

Lagen, schŏne Lagen, nicht za bezahlen. Hoffen, fragen schau. en, nicht verzagen. Wohnung gesucht, Wohnung gefunden, nicht geheuer. Weiter gesucht, wieder gefunden, aber zesucht, wieder gefunden, aber zu teuer. Immer noch suchen, immer noch inserat. Aber leider nicht in der Stadt Du hast die Agglo echt nicht gern! Aber wo wohnen in Bern? dst

Für bezahlbaren Wohnraum in Bern: SP wählen!

Abb. 37: Wahlflyer «30 Sekunden`, SP Bern.

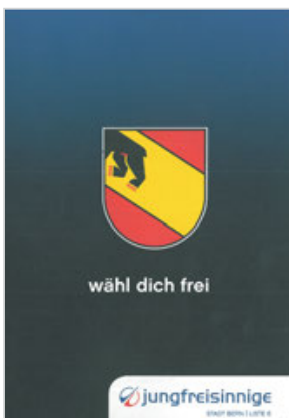

Abb. 38: Wahlprospekt Jungfreisinnige Bern.

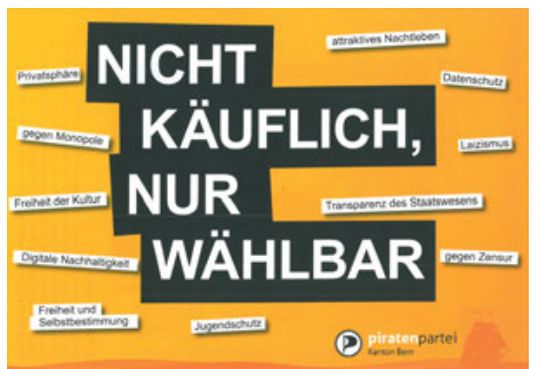

Abb. 39: Wahlprospekt Piratenpartei Bern. 
wie stempelartige Aufdrucke oder eine mit Stecknadel fixierte, in Pseudohandschrift verfasste Haftnotiz zu finden. Diese abweichenden, dekorativen Elemente erscheinen spontan eingefügt und sollen vermutlich eine «persönlichen Nuance» in die kühle Corporate-Welt der SP hineinbringen. Obschon keine stringente visuelle Sprache verwendet wird, könnte diese Eigenständigkeit der Lokalpartei, zusammen mit den selbstgemacht erscheinenden Elementen, engagiert wirken und Sympathien bei den Wählerinnen und Wählern wecken. Man zeigt, dass die Lokalpartei nicht einfach eine Kopie der Mutterpartei ist. Gezielt in Richtung Abgrenzung von der Stammpartei scheint der bereits erwähnte Prospekt der SVP Zollikofen (SVP Z 361, Abb. 35) zu gehen. Indem das ältere, schlichte SVP-Logo (anstelle des aktuellen volkstümlichen Parteilogos mit der Sonne), eine professionelle Fotografie, reduzierte Gestaltung und ein wertiges, ungestrichenes Papier (anstelle von dünnem Hochglanzpapier) gewählt wurde, hebt sich das Produkt vom Image der Zürcher SVP ab. Das bäuerisch-unreflektierte Bild, das diesem Parteiflügel anhaftet, wird gekonnt umgangen, um stattdessen eine zur Berner SVP passende bürgerlich-bodenständige Haltung auszudrücken.

Umstritten ist bei den Experten die Frage, wie weit Abweichungen von den gestalterischen Vorgaben der jeweiligen Partei zulässig sind. In der Stadt werden die Vorgaben im offiziellen Wahlmaterial sowie bei der Bewerbung der wichtigsten Kandidierenden sorgfältiger eingehalten als außerhalb, wie sich etwa bei der SP zeigt (z.B. offizieller Wahlprospekt, SP B 247; Kandidat für Gemeindepräsidium, SP B 249 und Kandidatin für Gemeinderat, SP B 212). Doch etliche der außeroffiziellen Materialien derselben Partei interpretieren das Corporate Design frei oder umgehen es ganz (z.B. die Wahlzeitungen «Holligen Zytig», SP B 168, 169 und «30 Sekunden〉, SP B 138-140, Abb. 37; und der Flyer «Stadtradfrauen〉, SP B 143, Abb. 36). Teils werden die abweichenden Exemplare als «selbstgebastelt», aber «sympathisch», teils aber auch als zu weit weg von der Partei oder als «angestrengt» bewertet. Besonders selbstgemacht oder wie von Hand hinzugefügt wirkende Stilelemente außerhalb des Corporate Design können - wie wir dies bereits im Fall der SP Zollikofen gesehen haben - als Versuche gelesen werden, die Leute stärker persönlich anzusprechen, etwa durch das Setzen von Text in einer Pseudohandschrift (z.B. CVP Z 363, Rückseite) oder eine Leuchtstiftmarkierung (gleich beide Elemente verwenden die Wahlprospekte der BDP Schüpfen, BDP S 390-392). Ähnliches gilt für unorthodoxe Formen und Formate wie Visitenkarte, Buchzeichen, Haftnotiz oder Steckbrief. Diese individuellen Noten müssen jedoch in das Gesamtgefüge integriert werden, da sie sonst als irritierend oder gar als Fehler wahrgenommen werden könnten - so etwa die Leuchtstiftmarkierungen, die aussehen wie Schlieren (BDP S 390), oder die selbstgebastelten Fotocollagen (AL B 240, Abb. 43). Gerade beim offiziellen Wahlmaterial sollte aus Expertensicht die Erkennbarkeit der Absenderpartei im Vordergrund stehen. 
Neben den überdurchschnittlichen bis passablen Beispielen findet sich im Profibereich auch eine Vielzahl von Arbeiten, die stärker in der Kritik stehen, weil sie gestalterisch fehlerhaft oder unsauber ausgeführt sind oder das Aptum nicht einhalten. Gerade die Suche nach einer originellen oder eigenständigen gestalterischen Form führt in der professionellen lokalpolitischen Kommunikation immer wieder zu fragwürdigen Resultaten, sei es weil die gestalterische Idee gesucht oder hilflos wirkt, der Zusammenhang zwischen Gestaltung, Inhalt und Absender verloren geht oder das Resultat gar nicht mehr als politische Kommunikation erkennbar ist. Gestalterische Originalität und Eigenständigkeit sind in der lokalpolitischen Kommunikation nach Einschätzung der Experten nicht zwingend erforderlich und das Streben danach führt in vielen Fällen zu unpassenden Resultaten. Bei manchem Beispiel wird die Anstrengung, etwas Originelles zu gestalten, regelrecht spürbar, doch wirkt die Idee am Ende weder originell noch scheint sie in ersichtlichem Zusammenhang mit der Absenderpartei zu stehen, wie etwa die Handy-Analogie auf dem Wahlprospekt der FDP Zollikofen (FDP Z 366, Abb. 40) oder die Illustrationen im «Keith Haring-Stil» der FDP Bern (FDP B 233, Abb. 41; 128, 129). Gar widersprüchlich erscheint der Zusammenhang zwischen Ausgestaltung und politischer Gesinnung beim Prospekt des Bürgerlichen Bündnisses (Bürgerliches Bündnis B 243, Abb. 33): Recycling-Papier, 〈Egyptienne`-Schrift und der hohe Grünanteil deuten auf eine grüne, linke und jüngere Partei hin. Aber auch wo ein Zusammenhang ersichtlich ist, kann dies kontraproduktiv sein: «Hilflos» bis «ungewollt komisch» wirkt etwa das Gemüse in den Händen der Kandidierenden des Grünen Bündnisses Bern (BG B 209), das vermutlich deren grüne Politik unterstreichen soll; «allzu banal» bis «anbiedernd» erscheint der «Andy Warhol-Filter» über den Abbildungen der Jungsozialisten Bern (JUSO B 231), der wohl Jugendlichkeit und «Pepp» vermitteln möchte.

Ein komplexeres gestalterisches Konzept vor Augen hatten offenbar die Gestalter der Grünen Freien Liste Bern: Die Wendung «Grün hinter den Ohren` aus dem Volksmund wird hier in metaphorischer Umkehrung fotografisch umgesetzt und provokativ mit dem Slogan «Grün allein reicht nicht` in Bezug gesetzt (GFL B 238, Abb. 42). Bei den Jungfreisinnigen Bern wird der Wahlslogan «Wähl dich frei originell durch einen Bären visualisiert, der aus dem Berner Wappen läuft (JFDP B 237, Abb. 38), und die SVP Bern setzt eine ausdrucksstarke metaphorische Bildsprache ein, um die eigene Haltung auszudrücken (SVP B 246). Ganz zu überzeugen vermögen besonders zwei dieser Beispiele jedoch nicht. Die von der SVP visuell umgesetzte Baummetapher, bei der die Baumwurzeln für Missstände stehen, die beseitigt werden sollen, ist nicht stimmig: Der Baum ist ein positiv besetztes Symbol und wer Bäume ausreißt, zeigt sich zwar als stark, gilt heutzutage aber vermutlich selbst in den Augen der anvisierten Wählerschaft als Grobian. Beim zum Plakat ausfaltbaren Prospekt der Grünen Freien Liste Bern gelingt die visuelle «Entmeta- 


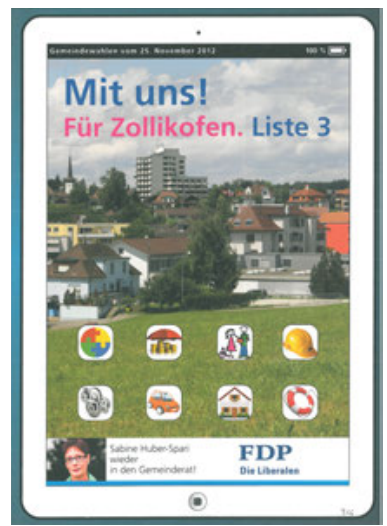

Abb. 40: Wahlprospekt FDP Zollikofen.

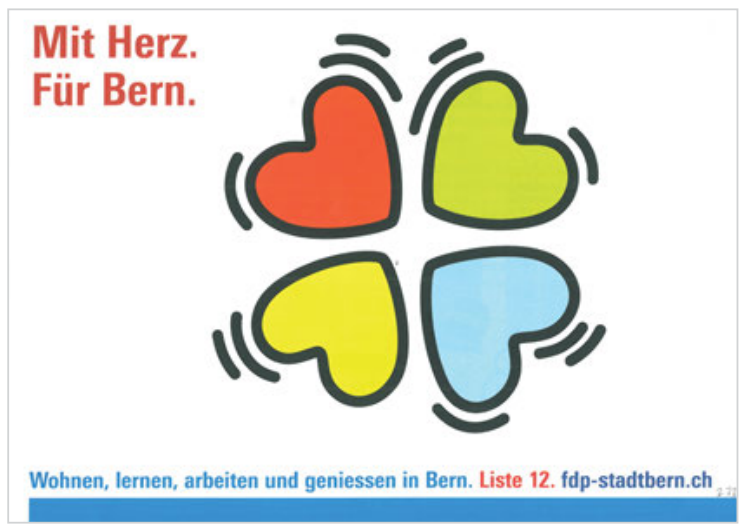

Abb. 41: Wahlprospekt FDP Bern.

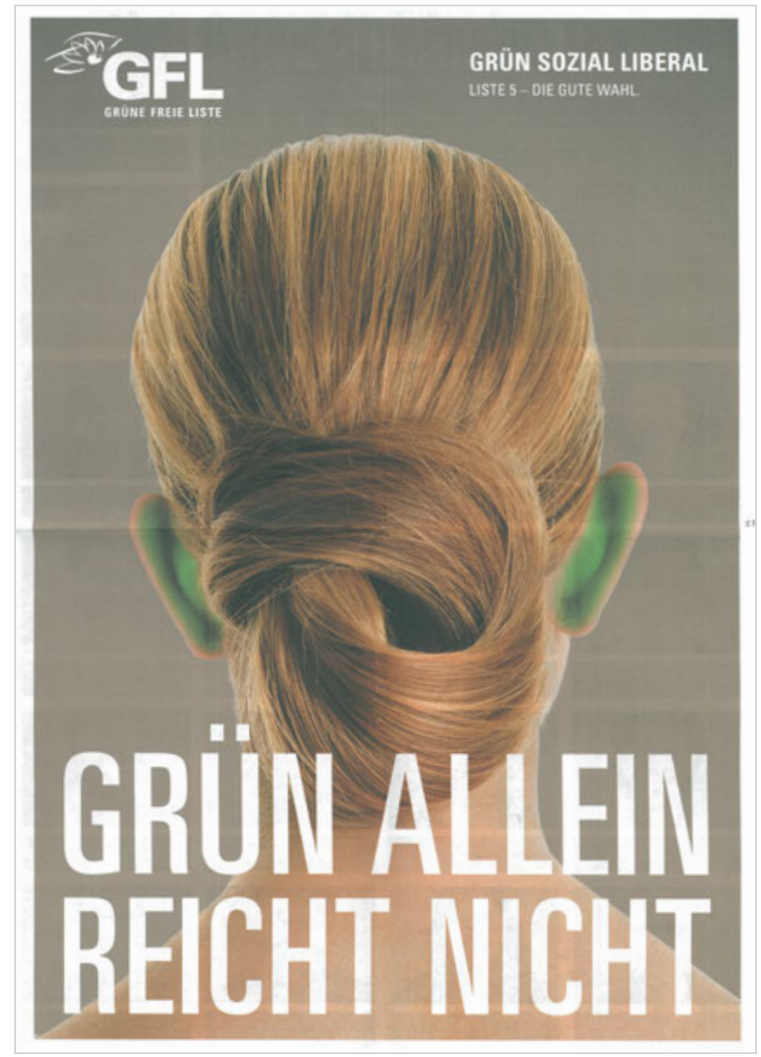

Abb. 42: Wahlprospekt GFL Bern. 
phorisierung» einer Sprachmetapher nur bedingt: «Grün hinter den Ohren〉 ist im Volksmund jemand, der naiv oder unreif ist. Die GFL zieht somit das grüne Anliegen, das sie selbst vertritt, ins Lächerliche - oder setzt sie auf Ironie? Ironische Aussagen können jedoch in der politischen Kommunikation leicht <ins Auge gehen`. Zudem erscheint die werberische Bildsprache des GFL-Prospekts unpassend. In der Wahlkommunikation geht es um die Präsentation der Kandidierenden: Man muss ihre Gesichter zeigen, keine anonymen, hübsch frisierten Models. Auch hier könnte natürlich eine ironische Absicht dahinterstecken, um gerade durch die Abweichung vom konventionellen Muster Aufmerksamkeit zu erlangen - ein heikles Spiel. Ein wenig aus der Art schlägt auch der Wahlprospekt der CVP Zollikofen (CVP Z 363, Innenseiten), der mit den freigestellten Stockfotografien (grüne Blätter, Fahrrad, Fußball, Buntstifte) im Innern eher an einen Krankenkassen-Prospekt erinnert als an Wahlkommunikation.

Als wie gelungen ein Artefakt eingestuft wird, hängt von der Übereinstimmung der Gestaltung mit den Gepflogenheiten der lokalpolitischen Kommunikation insgesamt und mit den Charakteristiken der Partei und ihrer Wählerschaft im Speziellen ab. Der Teufel liegt oft in den Details der technischen Ausarbeitung: So werden beispielsweise beim an sich solide gestalteten Prospekt der SVP Schüpfen (SVP S 387, Abb. 26) die teils zu niedrig aufgelösten Abbildungen sowie ihr «unentschieden» wirkender ovaler Zuschnitt bemängelt. Nehmen solche fehlerhaften, störenden oder unpassenden Elemente überhand, kann die Angemessenheit des Gesamtprodukts in Frage gestellt werden - oder dieses wird nicht mehr als Profiarbeit eingestuft. Wo genau der Elaborationsgrad in den Bereich des Intolerablen kippt, kann nicht absolut bestimmt werden. Gerade die Originalität oder die Besonderheit der Gestaltung, aber auch die gestalterische Qualität insgesamt scheinen nicht objektiv beurteilbar zu sein, einiges bleibt Geschmackssache oder wird aufgrund der lebensweltlichen oder gestalterischen Haltung des Betrachters unterschiedlich wahrgenommen - so dass sich auch die Experten in der Gesamtbewertung nicht immer einig sind. So wird die grafische Umsetzung des Wahlauftritts der Partei der Arbeit Bern (PDA B 234, 123-126) vom Experten als herausragendes Beispiel für die Verbindung von Inhalt und Form angeführt, von der Expertin jedoch als unbeholfener und uninspirierter Versuch, die Ästhetik der russischen Avantgarde zu zitieren, der in Bezug auf Typografie und Satz den Anforderungen professioneller Gestaltung nicht $\mathrm{zu}$ entsprechen vermöge. Wie sich in der praxisbasierten Designstudie (Kap. 4 in diesem Teil) noch zeigen wird, sind sich auch Laienbetrachterinnen und -betrachter über die Einschätzung von Professionalität und Angemessenheit nicht immer einig.

Als wichtige Erkenntnis lässt sich festhalten, dass der Maßstab, den die Experten an die lokalpolitische Kommunikation anlegen, je nach der Größe einer Partei oder Bekanntheitsgrad der kandidierenden Person variiert. So sollten sich eta- 
blierte Parteien und Politiker selbst im Rahmen der Lokalpolitik an ein gewisses gestalterisches Elaborations- und Professionalitätsniveau halten, während dieses von Randparteien oder politischen Neueinsteigern eher unterschritten werden dürfe. Zudem spielt die politische Ausrichtung der Partei eine Rolle dafür, ob der Auftritt eher seriös und solide oder frech und unkonventionell ausgestaltet werden sollte. Angesichts ihrer ansehnlichen Parteitradition wirkt deshalb etwa der Wahlauftritt der Stadtberner FDP (FDP B 233, Abb. 41; 128, 129) mit seiner unverbindlich fröhlichen Pop Art-Optik und dem Billigpapier komplett unangemessen. Warum wurde von einer ehemals staatstragenden, wirtschaftsfreundlichen Partei mit langer Geschichte so wenig Sorgfalt in die Entwicklung einer visuellen Identität gelegt und bei der Qualität der Werbematerialien gespart? Die Frage nach 〈guter> oder «schlechter` Gestaltung hängt also auch davon ab, ob Gestaltung und Elaborationsgrad zu einer Partei passen oder nicht. Eine solche Bewertung beinhaltet, ob die mit dem Kommunikationsmittel erreichte visuelle Erscheinung dem Bild entspricht, das die Partei von sich selbst vermitteln möchte, und die Werte sichtbar macht, die sie vertritt. Hier werden also zwei rhetorische Prinzipien wirksam, das Aptum und die im Artefakt verborgene Wirkungsintention. Passt die Gestaltung zum Kontext (Absender, Publikum, Anlass, Inhalt) und stimmen Wirkungsintention und tatsächliche Wirkung überein? Für die Bewertung der Angemessenheit ist ausschlaggebend, wie groß und etabliert eine Partei bzw. wie bekannt eine Politikerin oder ein Politiker ist. Die Anforderungen an den Professionalitäts- und Elaborationsgrad steigen mit der Bekanntheit und Bedeutung des Absenders.

Tatsächlich scheinen die meisten Beispiele aus der lokalpolitischen Kommunikation, die sich am Rand oder außerhalb der professionellen Gestaltung bewegen, von Klein-, Jung- oder Exotenparteien zu stammen oder von Personen, die noch nicht tief im Politbetrieb verankert sind. Es erstaunt dagegen nicht, dass jene gestalterischen Eigenleistungen oder semiprofessionellen Beispiele, die für größere Parteien oder bekannte Politiker werben, von den Experten nicht für passend befunden werden: Der semiprofessionell daherkommende Prospekt für die Gemeinderatskandidatur der grünen Politikerin Franziska Teuscher (GB B 127, Abb. 46), die sich als Nationalrätin und in anderen politischen Ämtern längst einen Namen gemacht hat, wird als unangemessen beurteilt, während das ebenfalls «selbstgebastelt» wirkende Buchzeichen einer Neukandidierenden (SP B 217, Abb. 47) oder die freche, aber leicht dilettierende Aktion zweier jüngerer SP-Politikerinnen (SP B 143, Abb. 36) für den Stadtrat (also ein deutlich weniger exponiertes Mandat) als frisch und engagiert wahrgenommen oder zumindest toleriert werden.

In den Augen der Gestaltungsexperten erscheint es zulässig, wenn sich alternativ oder auf ein junges Publikum ausgerichtete Parteien und Kandidierende von gewissen Konventionen der Gestaltung lösen, um ihre Besonderheit, ihr Anders- 
sein, ihre Abweichung vom Durchschnitt auch visuell herauszustellen. Dazu können auch das Umgehen professioneller Gestaltungsstandards und die wenig elaborierte Form gehören. Der Einsatz dilettantisch oder selbstgemacht wirkender Strukturierungsmerkmale und Stilelemente, die bei etablierten Parteien ein «No-Go» wären, wird bei verschiedenen jungen und eher an den Rändern des politischen Spektrums agierenden Parteien als angemessen wahrgenommen: das amateurhafte Logo und Gesamtlayout des Wahlprospekts der rechts orientierten Schweizer Demokraten (SD B 228), die laienhaften Illustrationen und Schriftzüge bei der linksgerichteten Partei Junge Alternative, (JA! B 250, Abb. 45, siehe Detailanalyse) oder die dilettantisch montierten Sprechblasen auf dem Prospekt der Alternativen Linken (AL B 240, Abb. 43).

Zumindest beim offiziellen Wahlmaterial erreichen selbst diese Kleinparteien einen gewissen Elaborationsstandard: Die Kommunikationsmittel wurden in professionellen Layoutprogrammen gestaltet und im Offsetdruck produziert. Die einzige offizielle Wahlkampfkommunikation im Untersuchungskorpus, die ganz von Laien in einem Anwenderprogramm gestaltet zu sein scheint (wenn auch Offset gedruckt), die Broschüre des Forums der Unabhängigen Zollikofen (FdU Z 362, Abb. 29), geht nur deshalb durch, weil sie augenscheinlich eine Partei bewirbt, die aus einer kleinen Gruppe querköpfiger Individualisten besteht. Hier stören auch die fehlende Farbangleichung bei den Kandidatenfotos und die gänzlich unbeholfen und ohne Raster unter- und nebeneinander geschichteten Textund Bildelemente nicht. Mitunter zeigt sich also der spezielle, vom «Mainstream» abweichende Charakter der Partei gerade in einer selbstgemachten, imperfekten grafischen Aufmachung - am rechten Rand als Zeichen von Volksnähe, am linken Rand im Sinne des «Do-it-yourself〉, als Ausdruck eines selbstbestimmten, alternativen Lebensgefühls. Auch bei den Parteiexoten wird nicht jedes Produkt als gleich gelungen beurteilt: Während der als Wohnungsinserat getarnte Straßenaushang in Laienoptik der Jungen Alternative Bern (JA! B 223, siehe Detailanalyse) als «überraschend anders» gelobt wird, bezweifeln die Experten die positive Wirkung der dilettantisch gezeichneten Illustration auf dem Wahlprospekt derselben Partei (JA! B 250, Abb. 45, siehe Detailanalyse), da sie allzu «Grau in Grau» daherkomme und ihre Aussage $\mathrm{zu}$ wenig klar vermittle. Noch schlimmer steht es um den Prospekt der Grünen Partei und Demokratischen Alternative (GPD/ DA B 227). Dieser erscheint mit seiner welligen Schrift und dem hinterlegten Spiralmuster derart «handgestrickt» und im «Mief der 70er Jahre» hängen geblieben, dass man sich fragen muss, ob diese Wirkung beabsichtigt wurde und einer politischen Haltung entspricht, oder ob schlicht gestalterisches Unvermögen für diese Optik verantwortlich ist.

Schließlich gibt es die wenigen reinen Laienarbeiten, die laut Experten komplett im «Homeoffice» oder Parteibüro entstanden sind: Kleinplakate und 


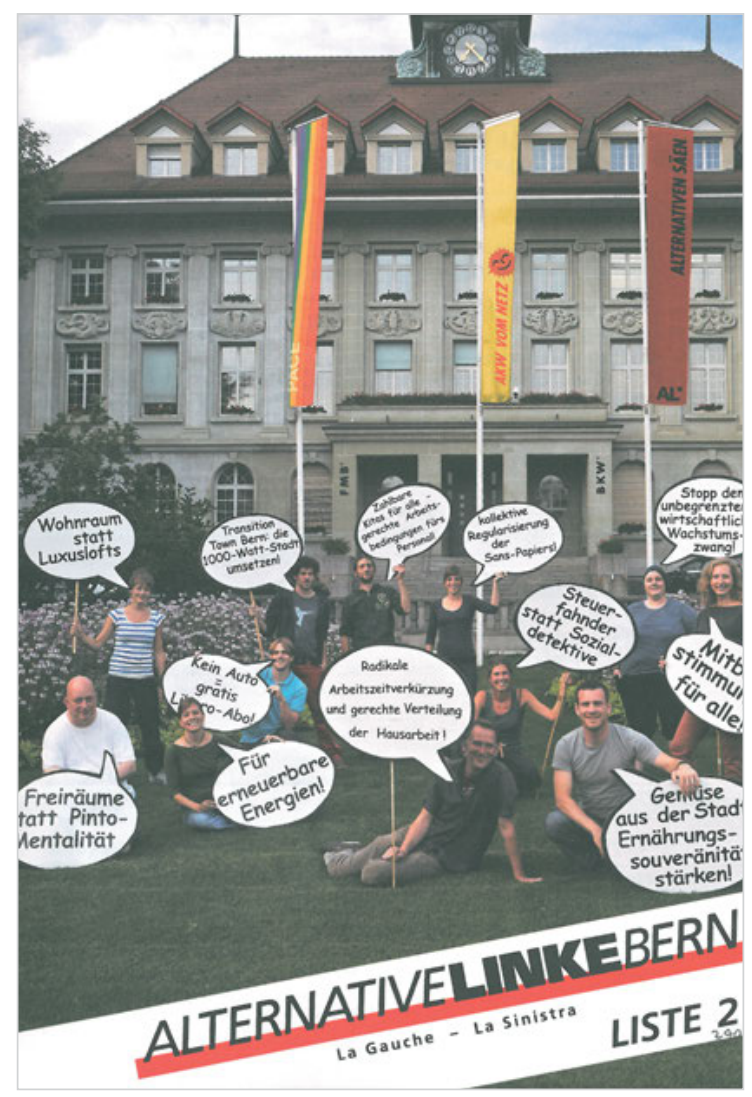

Abb. 43: Wahlprospekt Alternative Linke Bern.

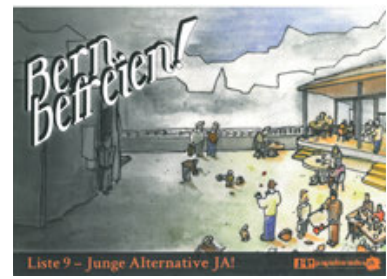

Abb. 44: Wahlflyer Junge Alternative Bern.

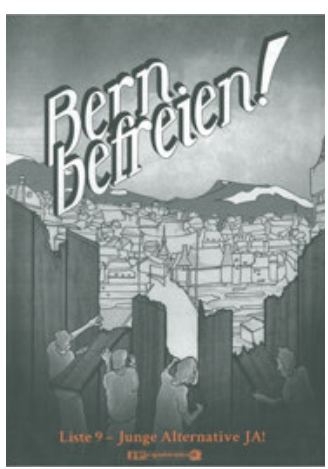

Abb. 45: Wahlprospekt Junge Alternative Bern. 
Flyer, die mittels Standard-Textverarbeitungsprogramm gestaltet und auf Standardpapier ausgedruckt oder fotokopiert wurden. Für die Bekanntmachung von kleineren, durch die Lokalpartei organisierten Veranstaltungen ist diese Gestaltungsform aus Sicht der Experten durchaus ausreichend und angemessen. Solche Zettel können unkompliziert und rasch gestaltet, reproduziert und verbreitet werden, indem sie öffentlich in der Gemeinde ausgehängt oder in Briefkästen geworfen werden. Man zeigt damit «ein gewisses Engagement», ohne für die Kommunikation ein eigenes Budget oder viel Zeit zu benötigen. Doch darf selbst hier ein gewisser gestalterischer Mindeststandard nicht unterschritten werden: Verschiedene Kleinplakate der Grünen Freien Liste Zollikofen, die vermutlich alle von derselben Laienperson gestaltet wurden (GFL Z 103, Abb. 31; 105, 106, 108, siehe Detailanalyse, 109, 110) verfehlen aus Expertensicht ihren Zweck, weil sie chaotisch, kaum lesbar und somit unseriös wirken. Der minimal übersichtlichere und weniger überladene Veranstaltungshinweis von SP und GFL Zollikofen für einen Fahrradmarkt (schweiz. «Velobörse») (SP/GFL Z 107) geht dagegen als passabel durch: Laiengestaltung darf simpel gestaltet sein, muss aber Minimalstandards wie Lesbarkeit und Verständlichkeit der Botschaft einhalten, damit sich das Publikum orientieren und ernst genommen fühlen kann.

Ein Problem bei der Laiengestaltung ist laut Experten, dass durch die mangelnde Beherrschung der Gestaltungsprogramme und Stilelemente manchmal Wirkungen erzeugt werden, die nicht beabsichtigt sind und die das Publikum ungewollt irritieren. Bei farbigen Reproduktionen wirkt das Resultat beispielsweise aufgrund der mangelhaften oder fehlenden Bildbearbeitung sowie der minderwertigen Drucktechnik rasch billig. Besonders Hauttöne sind heikel und nehmen oft einen unschönen Gelb- oder Rotstich an. Dieser ungewollte Effekt entstand etwa bei den Kleinplakaten der GFL Zollikofen, zusätzlich verstärkt durch das gelbe Kopierpapier (GFL Z 108, siehe Detailanalyse, 109), oder auf dem selbstkreierten Kärtchen der Anwärterin für das Gemeindepräsidium in Zollikofen (SP Z 116, Abb. 48), dessen rotstichiges Foto nicht nur unvorteilhaft wirkt, sondern die Wahlwerbung missverständlich und wie die «Visitenkarte einer Heilerin» aussehen lässt. Kann die SP-Frau so das Vertrauen der Wählerschaft gewinnen? Die engagierte Wirkung oder persönliche Note, die durch gestalterische Eigenleistungen vermittelt werden soll, kann also rasch ins Negative kippen, wenn sie ein elaboratives Mindestniveau unterschreiten. Wo professionell gestaltetes Material noch eigenhändig mit einer handschriftlichen Botschaft oder einer angehefteten Minischokolade versehen wurde, sind sich die Experten nicht sicher, ob das Resultat dadurch als «selbstgemacht, ergo engagiert» wahrgenommen wird, ob dieser minimale Zusatzaufwand überhaupt zur Kenntnis genommen wird oder ob dies am Ende gar als billige Anbiederungsaktion interpretiert werden könnte. 


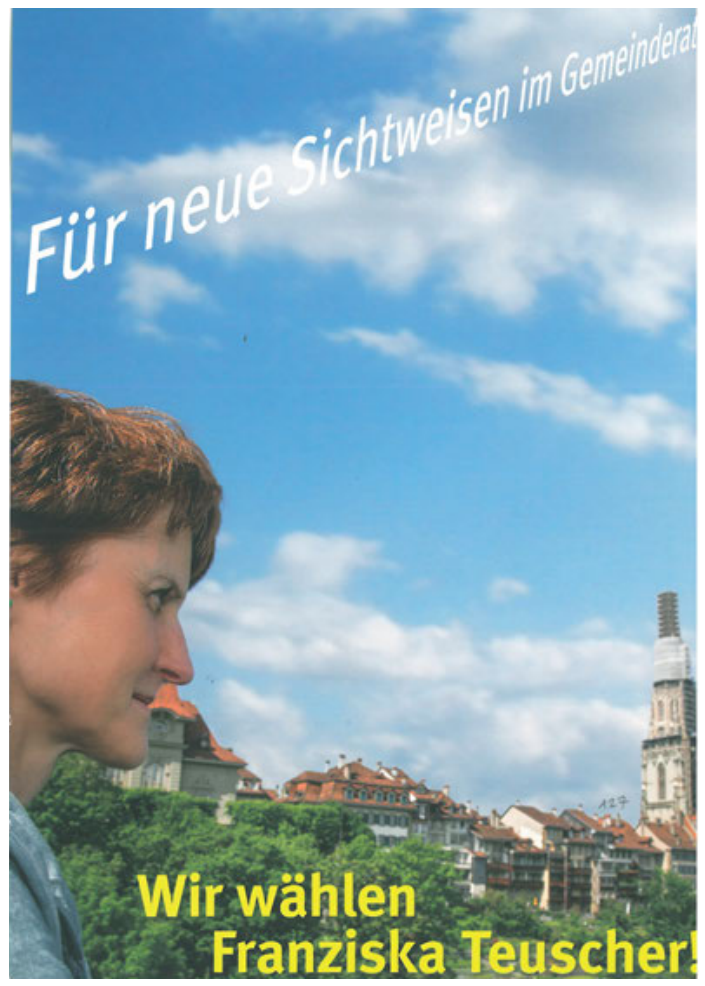

Abb. 46: Wahlprospekt Franziska Teuscher, Grünes Bündnis Bern.

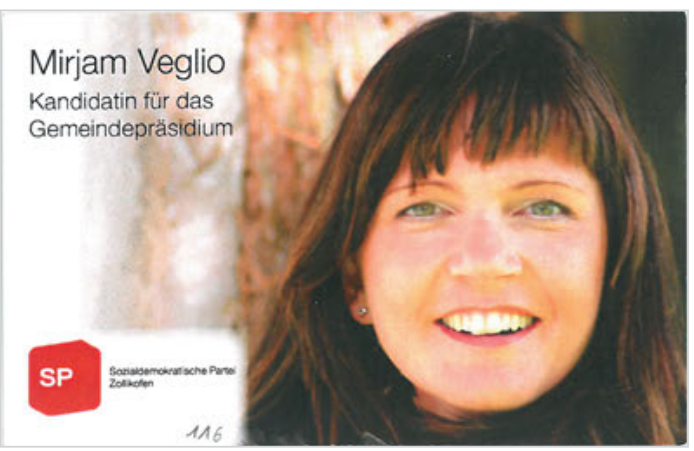

Abb. 48: Wahlwerbung im Visitenkarten-Format, Mirjam Veglio, SP Zollikofen.

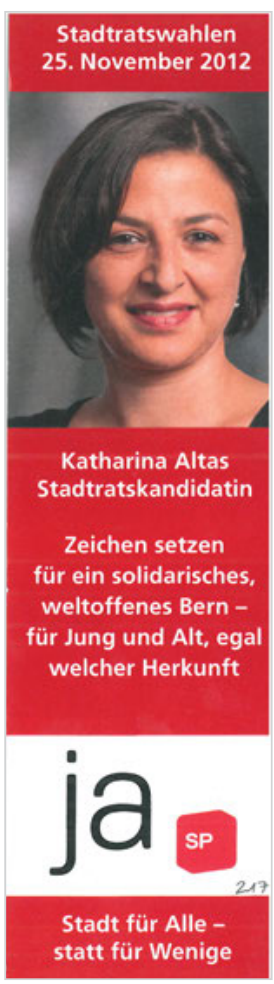

Abb. 47: Wahlwerbung im Buchzeichen-Format, Katharina Altas, SP Bern. 


\subsubsection{Imperfektion: Volksnah oder unseriös?}

Welche Rolle also spielen Imperfektionen in der visuellen Kommunikation der Lokalpolitik? Wo kommen Imperfektionen vor und wie werden sie beurteilt? Einerseits wird es als Imperfektion gedeutet, wenn semiprofessionelle Gestaltung oder Laiengrafik eingesetzt wird, jedoch aufgrund der Wichtigkeit des Absenders oder Anlasses professionelles Grafikdesign angebracht wäre. In der lokalpolitischen Kommunikation also überall dort, wo etablierte Parteien und Kandidaten oder ernsthafte politische Sachthemen propagiert werden. Andererseits können auch innerhalb der professionellen Gestaltung je spezifische Imperfektionen vorkommen, wie sich im Vorangehenden immer wieder gezeigt hat. ${ }^{3}$ Die häufigsten Imperfektionen sind bei den professionellen lokalpolitischen Kommunikationsmitteln mangelnde Originalität, inkonsequente Konzeption oder die Umsetzung einer hilflosen, gesuchten oder unklaren Idee (z.B. FDP Z 366, Abb. 40). Beinahe ebenso oft stellen die Experten Passungsfehler fest, sei es weil der Bezug zwischen gestalterischer Form und Inhalt mangelhaft ist oder weil die verwendeten Stilmittel und Elaborationsmerkmale sich nicht zusammenbringen lassen, im Widerspruch zu den Corporate-Vorgaben stehen, nicht zeitgemäß erscheinen oder unfreiwillige Assoziationen zu anderen Inhalten und Kontexten wecken (z.B. SP Z 119, BG B 209, JUSO B 231). Ein fehlendes «Geschichtsverständnis» bezüglich der grafischen Gestaltung kann laut Experteneinschätzung dazu führen, dass formale Elemente und Bildsprachen eingesetzt werden, die gestaltungshistorisch anders konnotiert sind. So sieht etwa das Wahlplakat der SP Zollikofen aus wie ein Fahndungsplakat (SP Z 120), was kaum «im Sinne des Erfinders» sein kann.

Solche Konzeptions- und Passungsfehler im Bereich der professionellen lokalpolitischen Kommunikation können negative Folgen mit sich bringen und im schlimmsten Fall dazu beitragen, dass eine Partei oder ein Politiker nicht ernst genommen wird. Auch technische Elaborationsfehler wie schlechte oder inadäquate Bild-, Druck- und Materialqualität, Mängel in Typografie und Layout, der Einsatz überflüssiger Stilelemente oder unreflektierte Abweichungen von den Corporate Design-Vorgaben der Partei können die gestalterische Qualität negativ beeinflussen und ein schlechtes Licht auf den Absender werfen. In Bezug auf die in der lokalpolitischen Kommunikation übliche Offsetdrucktechnik werden in den untersuchten Arbeiten kaum Mängel festgestellt. $\mathrm{Zu}$ wenig beachtet wird in der untersuchten lokalpolitischen Kommunikation jedoch die Papierqualität. Denn allein aufgrund einer minderwertigen oder inadäquaten Papierqualität kann eine professionelle Arbeit «billig» oder «unseriös» erscheinen oder der

3 Um Redundanzen zu vermeiden, werden die bereits ausgeführten Beispiele hier nur noch kurz beschrieben und in Klammer lediglich mit Kürzel und Identifikationsnummer genannt. 
Parteibotschaft entgegenwirken (z.B. FDP B 233, Abb. 41; 128, 129; Bürgerliches Bündnis B 243, Abb. 33). Durch die Koppelung von mehreren Imperfektionen werden manche Beispiele nur als semiprofessionelle Arbeiten eingestuft.

In gewissen Fällen scheint die wenig elaborierte, handgestrickte oder imperfekte Form ganz bewusst eingesetzt oder belassen worden zu sein. So kommt etwa der Einsatz von Handschrift in den professionellen Artefakten mehrfach vor, jedoch nur einmal in Form einer echten handschriftlichen Hinzufügung durch eine Kandidatin (EVP B 166): Dieses von Hand geschriebene Detail soll «für Authentizität bürgen» und das persönliche Engagement in den Vordergrund rücken. In den anderen Fällen wurde Handgeschriebenes im Rahmen der Profigestaltung eingebracht, indem Textteile in Schreibschrift gesetzt oder in Form einer vermeintlich von Hand gezogenen Leuchtstiftmarkierung hervorgehoben wurden. Diese gestalterischen Eingriffe suggerieren eine persönliche und informelle Ansprache der Wählerschaft und versuchen so eine «Nähe zum Publikum» zu schaffen. Ebenfalls im Rahmen der professionellen Gestaltung strategisch eingesetzt wurden zwei durch ihre handgemachte Form auffallende Gestaltungselemente auf dem Wahlprospekt der SVP Bern (SVP B 246), die als Insignien des visuellen Auftritts der SVP landesweit gelten: Zum einen das handgezeichnet wirkende Logo mit der lachenden Sonne, das einen laienhaften, beinahe kindlichen Charme verströmt und «Volksnähe» herstellen soll. Zum anderen der grob gezeichnete Illustrationsstil, welcher nicht den Amateurstil imitiert, sondern gekonnt, aber bewusst holzschnittartig ausgeführt ist. Durch ihre Rauheit entfaltet die Zeichnung eine «unmittelbare visuelle Kraft» und sorgt für die Wiedererkennbarkeit der SVP-Wahlwerbung. Bei den verschiedenen Formen der semiprofessionellen Gestaltung, in denen sich laienhafte Elemente und Strukturen mit Merkmalen professioneller Gestaltung und Produktion vermischen, geschieht der Einsatz wenig elaborierter Elemente vermutlich nicht bewusst, sondern dürfte vielmehr auf mangelndes Know-how zurückzuführen sein (z.B. Franziska Teuscher B 127, Abb. 46; 〈Stadratfrauen〉 B 143, Abb. 36; GPD/DA B 227). Der als Wohnungsinserat getarnte politische Aufruf der Jungen Alternative Bern (JA! B 223, siehe Detailanalyse) wird hier als Sonderfall bewertet, da hier ein Produkt der Laiengestaltung imitiert werde: Das Inserat muss gemäß Experten so aussehen, als hätte es ein Laie gestaltet - selbst wenn ein Profi dieses gestalten würde.

Für kleinere politische Anlässe sowie für weniger bekannte Kandidierende ist aus Sicht der Gestaltungsfachleute der imperfekte Look der Laiengrafik ausreichend, die in Word gestaltet, ausgedruckt und fotokopiert wird. Mängel in der Bildqualität, die von einer fehlerhaften Bildbearbeitung (z.B. Grauschleier, unterschiedliche Tonwerte bei nebeneinanderstehenden Bildern, Farbstich) oder bereits unzureichend aufgenommenen, unscharfen oder verpixelten Bildern herrühren, werden hier toleriert. Ein Layoutraster ist nicht nötig, sofern die entspre- 
chenden Artefakte geordnet und lesbar präsentiert werden und nicht chaotisch oder überladen wirken. Problematisch wird es laut Expertenaussagen dort, wo aufgrund der Missachtung minimaler Elaborationsstandards in Layout, Typografie, Bildbearbeitung und aufgewendeter Sorgfalt die Lesbarkeit der Information und die seriöse Wahrnehmung des Absenders beeinträchtigt werden (z.B. GFL Z 108, siehe Detailanalyse, 109, SP Z 116, Abb. 48).

\subsection{Auslegeordnung Gemeinwesenarbeit}

\subsection{1 Überblick über das Material: Dominanz der Amateurgestaltung}

Im Gegensatz zur lokalpolitischen Kommunikation mit einem überwiegenden Anteil an professioneller Gestaltung bildet in der Gemeinwesenarbeit die Laiengestaltung den Hauptbestandteil. Kleinplakate, die auf PCs in den Sekretariaten der jeweiligen Absenderinstitution des Gemeinwesens (Kirchgemeinde, Verein, Fachstelle, Quartierzentrum etc.) selbst gestaltet, ausgedruckt und auf Normpapier vervielfältigt werden und die vor Ort ausgehängt oder alternativ auch als Flyer aufgelegt werden können, sind hier der Normalfall. Der häufigste Verwendungszweck ist das Bewerben von Einzelveranstaltungen oder -angeboten, für deren Kommunikation kein eigenes Budget vorhanden ist. Typischerweise enthält diese Art von Laiengestaltung ein Veranstalterlogo, einen Text mit markant gesetztem Titel und den Eckdaten des beworbenen Anlasses sowie eine Fotografie oder Zeichnung, die das Thema illustriert. Für wiederkehrende Veranstaltungen wird eine simple Vorlage im Anwendungsprogramm verwendet, in welcher jeweils nur Datum, Text und Bild ausgetauscht werden müssen, während «Header` und Gesamtlayout gleich bleiben. Die gestalterische Anmutung ist hier noch austauschbarer, als es bereits in der Lokalpolitik der Fall war: Alles wirkt ähnlich, viele Arbeiten sind kaum voneinander zu unterscheiden und auch im Vergleich zwischen Stadt, Land und Agglomeration sind nur unbedeutende Unterschiede erkennbar. Eine Handvoll Laienarbeiten stechen weniger durch Elaboriertheit als durch eine witzige Nuance, einen gestalterischen Kniff, ein charmantes Detail, einen originellen Einfall oder eine kleine persönliche Zutat aus der Einförmigkeit des Ganzen heraus und wirken dadurch engagiert und sympathisch.

Ein kleinerer Anteil des Korpus wurde auch in der Gemeinwesenarbeit professionell gestaltet. Ähnlich wie in der Lokalpolitik werden die meisten professionellen Gestaltungsbeispiele als mittelmäßig und konventionell bewertet. Wie bei der Lokalpolitik das offizielle Wahlmaterial, wurden in der Gemeinwesenarbeit Drucksachen mit offiziellerem Charakter professionell in Auftrag gegeben, etwa die Informationsbroschüre zum allgemeinen Angebot einer Institution. Ein 
beträchtlicher Teil der Artefakte wird dem semiprofessionellen Bereich zugeordnet. Besonders die bei städtischen Institutionen und Quartierzentren beliebten Postkarten, aber auch zahlreiche Veranstaltungshinweise sind $\mathrm{zu}$ wenig elaboriert, um als professionell durchzugehen, zeugen aber von einer gekonnten und aufwändigeren Machart als das durchschnittliche Laienmaterial. Unauffällige, weder durch besondere stilistische Merkmale noch eine originelle Machart auffallende Gestaltung bildet in der Gesamtschau die Norm. Es scheint aus Expertensicht fast, als würde sich allzu elaborierte oder herausragende Gestaltung im Bereich der Gemeinwesenarbeit verdächtig machen.

\subsubsection{Zum Verhältnis von Amateur- und Profigestaltung: Wordgestaltung, professionelle Einzelaktionen und der Vormarsch semiprofessioneller Gestaltungsformen}

Mehr als die Hälfte der insgesamt rund 250 vorgefundenen Artefakte aus der Gemeinwesenarbeit wird von den Experten als einfache Amateurgestaltung beurteilt. Layout und Gestaltung erfolgen hier im Rahmen gängiger Büro- bzw. Anwendungsprogramme wie Microsoft Word oder PowerPoint. Anschließend wird das Produkt auf A4 (oder für einen A5-Flyer zweimal auf A4) ausgedruckt und mittels Fotokopierer auf Standardpapier vervielfältigt (und allenfalls auf A5-Format zugeschnitten). Fertig ist das Kleinplakat für den Aushang am schwarzen Brett oder der Flyer zum Auslegen im Kirchgemeindehaus, Quartierzentrum, Vereinslokal oder zum Versenden an die Mitglieder der Institution. Von der Gestaltung bis zum fertigen Produkt kann mit geringem Zeit- und Materialaufwand alles autonom in den Sekretariaten der jeweiligen Institution oder bei ehrenamtlicher Gestaltungstätigkeit im Homeoffice hergestellt werden. Inhaltlich bewerben diese wenig elaborierten Laienarbeiten meist Einzelanlässe oder -angebote der Institution: die Seniorenveranstaltung (z.B. B 261, B 300, S 69), das Kerzenziehen in der Kirchgemeinde (z.B. B 10, Z 379, siehe Detailanalyse), die Geschichtenerzählstunde der Gemeinde- oder Quartierbibliothek (z.B. Z 376, S 98, Abb. 50; B 253), den von der Quartierarbeit organisierten Spielnachmittag (z.B. B 286, Abb. 49) ${ }^{4}$ oder die im Quartierzentrum erhältlichen vergünstigten Tageskarten für den öffentlichen Verkehr (z.B. B 297, Abb. 51; B 263). Visuelle Kommunikation in der Gemeinwesenarbeit ist im Normalfall durch Pragmatismus und eine möglichst preiswerte und unkomplizierte Lösung gekennzeichnet. Laut Experten informiert diese Art der

4 Da es anders als bei den Parteien für die Institutionen des Gemeinwesens keine geläufigen Kürzel gibt, wird auf einen entsprechenden Hinweis in Klammern verzichtet, der Absender jedoch wo nötig im Text identifiziert. 


\section{Spielnachmittag zur}

Einweihung des neugestalteten Schlossmatt-Spielplatz und der Begegnungszone

Mi. 24.10 .2012 14-19 Uhr

\section{Schloss!}

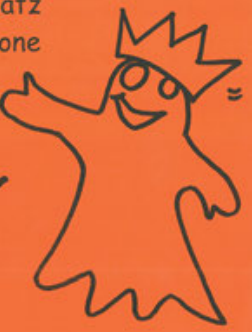

- Marroni brätle - Kronen basteln 0 Kuchen 0

- Kürbissuppe - Spili ausprobieren

- Verkleiderlikiste $\bullet$ Schloss-Sirup Chndershlina

0 mobil

Abb. 49: Kleinplakat «Spielnachmittag` Familienverein Holligen u.a.

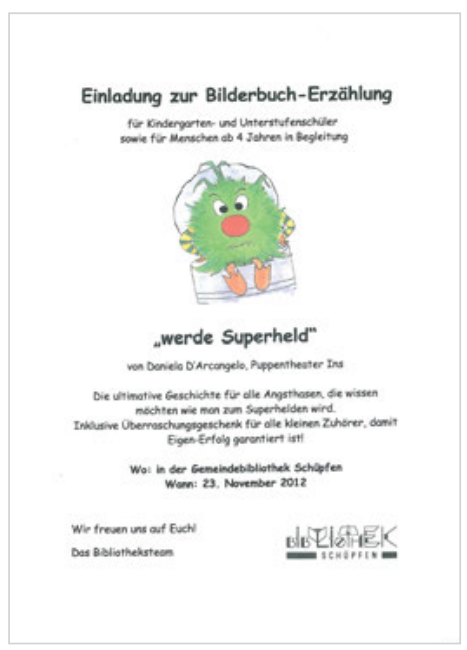

Abb. 50: Veranstaltungsinfo Bibliothek Schüpfen.

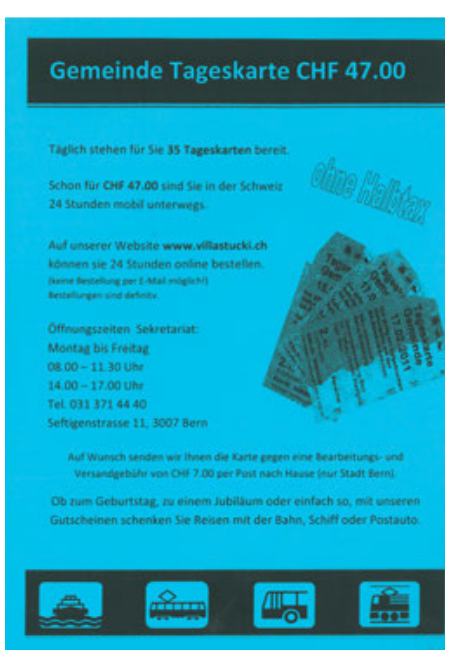

Abb. 51: Information Gemeindetageskarte, Villa Stucki Bern. 
Gestaltung über das laufende Angebot, ohne jedoch dafür zu werben. Dies kann aus ihrer Sicht nur deshalb ausreichen, weil sich solche Kommunikationsmittel in einem vertrauten Umfeld an jene Menschen richten, die bereits in das Leben der jeweiligen Gemeinschaft eingebunden sind oder die ein grundsätzliches Interesse für das entsprechende Angebot aufbringen.

Eine nicht geringe Anzahl von Artefakten aus allen drei Gemeinden, nämlich gut ein Viertel, bewegt sich im Grenzbereich zwischen professioneller und unprofessioneller Gestaltung. Diese Beispiele scheinen zwar nicht von professionellen Grafikdesignerinnen und -designern gestaltet worden $\mathrm{zu}$ sein, heben sich aber deutlich von den stets nach dem gleichen und simplen Muster erstellten Laienarbeiten ab. Ihre Erscheinung setzt gewisse Gestaltungsschritte voraus, die mit den Standardprogrammen bzw. von reinen Laienanwendern nicht - oder nur mit einigem Können - ausgeführt werden können, wie das Überlagern von Ebenen, den Einsatz von Spezialschriften oder die besondere Ausrichtung von Text, wie sie etwa in den Postkarten für die Villa Stucki oder den Quartiertreff Steigerhubel sichtbar werden (B 349, B 348). Meistens lassen sich die semiprofessionellen Beispiele von den Laienarbeiten auch durch eine elaboriertere Drucktechnik oder hochwertigere Papierqualität unterscheiden. Ob es sich um schlichte Polygrafengrafik von Druckereien handelt oder um Gestaltung, die im Ehrenamt von Amateuren mit gestalterischem Know-how und professioneller Ausrüstung ausgeführt wurde, ist für die Gestaltungsfachleute nicht immer klar ersichtlich, so etwa bei der Postkarte der Quartierarbeit Stadtteil III (B 356, Abb. 53), dem Flyer für das Adventsfenster in Schüpfen (S 40, Abb. 54), dem Werbeprospekt des Familienvereins Schüpfen (S 41) oder dem Handzettel der Ludothek Zollikofen (Z 54, Abb. 52). Verschiedene semiprofessionelle Beispiele kommen auf den ersten Blick professionell daher, weil sie hochwertig gedruckt oder von Format oder Machart her komplexer sind als die Standardbeispiele. Sie unterscheiden sich in den Augen der Experten von professionellen Arbeiten aber entweder aufgrund ihrer mangelhaften typografischen Ausführung, wie etwa das Faltblatt der Kirchgemeinde Dreifaltigkeit Bern für ein Weiterbildungsangebot für Eltern (B 31), oder eine ungelenke, übermäßige oder vorwiegend dekorative Verwendung von Gestaltungselementen, wie sie etwa der «Streetdance〉-Flyer für junge Frauen des Blauen Kreuzes aufweist (B 353). In der Gesamterscheinung bleiben viele semiprofessionelle Arbeiten für die Experten seltsam unbestimmt. Sie strahlen eine undefinierbare, beinahe neutrale Wirkung aus. So ist weder beim Kleinplakat 〈Story-Telling〉 der Villa Stucki (B 293) noch bei der Postkarte der Quartiermitwirkung Stadtteil 3 (B 359) eine eigene visuelle Identität erkennbar. Neben Informationen zu Einzelveranstaltungen oder Monats- und Jahresprogrammen der verschiedenen Organisationen geht es bei den semiprofessionell gestalteten Artefakten vor allem kleinerer Anbieter oft um allgemeine Angaben zum 


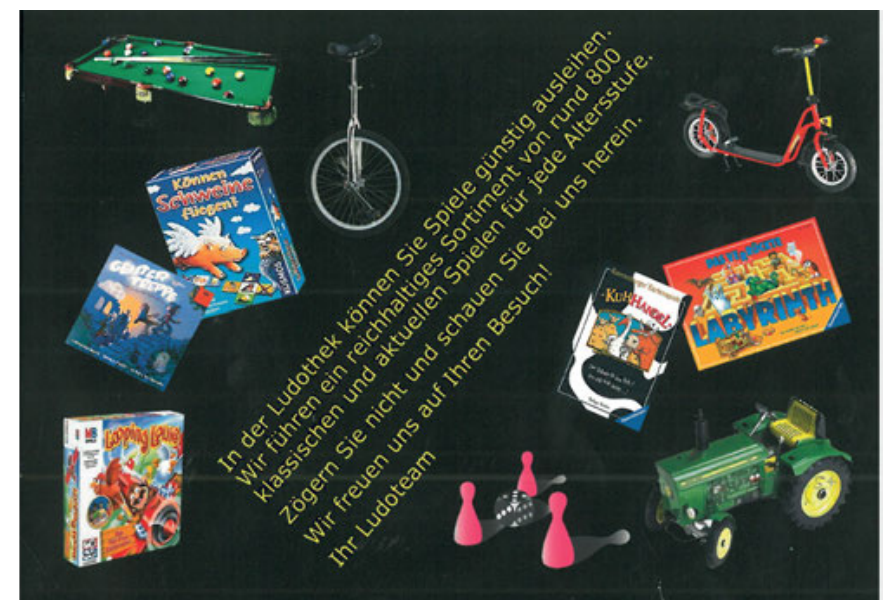

Abb. 52: Informationsflyer Ludothek Zollikofen.

\section{QUARTIERARBEITSTADTTEILIII}

informieren, unterstützen und vermitteln bei Quartieranliegen

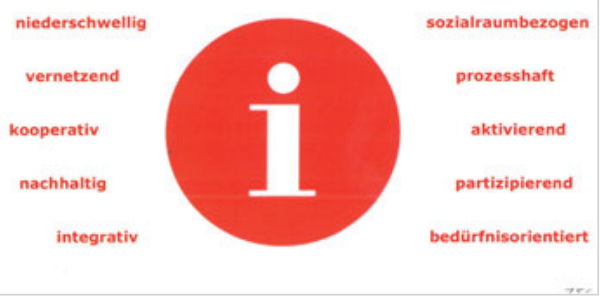

Abb. 53: Informationsflyer Quartierarbeit Stadtteil 3, Bern.

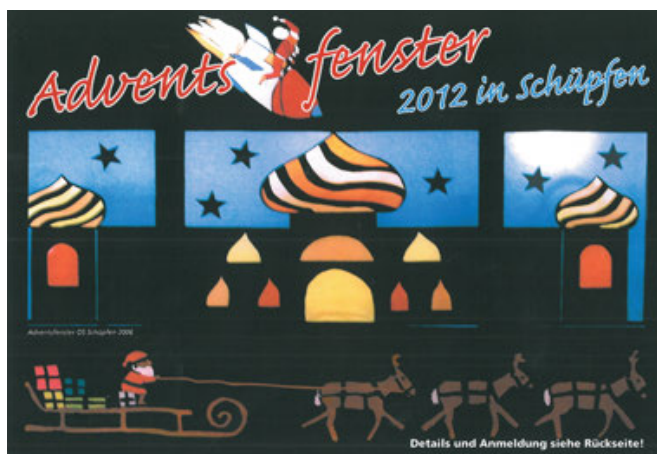

Abb. 54: Flugblatt Adventsfenster Schüpfen. 
Grundauftrag der Institution, zu den Öffnungszeiten oder $\mathrm{zu}$ wiederkehrenden Angeboten, z.B. bei der Karte von migraweb.ch, (B 273), dem Faltblatt des Schützenwegspielplatzes (B 267) oder dem Infoblatt der Bibliothek Schüpfen (S 102).

Bei einigen semiprofessionellen Arbeiten wurden vermutlich kostenlose Online-Gestaltungsprogramme verwendet, wie es sie seit einigen Jahren für die Herstellung von Flyern, Postkarten, Postern, Visitenkarten und Fotoalben gibt (z.B. canva.com, zazzle.com, bookfactory.com, vistaprint.com). Speziell fallen hier das Plakat und der Flyer für Jugendgottesdienste und -angebote der Kirchgemeinde Schüpfen ins Auge (S 75, siehe Detailanalyse, 85, 87, 413). Hinter den semiprofessionell gestalteten Artefakten werden eher Personen jüngeren Jahrgangs vermutet, die sich in ihrer Freizeit eingehender mit digitalen Gestaltungstools beschäftigen und deshalb auch nicht abgeneigt sind, in Freiwilligenarbeit oder im Rahmen ihrer Arbeit für die soziale Institution Kommunikationsmittel zu gestalten.

Die wenigen professionellen Arbeiten, die im gesammelten Kommunikationsmaterial der Gemeinwesenarbeit ausfindig gemacht werden konnten, ungefähr ein Zehntel, sind nach Einschätzung der Experten allesamt als Einzelaktionen oder im Rahmen kleinerer Kampagnen entstanden. Hierfür wurde vermutlich einmalig ein Grafikbüro engagiert oder bei größeren städtischen Institutionen vielleicht auch der dort angestellte Hausgrafiker beauftragt. Beispiele solcher professioneller Gestaltung sind die Postkarte für die 〈Kulturlegi〉 der Caritas Bern (B 345), die Werbekarte für eine Lesung in der Bibliothek Schüpfen (S 101) oder die Kampagne für die Berner Mütterberatung in verschiedenen Fremdsprachen (B 271, 272). Vermutlich bieten manchmal befreundete Gestalter oder lokal angesiedelte Druckereien den Institutionen des Gemeinwesens Sonderkonditionen oder Gratisdienste an, wie etwa für den Flyer des vom Quartierverein organisierten Frühlingsmarkts auf dem Loryplatz (B 333), der gemäß Aufdruck von der nahe gelegenen Druckerei 〈Aquaprint〉 kostenlos produziert wurde. Nur gerade drei professionelle Beispiele - die Visitenkarte als Teaser für den 〈Schtibäng〉, das Verzeichnis aller Organisationen im Kinder- und Jugendbereich, herausgegeben vom Jugendamt Stadt Bern (B 342), das diagonal zum Spezialformat zugeschnittene Faltblatt für das Jugendparlament (B 278) und die Informationen zum 〈Kinderbüro〉 Bern (B 279) - lassen dieselbe Handschrift erkennen. Aufgrund des eingängigen und dem Thema Kinder- und Jugendarbeit angepassten Illustrationsstils der Grafikerin Judith Zaugg sind diese Artefakte rasch zuzuordnen und wiedererkennbar. Beim städtischen Jugendangebot ist also ein Wiedererkennungseffekt feststellbar, der bei den restlichen «Einzelaktionen» nicht erreicht wird. Die wenigsten Profiarbeiten erwecken den Anschein, als wären sie das Resultat eines wohldefinierten Auftrags an eine externe Agentur oder in die Entwicklung einer Corporate Identity oder in ein übergreifendes Konzept eingebunden. Eine Ausnahme bildet hier das 
nach wiedererkennbarem Muster gestaltete Informationsmaterial des interkulturellen Frauentreffs 〈Karibu〉 Zollikofen (Z 61-63) - allerdings wirkt die visuelle Sprache veraltet und scheint bereits länger in Gebrauch zu sein. Die untersuchten professionell gestalteten Kommunikationsmittel erwecken deshalb insgesamt den Eindruck, dass die Kommunikationsbudgets - aber auch das Gestaltungsbewusstsein - im Bereich der Gemeinwesenarbeit gering sind, so dass das Elaborationsniveau kaum über «nett» gestaltete Einzelarbeiten hinaus auf die Ebene eines ganzheitlichen, zeitgemäßen Konzepts und Erscheinungsbilds ansteigt.

Betrachtet man die Absenderorganisationen der Profiarbeiten, so wird mehrheitlich bei größeren, oft zentral von der Stadt aus geleiteten Einrichtungen in professionelle Gestaltung investiert. Inhaltlich finden sich auf den professionell gestalteten Beispielen meist generelle Informationen $\mathrm{zu}$ den Institutionen des Gemeinwesens oder zu länger bestehenden Angeboten, was den größeren finanziellen Aufwand auch rechtfertigt. Zudem werden für Einzelanlässe, die großflächiger beworben werden, punktuell professionelle Gestalter hinzugezogen und auffallendere Formate gesucht. Dies etwa bei einem A3-Plakat der Quartierjugendarbeit, das ein Ferienangebot für junge Frauen bekanntmacht (B 337), oder dem illustrierten Flyer für ein Quartierfest in Holligen (B 319).

\subsubsection{Vergleich Stadt, Agglomeration und Land: Agenturarbeit aus der Stadt, dekorative Druckwerke von ausserhalb}

Die Bandbreite des visuellen Kommunikationsmaterials im Bereich Gemeinwesenarbeit ist in der Stadt etwas größer als in der Agglomeration oder auf dem Land. Wie bei der Lokalpolitik wird die städtische Vielfalt jedoch vor allem auf die größere Anzahl von Institutionen des Gemeinwesens sowie auf verschiedene in der Stadt lokalisierte Zentralstellen zurückgeführt. Im ländlichen Gebiet ist die Präsenz der Kirche sichtbarer, sie übernimmt und bewirbt hier auch Aufgaben, die in der Stadt von spezialisierten Institutionen oder Quartierzentren ausgeführt werden. Da die städtischen Dienststellen ihre Angebote oft professionell bewerben, ist auch der Anteil an professioneller Grafik in der Stadt leicht höher als auf dem Land oder in der Agglomeration - während in der Stadt fast zwanzig Prozent der Artefakte professionell gestaltet wurden, sind es außerhalb nur etwas mehr als zehn Prozent und auf dem Land noch weniger. Das Gesamterscheinungsbild ist jedoch in allen drei Gemeinden ähnlich. Die Experten konnten nicht feststellen, dass in der Stadt grundsätzlich gekonnter gearbeitet wird als in den anderen Gemeinden - weder im professionellen, semiprofessionellen noch im Laienbereich. Hochprofessionelle, meisterhafte oder besonders originelle Beispiele sucht man in allen drei Gemeinden vergeblich. Gleichwohl stammen jene Arbeiten, die 
am positivsten beurteilt wurden, allesamt aus der Stadt. Dazu gehören der Programmflyer mit kunstvoller Illustration und sorgfältiger Typografie des Integrationszentrums für Migranten 〈Zentrum5〉 (B 1) und der sauber gestaltete Flyer für ein Generationenprojekt der Berner 〈Job-Börse〉 und 〈Pro Senectute〉 Bern (B 269).

Einen Unterschied sehen die Experten darin, dass die städtische Profigrafik eher von Agenturen oder Grafikbüros gestaltet wurde, während jene auf dem Land und in der Agglomeration eher von lokalen Druckereien hergestellt und somit mehrheitlich von Polygrafen entwickelt worden sein dürfte. Dieser Umstand könnte auch eine Reihe auffallend aufwändig produzierter Druckwerke aus der Agglomeration erklären, wie den Faltprospekt des Sportzentrums 〈Hirzi〉 (Z 48), der mit Transparentlackmotiven veredelt wurde, oder den aufwändig hergestellten Katalog von «Dialog Gesundheit` aus Zollikofen (Z 34). Trotz hoher Produktionsqualität genügt vor allem der Katalog mit seinem dekorativen Ansatz den Maßstäben der Experten an gestalterische Qualität nicht. Andere Beispiele, die gestalterisch weniger elaboriert sind, wurden im Bereich der semiprofessionellen Arbeit angesiedelt, könnten aber auch von Druckereien gestaltet worden sein, z.B. die Gemeinde- und die Bibliotheksinformationen von Schüpfen (S 412, S 102) oder der Flyer für einen durch das «Märit-Komitee` veranstalteten Adventmarkt in Zollikofen (Z 375).

Auch die in allen Gemeinden überwiegenden Laienarbeiten weisen keine unmittelbar ins Auge stechenden Unterschiede auf, die auf ihren Herkunftsort zurückzuführen wären. Auf dem Land finden sich im Vergleich zur Agglomeration vielleicht etwas mehr «engagierte», «authentische» Laienarbeiten, die sich durch handgemachte Elemente oder aufgrund einer originellen Gestaltungsidee hervorheben, die teils «liebevoll» umgesetzt wurde. Beispiele hierfür sind die kreisförmige Handzeichnung und -beschriftung auf dem Flyer für einen Kindergottesdienst der Kirchgemeinde Schüpfen (S 86, Abb. 55) oder der von Hand in Form einer Tageskarte zugeschnittene Gemeindeaushang, der somit in origineller und freundlicher Weise das Angebot der vergünstigten Tageskarte bekanntmacht (S 96, Abb. 57). In der Laiengestaltung aus der Agglomerationsgemeinde wird zwar teilweise ein «großer Gestaltungswille» sichtbar, doch führen die am Computer hinzugefügten Fotos, «Cliparts», Schriftauszeichnungen und grafischen Zierelemente (vermutlich entgegen der Absicht) zu einer unpersönlichen oder auch langweiligen Wirkung. Die Einladungszettel von «Dialog Gesundheit〉 (Z 37-39) wirken durch ihre vielen Gestaltungs- und Auszeichnungsmerkmale gar «überorchestriert» und «übermotiviert». In der Stadt halten sich engagiert wirkende und ins «Verschnörkelte» bis «Lieblose» tendierende Laienarbeiten in etwa die Waage. 


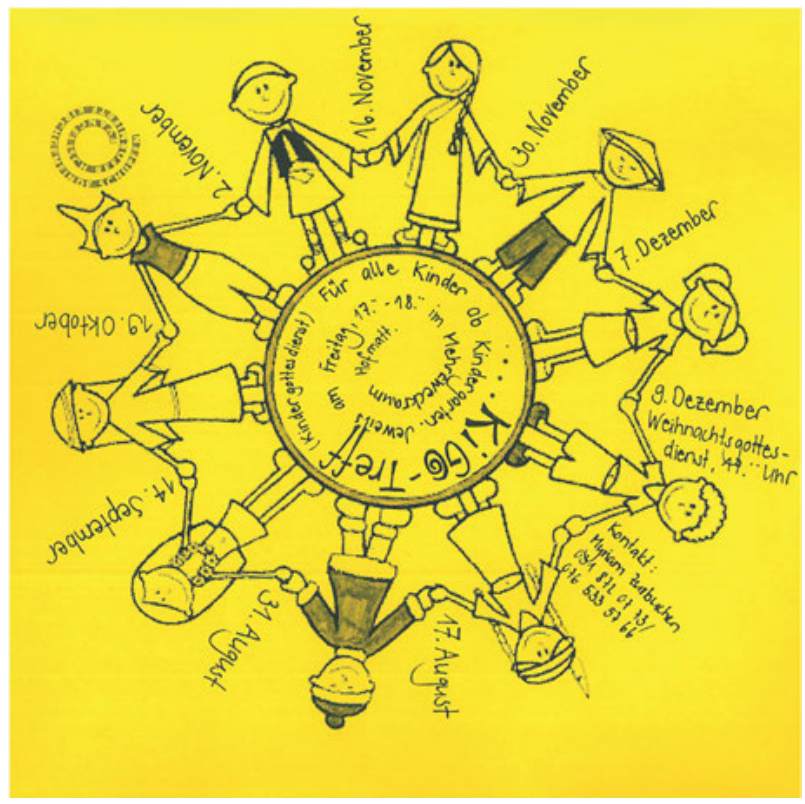

Abb. 55: Veranstaltungszettel 〈KIGO-Treff〉 reformierte Kirchgemeinde Schüpfen.

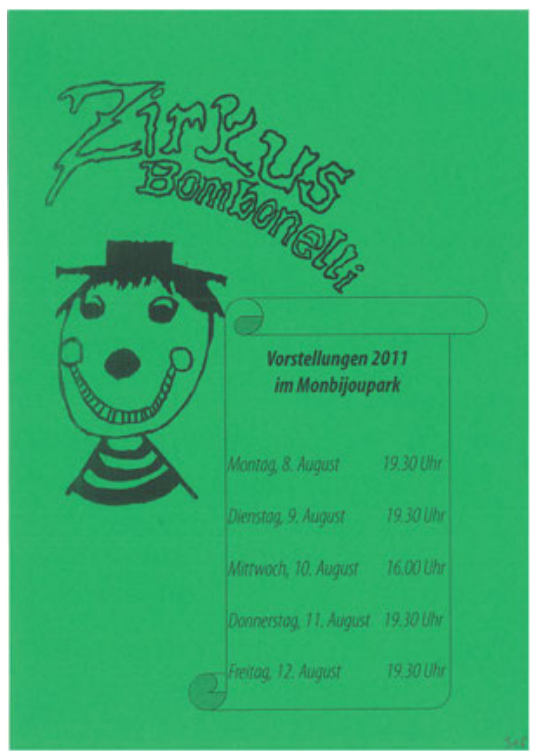

Abb. 56: Flyer ¿Zirkus Bombonelli〉 Bern.

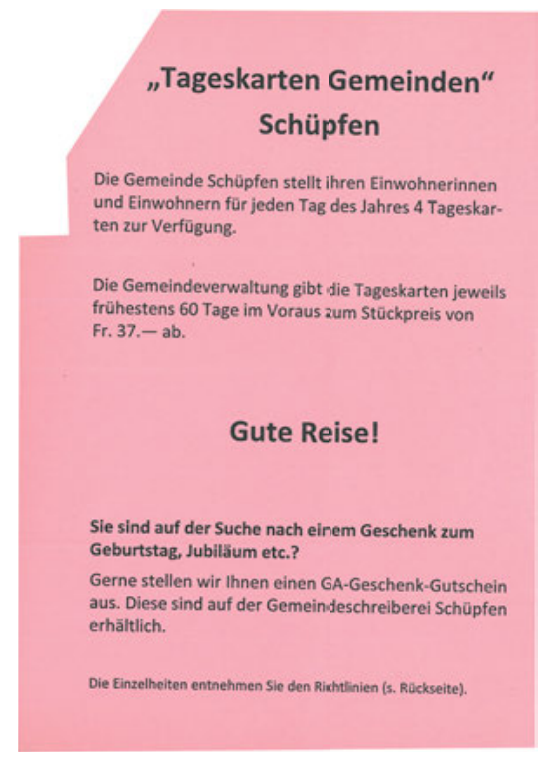

Abb. 57: Informationsblatt Gemeindetageskarten Schüpfen. 
In puncto Formaten stellen die Experten - ähnlich wie in der Lokalpolitik in der Stadt eine besondere Vorliebe für das Postkartenformat fest, doch kommen Postkarten und Handzettel im Postkartenformat auch in der Agglomeration häufig und auf dem Land vereinzelt vor. Aufgrund des hohen Laienanteils sind einfache Formate überall am häufigsten. Dazu gehören auf dem Standardformat A4 basierende (ganz, halbiert, geviertelt, gefaltet), ungebundene Formate sowie unverarbeitete, ungestrichene und leichtgewichtige Papiere. Die so produzierten Artefakte können gleichermaßen als Kleinplakate, Flugblätter oder Informationsschreiben eingesetzt werden. Spezialformate und -anfertigungen bilden überall die Ausnahme, kommen jedoch in allen drei Gemeinden vor, z.B. Visitenkartenund Buchzeichenformate oder auch Sonderzuschnitte (B 192, B 342, Z 43, B 276, S 41, S 410, B 278).

\subsubsection{Elaboration und Angemessenheit: Minimalstandards und professionelle Vorlagen für die Laiengestaltung statt semiprofessionelle «Charakterlosigkeit»}

Für die Experten gestaltete sich die Differenzierung und Einschätzung der Artefakte aus der Gemeinwesenarbeit schwieriger als in der lokalpolitischen Kommunikation, da eine große Zahl an Laienarbeiten $\mathrm{zu}$ beurteilen war, mit denen sie in ihrer Arbeit als Jurymitglieder, Gestaltungsdozierende und praktizierende Grafikdesigner kaum konfrontiert werden. Kriterien der Zuordnung und Bewertung waren hier erst $\mathrm{zu}$ definieren, um die auf den ersten Blick kaum unterscheidbaren Arbeiten in ihrer Eigenart sehen und würdigen zu können. Das Gros der vorgefundenen Laiengestaltung ist simpel in Aufbau und Aussage, wurde anscheinend ohne größere Anstrengung oder gestalterische Überlegung von Laien in Word gestaltet und mit ein, zwei das Thema illustrierenden Fotos oder «Cliparts` ergänzt. Bei der Beurteilung des Materials zeigt sich - gerade auch im Vergleich zu den zahlreichen Versuchen aus der lokalpolitischen Kommunikation, sich von der Menge abzuheben -, dass in der Gemeinwesenarbeit nur die wenigsten Beispiele darauf abzielen, auf textueller oder visueller Ebene etwas Originelles zu kreieren oder sich in irgendeiner Weise von anderen Kommunikationsangeboten zu unterscheiden. Text und Abbildungen beschreiben und illustrieren den beworbenen Anlass meist wörtlich und direkt und verwenden kaum griffige Slogans oder (visuelle oder verbale) rhetorische Figuren. So wird etwa das Angebot des Kerzenziehens mit einer Kerze illustriert (z.B. B 9, B 287, B 310, Z 379, siehe Detailanalyse), der Suppentag mit einem Teller Suppe (S 84), die Festtags-Öffnungszeiten der Bibliothek mit einem Weihnachtsbaum (B 254). Genau genommen sind selbst diese «direkten〉 Illustrationsmodi visuelle Figuren, meist 
Synekdochen oder Metonymien: Die Kerze und die Suppenschale sind Teile des propagierten Anlasses, der Weihnachtsbaum steht symbolisch für Weihnachten und Weihnachten wiederum ist die Ursache für die längeren Schließungszeiten der Bibliothek. Gleichwohl sind dies figurale Modi der Illustration, die wir ohne Umschweife $\mathrm{zu}$ deuten vermögen und die ins Standardrepertoire der visuellen Kommunikation übergegangen sind.

Eine Ausnahme bilden hier die auffälligen Wiederholungen von Text oder Bild auf den Plakaten zu einem Adventsanlass der Kirchgemeinde Frieden (B 327, 329) und einem Lesezirkel im Quartierzentrum Villa Stucki (B 6), die man im Sinne einer visuellen Repetitio deuten könnte. Auf den Plakaten des Adventsverkaufs wurde der markante, um die Ecke verlaufende Titel bildhaft eingesetzt und durch die Verdoppelung um beide Ecken ergibt sich eine Art Rahmen. Auf dem anderen Beispiel erzeugt die mehrfache Wiedergabe von «Lesemäusen» in unterschiedlichen Größen einen visuellen Effekt, der die Aufmerksamkeit anzieht. Ob die Wiederholung von Elementen bei diesen Artefakten figural intendiert ist oder ausschließlich dekorativen Zwecken dient, ist aus Sicht des Betrachters nicht $\mathrm{zu}$ entscheiden. Es ergibt sich sozusagen eine 〈Barbarismus〉-Situation, bei der nicht definitiv zwischen Figur und Fehler, zwischen Kunstgriff und Dilettantismus, unterschieden werden kann. Auch wenn das Gros der von Laien gestalteten Arbeiten auf den ersten Blick austauschbar erscheint, lassen sich unterschiedliche Elaborationsstufen und typische Ausformungen unterscheiden. Der Ausarbeitungsgrad reicht von «rudimentärer» Gestaltung, die von einem gänzlich ungeübten und unreflektierten Umgang mit dem Anwendungsprogramm zeugt, ${ }^{5}$ über unkomplizierte, aber übersichtlich und ansprechend gestaltete Laiengrafik, ${ }^{6}$ bis $\mathrm{zu}$ den verfeinerten Laienarbeiten, in der die limitierten Möglichkeiten der Software ausgeschöpft und die Stilmittel verhältnismäßig gekonnt eingesetzt werden. ${ }^{7}$ Bei der Produktion reicht die Palette vom simplen auf Standard-A4-Papier vervielfältigten Zettel zur etwas aufwändigeren, aber immer noch auf einem PC-Anwendungsprogramm gestalteten Arbeit, die nach dem Vervielfältigen noch von Hand zugeschnitten, geheftet, gefaltet oder verziert wurde.

5 Beispielsweise die Kleinplakate für einen Mädchentreff in Bern (B 288, siehe Detailanalyse), eine literarische Schreibwerkstatt der Berner Kirchgemeinden (B 16), einen Meditationsabend der Pfarrei Dreifaltigkeit (B 25), einen «Bring-und-Holtag` der Gemeinde Schüpfen (S 93) oder die Einladungen zu den Anlässen des «Dialog Gesundheit` in Zollikofen (Z 37-39).

6 Z.B. Information zur Spielplatzeinweihung in Bern (B 286, Abb. 49), Bibliotheksnacht (S 100), Kleinkindertreff in Schüpfen (S 89), Werbeflyer Feuerwehr Zollikofen (Z 370, siehe Detailanalyse).

7 Z.B. Kleinplakat (A4) und Flyer (A5) Kerzenziehen Kirchgemeinde Frieden Bern (B 9, 10), Flugblatt Gymnastikangebot der Frauenriege Zollikofen (Z 45), Infozettel Suppentag Kirchgemeinde Schüpfen (S 84). 
Das häufigste Format ist das «Flyer-Plakat» im Hochformat auf Standardpapier A4. Oft werden auf ein A4-Blatt zwei Programme gedruckt, so dass dieses zu zwei A5-Formaten zugeschnitten werden kann. Zwei Produktionsvarianten werden von den Experten unterschieden: Bei der «altmodischen» Version wird einfarbig Schwarz auf buntes Standardpapier fotokopiert, was das Plakat auffällig und freundlich wirken lassen soll. Ab und $\mathrm{zu}$ werden für denselben Anlass unterschiedliche Papierfarben als Varianten verwendet (z.B. Information zu den Gemeindetageskarten Bern, B 294, 297, Abb. 51; Anlass zum Kirchensonntag der reformierten Kirchgemeinde Frieden Bern, B 14, 15). Die aktuellere, der technischen Entwicklung und größeren Verbreitung des Farbdruckers und -kopierers folgende Variante ist der Farbausdruck oder die Farbkopie auf weißes Kopierpapier, wobei hier das Logo, farbig ausgezeichnete Schrift sowie Abbildungen in Farbe als «Eye-Catcher» fungieren.

Die Experten haben diverse typische Merkmale der Amateurgestaltung herausgearbeitet: Bei Laien beliebt sind «Cliparts〉, d.h. vorgefertigte, oft comicartige Illustrationen zuallen möglichen Themen sowieSchriftzüge mit Schattenwurf oder Verzerrung, wie sie etwa mit «WordArt〉 erstellt werden können - als Blickfang oder ganz einfach zur Ausschmückung. ${ }^{8}$ Ebenfalls bevorzugt werden «sympathische» Schreibschriften wie «Comic Sans `. ${ }^{9}$ Die Abbildungen werden in den Laienarbeiten vorwiegend wie Text - nach einem Zeilenumbruch - eingefügt. Alternativ werden Bilder von Laiengestaltern auch gerne transparent gemacht oder entsättigt und dem Text hinterlegt. ${ }^{10}$ Dieses Verfahren ist gestalterisch aus Sicht der Lesbarkeit und Trennung der Ebenen problematisch und sollte laut Experten in der Profigestaltung grundsätzlich vermieden werden. Die verwendeten Fotos und Illustrationen wurden vermutlich von Laien im Umfeld der Institution selbst aufgenommen bzw. gezeichnet oder aus dem Internet entnommen (was urheberrechtlich nicht unproblematisch wäre) - Quellenangaben sind auf den analysierten Kommunikationsmitteln kaum zu finden. Zur Kennzeichnung der Absenderinstitution verwenden die meisten Amateurarbeiten einen wiederkehrenden Schriftzug oder ein Signet, die als «Header» bzw. Kopfzeile fungieren. Bei den A4-Plakaten des «Chinderchübu> etwa wird ein markantes Logo jeweils über den ganzen linken Bildrand verlaufend gesetzt (B 309-314), bei den Flyern der Kornhausbibliotheken

8 Vgl. die Plakate zum «Badifest` und zur 1. August-Feier in Schüpfen (S 394, Abb. 58; S 92) oder zum Handwerkerbasar im Quartierzentrum 〈Wylerhuus〉 Bern (B 258, Abb. 59).

9 Vgl. Kindersingen Schüpfen (S 396), Spielnachmittag (B 286, Abb. 49), Spielgruppe Familienverein Holligen (B 298), Musik- und Tanzanlass Kirchgemeinde Frieden (B 8, Abb. 60), «Dialog Gesundheit> (Z 37-39).

10 Vgl. Flyer Kinderwoche (S 73), Krabbelgruppe Villa Stucki (B 289, 290), Feuerwehr (Z 370, siehe Detailanalyse). 


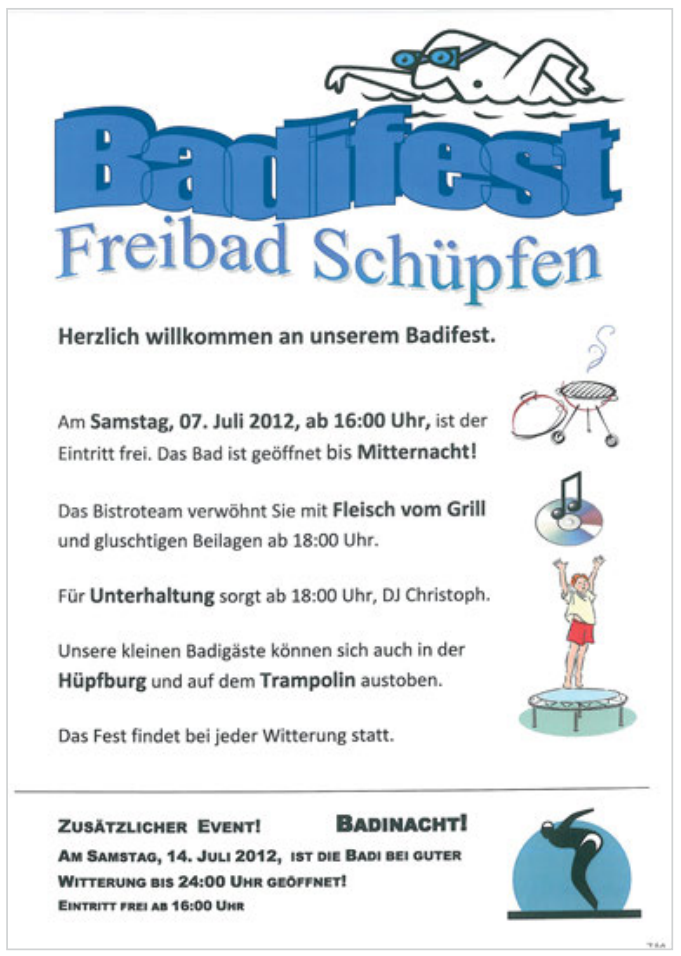

Abb. 58: Kleinplakat «Badifest` der Gemeinde Schüpfen.

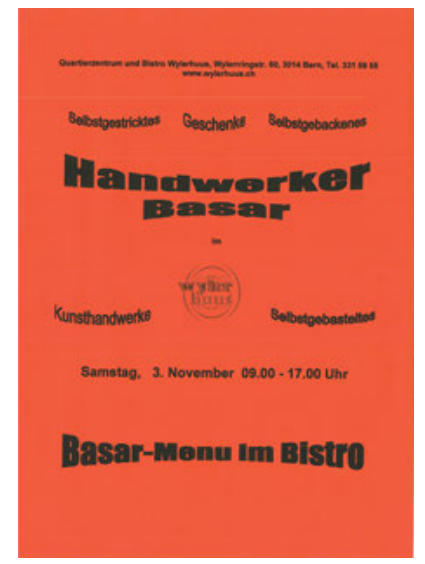

Abb. 59: Kleinplakat «Handwerkerbasar, Wylerhuus Bern.

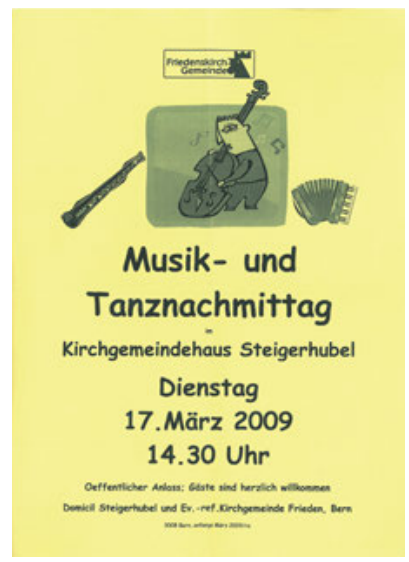

Abb. 60: Kleinplakat musikalischer Anlass, reformierte Kirchgemeinde Frieden Bern. 
Breitenrain und Zollikofen erscheint das Signet klassisch als Kopfzeile (B 252, 253 bzw. Z 52, 53, 376), ebenso bei den Kommunikationsmaterialien der Berner Kirchgemeinde Frieden (B 11, 12, 18, 27) und der reformierten Kirchgemeinde Zollikofen (Z 371-374). Trotz dieser Bemühungen um Einheitlichkeit bleiben die Laienarbeiten meist ohne durchgehende Sprache oder deutlichen Wiedererkennungswert.

Aus der weitgehend gleichförmigen Masse der Laienarbeiten hebt die Expertin in ihrer Schlussauswahl einige Beispiele hervor, die trotz - oder gerade wegen - ihrer spezifisch dilettantischen Ausführung etwas Bemerkenswertes ausstrahlen, das auch für Gestaltungsprofis interessant ist, sei es, weil die Artefakte aufgrund ihrer «handgestrickten» Machart engagiert oder liebevoll wirken oder weil sie auf einer simpel umgesetzten, aber überzeugenden Idee aufbauen (vgl. Grafik 4). So ergibt sich beispielsweise auf dem mit einfachsten Mitteln gestalteten Kleinplakat des «Zirkus Bombonelli〉 (B 315, Abb. 56) durch die Kombination einer grafischen «Clipart〉-Schriftrolle mit einer wackeligen Kinderzeichnung ein schönes Zusammenspiel von Stricharten und -dicken. Die Gestaltung verströmt etwas «Liebenswertes». Die Gesamtkomposition wirkt durch die Platzierung der Elemente auf einem großzügig belassenen waldgrünen Hintergrund gelungen. Auf ihre je eigene Weise «charmant» wirken für die Expertin auch der 〈MaxiEvent>-Flyer der Jugendarbeit Schüpfen (S 91) in seinem unbeschwerten, beinahe naiven Spiel mit Schriften und Farben und der Programmflyer für die Kindergottesdienste der Kirchgemeinde Schüpfen (S 86, Abb. 55), der gleich mit drei außergewöhnlichen Merkmalen aufwartet: Er wurde komplett von Hand gezeichnet und beschriftet, die Gestaltung baut auf dem Bild anstatt dem Text auf und das Papier wurde zu einem unüblichen quadratischen Format zugeschnitten. Ähnlich charmant und überzeugend wirkt auf die Expertin das Informationsblatt für die Gemeindetageskarten in Bern mit seiner simplen Idee, die Struktur des Bahnabonnements als Hintergrund zu verwenden (B 295). Wo die Idee überzeugt, wird für die Expertin eine professionelle Ausführung zweitrangig.

Sowohl über die Ansprüche an den minimalen Elaborationsgrad als auch über die Qualität der umgesetzten Ideen in der visuellen Kommunikation der Gemeinwesenarbeit sind sich die beiden Experten nicht immer einig. Kontrovers beurteilt wird etwa das billig und vermutlich semiprofessionell produzierte «Fotoalbum», das im Nachgang eines Seniorenanlasses verschiedener Berner Kirchgemeinden erstellt wurde (B 29). Einerseits wird dieses Album als originelles Angebot eingeschätzt, das die Zielgruppe abhole und ihr Bedürfnis nach «Sehen und Gesehen-Werden» erfülle. Andererseits könne ein solches Album durch die ungewohnte Form der Dokumentation eines bereits durchgeführten Anlasses inmitten der sonst üblichen Veranstaltungsankündigungen in diesem Bereich auch für Verwirrung sorgen. Solche neuartigen Kommunikationsformen müssten also erst ausgetestet werden - und hier wäre $\mathrm{zu}$ überlegen, wer als Zielgruppe 
gelten und wie das Album distribuiert werden sollte. Wird das Album nur an die Teilnehmenden verteilt oder soll es in größerer Stückzahl aufgelegt werden? Weniger aufgrund der Idee als wegen ihres rudimentären Elaborationsgrads sorgen andere Beispiele für Uneinigkeit. Bei der Ausschreibung des Programms für den «Moditreff` in Bern (B 288, siehe Detailanalyse) wird für die Expertin ein «unfreiwilliger Charme» spürbar, der durch die chaotische, komplett dilettantische Gestaltungsweise freigesetzt wird. Die Verbindung von Recyclingpapier mit den von Hand mit Leuchtstift kolorierten Elementen ließe sich aus ihrer Sicht gar für die professionelle Gestaltung adaptieren, z.B. für den Flyer eines Quartierfests. Für den Experten zeugen die gänzlich ungeordnete Platzierung der Elemente, die vor dem Kopieren noch rasch handschriftlich ergänzten Angebote und die unsauber handkolorierten Motive dagegen von einem «unzumutbaren» Dilettantismus. Ist diese Art von Gestaltung ein unverfälschtes, die Zielgruppe ansprechendes - oder sogar von dieser selbst gestaltetes - Beispiel? Oder sind solch offenkundig dilettantischen Produkte «einfach nur hässlich», ein «Affront» für gestalterisch geschulte Augen und stilbewusste, urbane Menschen? Diesen Fragen wird in den Detailanalysen (Kap. 2.6) und im Rahmen der designbasierten Wirkungsstudie (Kap. 3) genauer nachgegangen.

In ihrer Gesamtheit halten die Experten die vorgefundenen Kleinplakate und Faltprospekte aus dem Bereich der Laienarbeit durchaus für passend - bezogen darauf, was sie für die Gemeinwesenarbeit kommunikativ leisten wollen und sollen. Dem Kommunikationsmaterial ist anzumerken, dass sich die Absenderinstitutionen nicht allzu sehr bemühen müssen, ihr Zielpublikum zu erreichen. Im Gegensatz zur politischen Kommunikation findet ein Großteil der visuellen Kommunikation der Gemeinwesenarbeit vor Ort statt, d.h. in den Räumlichkeiten des Absenders selbst, im Kirchgemeindehaus, im Quartierzentrum, in der Bibliothek oder im Vereinslokal. Das anvisierte Publikum sei daher schon am Ort des Geschehens, wenn es das Flugblatt oder Plakat zu Gesicht bekommt, und es bringe daher vermutlich ein grundsätzliches Interesse für das Angebot der Institution mit. Viel mehr als eine Information mit den Eckdaten des Anlasses braucht es deshalb auch gar nicht. Bei langfristigen und wiederkehrenden Angeboten wie den Gemeindetageskarten, den Vorlesestunden der Bibliothek, den Seniorentreffs der Kirchgemeinde oder der Krabbelgruppe im Quartierzentrum dienen die FlyerPlakate aus der Sicht der Experten eher als «Reminder» für ein Angebot, das dem Zielpublikum bereits bekannt ist. Innerhalb jenes großen Bereichs der visuellen Kommunikation, der die Zielgruppe in ihrem vertrauten Umfeld anspricht, wird der Typus einfachster Laiengestaltung, der in Word oder anderen Anwendungsprogrammen gestaltet wird, deshalb als ausreichend und angemessen wahrgenommen. Diese Artefakte müssen laut Experten nicht «professionell gestaltet» sein und sie müssen sich weder durch Originalität auszeichnen noch besonders 
engagiert wirken. Aus Sicht der Rhetorik reicht hier die einfache Informationsebene (docere) aus, es braucht weder einen besonders gewinnenden oder unterhaltsamen Auftritt (delectare), noch eine starke emotionale Ansprache (movere).

Dennoch sind gewisse Ansprüche an die Elaboration selbst in der visuellen Kommunikation der Gemeinwesenarbeit unantastbar. Wie bereits bei der lokalpolitischen Laienkommunikation halten die Experten ein Grundmaß an Übersichtlichkeit und Lesbarkeit für unverzichtbar und eine sinnvolle Anordnung und Hierarchisierung der unterschiedlichen Text- und Bildelemente kann die Laiengestaltung deutlich verbessern. Als Grundregel lässt sich formulieren: Finde ich ohne Umschweife heraus, worum es geht? Ist der Text gut lesbar und die Botschaft verständlich? Zudem wird gefordert, dass eine minimale Einheitlichkeit der Kommunikationsmittel über die Zeit gewahrt bleibt - wobei es für serielle Anlässe ausreicht, Datum, Papierfarbe und Abbildung auszuwechseln und den Kopfteil beizubehalten. Schließlich sollte aus Expertensicht ein minimales Bemühen um Ästhetik, Qualität und Sauberkeit erkennbar sein. Der in die Gestaltung investierte Aufwand sollte auch hier der Wichtigkeit und Funktion der Absenderinstitution und ihrer Beziehung zu den Zielpersonen angepasst sein. Zur Erstellung eines Infozettels für den Schreibdienst der Freiwilligenagentur 〈Benevol` Bern (B 299) wurde offensichtlich einfach eine Webseite der Institution ausgedruckt - wobei die Hierarchie durcheinandergebracht und sogar Textteile abgeschnitten wurden. Ein solches Artefakt wirkt «schludrig», stellt den Absender in ein unseriöses Licht und wird dem engagierten Angebot der Freiwilligen nicht gerecht. Solche simplen Computerausdrucke sowie andere simple Elaborationsformen wie eine rasch hingeworfene, handschriftliche Notiz mögen in einem informellen Kontext oder im privaten Rahmen angebracht sein, sind zur Bekanntmachung von Angeboten der Gemeinwesenarbeit jedoch zu wenig elaboriert und können zu einer negativen Wahrnehmung der Absenderinstitution und ihrer Angebote führen. Die rhetorische Ebene des Ethos, die sich auf die Wahrnehmung der Glaubwürdigkeit des Absenders auswirkt, darf also selbst im Bereich der Laiengestaltung nicht unterschätzt werden.

Gleichzeitig hinterlässt gerade die «Einfachheit und Zurückgenommenheit», wie sie in vielen Laienarbeiten durch ihren niedrigen Elaborationsgrad zum Ausdruck gebracht wird, einen der Gemeinwesenarbeit angemessenen, positiven Eindruck. Deshalb wird der Hang zur opulenten Ausgestaltung, den einige Arbeiten aufweisen und der vorwiegend dekorativen Zwecken dient, eher als unpassend wahrgenommen. Der Versuch, durch eine Vielzahl von «Cliparts`, die keine zusätzliche Information bringen, durch hinterlegte Bilder, verschiedene Schriftarten, Auszeichnungen und Verzierungen oder auch schmückende Rahmen, Muster oder Spezialeffekte wie Schattenwürfe das eigene Werk zu verschönern 
oder «aufzupeppen», ${ }^{11}$ wird als «unnötig» oder gar «störend» betrachtet. Dieses bloße «Aufhübschen» der grafischen Arbeiten wird angesichts der immer vielfältiger werdenden Ausgestaltungsmöglichkeiten in Büroprogrammen, aber auch des Angebots von Gestaltungstools für Laien als beunruhigende Tendenz gesehen, in welche die visuelle Kommunikation in der Gemeinwesenarbeit in Zukunft gehen könnte. Die bislang einfache, auf Informativität ausgerichtete Laiengestaltung wird dadurch mehr und mehr «optisch aufgeladen». Die immer noch dominante, unkomplizierte Form der Wordgestaltung, die noch an die Fotokopierästhetik der 1970er Jahre erinnert, wirkt in den Augen der Experten letztlich sympathischer, ehrlicher und angemessener als die künstlich verschönerten bis «gestylten» Kommunikationsmittel.

Im Bereich der semiprofessionellen Gestaltung reichen die Möglichkeiten der Ausgestaltung aufgrund der Nutzung komplexer Gestaltungsprogramme wie Adobe 〈InDesign〉, 〈Illustrator〉 oder 〈Photoshop〉 noch weiter - und damit vergrößert sich in den Augen der Experten auch die Gefahr, dass Gestaltungsoptionen ohne Überlegung oder im Übermaß eingesetzt werden. Mehrere Ebenen können nach Belieben übereinander geschoben, Text- und Bildelemente frei positioniert, gedreht und transformiert, Farbverläufe, Texturen oder Lichteffekte integriert werden. Entsprechend ist der reichliche bis übertriebene Einsatz von Ornament und Zierrat geradezu ein Erkennungsmerkmal für die semiprofessionelle Gestaltung, die im Bereich der Gemeinwesenarbeit vorgefunden wurde: Vom Faltblatt der Villa Stucki (B 2) über die Postkartenflyer «Streetdance〉 des Blauen Kreuzes (B 353) und der kirchlichen Jugendarbeit (S 413) bis zum Kleinplakat für ein Jubiläumskonzert in der Kirche (S 78) - überall lässt sich die Verwendung vielfältiger, oft rein zierender Gestaltungselemente und -effekte feststellen. Die genannten Arbeiten werden als einfältig, aber immer noch akzeptabel eingeschätzt. Ein besonders opulent ausgeschmücktes und auffallendes Beispiel aus dem Korpus bilden das Kleinplakat für einen Jugendgottesdienst in Schüpfen (S 75, siehe Detailanalyse) und die in gleicher Manier gestaltete Postkarte (S 85). Die Experten vermuten, dass diese Arbeiten mit neuartigen Gestaltungstools hergestellt wurden, in denen professionell vorgefertigte Layouts zur Verfügung stehen, in denen Elemente wie «Header», Textfelder, Hintergründe, Fotos, Illustrationen oder Farbwelten mit einem Klick hinzugefügt oder verändert werden können. Das Resultat ist aufgrund der beliebig gewählten, disparaten Schriften, Stile und Motive aus Expertensicht schwer einzuordnen, wird aber als gestalterisch minderwertig eingeschätzt (für eine ausführliche Beurteilung siehe Detailanalysen). Neben einem Hang zum Dekorativen ist bei den meisten semiprofessionellen

11 Wie dies etwa auf dem Jahresprogramm des Kulturclubs oder einem Angebot für Fremdsprachige der Kirchgemeinde Frieden (B 19, 20, 23) der Fall ist. 
Arbeiten eine gewisse «Charakterlosigkeit» feststellbar. Obschon sie gekonnt gelayoutet wurden und zurückhaltend in der Verwendung schmückender Elemente sind, bleiben auch der Flyer «Story Telling〉 der Villa Stucki (B 293) oder die Karte zum Angebot «migraweb.ch` (B 273) in ihrer Wirkung seltsam ungreifbar - die einzelnen Elemente sind einfach zu wenig im Hinblick auf einen bestimmten Effekt abgestimmt. Noch undefinierter und weniger engagiert wirken auf die Experten etliche Beispiele im Postkartenformat, das auch von semiprofessionellen Gestalterinnen und Gestaltern geschätzt zu werden scheint. Die Postkarten wirken «gesichtslos», unübersichtlich und überladen, weil zu viele Schichten übereinandergelegt wurden (Einladungskarte zum Apéro des Quartierbüros Holligen, B 360) oder zu viele kleinformatige Bilder nebeneinandergestellt (Quartiermitwirkung Stadtteil 3, B 359) bzw. ineinander verschmolzen wurden (Quartiertreff Steigerhubel B 348). Weniger wäre hier mehr gewesen. Dem gewählten Medium der Postkarte, das auf kleinem Raum pointiert eine augenfällige Botschaft übermitteln soll, werden diese Kommunikationsmittel nicht gerecht. Es finden sich jedoch auch semiprofessionell gestaltete Postkarten, die eine klare visuelle Wirkung entfalten und ihre Zielgruppe in angemessener Weise erreichen, wie etwa der Flyer zu einem Yogaangebot für Kinder (B 35) oder die Infokarte der Jugendarbeit Bern Südwest (B 355).

Für Kommunikationsmittel der Gemeinwesenarbeit, die nicht vor Ort, in der eigenen Institution und im vertrauten Rahmen verwendet werden, sondern eine erweiterte Zielgruppe erreichen sollen, indem sie per Post an Nichtmitglieder verschickt, im öffentlichen Raum aufgehängt oder bei zentralen Stellen ausgelegt werden, scheint es den Experten sinnvoll, diese bei professionellen Gestalterinnen und Gestaltern in Auftrag zu geben. Soll die visuelle Kommunikation im öffentlichen Raum, inmitten von konkurrierenden Angeboten funktionieren, werden höhere Ansprüche an die Gestaltung gestellt. Die Vermittlung der Botschaft muss besser durchdacht und zugespitzt werden, um genügend Aufmerksamkeit, rasches Verständnis und ausreichendes Interesse beim Publikum zu generieren. Wie bereits bei der lokalpolitischen Kommunikation offenkundig wurde, korrelieren die Anforderungen an die Professionalität der Gestaltung mit der Wichtigkeit des Anlasses sowie der Größe und Position des Absenders. Je kleiner und eingeschränkter die Zielgruppe bzw. «Community» ist, je vertrauter die angesprochenen Personen mit den Angeboten und Eigenarten der Absenderinstitution sind, desto freier und «selbstgemachter» kann die Elaborationsform sein. Umgekehrt gilt: Je offizieller und breiter kommuniziert wird und je weniger Vorwissen vorausgesetzt werden kann, desto professioneller, elaborierter und weniger verspielt sollten die Artefakte ausgestaltet sein. Solange sich die visuelle Kommunikation an «Insider» wendet, reicht einfache Laiengestaltung aus - ja sie ist hier laut Experten sogar die angebrachte Kommunikationsart, da sie 
eine Nähe schaffen kann, die durch ein professionelles, hochelaboriertes Produkt rasch verhindert wird. Durch die professionelle Machart erhalten Drucksachen automatisch einen offiziellen und förmlichen Charakter. Gerade ein solcher ist in gewissen Kommunikationssituationen der Gemeinwesenarbeit nicht angemessen, in anderen wiederum schon.

Betrachtet man nun den Anteil professioneller Arbeiten aus dem Bereich Gemeinwesenarbeit, so zeigt sich, dass vor allem die generellen, über längere Zeit aktuell bleibenden Informationen einer Institution, die sich an ein breiteres Publikum richten, professionell gestaltet sind, während Einzelveranstaltungen oder -angebote desselben Absenders oft mittels Laien- oder semiprofessioneller Gestaltung kommuniziert werden. Eine solche Priorisierung erscheint den Experten grundsätzlich sinnvoll und angemessen, da gemeinnützige Institutionen, Vereine, Quartierzentren oder auch die Jugend- und Sozialarbeit mit kleinen Kommunikationsbudgets auskommen müssen. Die professionell gestalteten Artefakte im Untersuchungskorpus zeichnen sich - wie bereits in der Lokalpolitik - kaum durch eine meisterhafte oder herausragende Machart aus. Die Ausnahmen bilden das Kulturprogramm eines Integrationszentrums (B 1), das durch eine originelle, gekonnt von Hand gezeichnete Illustration, ein klares, schlichtes Layout und eine saubere typografische Gestaltung heraussticht, sowie der Flyer für ein generationsübergreifendes Projekt, der mit einfachen grafischen Mitteln das Thema in frischer Weise illustriert (B 269). Die Mehrheit der Profiarbeiten ist zwar sorgfältig ausgeführt und erfüllt die gestalterischen Standardanforderungen, wirkt aber «wenig inspiriert» und durchschnittlich bis langweilig. $\mathrm{Zu}$ nennen wären hier etwa die Postkarte für ein Kinder-Straßenprojekt in Bern (B 307), die Handzettel der Mütterberatung Bern (B 271, 272) oder das Faltblatt für das Rote Kreuz Bern Mittelland (B 256). Einige Beispiele werden als gestalterisch solide eingeschätzt, wirken aber in ihrer Schwarzweiß-Optik «verstaubt», z.B. die Postkarte der «Dargebotenen Hand (B 251) oder die Broschüren des interkulturellen Frauentreffs 〈Karibu〉 (Z 61-63). Nicht immer wird der von der professionellen Gestaltung erhoffte Mehrwert erreicht. So zweifeln die Experten beispielsweise daran, ob das bunt und mit auffälligen Effekten (pink eingefärbte, gerasterte Fotografie, auffällige Displayschrift mit Farbschlieren, sternförmiger Störer) ausgestaltete großformatige Plakat mit dem markigen Titel «Heldinnen`, das ein Ferienangebot für Mädchen bewirbt (B 337), seine jugendliche Zielgruppe visuell anzusprechen vermag und den propagierten Inhalt angemessen veranschaulicht. Auch zwei im Grunde ansprechend und aufwändig ausgearbeitete Beispiele verfehlen bei der visuellen Umsetzung Thema und Zielgruppe: Der A5-Flyer für ein Benefiz-Fest für Migrantinnen (B 193), der analog zur Infokarte des Nähateliers für Migrantinnen gestaltet wurde, das den Anlass organisierte (B 192), wirkt weder festlich noch wurde er mehrsprachig gestaltet, um die verschiedenen Nationalitäten anzuspre- 
chen. Auch die hübsch und aufgeräumt daherkommende Werbekarte für eine Kindertagesstätte verfehlt das Aptum - sie ist aufgemacht «wie ein Inneneinrichtungsprospekt» (B 274, siehe Detailanalyse).

Mitunter werden die professionellen Arbeiten von den Experten unterschiedlich bewertet. Dabei zeigt sich, dass sie ihren Fokus teilweise auf unterschiedliche Elaborationskriterien richten oder in der Beurteilung von divergierenden Ansprüchen geleitet werden. Die Kommunikationsmittel der städtischen Kinderund Jugendarbeit (B 342, 278, 279) etwa werden vom Experten als adäquat und überlegt gestaltete Profiarbeiten hervorgehoben, die aufgrund der darauf abgebildeten grafischen Kinderfiguren einen hohen Wiedererkennungseffekt aufweisen sowie Eltern und Kinder gleichermaßen ansprechen würden. Die Expertin dagegen bewertet dieselben Artefakte aufgrund ihrer billigen Papierqualität und der unsauberen typografischen Ausführung als mangelhaft, ja beinahe schon semiprofessionell. Für eine professionelle Gesamterscheinung kann eine hochwertige Papier- und Druckqualität (hohe Grammatur, Offsetdruck) aus ihrer Sicht ausschlaggebend sein. Denn die Materialität des Trägermaterials übt neben der visuellen auch eine haptische Wirkung aus, die sich in der Gesamtbeurteilung des Artefakts niederschlägt. So wird etwa die Kombination von gestrichener Vorderseite und ungestrichener Rückseite bei der Postkarte der «Dargebotenen Hand> (B 251) von ihr als überraschender, positiver Effekt beurteilt. Unterschiede bestehen zwischen den Experten auch in der Gewichtung der Originalität und des gestalterischen Konzepts der Profiarbeiten der Gemeinwesenarbeit: Sind eine originelle Idee, eine «inspirierte» Ausführung und ein sichtbares Konzept wesentliche Bestandteile professioneller Gestaltung? Oder können auch mittelmäßige, «ideenlose» Entwürfe angemessen sein, solange sie verständlich gestaltet sind und von einer gewissen Selbstverständlichkeit und Souveränität im Umgang mit Schrift, Bild, Leerraum und gewähltem Material zeugen?

Sicherlich sind für die Beantwortung der Frage, wie hoch die Messlatte angesetzt werden kann bzw. welche Anforderungen an die professionelle Gestaltung im Bereich der Gemeinwesenarbeit gestellt werden können, auch die limitierten finanziellen Möglichkeiten der Absenderinstitutionen zu berücksichtigen. Beim untersuchten Status quo vermuten die Gestaltungsfachleute selbst dort, wo professionelle Gestalter engagiert wurden, ein beschränktes Budget. Um mit den bescheidenen Mitteln sinnvoll umzugehen, empfehlen sie - anstatt wie bei den analysierten Beispielen in Einzelaktionen zu investieren -, die Mittel zu bündeln und eine einheitliche und durchdachte Gestaltungslösung entwickeln zu lassen, die sich mit wenig Aufwand für zukünftige Kommunikationsmittel nutzen lässt. Dasselbe Prinzip wie bei der Laiengestaltung kann auch auf die professionelle Gestaltung angewendet werden, wenn das Budget «größere Sprünge» verbietet: Die Gestaltungsprofis erstellen Vorlagen, in welche Laiengestalter anschließend 
selbst Inhalte einfügen und von Mal zu Mal Daten, Abbildungen oder einzelne Farben anpassen können, während der professionell vordefinierte Rahmen beibehalten wird. Dabei sollte jedoch der gestalterische Spielraum limitiert werden, indem nur gewisse Schriften, Größen, Auszeichnungen, Anordnungen und Farben zugelassen sind. Eine solche Kompromisslösung wird von den Experten den mittelmäßigen «Solitären» vorgezogen, wie sie beim professionellen Untersuchungsmaterial der Normalfall sind - aber auch den vielen gesichtslosen und unbefriedigenden semiprofessionellen Lösungen, für deren Druck Geldmittel aufgewendet werden, anstatt sie konzentriert für professionelle Vorschläge einzusetzen.

\subsubsection{Imperfektion: Von mangelnder Sorgfalt bis zum übertriebenen Gestaltungswillen}

Die am meisten verbreitete Form der von Laien gestalteten, einfachen Wordgestaltung verzichtet auf besondere Einfälle oder Abweichungen vom gängigen Gestaltungsmuster. Der Mangel an originellen Ideen ist aus Sicht der Experten bei den Laienarbeiten kein eigentlicher Fehler, da gestalterische Einförmigkeit und die direkte, «buchstäblich» zu verstehende Vermittlung der Information hier Programm sind und entsprechend auch so erwartet werden. Das untersuchte Material enthält eine Vielzahl von typografischen Fehlern und gestalterischen Dilettantismen, die als typisch für diese Art der Laiengestaltung gelten können und für die visuelle Kommunikation der Gemeinwesenarbeit durchaus zulässig sind. Das fehlende Raster, die ungeschliffene typografische Ausgestaltung, die Vorliebe für Pseudohandschriften wie «Comic Sans` und andere verspielt anmutende Schriften (z.B. B 301) oder auch der Einsatz vieler verschiedener Stilelemente (Schriften, Auszeichnungen, Abbildungen etc.). Insbesondere wird in den Laienarbeiten meist zu wenig Weißraum belassen und der Satzspiegel weit nach außen gedehnt (z.B. B 25, B 264). Auf dem verfügbaren Raum wird versucht, möglichst viele Informationen oder Bilder wiederzugeben - bei einem Beispiel wurden gleich neun Fotos in einem Postkartenformat «verpackt» (B 358). Die Qualität der Bilder muss bei der Laiengrafik nicht hoch sein: Fotos können ruhig selbst aufgenommen werden und es reicht aus, wenn sie etwas zu dunkel oder zu hell, verzerrt, in mangelhafter Auflösung oder ohne Farbtonabstimmung abgebildet werden (z.B. B 25, B 55, B 194, Z 370, siehe Detailanalyse). Vorgefertigte «Cliparts〉 dürfen aus Expertensicht durchaus zu illustrativen oder sogar maßvoll zu rein dekorativen Zwecken eingesetzt werden (z.B. B 8, Abb. 60; S 99, Z 371) und selbst das Überlagern des Texts über ein Bild ist für sie im Bereich der Laiengestaltung tolerabel (z.B. S 93, B 15, B 22, B 306). Das (vermutlich ungewollte) Überlappen eines Bildelements über den gesetzten Rahmen und die disparaten, 
teilweise verpixelten Bilder auf dem Zettel für ein Angebot für tamilische Kinder der Friedenskirche Bern (B 23) wirken fast schon charmant. All diese im Grunde fehlerhaften Elaborationsmerkmale, welche die Laiengestaltung sympathisch machen können, wären in der Profigestaltung dagegen «echtes Fehler und nicht zu akzeptieren. Durch die typische Herstellungsweise der Laienartefakte wird die Druck- und Papierqualität automatisch niedrig: Gedruckt und vervielfältigt wird am Bürodrucker oder -kopierer, verwendet wird handelsübliches Kopierpapier in Standardfarben und meist niedriger Grammatur $\left(80 \mathrm{~g} / \mathrm{m}^{2}\right)$. Gerade durch die Kombination verschiedener niedriger Elaborationsmerkmale wird die Laiengestaltung für die Betrachtenden als eigenständiges Genre erkennbar.

Der Dilettantismus hat jedoch auch im Bereich der Gemeinwesenarbeit seine Grenzen. Ist die investierte Sorgfalt zu gering und gerät der technische Elaborationsgrad allzu tief, wird auch die Laiengestaltung als inadäquat verworfen. Artefakte, die ihren Kommunikationszweck erst nach eingehender Betrachtung verraten, weil die wesentliche Information zu wenig hervorgehoben wurde oder aufgrund zu vieler Auszeichnungen und Stilmittel kaum mehr gefunden werden kann (B 288, siehe Detailanalyse, B 313, Z 38), betrachten die Experten als unangemessen. Die übermäßige Verzerrung von Fotos (z.B. Z 384, B 13), die Verwendung von Bildern, deren Sujets aufgrund der schlechten Wiedergabequalität kaum zu erkennen (z.B. B 318) oder verunstaltet sind (Z 53), abgeschnittener Text (B 299) oder schief gedruckte Kommunikationsmittel (z.B B 17, S 97), bei denen man sich offenbar nicht einmal die Mühe gemacht hat, die Vorlage sauber auf den Kopierer zu legen, unterschreiten für sie das elaborative Mindestmaß für Laiengestaltung in der Gemeinwesenarbeit. Zudem sollten dort, wo mit Gestaltungstemplates gearbeitet und auf Einheitlichkeit Wert gelegt wird, die Vorgaben auch eingehalten werden. Der «Header` auf den Flyern der Kirchgemeinde Zollikofen sollte also nicht mal oben links, mal oben mittig platziert sein (Z 371-374).

Die weniger häufigen semiprofessionellen Arbeiten aus der Gemeinwesenarbeit fallen den Experten zwar durch elaboriertere Gestaltungstechniken wie die Überlagerung und Verschmelzung von Ebenen oder eine höhere Druck- und Papierqualität mit hoher Grammatur auf (besonders bei den Postkartenformaten). Diese Elaborationsmerkmale, die grundsätzlich Indikatoren für eine professionelle Gestaltung sind, können aus Expertensicht jedoch im Widerspruch zur oftmals gleichwohl niedrigen technischen und konzeptuellen Elaboration stehen. Eine Gestaltungsidee fehle bei den semiprofessionellen Arbeiten eigentlich immer, so dass die gewählten Techniken oft beliebig, aufgesetzt oder untereinander nicht abgestimmt wirkten. Eine charaktervolle oder engagierte Erscheinung wird in der semiprofessionellen Gestaltung auch durch technische Mängel verhindert, wie etwa Fehler bei der Bildaufnahme und -bearbeitung (z.B. B 7, B 30, siehe Detailanalyse, B 347, Z 381), eine fehlerhafte typografische Ausgestal- 
tung (z.B. B 31, B 268, B 316, S 92) oder mangelhafte Papier- oder Druckqualität (B 30, siehe Detailanalyse; B 283, hier auch wegen nicht randlosen Drucks).

Im Vergleich zur lokalpolitischen Kommunikation fällt den Experten auf, dass in der Gemeinwesenarbeit selbst bei professionellen Artefakten kaum nach originellen Gestaltungsformen gesucht wurde. Besondere Originalität oder eine herausragende Gestaltung wird bei den Profiarbeiten mit offiziellem Charakter nicht zwingend erwartet, jedoch wäre ein minimales gestalterisches Konzept, das über die Zeit einheitlich angewendet wird, durchaus wünschenswert. Auch bei den Profiarbeiten der Gemeinwesenarbeit kommen Elaborationsfehler technischer Art vor. Eine leicht verminderte Bild- und Wiedergabequalität (z.B. Z 47) wird hier noch als verzeihlich beurteilt. Es konnten aber auch Fehler festgestellt werden, die einem Profi nicht passieren dürften, wie etwa «gepixelte» Schrift (B 274, siehe Detailanalyse), die nicht hochaufgelöst gedruckt ist, weil sie in 〈Photoshop erstellt oder nicht im 〈PostScript〉-Format an die Druckerei geliefert wurde. Auch vermeidbare Passungsfehler werden negativ bewertet: wenn die formale Ausgestaltung oder die verwendeten Bilder der anvisierten Zielgruppe und dem Thema nicht $\mathrm{zu}$ entsprechen vermögen - als Beispiele erwähnt wurden bereits der «unbelebte» Kita-Flyer (B 274, siehe Detailanalyse), der «unfeierliche» Festflyer (B 193) und der wenig gelungene Versuch, sich optisch der Zielgruppe junger Mädchen anzunähern (B 337).

In den nun folgenden Detailanalysen werden zwölf Beispiele unterschiedlichen Elaborationsgrads, die in der Auslegeordnung aufgefallen sind, kontrovers beurteilt wurden oder Fragen aufgeworfen haben, noch einmal genauer untersucht. Welche Anforderungen an die Elaboration gelten in der visuellen Kommunikation der Lokalpolitik und der Gemeinwesenarbeit, und welche Spielräume oder gar positiven Einsatzmöglichkeiten der gestalterischen Imperfektion tun sich auf? 


\subsection{Rhetorische Detailanalysen: Lokalpolitik}

\subsubsection{Professionell, sauber, zeitgemäß - und langweilig? Wahlprospekt Sozialdemokratische Partei (SP) Länggasse-Felsenau}

Elaboration und Imperfektion: Die vier Gestaltungsexpertinnen und -experten, welche die Detailanalysen durchgeführt haben, ${ }^{12}$ sind sich einig darüber, dass die Stilmittel im Wahlprospekt der SP Länggasse Felsenau (Abb. 61) grundsätzlich adäquat und professionell eingesetzt wurden (vgl. Grafik 7) und sich weder gröbere Gestaltungsfehler noch bewusst eingesetzte Imperfektionen darauf finden lassen - allenfalls der betont lockere Kleiderstil der Kandidierenden. Das Papier scheint ihnen gut gewählt: Es ist passend für den Bilderdruck, jedoch nicht zu hochwertig, um keine unnötigen Ausgaben zu generieren; und weil auf Hochglanz verzichtet wurde, wirkt es natürlicher. Die Druckqualität ist für sie ausreichend und die Bildbearbeitung stimmig. Wenige Detailfehler konstatieren sie jedoch in Fotografie und Satz: Durch einen leichten Weitwinkel im Gruppenbild werden die Personen links im Bild unvorteilhaft dargestellt, die Gesichter weisen zu wenig Kontrast auf und wirken flächig. Aufgrund des hohen Rotanteils sollten ihrer Ansicht nach zudem die roten Partien in den Fotos zurückgenommen und die Schattenzeichnung verstärkt werden. Die typografische Gestaltung des grauen Farbfelds auf der Innenseite wird am stärksten kritisiert: Der Blocksatz eignet sich schlecht für die gemäß Raster verfügbare Spaltenbreite. Denn für den Ausgleich der Wortabstände stehen zu wenige Zeichen auf der Zeile, weshalb die Textfläche mit übergroßen Wortabständen aufgerissen wird. Zudem fordert die Situation ein häufiges Trennen von Einzelwörtern, was das Erfassen von Sinneinheiten erschwert. Durch den kleinen, in magerem Schriftschnitt und auf grauem Hintergrund gesetzten Text erscheinen die Inhalte auch sonst wenig lesefreundlich präsentiert. Schließlich sind die Zeilen- und Spaltenumbrüche nicht optimal gelöst. Auf den Innenseiten wurde insgesamt etwas wenig Weißraum belassen. Auch die allzu monotone Wiederholung von Bild- und Textblöcken fällt negativ auf. Eine übergeordnete Kommunikationsidee, welche auch über die Bilder vermittelt wird, fehlt aus Sicht der Bewertenden.

Wirkungen: Das Produkt als Ganzes präsentiert sich professionell, klar, übersichtlich, sauber, aufgeräumt, ordentlich, harmonisch, gut lesbar und informativ. Auch als frisch, luftig, locker, kräftig, dynamisch, sympathisch und anspre-

12 Sämtliche Bewertungen, Einschätzungen und Beschreibungen zu den untersuchten Artefakten, die in den Rhetorischen Detailanalysen genannt werden, geben die Aussagen der Gestaltungsexpertinnen und -experten wieder. 
chend wird das Artefakt beschrieben. Die Gestaltung wirkt etwas kühl - aber nicht steril, einfach - aber nicht eintönig. Durch die professionelle und relativ solide typografische und gestalterische Umsetzung wirkt das Informationsmittel zugleich dynamisch, authentisch und glaubwürdig. Es werden für den Betrachter keine Fragen offengelassen, die Bildsprache funktioniert simpel, aber zuverlässig: Jedes Element hat seinen Raum und seine Formatierung, die einzelnen Elemente stehen sich nicht im Weg und die Information wurde stimmig und übersichtlich organisiert. Aufgrund der konsequenten Umsetzung des Corporate Design der Partei, besonders durch die große Rotfläche und den einprägsamen Schrifttyp, ist der Absender rasch wiedererkennbar. Die auffallende rote Fläche führt auch dazu, dass der Prospekt nicht zurückhaltend erscheint, sondern aus der Masse der Parteiwerbung heraussticht, ohne jedoch aufdringlich zu sein. Die starke Präsenz der Corporate Design-Elemente lässt den Wahlprospekt jedoch auch unpersönlich erscheinen.

Die noch junge Schrift 〈Replica〉 sorgt laut den Expertinnen und Experten für einen frischen, zeitgemäßen bis avantgardistischen Eindruck. Rot, Weiß und Schwarz wirkten als klassische Farben der Linken (russischer Konstruktivismus), was im Zusammenhang mit der «braven» Gesamterscheinung aber lediglich ein «ferner Abklang auf eine einst streitlustige Oppositionspartei» sei. Der Zusammenhang mit den Schweizer Wappenfarben dagegen entstehe unfreiwillig. Insgesamt wird das Grafikdesign als «frei von gestalterischen Attitüden» bewertet, aber auch als wenig originell, wenig überraschend, wenig inspiriert oder als absehbar bis langweilig. Die Gesamtgestaltung erscheint durchaus aktuell, jedoch nicht fortschrittlich, sie wirkt angepasst und wenig aufrührerisch.

Auf der Frontseite erkennen die Experten eine klare Rezeptionssteuerung vom Bild über den Slogan hin zum Absender. Das Foto vermittelt eine «urbane Oase», das «Dörfliche in der Stadt», und die darauf zu sehenden Personen sind - abgesehen von den genannten Bildmängeln - vorteilhaft und doch natürlich dargestellt.

Wirkungsdimension und Stilhöhe: Der Prospekt agiert laut Experteneinschätzung primär auf der Logos- und Ethos-Dimension: Die Inhalte werden auf «nüchterner Bühne» präsentiert und die Gesamtanlage ist «kopflastig» auf die verbale Botschaft ausgerichtet: Die Information will und soll gelesen und erschlossen werden. Das Wortspiel «Stadt für alle statt für wenige〉 erfordert Denk- und Kombinationsfähigkeit. Die Bildebene dagegen bedient das Ethos und soll den Charakter der Absenderpartei sichtbar machen - freundlich, sympathisch, natürlich, locker und doch zuverlässig. Auch die professionelle, übersichtliche und klare Anlage schlägt sich in der Wahrnehmung der Charaktereigenschaften des Absenders nieder. Einzig die dominant eingesetzte Farbe Rot könnte laut Experten auf 


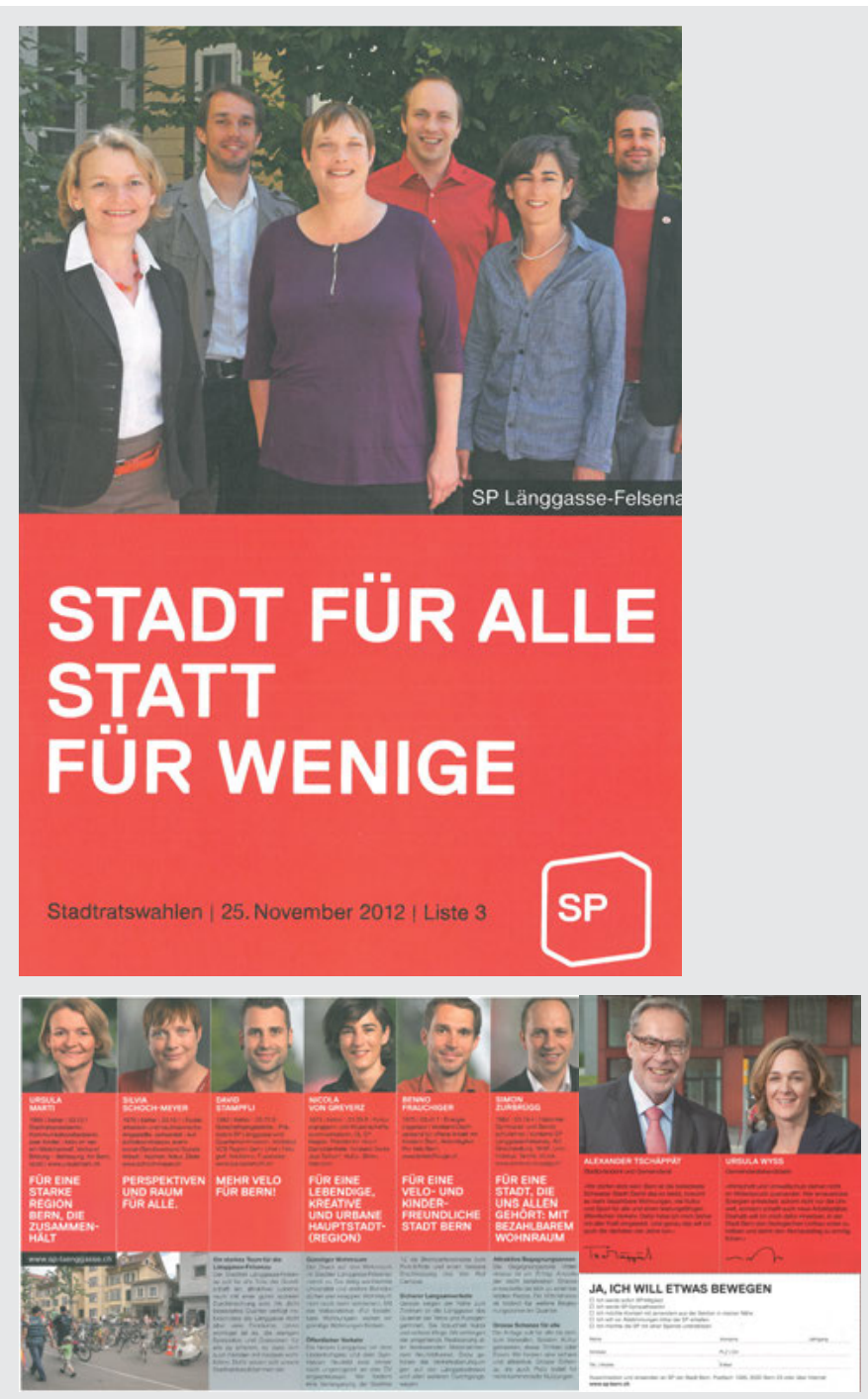

Der Wahlprospekt der SP Länggasse-Felsenau wird unisono als professionell aufbereitete und stimmige Parteiwerbung mit sauberer, klarer und zeitgemäßer Gestaltung bewertet, die eine starke Identität und einen guten Wiedererkennungseffekt erzielt. Durch das konsequente Festhalten am Corporate Design der Partei ergeben sich jedoch auch kontroverse Wirkungen: Was auf die einen frisch und dynamisch wirkt, ist für die anderen langweilig, angepasst und unpersönlich.

Abb. 61: Wahlprospekt SP Bern Länggasse-Felsenau 


\section{Wahlprospekt Sozialdemokratische Partei (SP) Länggasse-Felsenau Formale Analyse}

\begin{tabular}{|c|c|}
\hline Art und Produktion & $\begin{array}{l}\text { Faltblatt, Offsetdruck vollflächig, vierfarbig, doppelseitig auf leicht } \\
\text { satiniertem, holzhaltigem Papier } 70 \mathrm{~g} / \mathrm{m}^{2}\end{array}$ \\
\hline Format & DIN A5 (148.5 mm x $210 \mathrm{~mm}$ ) hoch (geschlossen), 4 Seiten \\
\hline Grafische Mittel & Fotografie, Schrift, Farbflächen, Linien, Wortmarke, Unterschriften \\
\hline $\begin{array}{l}\text { Typografie } \\
\text { Layout } \\
\text { Gesamtanmutung }\end{array}$ & $\begin{array}{l}\text { Die Vorderseite besteht aus zwei Teilen: einem Gruppenbild in der } \\
\text { oberen Hälfte, einer roten Fläche mit großer weißer Headline in } \\
\text { Versallettern («Replica Bold`), einem schwarzen Schriftzug in «Hel- } \\
\text { vetica` und dem Parteisignet in der unteren Hälfte. Die Farbe Rot in } \\
\text { Kombination mit dem Logo und der gewählten Typografie (die beiden } \\
\text { Groteskschriften, Bold/Light, Schriftfarben Weiß bzw. Schwarz, Hie- } \\
\text { rarchisierung der Schriftgrößen) entstammt den Corporate Design- } \\
\text { Richtlinien der Partei und zieht sich durch das ganze Produkt. Das } \\
\text { vertikale Regulativ sieht eine Platzierung randabfallender Bilder im } \\
\text { oberen Formatbereich vor (mit einer Ausnahme). Im streng orthogo- } \\
\text { nal angelegten Rastersystem folgt auf jeder Seite unterhalb der Bild- } \\
\text { fenster eine jeweils funktionsbezogen verschieden dimensionierte } \\
\text { Rotfläche und teilweise zusätzlich eine Grau- oder Weißfläche. Hie- } \\
\text { rarchisch klar orchestriert werden Titel- und Kolumnensatz stilistisch } \\
\text { voneinander getrennt. In der Horizontalen weist die Innenseite ein } \\
\text { sechsspaltiges Gestaltungsraster mit Grundlinienraster aus. Weiße } \\
\text { Spaltentrennlinien verstärken die optische Trennung der Einzelspal- } \\
\text { ten. Der Text ist linksbündig gesetzt, mit Ausnahme des Blocksatzes } \\
\text { auf der grauen Farbfläche im Mittelteil. }\end{array}$ \\
\hline $\begin{array}{l}\text { Bildinhalt } \\
\text { Topos } \\
\text { Figur }\end{array}$ & $\begin{array}{l}\text { Gruppen- und Porträtaufnahmen dominieren das Gesamtbild, } \\
\text { ergänzt von einem Straßenausschnitt, welcher das rege, unmoto- } \\
\text { risierte Quartierleben zeigt. Die Personen lächeln, um zu demons- } \\
\text { trieren, dass sie freundlich und auf einer Augenhöhe mit dem } \\
\text { Betrachter sind. Kleidung «leger» und doch gepflegt, transportiert } \\
\text { eine «Bonvivant»-Atmosphäre. Die Umrahmungslinie des SP-Logos } \\
\text { deutet einen räumlichen Körper/Kubus an. }\end{array}$ \\
\hline $\begin{array}{l}\text { Art der } \\
\text { Bildgestaltung }\end{array}$ & $\begin{array}{l}\text { Professionell, freundlich und volksnah, frontal aufgenommene, } \\
\text { farbige und farbkorrigierte Porträt- und Gruppenaufnahmen (ab } \\
\text { Hüfte) im Außenraum, direktes und reflektiertes Naturlicht, ergänzt } \\
\text { mit Kunstlicht (Blitz). Ausnahme: Schnappschuss mit Weitwinkel } \\
\text { von Quartierstraße. }\end{array}$ \\
\hline Farbe & $\begin{array}{l}\text { Das Farbklima repräsentiert die Corporate Design-Farben der } \\
\text { Partei. Rot dominiert, Grau und Weiß sind ebenfalls präsent. Die } \\
\text { Vierfarbigkeit konzentriert sich einzig auf die Bildanteile und bricht } \\
\text { das rigide Rot-Weiß-Grau kontraststark auf. }\end{array}$ \\
\hline
\end{tabular}




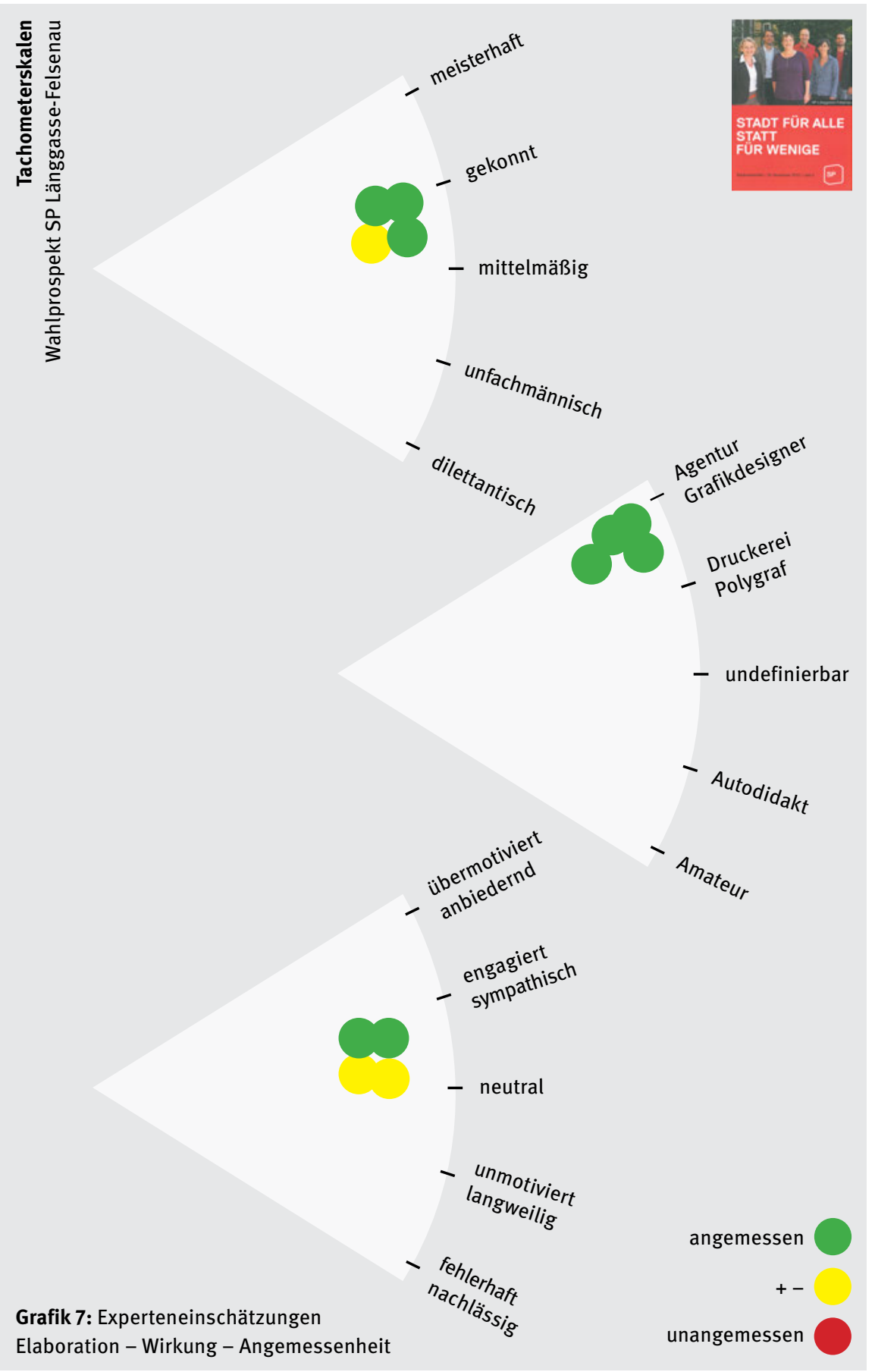


der Pathos-Ebene historische, parteipolitische oder symbolische Assoziationen und Gefühle wachrufen. Aufgrund ihrer primär identitäts- und funktionsorientierten Gestaltung im Rahmen eines umfassenden Corporate Design, das die Einfachheit und Wiederkennbarkeit des Resultats sicherstellt, wird die Stilhöhe als niedrig bis mittel beschrieben. Das Rot wirkt zwar stark bis leidenschaftlich, wird aber durch die sonst sehr konventionelle Gestaltung und Bildsprache entschärft. Die Corporate-Schrift 〈Replica〉 in Versalsatz wird ebenfalls als stark augenfällig wahrgenommen, da sie aus dem explorativen, avantgardistischen Grafikdesign stammt, was sich aber nur geringfügig auf die Gesamtwirkung des Flyers auswirke. Kurzum: Die wirkungsstarken Elemente werden durch die nüchterne und konventionelle Gesamtgestaltung gebändigt.

Angemessenheit und Empfehlungen: Die Drucksache dient als Informationsund Werbemittel der Sozialdemokratischen Partei auf Quartierebene, möchte zur Wahl der Kandidierenden aufrufen und neue Parteimitglieder akquirieren. Aus Sicht der Experten tragen die typografische und grafische Klarheit, die klare Hierarchisierung und die durchdachte Erscheinung dazu bei, dass der Prospekt den Anschein von «Wahlinformation anstatt Propaganda» erhält. Der Prospekt widerspiegle das «aktuelle bürgerlich-intellektuelle Selbstverständnis einer regierenden Partei», indem sie sich als etablierte und angepasste Mittelstandspartei darstelle - und nicht mehr als die widerständische Partei, die sie einst war. Die Gestaltung spricht somit eher urbane, gebildete Menschen, d.h. den Mittelstand, an und weniger die einfachen Leute oder die Arbeiterschaft. Da sich auch die einst linke Wählerschaft in eine bürgerlich-intellektuelle Richtung entwickelt hat, dürfte die Gestaltung damit dem Zielpublikum angepasst sein. Einzelne Aspekte werden jedoch als unangemessen oder wenig gelungen eingeschätzt, sowohl auf Ebene der technischen als auch konzeptuellen Ausarbeitung. So ist die Gestaltung zwar den Grundwerten der «guten Schweizer Grafik» verpflichtet, doch fehlt der gekonnte Regelbruch, d.h. gestalterische Details, die mit der Corporate Identity brechen. Die Bildebene biete weder Unterstützung noch einen provokativen Kontrast zur Textaussage, sondern repetiere einfach das bekannte Muster des «Köpfe Zeigens». Immerhin würden die Fotos den nüchternen Slogans eine persönliche Note und ein Gesicht geben. Die verwendete Schrift 〈Replica〉 soll offensichtlich eine jüngere Szene ansprechen, was allerdings auch als anbiedernd wahrgenommen werden kann. Die Adäquatheit des SP-Slogans wird verschiedentlich in Frage gestellt: Der Ausspruch «Stadt für alle statt für wenige» wird als umständlich, als Zungenbrecher, als wenig lustig, bemüht oder lahm kritisiert. Wird der Anspruch «Stadt für alle» noch eingelöst, wenn die SP sich für das Establishment stark macht? Ausgerechnet der Text auf grauem Hintergrund, der das Parteiprogramm verkündet und somit den entscheidenden Beitrag zur 
Entscheidungsfindung liefern sollte, wurde typografisch am schlechtesten aufbereitet sowie trist und uninteressant gestaltet. Als verbesserungswürdig erachten die Experten daher vor allem die Positionierung der Partei sowie die Aussagekraft des Slogans und weniger die zwar konventionelle, aber angemessen solide technische Ausarbeitung.

\subsubsection{Seriös und konservativ - mit vermeintlich spontanem Anstrich: Wahlprospekt Bürgerlich-Demokratische Partei (BDP) Schüpfen}

Elaboration und Imperfektion: Nach Einschätzung der vier Gestaltungsexperten wurde die Wahlwerbung der BDP Schüpfen (Abb. 62) von einer Person mit gewissen technischen Fertigkeiten in einem professionellen Layout- und Bildbearbeitungsprogramm einigermaßen sauber gestaltet (vgl. Grafik 8). Jedes Element hat seinen Platz, der Weißraum ist ausreichend - aber nicht immer gut verteilt. In der Detailtypografie sind außer ein paar optimierbaren Worttrennungen keine Fehler auszumachen. Lediglich die Laufweite im Haupttext liegt an der unteren Grenze. Über die Professionalität der Fotografien sind sich die Experten uneinig: Hier reicht die Einschätzung von laienhaft (mangelhafte Bildnachbearbeitung und fehlende Abstimmung im Druck) bis professionell («Hintergrund wird mitgedacht»). In jedem Fall wurden die Ton- und Farbwerte der Porträts ungenügend abgeglichen. Außerdem wirkt das Gruppenfoto farblos und blass. Der Versuch, mit vermeintlich von Hand hinzugefügten Elementen wie der Pinselstrich-Optik und der Schreibschrift Authentizität oder eine direkte Ansprache zu suggerieren, wirkt aus Sicht der Experten unbeholfen bis laienhaft. Auch die Neigung der 〈Script〉-Schrift wird kritisiert: Besser sollte sie horizontal gesetzt werden oder, falls im spitzen Winkel, mindestens $30 \mathrm{Grad}$. Der verwendete Schrifttyp wird als Systemschrift eingestuft, die von Profis eher nicht verwendet werde.

Ebenfalls unprofessionell wirkt das Fehlen einer kreativen Bildidee, welche die (bereits wenig originellen) Slogans erweitern, ergänzen oder unterstützen könnte. Die inhaltlichen Hierarchien scheinen unklar und die Rückseite kommt durch die Wiederholung des Kopf- und Fußteils wie die Vorderseite daher. Durch das Wiederholen von Bildzeichen werden diese eher übersehen, da ein «visuelles Rauschen» entsteht. Laut Experten sind all diese Schwächen Indizien dafür, dass es der Gestalterin oder dem Gestalter an Erfahrung und Gefühl für den Umgang mit einer mehrseitigen Drucksache fehlt.

Wirkungen: Die Aufmachung des Wahlprospekts wird von den Experten als bieder und bodenständig, als konservativ, konventionell und altbacken (stilistisch auf die 1970er/1980er Jahre zurückgehend) bezeichnet. Der Prospekt 
wirkt auf sie nüchtern, farb- und profillos, fad, unauffällig, uninteressant. Die Wahlwerbung setzt sich einzig durch das Farbklima von der Flut gleich konzipierter Erzeugnisse ab und ist auch vom Inhalt her austauschbar. Es wird kein weitreichender gestalterischer Anspruch manifest, doch immerhin entfaltet sich eine gewisse plakative Wirkung. Das Produkt lässt sich gut überschauen und erscheint - ganz besonders im Innenteil - sauber, kontrolliert, klar, aufgeräumt, ordentlich und übersichtlich. Dank genügend Weißraum kommen die einzelnen Elemente gut zur Geltung. Die auch durch die Fotos vermittelte Anmutung ist aus Sicht der Experten seriös, einigermaßen natürlich, jedoch wenig herzlich. Die farblose Wirkung wird durch den ausgebleichten Hintergrund und die pastelligen Kleider auf den Fotos verstärkt. Frech, spontan und dynamisch gemeint sind laut Experten die gelben Pinselkleckse, doch führen sie nicht wie beabsichtigt dazu, das Ganze aufzulockern. Sie wirken in der Strichführung gehemmt und erzeugen eine unnötige Unruhe. Zudem gehören Pinselstrich-Optik und handschriftliche Computerschrift gemäß Experten inzwischen zum «ausgeleierten» Standardrepertoire der Grafik und wirken alles andere als originell oder persönlich.

Wirkungsdimension und Stilhöhe: Die Wahlwerbung soll primär auf Ethos-Ebene den konservativ-bürgerlichen Charakter des Absenders und dessen Seriosität und Verlässlichkeit betonen. Die Stilhöhe wird als niedrig bis mittel eingestuft. Minimal affektive Akzente erhält der Prospekt durch die auffälligen und kontrastreichen, schon fast «aggressiv-warnenden» Parteifarben und die erwähnten selbstgemacht wirkenden Elemente: die leicht schräg gesetzte 〈Script〉-Schrift im Titel und die illustrative gelbe Hinterlegung von Wahlslogan und Listenbezeichnung.

Angemessenheit und Empfehlungen: Der Wahlprospekt adressiert wahlberechtigte Bürgerinnen und -bürger einer ländlichen Gemeinde - insbesondere die Stammwählerschaft der BDP. Aufgrund seiner Aufmachung präsentiert er die BDP als seriöse Partei der Mitte. Der durch die konventionelle Aufmachung vermittelte bodenständige Konservatismus könnte aus Sicht der Experten Nähe zu einer Zielgruppe schaffen, die sich auch visuell nicht überraschen lassen will. Auch die hohe Papierqualität und die damit verbundene Haptik erscheinen kongruent mit der bürgerlichen Ausrichtung der Absenderpartei. Die Experten vermuten jedoch, dass der Prospekt mit seiner «espritlosen» Gestaltung und den austauschbaren Slogans bei zielgruppenfernen Betrachtern kaum Interesse wecken kann. Eventuell sei es auch nicht die Intention des Prospekts, neue Wählergruppen anzusprechen, sondern «die Mitte abzusichern», d.h. die Partei von anderen Mitteparteien abzugrenzen. Bildhintergrund und Gemeindewappen verweisen aus Sicht der Experten richtigerweise auf die lokale Gebundenheit. Andere 


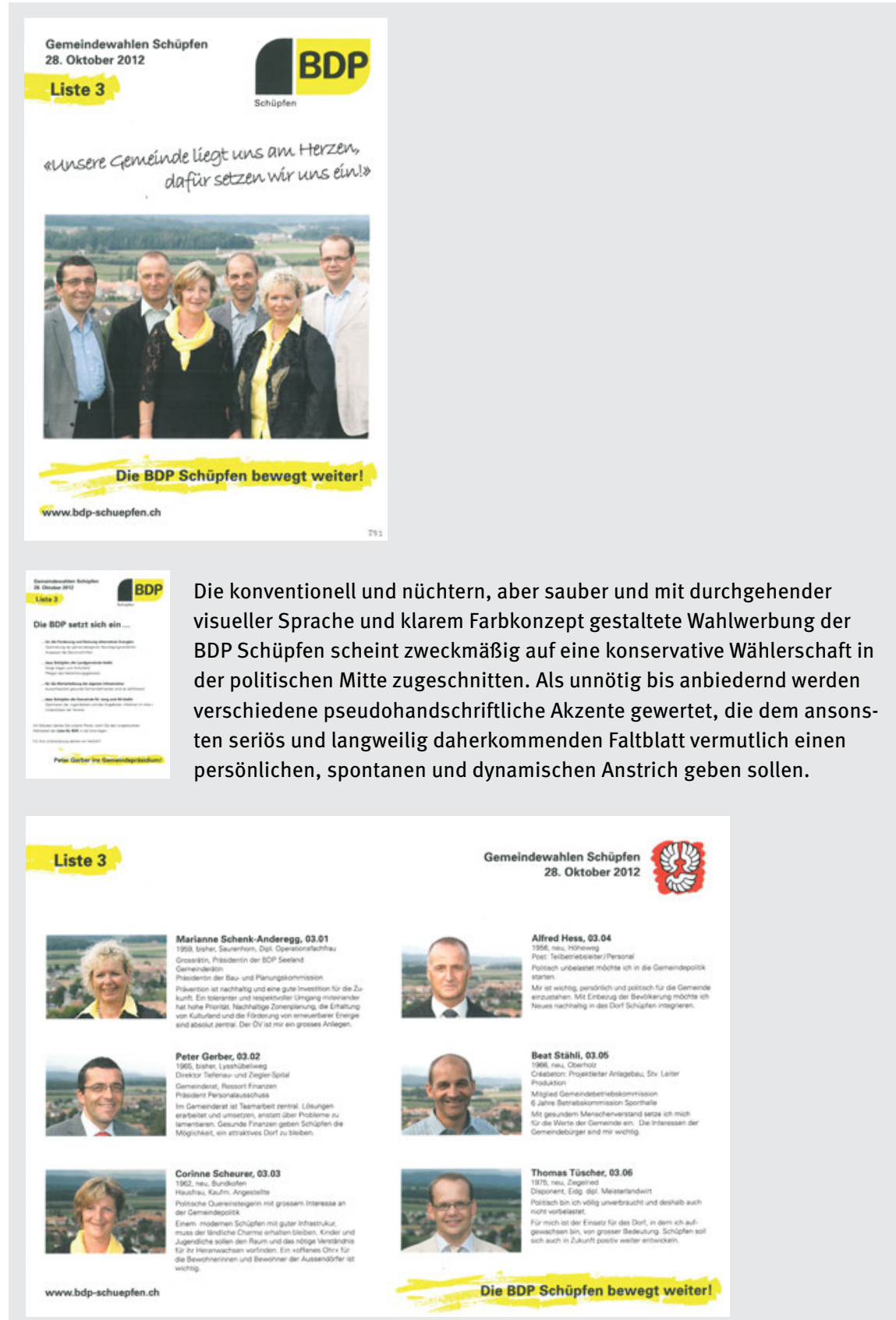

Abb. 62: Wahlprospekt BDP Schüpfen 


\section{Wahlprospekt Bürgerlich-Demokratische Partei (BDP) Schüpfen} Formale Analyse

\begin{tabular}{|c|c|}
\hline Art und Produktion & $\begin{array}{l}\text { Faltblatt, Offsetdruck vollflächig, vierfarbig, doppelseitig auf gestri- } \\
\text { chenem, leicht glänzendem, weißem Papier } 100 \mathrm{~g} / \mathrm{m}^{2}\end{array}$ \\
\hline Format & DIN A5 (148.5 mm x $210 \mathrm{~mm}$ ) hoch (geschlossen), 4 Seiten \\
\hline Grafische Mittel & $\begin{array}{l}\text { Fotografie, Schrift, Wortmarke, Gemeindewappen, farbig-illustra- } \\
\text { tive Hinterlegung einzelner Textelemente }\end{array}$ \\
\hline $\begin{array}{l}\text { Typografie } \\
\text { Layout } \\
\text { Gesamtanmutung }\end{array}$ & $\begin{array}{l}\text { Auf allen Seiten durchgehender Satzspiegel mit wiederkehrenden } \\
\text { Elementen - die visuelle Sprache und das Farbkonzept ziehen sich } \\
\text { durch den ganzen Prospekt. Vorderseite mit etwas weniger als } \\
\text { die Hälfte einnehmendem Gruppenbild. Gestaltungsraster nur auf } \\
\text { der inneren Doppelseite erkennbar. Dort Bildanordnung in linkem } \\
\text { Seitenbereich untereinander, rechts daneben stehen, in leicht } \\
\text { breiterer Spalte, die zugehörigen Personenprofile. Seitenfüllender } \\
\text { und akzentarmer Einsatz von Schriftelementen und Bildfenstern } \\
\text { ohne Kontrast- und Schwerpunktbildung. Horizontal-vertikale Aus- } \\
\text { richtung aller Elemente (Ausnahme: } 10 \text { Grad gewinkelter Slogan in } \\
\text { Schreibschrift). Verwendete Schrifttypen: Serifenlose Lineargrotesk } \\
\text { in zwei Schriftstärken und verschiedenen Größen (9pt bis ca. 36pt), } \\
\text { auf der Titelseite ergänzt durch eine handschriftliche Script-Schrift. } \\
\text { Auszeichnungen mit Größen und Fettenunterschied, auffallend } \\
\text { auch mit hinterlegter Leuchtmarkerstruktur. Parteilogo auf erster } \\
\text { und letzter Seite, sehr dominant, in drittem Schrifttyp gesetzt. } \\
\text { Links- und rechtsbündige Einzelblöcke und Schriftzeilen in teil- } \\
\text { weise proportional unterschiedlichem Zeilenabstand. Absatzkenn- } \\
\text { zeichnung durch halbe oder ganze Leerzeilen. Schrift durchgehend } \\
\text { positiv schwarz auf Weiß oder Gelb stehend. }\end{array}$ \\
\hline $\begin{array}{l}\text { Bildinhalt } \\
\text { Topos } \\
\text { Figur }\end{array}$ & $\begin{array}{l}\text { Gruppenaufnahme (zwei Frauen, vier Männer) und Kandidieren- } \\
\text { den-Fotos vor ländlichem Hintergrund - hier wird eine bewusste } \\
\text { Verortung im ländlichen Gemeindegebiet vorgenommen, um die } \\
\text { Identifikation mit dem dörflichen Umfeld sicherzustellen. Ansons- } \\
\text { ten keine sofort ersichtlichen symbolischen Metaebenen. }\end{array}$ \\
\hline $\begin{array}{l}\text { Art der } \\
\text { Bildgestaltung }\end{array}$ & $\begin{array}{l}\text { Semiprofessionelle Aufnahmen, frontal in normalem Aufnahme- } \\
\text { winkel, gleiche Kulisse für Gruppen- und Porträtaufnahmen (z.T. } \\
\text { vermutlich Fotomontagen, an unterschiedlicher Lichtsituation auf } \\
\text { Porträts und unterschiedlichen Ton- und Farbwerten ersichtlich). } \\
\text { Gruppenfoto im Hintergrund ausgebleicht (Polfilter). }\end{array}$ \\
\hline Farbe & $\begin{array}{l}\text { Dominanz der Parteifarben Gelb und Schwarz (auch in der Kleidung } \\
\text { der beiden Kandidatinnen) sowie der Papierfarbe Weiß über die } \\
\text { gesamte Drucksache. Der Weißanteil ist am höchsten. Rot kommt } \\
\text { nur im Gemeindewappen und im Krawattenausschnitt eines Kandi- } \\
\text { daten vor. Kandidatenbilder sind farbig, bewegen sich jedoch mit } \\
\text { niedriger Sättigung im Grün-Gelb-Grau-Blau-Spektrum. }\end{array}$ \\
\hline
\end{tabular}




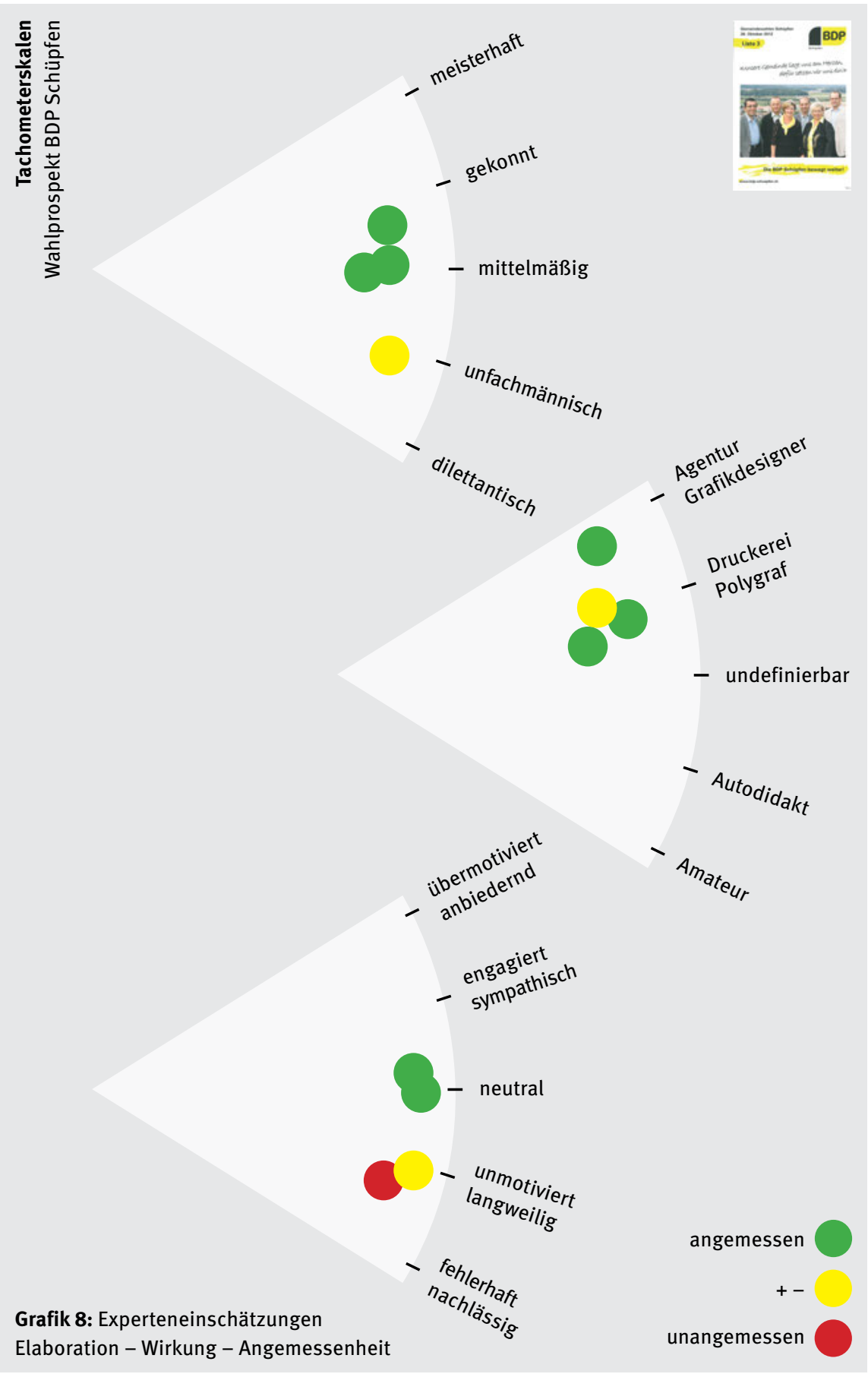


Elemente werden jedoch als störend empfunden: Die Aufnahme der Parteifarben in den Kleidern bei den beiden Frauen lässt diese zur «Dekoration» verkommen. Die schräg gesetzte Schreibschrift und die gelben Pinselstriche werden als widersprüchliche Gestaltungsmittel innerhalb der angewendeten visuellen Rhetorik bewertet, welche nicht die politische Kultur des Absenders repräsentieren. Aus Sicht der Experten dienen sie einzig dem - uneingelösten - Zweck, das ansonsten unauffällige Layout «aufzupeppen». Überhaupt wird die digitale Simulation handgemachter Elemente als problematisch bewertet, da sie künstlich und falsch wirken kann. Sie bildet ein grafisches Standardmittel, das in der visuellen Kommunikation oftmals unreflektiert übernommen werde. Die typografischen Anführungszeichen bei der Schreibschrift scheinen besonders widersinnig, weil sie den Anschein von Unmittelbarkeit gleich wieder aufheben.

Anstatt auf einer gestalterischen Idee baut die Gestaltung gemäß den Experten auf dem Corporate Design der Partei auf - weil die eher jüngere Partei eventuell noch an der Wiedererkennung arbeiten muss. Die Parteifarben selbst werden als fragwürdig betrachtet: zu aggressiv für eine Partei, die ins Leben gerufen wurde, um den extremen Tendenzen ihrer Stammpartei auszuweichen. Zudem werden Gelb und Schwarz in der Schweiz eher mit links-alternativen oder kulturellen Inhalten verbunden, z.B. mit der linken Wochenzeitung 〈WoZ〉 oder dem Filmfestival Locarno. Eine Verbesserung müsste aus Sicht der Experten also bereits beim Corporate Design der Partei, insbesondere bei den Parteifarben und beim Logo mit den abgerundeten Elementen, aber auch bei der Typografie und der Fotografie ansetzen. Wenn man Authentizität durch persönliche Ansprache erreichen wolle, müsste das handschriftliche Motto tatsächlich von Hand geschrieben und ohne Anführungszeichen gesetzt werden. Anstatt standardisierte Gestaltungsmittel wie Pseudo-Pinselstrich und -handschrift zu verwenden, ließe sich durch eine kreative Idee echter «Pepp» in die Gestaltung bringen.

\subsection{3 Überfrachtete Biederkeit: Wahlprospekt Evangelische Volkspartei (EVP) Zollikofen}

Elaboration und Imperfektion: Die Gestaltung des Wahlprospekts der EVP Zollikofen (Abb. 63) wirkt aus Sicht der Experten nur semiprofessionell, da die ganze Drucksache gestalterische und typografische Konsistenz oder die bewusste Gestaltung von Weißraum vermissen lässt (vgl. Grafik 9). Aus diesem Mangel heraus ist ein Mix von Schriftschnitten, Anordnungen und grafischen Elementen entstanden. Eine solche Mischung entspreche keiner professionellen Haltung, sondern eher der typografischen Laienvorstellung von «möglichst viel Information auf kleinem Raum». Der heterogene und pluralistische Gestaltungsansatz 


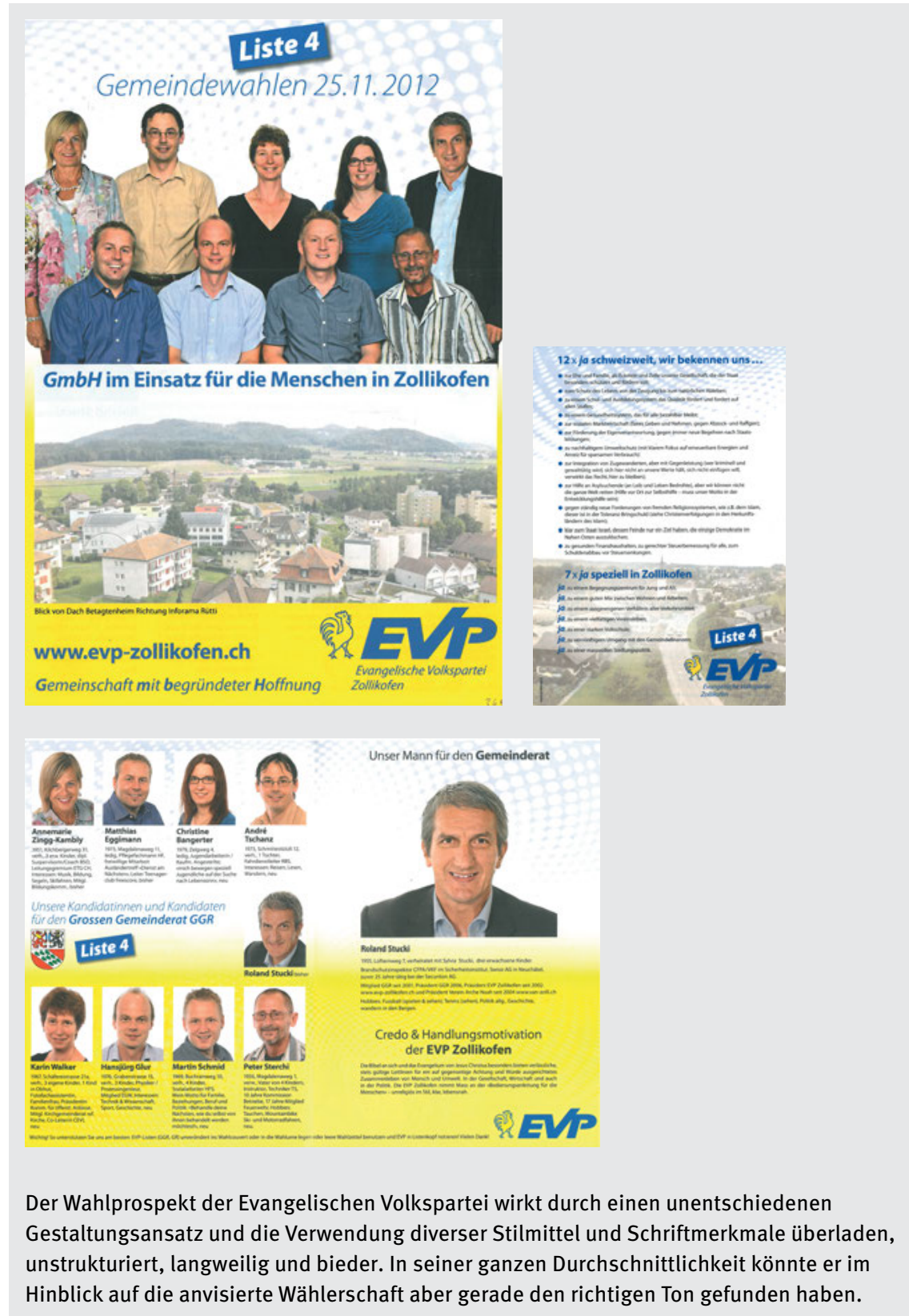

Abb. 63: Wahlprospekt EVP Zollikofen 


\section{Wahlprospekt Evangelische Volkspartei (EVP) Zollikofen}

Formale Analyse

\begin{tabular}{|c|c|}
\hline Art und Produktion & $\begin{array}{l}\text { Faltblatt, Offsetdruck vollflächig, vierfarbig, doppelseitig auf gestri- } \\
\text { chenem, leicht glänzendem, weißem Papier } 60 \mathrm{~g} / \mathrm{m}^{2} \text { (dünn) }\end{array}$ \\
\hline Format & DIN A5 (148.5 mm x $210 \mathrm{~mm}$ ) hoch (geschlossen), 4 Seiten \\
\hline Grafische Mittel & $\begin{array}{l}\text { Fotografie, Schrift, Wortbildmarke, Gemeindewappen, dreidimen- } \\
\text { sional wirkendes Punkteraster, Farbverlauf, dem Text hinterlegtes, } \\
\text { abgeblendetes Bild }\end{array}$ \\
\hline $\begin{array}{l}\text { Typografie } \\
\text { Layout } \\
\text { Gesamtanmutung }\end{array}$ & $\begin{array}{l}\text { Satzspiegel und Gestaltungsraster sind nicht erkennbar. Bild- und } \\
\text { Textteile wechseln sich in formatfüllender Anordnung ab. Alle } \\
\text { Bild- und Textbestandteile sind horizontal ausgerichtet und halten } \\
\text { sich proportional die Waage, die Titelseite ist horizontal in zwei } \\
\text { Hälften unterteilt. In Größe und Breite unterschiedliche Text- und } \\
\text { Bildelemente werden in der jeweiligen Platzsituation verteilt - } \\
\text { ohne bewusst gesetzten Leerraum, ohne Hervorhebung einzelner } \\
\text { Elemente. Mittelachsensymmetrische Seitengestaltung nach von Fall } \\
\text { zu Fall vorherrschenden Bedingungen. Seiten werden jeweils rechts } \\
\text { unten mit dem Parteilogo geschlossen. Die Listenzahl in Kasten ist } \\
\text { auf jeder Seite an jeweils anderer Position aufgeführt. Der Schrifttyp } \\
\text { «Frutiger` wird chaotisch und ohne sichtbares Gestaltungsregulativ } \\
\text { eingesetzt. Die abwechselnde Verwendung des Schrifttyps in ver- } \\
\text { schiedenen Dicken, Lagen und Größen erfolgt nach keinen nach- } \\
\text { vollziehbaren Kriterien. Es finden sich zahlreiche Auszeichnungen } \\
\text { wie Farbe, Kästchen, Größen, kursiv und fett sowie unterschiedliche } \\
\text { Spalten- und Blockbreiten sowie Satzarten. Die Abschnittlenkung } \\
\text { erfolgt durch halbe oder ganze Leerzeilen. }\end{array}$ \\
\hline $\begin{array}{l}\text { Bildinhalt } \\
\text { Topos } \\
\text { Figur }\end{array}$ & $\begin{array}{l}\text { Gruppenaufnahme, Einzelporträts, Siedlungs- und Landschaftsauf- } \\
\text { nahmen. Keine eindeutige Symbolik auf Metaebene. Wellenförmiges } \\
\text { Punkteraster kann allenfalls als Symbol für eine «zukunftsgerich- } \\
\text { tete und glasfaserverbundene» Parteiarbeit gesehen werden. Für } \\
\text { politische Werbung konventionelle Personendarstellung: Lachen und } \\
\text { weiße (bei der Bildbearbeitung aufgehellte) Zähne als Symbol für } \\
\text { glückliche, umgängliche, freundliche Kandidierende. Direkter Blick } \\
\text { als Zeichen von Offenheit, Ehrlichkeit. }\end{array}$ \\
\hline $\begin{array}{l}\text { Art der } \\
\text { Bildgestaltung }\end{array}$ & $\begin{array}{l}\text { Professionelle Gruppen- und Porträtaufnahmen im Studio vor } \\
\text { weißem Hintergrund in normalem Aufnahmewinkel. Gruppenauf- } \\
\text { nahme freigestellt, hinterlegt mit Punkteraster. Aufnahmen von Dorf } \\
\text { und Umgebung von erhöhtem Standpunkt in sommerlicher Schön- } \\
\text { wetterlage, in der Deckkraft zurückgenommen, blass, gegen unten } \\
\text { gelb hinterlegt. }\end{array}$ \\
\hline Farbe & $\begin{array}{l}\text { Dominanz von Gelb, Blau, Weiß, Schwarz. Die Parteifarben Gelb und } \\
\text { Blau bzw. Blauweiß nehmen anteilig die größte Fläche ein. Blau } \\
\text { kommt auch mehrfach in der Kleidung der Kandidierenden vor. }\end{array}$ \\
\hline
\end{tabular}




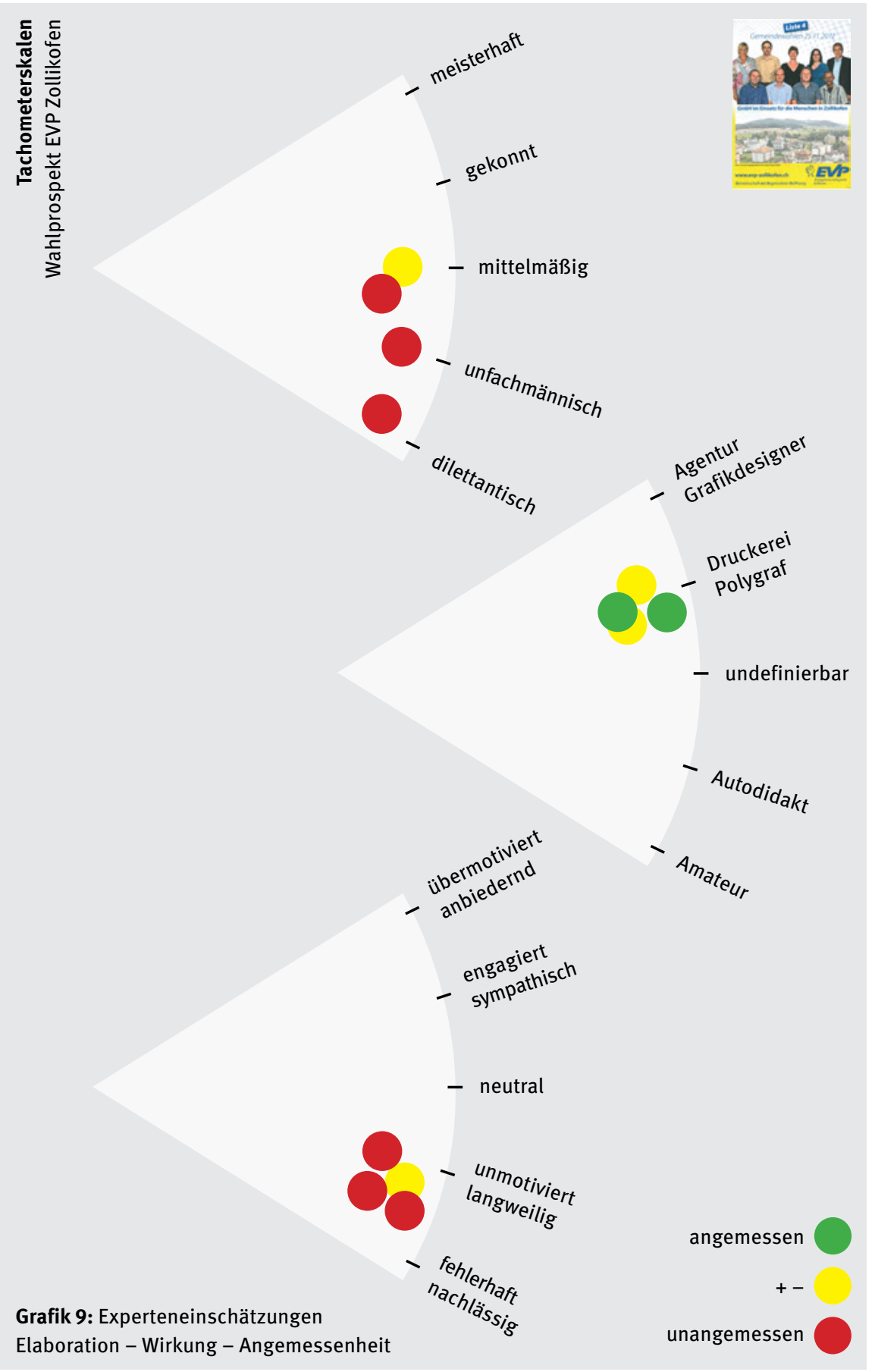


führt auch in der Seitenfolge zu einem unruhigen und überfrachteten Erscheinungsbild. Auf der Vorderseite wurden zu viele Elemente auf zu kleiner Fläche angeordnet, so dass keines der Elemente hervorsticht, um die Aufmerksamkeit auf sich zu lenken oder den Lesefluss zu steuern. Die schwache Hierarchisierung führt laut Experten zu einer «gegenseitigen Kannibalisierung» der Informationen. Der Urheber scheint zwar über Layout-Programmkenntnisse zu verfügen, jedoch kommunikativ nicht ausreichend ausgebildet, um die Rezeption steuern zu können. Viele Gestaltungsschritte könnten direkt in einem üblichen Anwenderprogramm vorgenommen worden sein, was den Eindruck gestalterischer Beliebigkeit verstärkt. Die Fotografien sind zudem von mangelhafter Qualität: Das untere Foto wurde zu stark abgeblendet, so dass es blass wirkt - als wäre es nur ein Hintergrundbild. Das Gruppenbild wurde dagegen ordentlich freigestellt, was bei Personenbildern aufgrund der Haare keine einfache Aufgabe ist und auf ein gewisses technisches Know-how hindeutet.

Wirkungen: Der Prospekt wird als unruhiger, überfrachteter, überinstrumentierter, unstrukturierter, schlecht lesbarer, unentschlossener, uninspirierter, uninteressanter, biederer, rückwärtsgewandter und braver Gestaltungsauftritt wahrgenommen. Durch seine «Hemdsärmeligkeit» wirkt er bestenfalls bodenständig. Ein Gestaltungskonzept ist nicht erkennbar. Die Typografie erscheint fahrig und uneinheitlich, obschon überall dieselbe Schrift eingesetzt wird - dies jedoch in unzähligen Graden, Schnitten, Auszeichnungen, Satzformen. Die Experten vermuten, dass die Parteiwerbung mit dem hinterlegten Punkteraster modern und «ein wenig peppig» wirken möchte, ohne allzu stark aufzufallen - der Effekt wird jedoch als bieder wahrgenommen. Innerhalb der unentschiedenen Gesamtgestaltung erscheint das Raster zwar dominant, ist jedoch in seiner Bedeutung nicht zu entschlüsseln und zieht sich somit komplett ohne Nutzen über das Faltblatt. Auch die Fotos bringen dem Prospekt aus Sicht der Experten keine Sympathien, sondern wirken steif und angestrengt. Diese Faktoren ergeben zusammen mit dem schlechten Papier den Eindruck einer «Drucksache ohne Qualitätsanspruch»: Durch die Repetition alltäglicher Gestaltungselemente kann es dem Prospekt nicht gelingen, sich von der Flut gewöhnlicher Werbepost abzuheben.

Wirkungsdimension und Stilhöhe: Auf Ethos-Ebene vermittelt die Wahlkommunikation in der Einschätzung der Experten Biederkeit und eine gewisse Mut- und Orientierungslosigkeit. Auf Pathos-Ebene wirkt das Artefakt unsinnlich bis verkrampft. Durch seine Unentschiedenheit wird das Artefakt auf einer mittleren Stilhöhe - zwischen «bemühtem Aktivismus» und «langweiliger Aufgeräumtheit» angesiedelt. 
Angemessenheit und Empfehlungen: Die Absenderpartei EVP versucht mit dem Faltblatt Aufmerksamkeit zu erregen und in der Agglomerationsgemeinde Wählerstimmen zu gewinnen. Die Experten schätzen, dass sich die Partei der Wichtigkeit klar und lesefreundlich präsentierter Wahlwerbung nicht bewusst ist. Die Qualität der Gestaltung ist nicht deckungsgleich mit dem vom Absender verkündeten Parteiprogramm. Durch die Anwendung von abgedroschenen formalästhetischen Gemeinplätzen erscheint der Prospekt äußerst durchschnittlich. Gleichzeitig geben die Experten zu bedenken, dass sich die EVP ja auch an eine Zielgruppe wendet, die Mittelmäßigkeit anstrebt: Nicht besonders auffallen, aber doch nicht allzu konservativ wirken.

Insofern also die biedere, profillose und leicht angestrengt wirkende Gestaltungskultur der politischen Kultur des Absenders entspricht und es sich um eine kleinere Partei mit wenig Kommunikationsbudget handeln könnte, bewerten die Experten das Produkt gerade noch als passabel. Der Witz, 〈GmbH〉 als 〈Gemeinschaft mit begründeter Hoffnung> zu entschlüsseln, steht für die Experten in großem Kontrast zur ansonsten komplett humorfreien und konventionellen Darstellung von Menschen, Gemeindeansicht und Gesamtgestaltung: Weder der Slogan noch sein Witz werden grafisch oder bildlich in irgendeiner Weise unterstützt.

Um eine Verbesserung zu erreichen, könnten anstelle einer menschenleeren Gemeindeansicht jene Menschen zu sehen sein, für die sich die EVP einzusetzen verspricht. Damit würde die im Slogan angesprochene «Gemeinschaft`auch optisch hergestellt. Um eine professionelle Wirkung zu erzeugen, müsste nach Sicht einiger Experten jedoch sektionsübergreifend und gesamtschweizerisch die Entwicklung eines stringenten Corporate Design eingeleitet werden. Andere halten den Prospekt aber gerade in seiner Mittelmäßigkeit, Biederkeit und Unentschiedenheit für perfekt auf seinen Einsatzzweck zugeschnitten. In diesem Verständnis ließe sich die Gestaltung des Prospekts nicht verbessern.

\subsubsection{Unkonventionell oder dilettantisch? Wahlprospekt Junge Alternative (JA!) Bern}

Elaboration und Imperfektion: Der Wahlprospekt der Jungen Alternative Bern (Abb. 64) wirkt auf die Experten in seiner Elaborationsweise insgesamt laienhaft bis semiprofessionell, «wie aus einem gestalterischen Vorkurs» (vgl. Grafik 10). Sie vermuten, dass das Produkt von einem Laiengestalter auf professioneller Software gestaltet wurde. Der Haupttitel offenbart für sie einen ausgeprägten typografischen Dilettantismus - die 3D-Schrift ist linkisch ausgestaltet und schlecht lesbar, aber auch die Illustration offenbart mangelhaftes Können und 
bewegt sich auf niedrigem zeichnerischen und gestalterischen Qualitätsniveau: gestisch zu wenig locker und in der Darstellung nicht ausreichend präzise (z.B. Körperteile oder Häuser) - und durch die Wiedergabe der einst farbigen Illustration in Graustufen wirkt sie seltsam kraftlos. Gleichzeitig erhält der Prospekt dadurch einen agitatorischen Hauch, wie die Demoflyer der 1980er-Jugendbewegung. Von einem gewissen Gestaltungswissen zeugt die Tatsache, dass auf der Titelseite wenige Elemente zentral gewichtet und mit gezielten Aufgaben versehen worden sind. In der Innenseite dagegen fehlt die Leseführung und werden typografische Mängel offensichtlich: Für den Lesetext wurde ein zu kleiner Schriftgrad gewählt, der Blocksatz ist unausgeglichen, die Punktzunahme im Druck wurde missachtet und die schwarzen Kästchen verwenden zwei Schrifttypen, wo eine genügt. Zudem zeigt sich auf den Innenseiten der für gestalterische Laien typische Horror Vacui: Es wird kein Raum freigelassen. Neben handwerklichen Fehlern werden auch Mängel bei der Ausformulierung bzw. stringenten Einhaltung des Gestaltungskonzepts konstatiert: Warum sind die Textfelder in der Mitte nicht auch durch Reißnägel/Klebepunkte gehalten? Warum haben die Felder alle einen Schatten, obschon sie doch an einem Zaun hängen und nicht davor schweben sollten?

Durch das unreflektierte, aber eilfertige Ausgestalten mit vielerlei Stilmitteln eröffnet sich eine unkontrollierbare Reihe von nicht intendierten, nicht beachteten oder gar schief zur verfolgten Intention stehenden Assoziationen: Die roten Klebepunkte werden normalerweise assoziiert mit dem Verkauf von Kunstwerken, die Täferwand lässt an ein rustikales oder bürgerliches Umfeld denken, das Absperrband insinuiert eher Schutz als Käfig und die massige 3D-Schrift im Titel wirkt solide und statisch statt agitatorisch und dynamisch.

Wirkungen: Die Wahlwerbung der jungen Alternative wirkt auf die Experten handgestrickt und düster. Eine agitatorische Absicht wird spürbar. Die Illustration auf der Titelseite entfaltet für sie eine jugendlich naive und zugleich triste Wirkung, die Schrift darüber geht zwar auf das Thema des Bildes ein, erscheint typografisch jedoch beliebig. Die Gesamtwirkung wird als widersprüchlich wahrgenommen, da verschiedenste Motive und Stilelemente verwendet wurden. Durch die wenig souveräne oder flüssige Schrift- und Bildgestaltung wirkt der «Befreiungsschlag» kontrolliert statt spontan. Bei den Experten provoziert das Produkt stark negative Geschmacksurteile wie «grässlich», «schockierend» oder «jenseits von Gut und Böse». In der Flut der anderen Parteiwerbung könnte dieser Wahlflyer jedoch auffallen. 

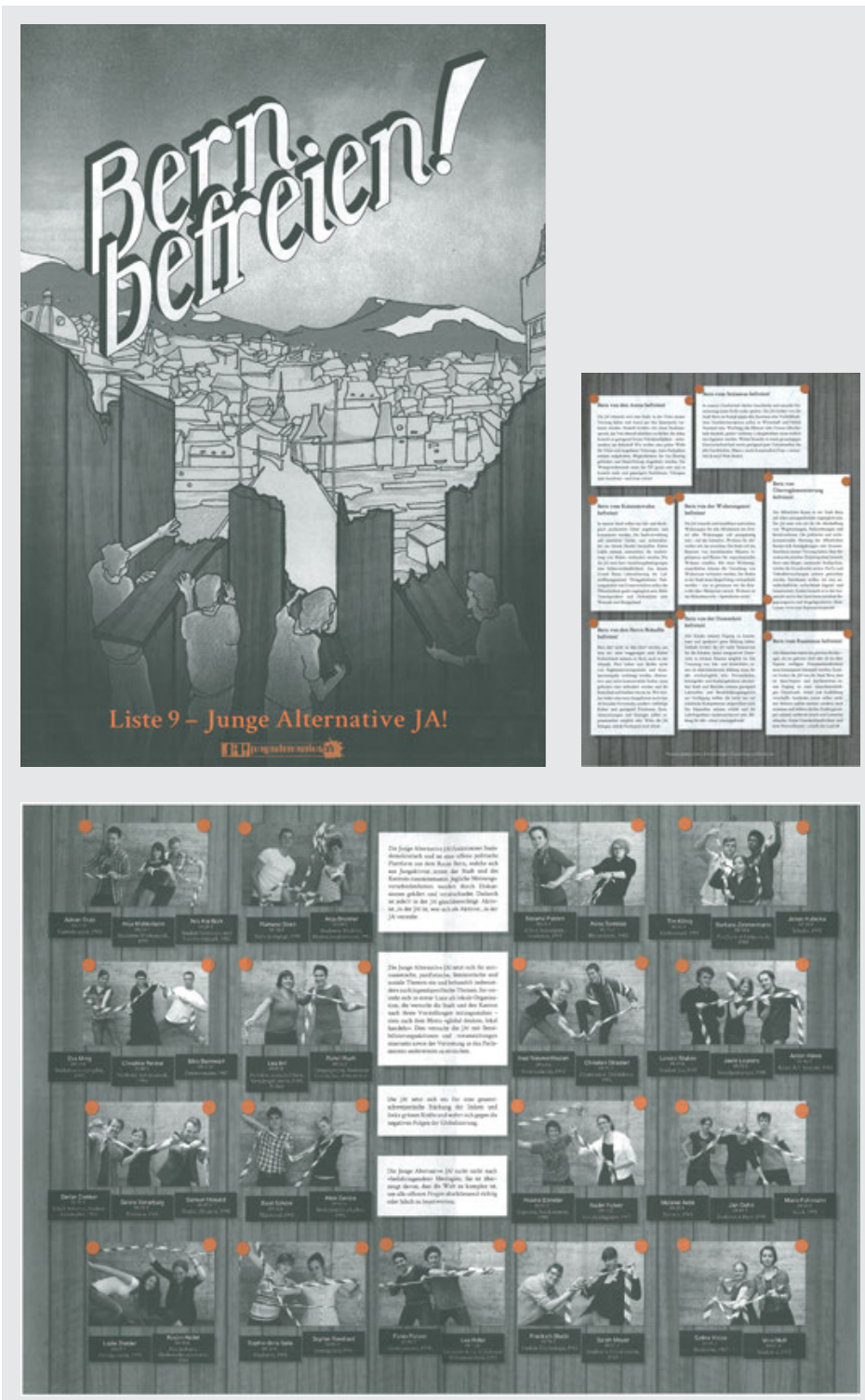

Der Wahlprospekt der Jungen Alternative Bern versucht mit seiner unkonventionellen und auffälligen handgemachten Optik lebendigen Aktivismus zu verströmen, scheitert jedoch an einer allzu dilettantischen und heterogenen Umsetzung, die ihn düster und verkrampft anstatt kämpferisch und frisch erscheinen lässt.

Abb. 64: Wahlprospekt Junge Alternative Bern 


\section{Wahlprospekt Junge Alternative (JA!) Bern}

\section{Formale Analyse}

\begin{tabular}{|c|c|}
\hline $\begin{array}{l}\text { t und } \\
\text { oduktion }\end{array}$ & $\begin{array}{l}\text { Faltblatt (Kreuzbruch), Offsetdruck vollflächig, zweifarbig schwarz/Vollton } \\
\text { orange, doppelseitig auf ungestrichenem Offsetpapier } 70 \mathrm{~g} / \mathrm{m}^{2}\end{array}$ \\
\hline ormat & DIN A4 (210 mm x $297 \mathrm{~mm}$ ) hoch (halb geöffnet) \\
\hline he Mittel & Schrift, Illustration, Wortbildmarke, Collage, Fotografie \\
\hline $\begin{array}{l}\text { pografie } \\
\text { yyout } \\
\text { esamt- } \\
\text { imutung }\end{array}$ & $\begin{array}{l}\text { Titelseite von einer vollflächigen tonalen schwarzweißen Handzeich- } \\
\text { nung auf Ingres-Papier geprägt. Titelsatz auffällig und schräg nach oben } \\
\text { laufend im oberen Drittel in 3D-extrudierter, kursiver, selbstgezeichneter } \\
\text { Antiquavariante mit stilfremdem Ausrufezeichen. Schrift interagiert mit } \\
\text { Illustration, Himmel schafft Platz für Überschrift. Absenderangabe in } \\
\text { zentrierter französischer Renaissance-Antiqua (eventuell «Garamond`) } \\
\text { auf sekundärer Hierarchiestufe unten. Innen ungewöhnliches Layout mit } \\
\text { fünfspaltigem Bild- und Kolumnenraster vor schwarzweißem Bildhinter- } \\
\text { grund in Holztäfer-Optik. Layout mittelachsensymmetrisch. Bildfenster } \\
\text { mit unterschiedlichen Vertikal- und Horizontalabständen, scheinbar mit } \\
\text { orangen Bildpunkten oder Reißnägeln auf Hintergrund fixiert. Vier domi- } \\
\text { nierende, höhenverschiedene, breitengleiche Textfenster in unregelmä- } \\
\text { ßigem Blocksatz in Antiqua, klein (7pt). Namens- und Zusatzangaben der } \\
\text { Kandidierenden Weiß auf Schwarz in traditioneller Grotesk und Antiqua, } \\
\text { ca. 5-7pt, in zu zweit oder zu dritt stehenden, breitengleichen, in unter- } \\
\text { schiedlichen Höhen angeordneten Textfenstern, die quasi «über das Blatt } \\
\text { tanzen». Rückseite entspricht den Innenseiten. }\end{array}$ \\
\hline $\begin{array}{l}\text { ildinhalt } \\
\text { opos } \\
\text { igur }\end{array}$ & $\begin{array}{l}\text { Titelillustration zeigt Stadt hinter bretterartiger Barrikade, aus der Per- } \\
\text { sonen Bretter herausreißen. Im Bildhintergrund Berge. Dass es sich um } \\
\text { Bern handelt, wird durch Slogan «Bern befreien!ı nahegelegt. Sujet spielt } \\
\text { auf das Erkämpfen von Freiheit an und knüpft an historische Ereignisse } \\
\text { an (z.B. Julirevolution in Paris, Mauerfall in Berlin). Der holzige Bildhin- } \\
\text { tergrund innen soll Barrikaden visualisieren, erinnert aber an getäferten } \\
\text { Raum und somit kleinbürgerliches, rustikales, rurales Wohnungsinterieur, } \\
\text { was auf rechte Parteilandschaft hindeutet. Kandidierende jeweils zu } \\
\text { zweit oder dritt auf Fotografie, vor Sichtbetonwand, halten, spannen oder } \\
\text { unterlaufen ein Absperrband - was die befreiende und kämpferische } \\
\text { Absicht visualisieren soll. Sichtbeton verweist auf Kerker oder Bunker. } \\
\text { Absperrband symbolisiert nicht Eingrenzung, sondern Schutz vor Gefahr. } \\
\text { Rote Bildpunkte wecken Assoziationen mit verkauften Bildern. }\end{array}$ \\
\hline $\begin{array}{l}\text { Art der } \\
\text { Bildgestaltung }\end{array}$ & $\begin{array}{l}\text { Illustration vorne in Mischtechnik (Filzstift, evtl. Aquarell, Bleistift, Kohle } \\
\text { und eine computergenerierte Bretterstruktur) mit zentralperspektivischer } \\
\text { Tiefenwirkung. Gruppenaufnahmen im Querformat innen zeigen Kandi- } \\
\text { dierende ca. bis Beinansatz in dynamischen Bewegungen, unterschied- } \\
\text { lichem, natürlichem Licht und normalem Aufnahmewinkel. Bilder und } \\
\text { Textfelder leicht schattiert für räumlichen Effekt. }\end{array}$ \\
\hline
\end{tabular}



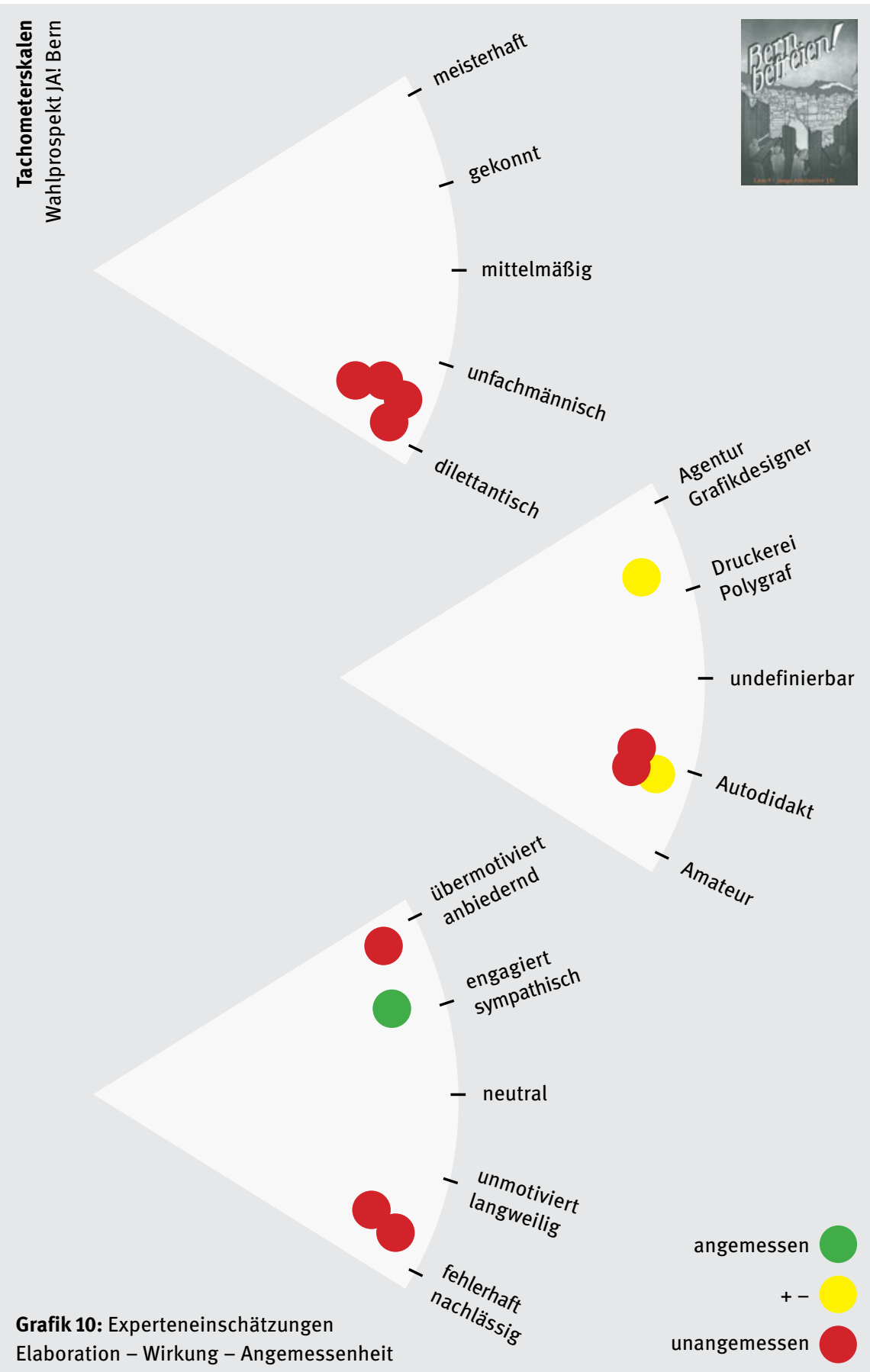
Wirkungsdimension und Stilhöhe: Der Wahlprospekt offenbart einen stark Pathos-orientierten Gebrauch der Stilmittel, z.B. durch die großformatige Illustration, die 3D-Schrift, die düstere Farbstimmung und die dynamisch inszenierten Fotos. Es wird vermutet, dass die agitatorische Vorderseite zusammen mit dem verspielten Layout in «Pinwand-Optik» eine engagierte und zugleich sympathische Wahrnehmung des Absenders auf der Ethos-Ebene befördern soll. Insgesamt wird das Artefakt auf einer mittleren bis hohen Stilhöhe angesiedelt: Es versucht stark affektiv zu wirken, was aber aufgrund der minderen Gestaltungsqualität nicht überzeugend gelingt.

Angemessenheit und Empfehlungen: Adressatinnen und Adressaten der Drucksache sind junge, engagierte und politisch links stehende Menschen mit einer Vision von Politik und Veränderung. Das Artefakt vermag jedoch aus Sicht der Experten mit seinem düsteren Farbklima, der schwer einzuordnenden Illustration, dem dilettantischen Titelschriftzug und der mangelhaften gestalterischen und typografischen Umsetzung dem Wahlkontext, aber auch den Sehgewohnheiten des Zielpublikums nicht wirklich $\mathrm{zu}$ entsprechen: Für eine junge Zielgruppe erscheint die Gesamtaufmachung zu bieder und brav, aber auch zu bemüht, inszeniert und forciert. Die visuelle Aussage ist widersprüchlich und zu wenig durchdacht, so dass das Produkt die Betrachtenden mehr verwirrt, als eine klare Botschaft zu vermitteln. Die verschiedenen symbolischen und ikonografischen Bedeutungsebenen der einzelnen Elemente und ihres Zusammenspiels wurden zu wenig bedacht.

Offenkundig lehnt sich die Illustration an der visuellen Rhetorik der Flyer und Zeitungen der autonomen Jugendbewegung der 1980er Jahre an, z.B. an die Berner Zeitung «Drahtzieher〉. Sie vermag diesen Vergleich jedoch qualitativ nicht einzulösen. Das Layoutkonzept mit der Bretterwand und den Reißnägeln bzw. Klebepunkten wirkt gesucht und überfrachtet. Ebenso wenig überzeugend erscheint aus Expertensicht das Fotokonzept mit den Absperrbändern - selbst die Abgebildeten scheinen die Idee nicht ganz begriffen zu haben. Vereinzelt wird die Umsetzung der Kandidierendenbilder zwar als «erfrischend anders» wahrgenommen, was wohl die beabsichtigte Wirkung spiegelt. Auf die Mehrheit der Experten wirken diese inszenierten Fotos aber eher verkrampft und altbacken und keineswegs spontan oder lustig. In jedem Fall steht die vorgespielte Leichtigkeit auf den Innenseiten in einem Gegensatz zum «Grau in Grau» und zur düsteren agitatorischen Vision: 〈Wir reißen alle Schranken nieder!〉.

Darüber, ob das Resultat am Ende als gescheitert betrachtet werden muss oder vielleicht trotzdem engagiert, sympathisch und authentisch wirkt, herrscht bei den Experten Uneinigkeit. Ist der Anspruch, mit einer jungen Partei Bern zu befreien, als frech und mutig oder als naiv und dümmlich zu beurteilen? Könnte 
gerade die handgestrickte Umsetzung Sympathien bei den jüngeren linken Wählerinnen und Wählern schaffen? Während von einer Seite positiv bemerkt wird, dass hier zumindest versucht werde, mit bildnerischen Mitteln eine Aussage und eine Haltung zu vermitteln, anstatt auf konventionelle Gruppenfotos und Slogans zurückzugreifen, wendet die andere Seite kritisch ein, hier bediene sich eine alternative Jugendpartei der Methoden der Werbung, wo nicht der Inhalt im Vordergrund stehe, sondern ein leeres formales Konzept angewendet werde.

Grundsätzlich wird der Einsatz einer handgemachten Illustration als geeignetes Mittel betrachtet, um Aktivismus und Protest zu demonstrieren. Dabei müsste die Umsetzung jedoch dynamischer und lebendiger sein. Für eine Verbesserung wären zudem die zahlreichen unstimmigen Elemente nochmals zu überdenken oder ganz wegzulassen.

\subsubsection{Gewitzte Laiengestaltung oder professionelles Zitat: Aushang Junge Alternative (JA!) Bern}

Elaboration und Imperfektion: Die Experten beurteilen den orangen Zettel der Jungen Alternative Bern (Abb. 65) als eine aufgrund der Gestaltungsidee bewusst laienhaft, selbstgebastelt und billig produzierte Wahlwerbung (vgl. Grafik 11). Alle Aspekte der Elaboration verweisen auf das zitierte Objekt der Wohnungsannonce: Das Trägermaterial ist Papier aus dem «Copyshop», die Produktion erfolgte durch simple Schwarzweiß-Kopie, die Typografie ist einfach, die Abrisszettel wurden von Hand unregelmäßig eingeschnitten. Die verwendete Schreibschrift soll nach Einschätzung der Experten Nähe schaffen, schadet jedoch der Lesbarkeit.

Wirkungen: Der Aushang wird als auffällig, erfrischend, kreativ, witzig, ironisch, doppelbödig, hintersinnig, lustvoll, ungewöhnlich, «andersdenkend» und risikofreudig beschrieben. Das leuchtende Orange verleiht dem Zettel eine junge, frische Ausstrahlung und Auffälligkeit. Mit seiner selbstgebastelten Elaborationsweise und der Schreibschrift erzielt das Artefakt eine sympathische, authentische, rührende, liebevolle, wenn auch etwas naive Wirkung. Durch die direkte Ansprache («... findest Du〉) und den persönlichen Absender ( (Deine JA! ’) versucht der Zettel, zusätzliche Nähe zu schaffen und Sympathien zu wecken. In seiner typischen Form tritt er unverkennbar als Anschlagzettel auf, wie man ihn in Supermärkten, an Universitäten am schwarzen Brett oder im urbanen Raum wild gehängt sieht - weshalb er auf den ersten Blick nicht als Wahlwerbung zu erkennen ist. Das Artefakt zielt in seiner Anlage auf ein Überraschungsmoment, in welchem der Betrachter erkennt, dass es sich nicht wie erwartet um eine gewöhn- 
liche Wohnungsanzeige handelt, sondern um politische Kommunikation. Gerade durch die Abweichung von der konventionellen Wahlkommunikation gelingt es der Partei in den Augen der Experten mit einem gänzlich unaufwändig gestalteten grafischen Kommunikationsmittel Aufmerksamkeit auf sich zu ziehen und Interesse durch Irritation zu wecken. Die inhaltliche Verbindung von Wohnungssuchinserat und politischer Agenda (Wohnungsnot) wird als kongenial und doch überraschend bewertet: Indem die Partei ein aktuelles Thema in origineller Weise aufnimmt, zeigt sie sich am Puls der Zeit.

Wirkungsdimension und Stilhöhe: Die Wirkung der Drucksache spielt sich gemäß Experteneinschätzung auf der intellektuellen Ebene (Logos) ab, da sie ein Erkennen der Kontextverschiebung bzw. des Zitats voraussetzt. Dies kann sich wiederum auf die Wahrnehmung des Absenders, also die Ethos-Ebene, niederschlagen: Die Partei erscheint dadurch witzig und geistreich. Mit der Botschaftund der leuchtenden Farbe appelliert der Wahlzettel schließlich an die Emotionen (Pathos) der Adressaten. Die Stilhöhe wird dennoch als niedrig eingestuft, da sich die Gestaltung auf minimale, nüchterne visuelle Stilmittel beschränkt. Erst durch den Überraschungseffekt und den inhärenten Witz wird eine intensivere Wirkung erzielt.

Angemessenheit und Empfehlungen: Die Absenderpartei versucht mit einer Drucksache im Stil von Wohnungsannoncen Interesse zu wecken und auf die Problematik der Wohnungsnot aufmerksam zu machen und gleichzeitig auf das politische Engagement der Partei hinzuweisen, die sich für günstigen Wohnraum in der Stadt Bern einsetzt. Die Abreißzettel können als Erinnerungsstütze mitgenommen werden, für welche Partei der Wahlzettel einzulegen ist. Nach Einschätzung der Experten unterstützt die gewählte Form die Kommunikationsidee, Inhalt und Form beziehen sich aufeinander. In untypischer Weise zeigt sich dieses Beispiel nicht dem modernistischen Gestaltungsideal verpflichtet, sondern bedient sich eines postmodernen Zitats. Die Form bestimmt sich aus der Idee der Kontextverschiebung - «The medium is the message -, weshalb die Ausgestaltung notwendig mit einer «schlechten〉 grafischen, typografischen und materiellen Qualität einhergehen muss. Laut Meinung der Experten bespielt die Partei mit dieser Annonce den urbanen Raum, indem sie sich seine Gesetze zu eigen macht. Einerseits kann sich das Kommunikationsmittel so stark vom restlichen Wahlkampfmaterial absetzen. Andererseits nimmt die Absenderpartei in Kauf, dass ein Teil der Adressatengruppe die Kontextverschiebung nicht erkennt oder die Wahlwerbung nicht einmal wahrnimmt. 


\section{Woboung gesucht!}

In der Stadt Bern gibt es heute 333 treie Webaungen. Und jene, die es gibt, werden inmer teurer: 2000 hat eine 3-Zimmer-Wohnung noch 972 Franken gekostel 2010 schon 1143. - Die Junge Alternative JA' setat sich für mehr günstige Wohnungen und sinarolle Massnabmen zur Verteilung des bestehenden Wohnraums ein. So wollen wir beispielsweise eine Wobaungstauscbbörse, die alteren Menschen in grossen Wobnungen exmöglicht, mit jüngeren Menschen, die eine WG gründen wollen, zu tauschen. Weitere Infós findest Du aut unserer Website.

Herzliche Grüsse

Deine JA! www; jungealternative.ch

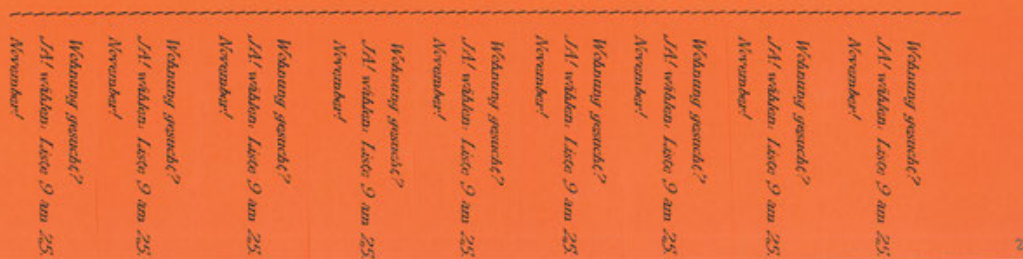

Der Aushang der Jungen Alternative Bern ist ein witziges und hintersinnig konzipiertes, auf einen Überraschungseffekt angelegtes politisches Kommunikationsmittel, das den Stil von selbstgestalteten Wohnungsannoncen zitiert und damit in unkonventioneller Weise das Problem der Wohnungsnot thematisiert. Das Produkt wird mehrheitlich als sehr gelungene Parteikommunikation gegenüber einem jungen, linken Publikum aufgefasst, die bewusst - auch aus finanziellen Gründen - Abstriche bei der gestalterischen Professionalität und Materialqualität in Kauf nimmt.

Abb. 65: Aushang ‘Wohnung gesucht!) Junge Alternative Bern 


\begin{tabular}{|c|c|}
\hline \multicolumn{2}{|c|}{$\begin{array}{l}\text { Aushang Junge Alternative (JA!) Bern } \\
\text { Formale Analyse }\end{array}$} \\
\hline Art und Produktion & $\begin{array}{l}\text { Aushang bzw. Flugblatt, eingeschnitten, Schwarzweiß-Fotokopie, } \\
\text { einseitig auf handelsüblichem, zinnoberrotem Kopierpapier } 80 \mathrm{~g} / \mathrm{m}^{2}\end{array}$ \\
\hline Format & DIN A5 (210 mm x $148.5 \mathrm{~mm})$ quer \\
\hline Grafische Mittel & Schrift, gestrichelte Linie \\
\hline $\begin{array}{l}\text { Typografie } \\
\text { Layout } \\
\text { Gesamtanmutung }\end{array}$ & $\begin{array}{l}\text { Der Aushang ist ohne Gestaltungsraster bzw. bewusste Randstegpro- } \\
\text { portionierung gestaltet. Der Haupttextblock verläuft horizontal über } \\
\text { 9/10 der Formatbreite, enthält eine fett ausgezeichnete Titelzeile } \\
\text { und ist in einer schräggestellten, klassizistischen Antiqua mit hand- } \\
\text { schriftlichem Duktus gesetzt. Der Text enthält keine Worttrennungen, } \\
\text { hat ca. } 1.5 \text {-fachen Zeilenabstand und steht als linksbündiger Rausatz } \\
\text { in einer Schriftgröße von ca. 10pt und ca. } 80 \text { Anschlägen pro Zeile. } \\
\text { Die zweite Informationsebene wird repetiert auf abreißbaren, ca. } \\
18 \text { mm breiten, vertikalen Papierstreifen, die randabfallend an der } \\
\text { unteren Formatbegrenzung nebeneinander angeordnet und durch } \\
\text { eine dekorative Linie vom oberen Textblock getrennt sind. Zwischen } \\
\text { dem Haupttext und den Papierstreifen ist ein größerer Leerraum. }\end{array}$ \\
\hline $\begin{array}{l}\text { Bildinhalt } \\
\text { Topos } \\
\text { Figur }\end{array}$ & - \\
\hline \multicolumn{2}{|c|}{ Art der Bildgestaltung - } \\
\hline Farbe & Dominanz von Orange durch die verwendete Papierfarbe \\
\hline
\end{tabular}



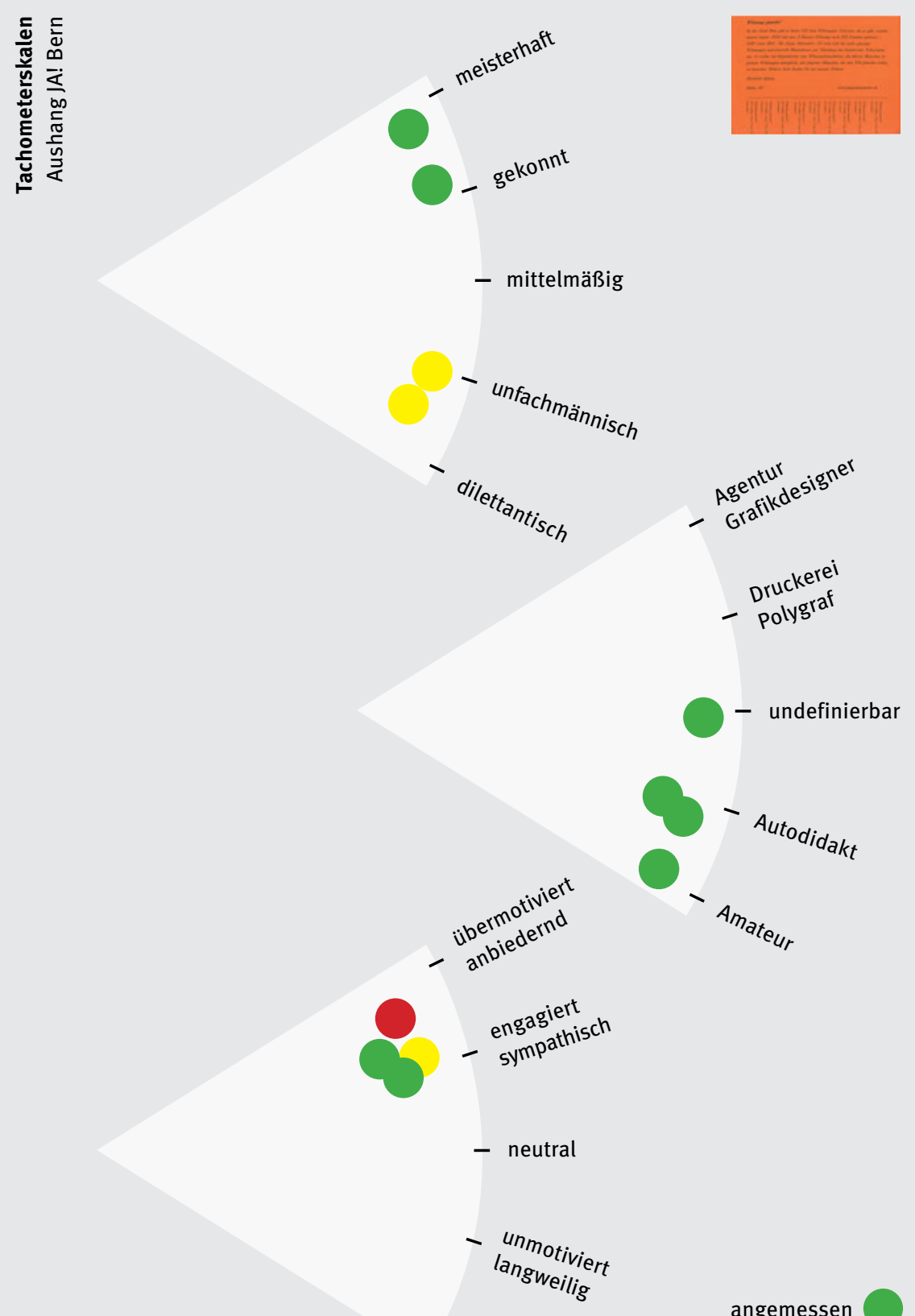

Grafik 11: Experteneinschätzungen

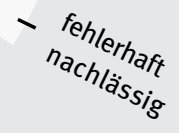

angemessen

Elaboration - Wirkung - Angemessenheit 
Eine weitere Gefahr wird darin gesehen, dass der Lesekomfort und die Professionalität des Kommunikationsmittels zu Gunsten der stringenten Umsetzung der Idee «geopfert» werden mussten. Zudem ist die Idee nicht auf andere Themen und Kommunikationsmittel der Partei übertragbar, was sie untauglich macht für das Transportieren einer visuellen Parteiidentität. Die gewählte Form fördert schließlich auch Assoziationen von «WG-Mief» und «Wollsockenidealismus» zutage. So werden die Risiken, die mit der zwar originellen Idee einhergehen, teilweise als zu groß eingestuft und der witzige Ton als der Wichtigkeit des Wahlkontexts unangemessen erachtet. In der Mehrheit wird das Beispiel hingegen als sehr gelungene, adäquate und originelle Idee für eine junge, spontane, linke Partei bewertet, welche kaum über eigene Werbemittel verfügt. Denn eine solche Werbemaßnahme ist günstig und könnte sogar wirksamer sein als der Druck teurer vierfarbiger Flyer, weil sie sich stärker von der Norm abhebt. Aus diesen Gründen wird auch vermutet, dass diese Form der Kreativität gerade aus einem Mangel an finanziellen Mitteln entstanden sein könnte: Die Partei macht aus der Not eine Tugend und zeigt, dass für sie «geistiges Kapital» über finanziellem Kapital steht.

Um den gewünschten Effekt zu verstärken und das Produkt noch sympathischer und authentischer wirken zu lassen, könnte man das Blatt aus Sicht der Experten tatsächlich von Hand oder mit der Schreibmaschine beschriften. Damit die Inserate auch breit wahrgenommen werden, empfehlen die Gestaltungsprofis zudem, die Zettel nicht nur an Anschlagbrettern oder im öffentlichen Raum auszuhängen, sondern sie persönlich und von Hand zu verteilen - so dass die Zielgruppe gleich in ein Gespräch über die Anliegen der Partei verwickelt werden könnte.

\subsection{6 Überbordender Dilettantismus: Flugblatt Grüne Freie Liste (GFL) Zollikofen}

Elaboration und Imperfektion: Die Elaborationsform des Veranstaltungsprogramms der Grünen Freien Liste Zollikofen (Abb. 66) deutet aus Sicht der Gestaltungsexperten darauf hin, dass eine Amateurin oder ein Amateur ohne jegliches gestalterische Können oder ästhetische Grundgefühl - das viele Amateurgestalter durchaus haben - am Werk gewesen ist (vgl. Grafik 12). Es handelt sich allem Anschein nach um ein zu Hause oder im Büro in einem normalen PC-Anwendungsprogramm erstelltes Elaborat, das selbst ausgedruckt und auf handelsüblichem, hellgelbem Kopierpapier vervielfältigt wurde. Auffallend ist die mangelnde Hierarchisierung: $\mathrm{Zu}$ viel Text wurde fett ausgezeichnet oder groß gesetzt und es finden sich über das ganze Artefakt hinweg kaum Lücken. Die typografische Gestaltung scheint beseelt von dem Versuch, eine bestmögliche Ausfüllung 
Am 25. November 2012 gibt's in Zollikofen eine Kampfwahl ums Gemeindepräsidium!

Mirjam Veglio (SP) und Daniel Bichsel (SVP) wollen die Nachfolge von Stefan Funk (FDP) antreten.

Und Sie? Wollen Sie wissen, was die beiden zu
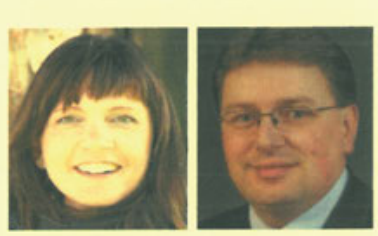

> ökologischen

$>$ sozialen

> kulturellen

> schulpolitischen

> basisdemokratischen

> wirtschaftlich nachhaltigen ...

kurz: zu grünen Anliegen denken und sagen?

Dann machen auch Sie mit an der öffentlichen Befragung - kommen Sie an unser

\section{grünes Hearing}

mit Fragensteller Gilbert Hangartner (Gemeindepräsidiumskandidat von 2008). Aber selbstverständlich können auch Sie die beiden Kandidierenden befragen.

\section{Donnerstag, 10. Mai, ab 19.00, Restaurant Kreuz, Zollikofen}

Anschliessend an das „grüne Hearing“, ca. ab 20.45 Uhr, jährliche Mitgliederversammlung der Grünen Freien Liste GFL Zollikofen.

Der Anlass ist öffentlich auch (Noch-)NichtMitglieder und Parteilose sind herzlich willkommen!

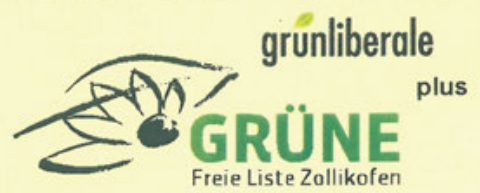

\section{Weitere Informationen: www.gfl-zollikofen.ch}

Der komplett dilettantisch und unübersichtlich gestaltete Veranstaltungshinweis der Grünen Freien Liste Zollikofen ist eine Zumutung für das Publikum und wirft ein schlechtes Licht auf die Absenderpartei, obschon ihm eine gewisse authentische Wirkung nicht abzusprechen ist.

Abb. 66: Informationszettel Wahlveranstaltung Grüne Freie Liste Zollikofen 


\section{Flugblatt Grüne Freie Liste (GFL) Zollikofen}

Formale Analyse

\begin{tabular}{|c|c|}
\hline Art und Produktion & $\begin{array}{l}\text { Flugblatt oder Kleinplakat, vermutlich Farbfotokopie, einseitig, vier- } \\
\text { farbig auf hellgelbem, holzhaltigem Werkdruckpapier } 80 \mathrm{~g} / \mathrm{m}^{2}\end{array}$ \\
\hline Format & DIN A4 (210 mm x $297 \mathrm{~mm})$, hoch \\
\hline Grafische Mittel & Schrift, Fotografie, Wortbildmarke \\
\hline $\begin{array}{l}\text { Typografie } \\
\text { Layout } \\
\text { Gesamtanmutung }\end{array}$ & $\begin{array}{l}\text { Das Layout wurde ohne Gestaltungsraster erstellt und zeichnet } \\
\text { sich durch eine unübersichtliche, hierarchisch unstrukturierte bis } \\
\text { chaotische, formatfüllende Anordnung verschiedener horizontaler } \\
\text { Abschnitte und Textzeilen ohne erkennbare Schwerpunktsetzung, } \\
\text { Leseführung und kompositorische Akzentuierung aus. Zwei klein- } \\
\text { formatige Kandidatenbilder wurden asymmetrisch im oberen linken } \\
\text { Formatbereich platziert, so dass sie an die linke Satzspiegelbegren- } \\
\text { zung stoßen. Die Bilder sind gegenüber der Umgebungstypografie } \\
\text { hierarchisch untergeordnet und werden vom Text umflossen. Die } \\
\text { Größen, Tonwert- und Schriftstärkenunterschiede der Zeilen und } \\
\text { Abschnitte erfolgen ohne erkennbare, inhaltlich begründbare Logik. } \\
\text { Unten rechts finden sich zwei Parteilogos. Der Text wurde in Barock- } \\
\text { Antiqua (‘Times New Roman`) in normalem und fettem Schriftschnitt } \\
\text { und normaler Laufweite gesetzt. Alle Textblöcke und Textzeilen sind } \\
\text { linksbündig angeordnet. Es wurden mindestens vier Schriftgrößen } \\
\text { zwischen } 16 \text { pt und ca. } 42 \text { pt verwendet. Die Zeilenzwischenräume } \\
\text { sind erhöht und je nach Schriftgröße verschieden groß. Neben den } \\
\text { Kandidatenbildern werden zur Absatzkennzeichnung pfeilartige } \\
\text { Bullet Points eingesetzt. }\end{array}$ \\
\hline $\begin{array}{l}\text { Bildinhalt Topos } \\
\text { Figur }\end{array}$ & $\begin{array}{l}\text { Kandidatenporträts mit glücklichem Gesichtsausdruck, der für } \\
\text { Umgänglichkeit und Freundlichkeit sowie für Freude am Leben und } \\
\text { am politischen Engagement steht. }\end{array}$ \\
\hline $\begin{array}{l}\text { Art der } \\
\text { Bildgestaltung }\end{array}$ & $\begin{array}{l}\text { Fotos in qualitativ sehr schlechter Aufbereitung: unscharf und } \\
\text { ungleich in Kontrast, Tonalität, Sättigung und Helligkeit (überbelich- } \\
\text { tet bzw. unterbelichtet), mit Breitverzug, mit Farbstich, vor unter- } \\
\text { schiedlichem Hintergrund, einmal Außen-, einmal Studioaufnahme. }\end{array}$ \\
\hline Farbe & $\begin{array}{l}\text { Dominanz von Hellgelb, gegeben durch die Papierfarbe, mit Grünak- } \\
\text { zent durch das Parteilogo }\end{array}$ \\
\hline
\end{tabular}




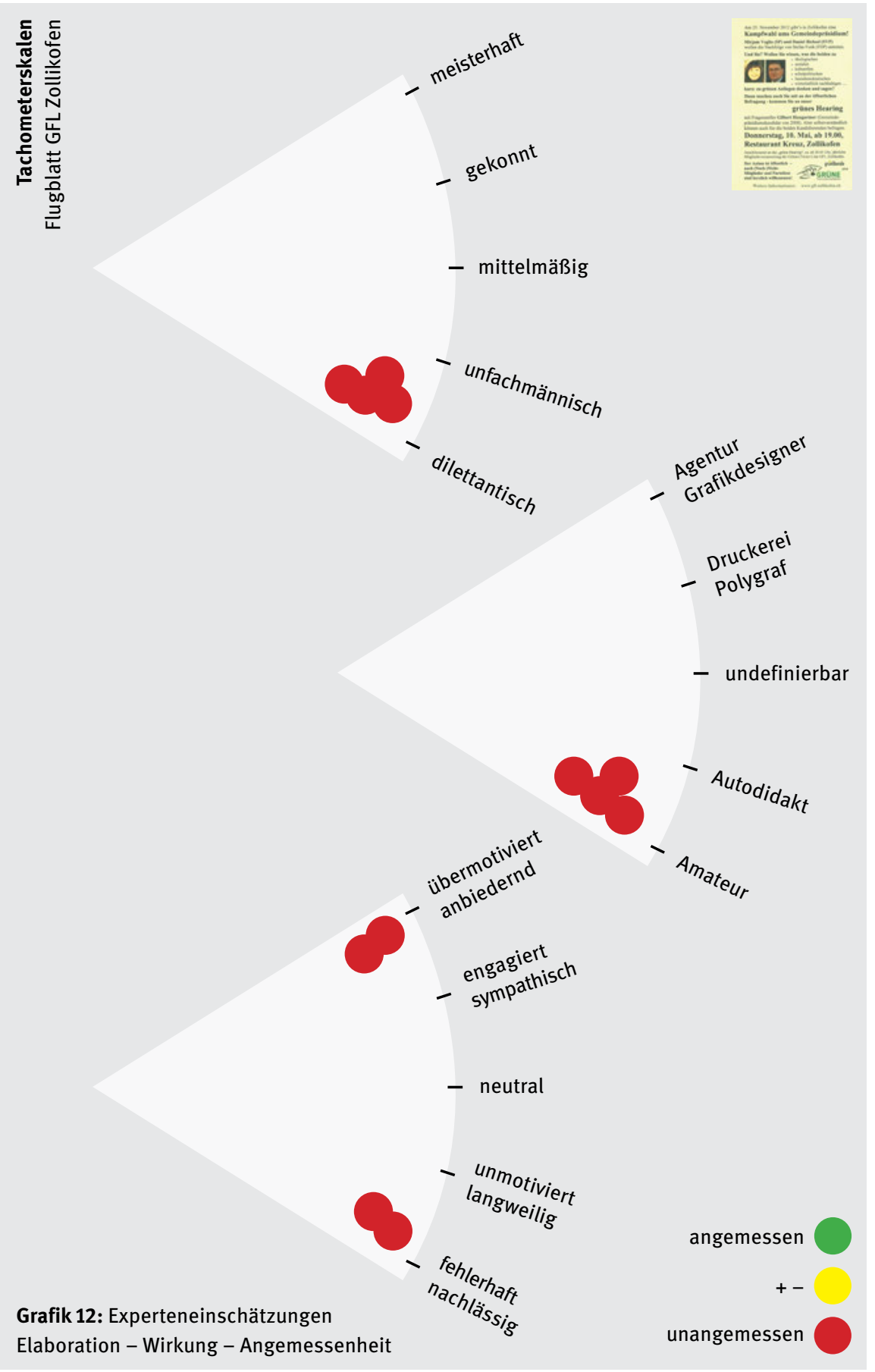


der zur Verfügung stehenden Fläche zu erreichen - was typisch ist für nicht ausgebildete Gestalter. In der Ausbildung lernt man schon früh, dass die nicht bedruckte Fläche mindestens so wichtig ist wie die bedruckte. Generell wird aus Expertensicht $\mathrm{zu}$ viel (und inhaltlich zu wenig pointierter) Text für die vorhandene Fläche verwendet. Auch die mangelhafte Detailtypografie, wie etwa der zu kurze 〈Divis〉 (Gedankenstrich) sowie fehlende oder überflüssige Abstände und Satzzeichen deuten auf eine Person ohne jedes fachliche Know-how hin. Der Blattrand rechts franst aus, weil keine Randzone definiert wurde. Immerhin wird die Einsicht gelobt, für die Textgestaltung nur eine Schriftart zu wählen, und die benutzte 〈Times〉 wird neben «Helvetica〉 eigentlich als «sicherer Wert» für Amateurgestalter beurteilt.

Eine Art Regel, die jedoch kaum bewusst befolgt wurde, erkennen die Gestaltungsprofis im Schriftbild: Für jeden Absatz wurde die Schriftgröße so gewählt, dass der Absatz die Spalte ausfüllt - woraus auch die diversen Schriftgrößen resultieren. Dieser Stil verweise ungewollt auf die Tradition der 〈Woodtype〉Plakate aus dem 19. Jahrhundert. Die Bildaufbereitung wird nicht nur als fehlerhaft, sondern als gänzlich «unbrauchbar» bewertet, da sie die Kandidaten extrem unvorteilhaft zeigt und sich bei der Wiedergabe auf dem gelben Papier die Gesichtsfarbe zusätzlich negativ verändert hat. Schließlich wurden die Bilder denkbar schlecht ins Ganze integriert: Sie wirken «reingepappt», sind nicht aufeinander abgestimmt, schlecht beschnitten und minderwertig reproduziert. Besonders das verpixelte Logo am unteren Seitenrand halten die Experten für vermeidbar, da via Parteigeneralsekretariate oder -websites Logos in hochaufgelöster Qualität leicht verfügbar seien.

Wirkungen: Das Artefakt erscheint aus Expertensicht äußerst unprofessionell, unüberlegt und dilettantisch gestaltet. Es kommt als «Bleiwüste» daher, wirkt chaotisch, unübersichtlich, wirr, unleserlich, uninspiriert, flach und billig - und dabei auch noch geschwätzig und marktschreierisch. Die dilettantische und unübersichtliche Wirkung wird der mangelnden Hierarchisierung und Strukturierung und einer auch ansonsten zweifelhaften technischen Ausarbeitungsqualität zugeschrieben: der regellos eingesetzten, unbegründet variierten Typografie, der formatfüllenden Anordnung der Elemente bzw. dem fehlenden Weißraum, der mangelhaften Wiedergabe- und Papierqualität - aber auch einer fehlenden Bündelung und Schärfung der sprachlichen Botschaft selbst. Besonders die mangelnden Größenhierarchisierungen führen laut Experten zu einer gegenseitigen «Kannibalisierung» der Hauptaussagen.

Wirkungsdimension und Stilhöhe: Bei der Gestaltung dieses Veranstaltungsprogramms wurde offenbar weder versucht, auf Logos-Ebene eine klare Botschaft 
oder Argumentation aufzubauen, noch auf Ethos-Ebene eine Identität des Absenders zu kreieren oder auf Pathos-Ebene eine emotionale Wirkung zu hinterlassen - höchstens vielleicht Aufmerksamkeit zu wecken durch die vielen Textauszeichnungen und das Ausrufezeichen im Titel. Dennoch resultieren laut Experten Wirkungen auf verschiedenen Ebenen: Auf Logos-Ebene verunmöglicht die grafische und typografische Dysfunktionalität dem Publikum einen schnellen und lesefreundlichen Informationszugang. Das gänzlich dilettantische Agieren führt auf Ethos-Ebene dazu, dass die Absenderpartei in einem naiven bis unseriösen Licht erscheint - auch die beiden unvorteilhaft gezeigten Kandidaten verlieren dadurch an Glaubwürdigkeit. Die Stilhöhe ist für die Gestaltungsprofis schwer anzugeben: Das Artefakt verwendet ein äußerst primitives typografisches Vokabular, das sich jedem bekannten gestalterischen Regelwerk entzieht - und das zugleich exzessiv und marktschreierisch eingesetzt wurde.

Angemessenheit und Empfehlungen: Die Drucksache möchte auf die kommenden Lokalwahlen in Zollikofen und auf das von der Absenderpartei GFL (zusammen mit den Grünliberalen) veranstaltete Hearing der zwei Kandidierenden für das Gemeindepräsidium aufmerksam machen. Gleichzeitig soll das Plakat auch Wahlwerbung für den Organisator - also die GFL Zollikofen selbst - sein. Nach Expertenmeinung sind sich die Verantwortlichen offensichtlich nicht bewusst über die Macht der visuellen Gestaltung und den Eindruck, den man damit vermittelt. Angesichts des ernsthaften Inhalts der angekündigten Veranstaltung wird die eingesetzte Gestaltungssprache als nicht angemessen und unseriös betrachtet. Grundsätzlich beurteilen die Experten die einfache Produktionsweise am PC und Fotokopierer für einen lokalpolitischen Anlass, der von Kleinparteien einer mittelgroßen Gemeinde organisiert wird, noch als knapp angemessen. Der erreichte Elaborationsgrad des vorliegenden Artefakts ist jedoch ungenügend und es wird durch seine chaotische und wirr orchestrierte Gestaltung als abschreckend und aufdringlich wahrgenommen. Bereits das Entziffern der Botschaft ist eine Zumutung für den Betrachter - was kaum im Sinn des Absenders sein kann. Das Artefakt erscheint zudem unentschlossen in seiner Funktion: Für ein Flugblatt ist es den Experten zu groß, für einen Aushang zu unübersichtlich und kleinteilig organisiert. Immerhin: Die Gestaltung wirkt auf die Experten hoch authentisch und unverfälscht Man spürt, dass hier ein echtes Anliegen vermittelt wird. Die Optik erinnert sie an die simplen Anschläge, die man an Bushaltestellen in ländlichen Gemeinden findet, was die authentische Wirkung verstärkt. Auch die Tatsache, dass möglichst wenig Geld für die Kommunikation ausgegeben wurde, könnte allenfalls «Goodwill» bei den Wählerinnen und Wählern auslösen.

Für eine Verbesserung der Gestaltung empfehlen die Experten, die Typografie vollständig neu aufzusetzen und die Botschaft sprachlich neu zu formulieren 
und zu schärfen, aber auch die Bilder und die Wortbildmarke müssten qualitativ besser aufgearbeitet sein. Mit den freien Zonen sollte sorgfältiger umgegangen werden und die Bildebene müsste der Vermittlung der Botschaft dienen, um den Text zu entlasten. Sollte der Flyer weiterhin selbstgemacht wirken, könnte gleich alles lustvoll von Hand ausgestaltet werden, anstatt «halbherzige» Arbeit am Computer zu leisten. Um die ökologische Orientierung der Absenderpartei auch gestalterisch auszudrücken, wäre Recyclingpapier oder lindgrünes Papier passender.

\subsection{Rhetorische Detailanalysen: Gemeinwesenarbeit}

\subsubsection{Funktion kommt vor Emotion: Flugblatt Kerzenziehen Römisch- katholische Pfarrei Zollikofen}

Elaboration und Imperfektion: Das Infoblatt zum Kerzenziehen der Pfarrei Zollikofen (Abb. 67) entspricht nach Erachten der Gestaltungsfachleute den Kriterien einer alltäglichen, genretypischen, von Laien gestalteten Drucksache (vgl. Grafik 13). Es erfüllt den kommunikativen Mindestanspruch, wirkt aber beliebig, nichtssagend und uninspiriert. Aus der visuellen Einförmigkeit sticht laut Experten lediglich die Wortbildmarke 〈Kerzen ziehen` am oberen Bildrand heraus, da sie mittig am oberen Rand platziert wurde, den größten Schwarzanteil besitzt und als einziges Element eine - wenn auch leicht veraltet wirkende - gestalterische Qualität aufweist. Bei der Schriftgestaltung stellen die Experten Mängel in Textgliederung und formativer Struktur fest. Die Hierarchisierung des Texts oder eine inhaltliche Differenzierung und Kontrastierung fehlt - und somit auch eine eigentliche Leseführung. Wegen der unregelmäßigen Weißräume und den großzügig, aber nicht immer einsichtig verwendeten Textauszeichnungen ergibt sich ein unschönes bis unruhiges Schriftbild. Eigentliche Fehler wurden in der tabellarischen Struktur der Zeitangaben gefunden, wo die Uhrzeiten zuerst in Minuten angegeben werden, darunter jedoch nur in Stunden. Ein weiterer Bruch erfolgt bei der untersten Zeitangabe, wo die Uhrzeit nur einstellig anstatt wie zuvor zweistellig angezeigt wird. Dies führt dazu, dass gleiche Angaben nicht untereinander zu stehen kommen und die Weißräume zerfleddern. Als Fehler - oder typografische Eigenwilligkeit - können auch die zu kleinen Einzüge gelten, die es verunmöglichen, die Informationen zu den einzelnen Punkten (〈Preis〉, 〈Tipps〉, «Mitnehmen`) auf derselben Zeile anzusetzen. 


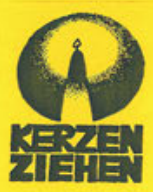

Die Pfarrei St. Franziskus und der Familienclub Zollikofen laden alle zu einem vorweihnachtlichen schönen Brauch ein.

\section{OFFENES KERZENZIEHEN IN ZOLLIKOFEN}

ÖFFNUNGSZEITEN IN 2012 (Änderungen bleiben vorbehalten!):

$\begin{array}{lll}\text { Sonntag, } & \text { 18. November } & 10.30-16 \mathrm{Uhr} \\ \text { Montag, } & \text { 19. November } & 14-18 \mathrm{Uhr} \\ \text { Dienstag, } & \text { 20. November } & 14-18 \mathrm{Uhr} \\ \text { Mittwoch, } & \text { 21. November } & 14-18 \mathrm{Uhr} \\ \text { Donnerstag, } & \text { 22. November } & 14-18 \mathrm{Uhr} \\ \text { Freitag, } & \text { 23. November } & 14-20 \mathrm{Uhr} \\ \text { Samstag, } & \text { 24. November } & 9-13 \mathrm{Uhr}\end{array}$

ORT: Foyer vom Pfarrheim St. Franziskus, Stämpflistrasse 30. Neben der katholischen Kirche in Zollikofen.

PREIS:

Fr. 3.- pro $100 \mathrm{~g}$ fertige Kerze

TIPPS:

Die Zeiten zwischen 14.00 und $15.30 \mathrm{Uhr}$ sind in der Regel geeignet, um in ruhe Kerzen zu ziehen.

Ältere Kleider anziehen.

Kinder im Vorschulalter bitte in Begleitung. Versicherung ist Sache der Teilnehmenden.

MITNEHMEN:

Baumwolllappen zum Trocknen der Kerzen, Schachteln und

(.)

Tasche für den Transport.

Katholische Kirche Region Bern

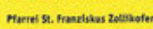

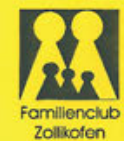

Das einfache gelbe Flugblatt, das zum Kerzenziehen der Pfarrei St. Franziskus und des Familienclubs Zollikofen einlädt, erfüllt mit seiner minimalen, textlastigen Gestaltung zwar seine kommunikative Grundfunktion, wirkt aber zugleich unnötig amtlich, austauschbar, nichtssagend und lieblos. Hier wurde eine gute Gelegenheit verpasst, die Ankündigung eines stimmungsvollen Anlasses angemessen und emotional wirkungsvoll in Szene zu setzen: Mit sehr wenig Aufwand wäre auch im Rahmen von Laiengestaltung ein weit besseres Resultat möglich gewesen.

Abb. 67: Informationsblatt «Kerzenziehen` Römisch-katholische Pfarrei Zollikofen 


\section{Flyer Kerzenziehen Römisch-katholische Pfarrei Zollikofen}

\section{Formale Analyse}

\begin{tabular}{|c|c|}
\hline Art und Produktion & $\begin{array}{l}\text { Flugblatt, Schwarzweiß-Fotokopie, einseitig, auf goldgelbem Kopier- } \\
\text { papier } 80 \mathrm{~g} / \mathrm{m}^{2}\end{array}$ \\
\hline Format & DIN A5 (148.5 mm x $210 \mathrm{~mm})$, hoch \\
\hline Grafische Mittel & Schrift, Bildmarke \\
\hline $\begin{array}{l}\text { Typografie } \\
\text { Layout } \\
\text { Gesamtanmutung }\end{array}$ & $\begin{array}{l}\text { Für den Text wurde als Schrifttyp eine serifenlose Linear-Antiqua/ } \\
\text { Grotesk (vermutlich ‘Arialı) verwendet, überwiegend in 12pt Größe. } \\
\text { Der Text wurde im Mittelachsen- und Tabellensatz mit Einzügen und } \\
\text { Auszeichnungen formatmittig und flächenfüllend platziert. Versal- } \\
\text { und Minuskeltext sowie normale und fette Schriftschnitte wechseln } \\
\text { sich ab. Es scheint keine klare Auszeichnungs- und Hierarchieregel } \\
\text { angewendet worden zu sein, so dass sich ein fragmentiertes Kolum- } \\
\text { nenbild mit undifferenzierter horizontaler und vertikaler Leseführung } \\
\text { ergibt. Drei Bildmarken wurden am oberen und unteren Bildrand } \\
\text { platziert, wobei eine durch ihre prominente Position zuoberst in der } \\
\text { Mitte und den größten Schwarzwert hervorsticht. }\end{array}$ \\
\hline $\begin{array}{l}\text { Bildinhalt } \\
\text { Topos } \\
\text { Figur }\end{array}$ & $\begin{array}{l}\text { Die Bildmarken repräsentieren metonymisch und symbolisch den } \\
\text { Inhalt des Anlasses und die damit verbundenen Themen und Rituale } \\
\text { (Kerze: Kerzenziehen, Kerzenlichtstimmung, Heiligenschein, Weih- } \\
\text { nachten) bzw. in unterschiedlichen Abstraktionsgraden zugleich } \\
\text { Absender und Adressaten (große und kleine «Kegelmenschen»: für } \\
\text { Groß und Klein, Kind und Kegel). Beim Kirchenlogo wird der Inter- } \\
\text { pretationsspielraum groß gelassen (Halbkreise, Punkt: Der Einzelne } \\
\text { wird von der Gemeinschaft getragen, die Kirche ist gegen oben (Gott) } \\
\text { offen). }\end{array}$ \\
\hline $\begin{array}{l}\text { Art der } \\
\text { Bildgestaltung }\end{array}$ & $\begin{array}{l}\text { Bildmarken schwarzweiß in Strich bzw. Halbton. Logo oben ver- } \\
\text { mutlich ursprünglich Linoldruck oder Handzeichnung. Effekt einer } \\
\text { Positiv-Negativ-Kombination des Sujets im Quadrat bzw. Kreis. }\end{array}$ \\
\hline rbe & nd Schwarz. Ausgeprägter Hell-Dunkel-Kontrast. \\
\hline
\end{tabular}



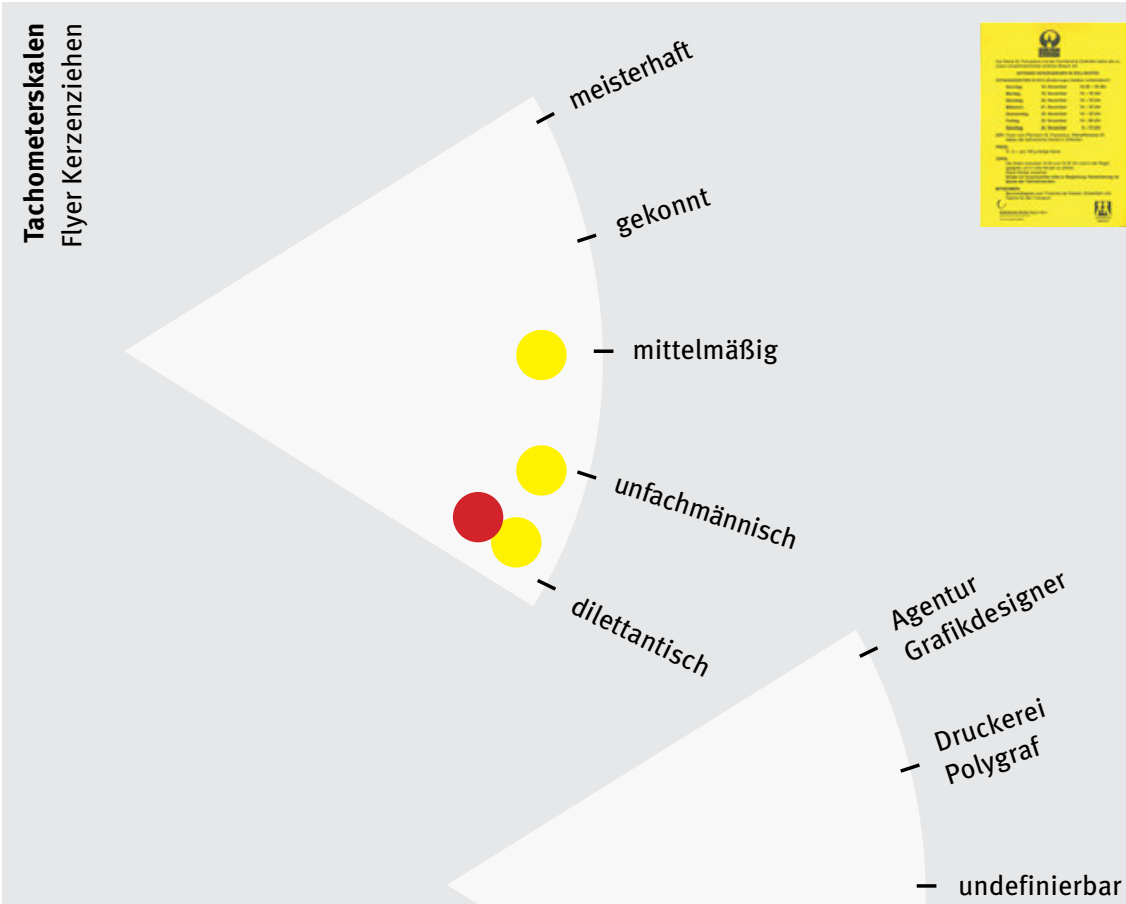

Grafik 13: Experteneinschätzungen Elaboration - Wirkung - Angemessenheit

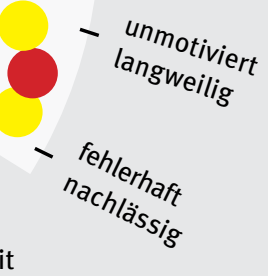

angemessen engagiert
- sympathisch

- neutral
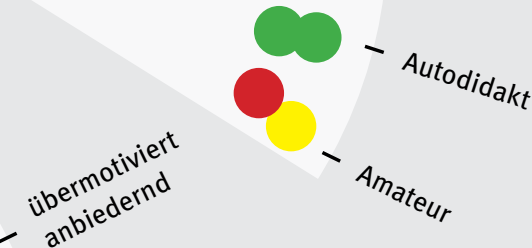
Ansonsten wirkt die Typografie relativ sorgfältig gesetzt; sie ist lesbar und verständlich. Sogar die Verwendung des Geviertstrichs bei der Preisangabe ist korrekt, wenn auch etwas altmodisch. Die Abbildungen werden als fehlerlos beurteilt - abgesehen von der schlechten Druckqualität der Graustufen beim Logo links unten und der sichtbaren Klebekante und leicht schrägen Positionierung des Logos «Kerzen ziehen〉. Dies deutet darauf hin, dass das Infoblatt nicht integral in einem Anwendungsprogramm gestaltet, sondern als Kopier-Vorlage aus verschiedenen Elementen zusammengeklebt wurde. Was die Proportionen und Positionierung der einzelnen Elemente betrifft, ist laut Experten der Anteil des themengebenden, oberen Signets relativ zum Textteil deutlich zu klein. Zudem wurde das Logo der katholischen Kirche $\mathrm{zu}$ weit nach oben gerückt, so dass der linke Halbkreis bereits in den Textbereich übergreift. Überhaupt weisen die unteren Logos keine optischen Bezüge zum restlichen gestalteten Feld auf.

Wirkungen: Die Gesamtwirkung des Infoblatts wird von den Gestaltungsexperten als laienhaft, identitätslos, langweilig, amtlich oder gar als steril und lieblos beschrieben. Einzig die sichtbar von Hand gestaltete Machart des Kerzen-Signets verweist in ihren Augen auf das Handwerkliche, das Selbermachen, die Basteltätigkeit des Anlasses. Durch den positiv/negativ-Wechsel von Kerze und Strahlenkranz ergibt sich zudem die Assoziation mit einem Heiligenschein. Neben dem Signet fällt die gelbe Signalfarbe des Papiers auf - doch scheint die Papierwahl lediglich auf die Erregung von Aufmerksamkeit angelegt zu sein, anstatt einer ganzheitlichen gestalterischen Überlegung zu entspringen: Es ist kein warmes Kerzenscheingelb, sondern ein «signaletisches» Gelb, das im gegebenen Kontext aggressiv, unsinnlich und unfreundlich wirkt. Die negativen Wirkungen resultieren laut Expertenmeinung aus den limitierten «low-end»-Gestaltungsoptionen der Anwendungssoftware (vermutlich 〈Word〉) zusammen mit den offensichtlich beschränkten gestalterischen Fähigkeiten des Laienanwenders. Minderwertig bis billig wirkt das Flugblatt auch aufgrund seiner günstigen Produktionsweise, der Optik und Haptik des einfachen gelben Kopierpapiers.

Wirkungsdimension und Stilhöhe: Die Experten erkennen in der Ausgestaltung des Flugblatts eine Konzentration auf die Vermittlung der nötigen Information zum Besuch des Anlasses: Es scheint primär um die Erfüllung der kommunikativen Grundbedürfnisse auf der Logos-Ebene zu gehen. Auf Ebene des Pathos dagegen vermag das Informationsblatt keine besondere Stimmung zu erzeugen: In seiner Beliebigkeit weckt es kaum weihnachtliche Vorfreude beim Betrachter. Allein durch die Signalfarbe wirkt es leicht affektiv. Der nüchterne, identitätslose und minderwertige Auftritt könnte sich laut Experten jedoch auf die Ethos-Dimension niederschlagen, also die Wahrnehmung des Absenders und 
des Anlasses negativ beeinflussen. Die Stilhöhe wird in jeder Hinsicht als ganz niedrig wahrgenommen.

Angemessenheit und Empfehlungen: Das Infoblatt lädt «alle`, besonders Kinder und ihre Erziehenden sowie die Mitglieder der Kirchgemeinde und des Familienclubs zum Kerzenziehen in Zollikofen ein. Das Ziehen von Kerzen als wiederkehrendes Ritual hat, so vermuten die Experten, einen festen Platz in den Familien- und Schulkalendern, so dass die Zielgruppe bereits motiviert ist und ein gewisses Insiderwissen zum Angebot mitbringt. Ein werberischer Auftritt scheint deshalb nicht vonnöten. Das Artefakt agiert «auf der niedrigsten Stufe der Wahrnehmung» und erfüllt damit den gestalterischen Mindeststandard: Man kann es lesen und erfährt die relevanten Daten. Das Flugblatt funktioniert somit als unkompliziertes Informationsmittel und ist insofern zweckmäßig.

Das Infoblatt verpasst jedoch nach Einschätzung der Experten die Chance, sein Publikum stimmungsvoll anzusprechen und so vielleicht eine positivere und größere Breitenwirkung zu entfalten. In seiner pedantisch nüchternen und textlastigen Ausgestaltung kann das Blatt in keiner Weise die festliche Stimmung des beworbenen Anlasses vermitteln und wirkt somit lieblos an der Zielgruppe der Kinder und ihrer Eltern oder Lehrpersonen «vorbei gestaltet». Da das an sich passende Kerzensignet nur ganz klein reproduziert wurde, wird sein Wirkungspotenzial nicht ausgeschöpft: Das Flugblatt wirkt kalt und distanziert anstatt vorweihnächtlich. Das Potenzial, das der feierliche Anlass der Gestalterin oder dem Gestalter geboten hätte, einen Hauch Charme oder eine feierliche Stimmung zu verströmen, bleibt in der vorliegenden Form gänzlich ungenutzt. Erwartet man neben der Logos-Ebene auch eine minimale Ansprache des Publikums auf Pathos-Ebene, müsste das Produkt daher als unangemessen gelten.

Wie die Experten betonen, wäre bei diesem Beispiel selbst für unerfahrene Laiengestalter mit kleinstem Aufwand ein stimmiges Resultat erzielbar gewesen. Für eine Verbesserung könnte das bestehende Kerzenlogo als zentrales Sujet verwendet werden, um eine weihnachtliche Stimmung zu verströmen und den amtlichen Charakter zu vermeiden: Der Aspekt der Handarbeit kommt durch die Form und Qualität des Signets und des Schriftzugs sehr gut zum Ausdruck. Richtig stimmungsvoll könnte das Motiv eingesetzt werden, indem auf einem beidseitig bedruckten Flyer auf der Frontseite das Signet formatfüllend vergrößert und negativ gesetzt würde und auf der Rückseite dann der Text mittelachsig in Antiqua. Dabei dürften die aktuellen, wenig aufwändigen Produktionsmittel und das billige Papier durchaus beibehalten werden, jedoch lieber in einem sanfteren Gelbton. Als auch von Laien rasch und einfach $\mathrm{zu}$ realisierende Alternative könnte ein Zeichenwettbewerb unter den Kerzen ziehenden Kindern veranstaltet oder das Leuchten in deren 
Augen fotografiert werden - um die so entstandenen Bilder als zentrale Sujets für das nächstjährige Infoblatt zu verwenden.

\subsubsection{Authentisch oder unseriös? Aushang Mädchentreff Bern}

Elaboration und Imperfektion: Das Kleinplakat, das die Angebote des «Moditreff» in der Stadt Bern bekannt macht (Abb. 68), resultiert für die Experten offensichtlich aus Laienarbeit (vgl. Grafik 14): Es wurde mit rudimentärsten Mitteln in einem Textverarbeitungsprogramm gestaltet und der Titel in 〈WordArt〉 erstellt. Bereits die Druckvorlage scheint schlecht geschwärzt gewesen zu sein und wurde zudem schräg aufgelegt, könnte also auf einem älteren oder billigen Fotokopierer erstellt worden sein. Aus Sicht des professionellen Grafikdesigns wurde hier «alles falsch gemacht, was man falsch machen kann», was die Experten auf mangelndes Können der Urheberin bzw. des Urhebers zurückführen. Unter den typografischen Imperfektionen lassen sich etwa eine inhaltlich unmotivierte Schriftwahl und -kombination oder die fehlende Hierarchisierung nennen, im Detail auch doppelte Leerschläge und eine mangelhafte Spationierung: Die optischen Zeilenabstände liegen unter den Wortabständen, was die Textflächen optisch aufbricht.

Die unmotivierten Einzüge und die im Blocksatz aufgerissenen Zeilen und Löcher im Text - die nicht mit aktiv gestaltetem Leerraum $\mathrm{zu}$ verwechseln sind - verstärken die regellose, fast schon anarchistische Wirkung des Kleinplakats. Außerdem sind die handschriftlichen Ergänzungen schlecht lesbar und können den Einzelveranstaltungen nicht eindeutig zugeordnet werden. Schließlich finden sich vermeidbare Redundanzen in der Titelzeile (dreimal das Wort 〈Treff〉 untereinander) und ein - vermutlich unbeabsichtigter - Stilbruch passiert durch die Verwendung der «Monospaced〉-Schrift in unterschiedlichen Schriftgrößen: Diese Schrift verweist laut Experten auf die Schreibmaschine oder eine Programmierumgebung, wo charakteristischerweise nur eine Schriftgröße zur Verfügung steht.

Wirkungen: Auf die Gestaltungsprofis wirkt das Kleinplakat komplett dilettantisch, unprofessionell, unübersichtlich und fehlerhaft - eine «gestalterische Katastrophe». Die leuchtend bunt hingeworfenen Icons, der unpräzis lockere Ausmalgestus und die handschriftlichen Teile lassen das Ganze frisch und spontan, aber auch ziemlich fahrig wirken. Die freie Positionierung der Textblöcke, die fehlende Stringenz in Schriftwahl, Satzart, Absatztrennung und generell im Layout führen zu Unübersichtlichkeit, zugleich aber auch zu einer gewissen Lässigkeit und Unverfrorenheit im Gesamtbild. Das Artefakt zeugt in den Augen 


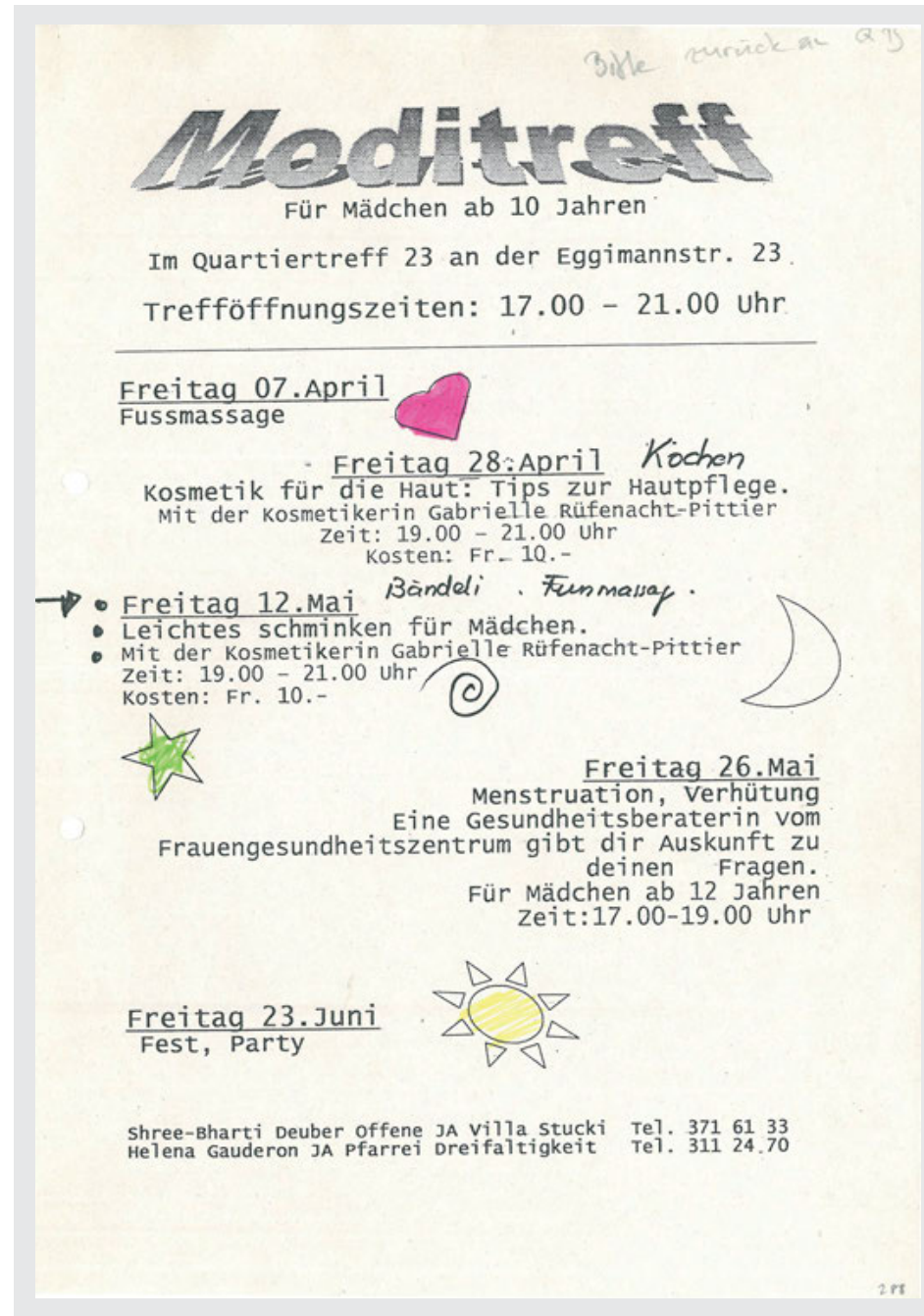

Der Aushang für einen Mädchentreff in der Stadt Bern wurde mit seinem unreflektiert eingesetzten Schriftenmix offensichtlich komplett dilettantisch gestaltet und weist unzählige Gestaltungsfehler auf. Die auffälligen, nachträglich von Hand hinzugefügten und kolorierten Elemente bringen zusätzliche Unruhe und Unbedarftheit, aber zugleich auch einen handgemachten bis charmanten Charakter ins Gesamtbild. Die Einschätzung der Wirkung und Angemessenheit hat die Experten stark polarisiert. Entweder fiel das Artefakt komplett durch und wurde als schludrig, lieblos und unglaubwürdig bewertet oder aber es wurde gerade aufgrund seiner gestalterischen Unbeschwertheit als spontan, authentisch und sympathisch - und teilweise sogar maximal zielgruppengerecht - wahrgenommen.

Abb. 68: Kleinplakat «Moditreff`, Jugendarbeit Villa Stucki und Pfarrei Dreifaltigkeit Bern 


\section{Aushang Mädchentreff Bern}

Formale Analyse

\begin{tabular}{|c|c|}
\hline Art und Produktion & $\begin{array}{l}\text { Flyer oder Aushang, Schwarzweiß-Fotokopie, einseitig, auf Recyc- } \\
\text { ling-Papier } 80 \mathrm{~g} / \mathrm{m}^{2} \text {, mit Handkolorierung }\end{array}$ \\
\hline Format & DIN A4 (210 mm x $297 \mathrm{~mm})$, hoch \\
\hline rafische Mittel & $\begin{array}{l}\text { Text im digitalen Schriftsatz und in Handschrift, digitale und manuell } \\
\text { eingebrachte dekorative «Clipart }>\text {-Elemente }\end{array}$ \\
\hline $\begin{array}{l}\text { Typografie } \\
\text { Layout } \\
\text { Gesamtanmutung }\end{array}$ & $\begin{array}{l}\text { Unter einem dominierenden, räumlich verzerrten und gerasterten } \\
\text { Titel mit 3D-Effekt sowie Verlaufs- und Schattenwurf, der for- } \\
\text { matmittig platziert ist, reihen sich drei Zeilen mit Absender- und } \\
\text { Adressatenangaben und einer Trennlinie sowie fünf links, mittig } \\
\text { oder rechtsbündige Schriftblöcke mit Veranstaltungshinweisen in } \\
\text { unterschiedlichen Schriftgrößen. Die Abstände sind durch keine } \\
\text { sichtbaren Verbindlichkeiten definiert. Die Komposition wird durch } \\
\text { zwei Absender-Fußzeilen am unteren Formatende geschlossen. } \\
\text { Außer den Randstegen ist kein Gestaltungsraster erkennbar. Die } \\
\text { einzelnen Textblöcke sind hierarchisch strukturiert und bestehen } \\
\text { aus einer ausgezeichneten Datumsangabe auf erster Hierarchie- } \\
\text { stufe (Unterstreichung, halbfett), gefolgt vom Veranstaltungstitel } \\
\text { auf zweiter (halbfett) und Inhalts-, Personen- und Zeitangaben auf } \\
\text { dritter Ebene. Der Schriftsatz bedient sich in vier unterschiedlichen } \\
\text { Größen einer «Monospaced`-Schrift («Letter Gothic`). Auszeichnungen } \\
\text { erfolgen mit Unterstreichungen, Größen und Schriftstärkenwechsel. } \\
\text { Typografie und Gesamtkomposition wurden regellos, undifferenziert } \\
\text { und heterogen eingesetzt, was durch zusätzlich manuell einge- } \\
\text { brachte Elemente stilistisch noch verstärkt wird. Die von Hand mit } \\
\text { Leuchtstift ausgemalten Computergrafiken und handschriftlichen } \\
\text { Ergänzungen (teils krakelig, teils schwungvoll, aber nie exakt) fallen } \\
\text { besonders ins Auge. }\end{array}$ \\
\hline $\begin{array}{l}\text { Bildinhalt } \\
\text { Topos } \\
\text { Figur }\end{array}$ & $\begin{array}{l}\text { Außer den fünf auf simple Strichkonturen (dreimal mit Handkolo- } \\
\text { rierung) reduzierten Icons Herz, Stern, Sonne, Mond und Spirale } \\
\text { werden keine Bild- oder Grafikelemente verwendet. Mit den Motiven } \\
\text { scheint keine besondere Aussage gemacht zu werden - die Elemente } \\
\text { dienen der Dekoration. }\end{array}$ \\
\hline $\begin{array}{l}\text { Art } \\
\text { der Bildgestaltung }\end{array}$ & $\begin{array}{l}\text { Unsorgfältig hingeworfene Zeichen (Punkt, Pfeil, Spirale) und Hand- } \\
\text { kolorierung. }\end{array}$ \\
\hline Farbe & $\begin{array}{l}\text { Das Recycling-Grau des Trägerpapiers bestimmt die Farbstimmung. } \\
\text { Die nach dem Kopierverfahren hinzugefügte Handkoloration setzt } \\
\text { drei Leuchtfarbenakzente. }\end{array}$ \\
\hline
\end{tabular}



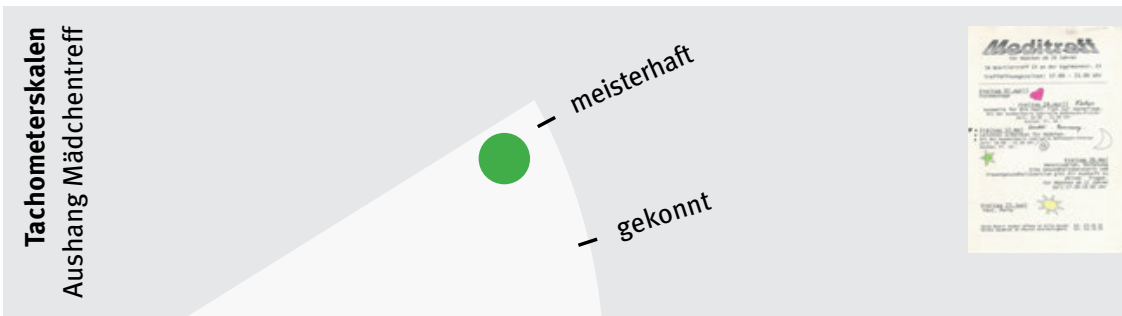

- mittelmäßig
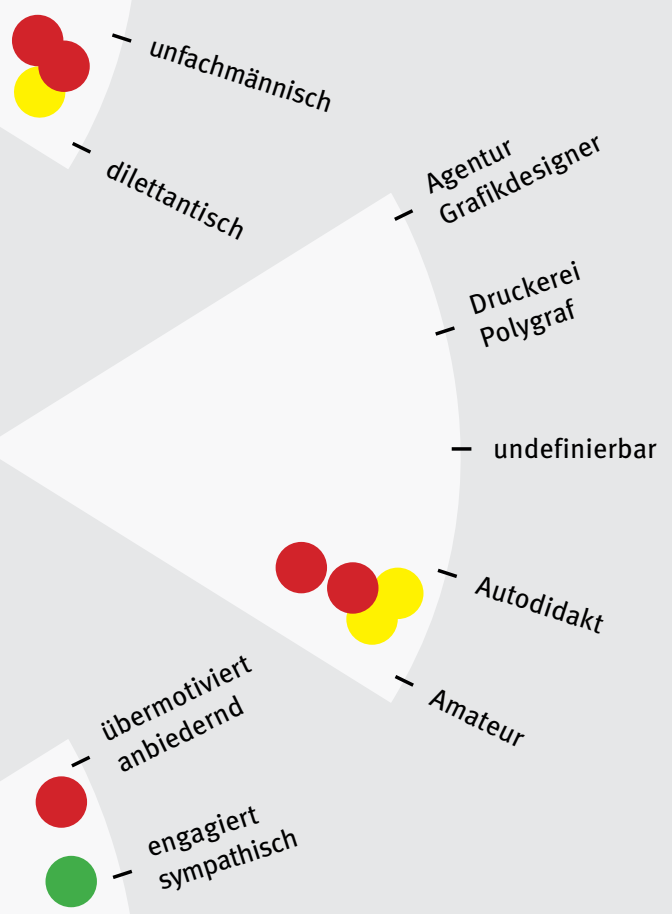

- neutral

Grafik 14: Experteneinschätzungen Elaboration - Wirkung - Angemessenheit

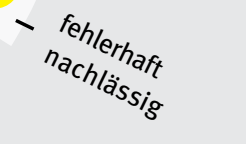


der Experten von einer extremen Flüchtigkeit, einer selbst bei Laien ungewöhnlichen gestalterischen Unkultiviertheit und Unkenntnis. Dieser extreme Dilettantismus führt bei den Experten zu konträren Wirkungen: Einige verbinden das Artefakt mit einer lieblosen bis «schlampigen» oder einer infantilen und dümmlichen Wirkung. Andere wiederum nehmen die Gestaltung als spontan und lustvoll wahr, als frech, fröhlich, bunt, «freakig» oder alternativ, was sie mit einer authentischen und sympathischen Ausstrahlung verbinden. Durch die selbstgebastelte, insgesamt imperfekte Ausführung werde die Distanz zwischen Hersteller und Zielpublikum reduziert. Für jene, die das Produkt ablehnen, führt jedoch gerade der ausufernde Dilettantismus zu einer Entfremdung. Es entstehen auch gemischte Gefühle: der Flyer wirke «grässlich-schön», oder die Gestaltung sei «so schlecht, dass sie fast schon wieder gut ist».

Wirkungsdimension und Stilhöhe: Neben den Veranstaltungsinformationen, die der Flyer auf Logos-Ebene vermittelt, wirft die stark dilettantische Gestaltungsweise auf Ethos-Ebene - je nach Einschätzung der Betrachter - ein unseriöses, unprofessionelles und negatives Licht auf die Absenderinstitution oder aber sie zeigt diese als sympathische und lebendige Institution. Emotionale Akzente auf Pathos-Ebene werden durch die improvisierten bunten Symbole gesetzt, doch auch hier wird die Wirkung unterschiedlich wahrgenommen: von trist bis lustig. An sich wäre der Flyer auf der niedrigsten Stilhöhe zu verorten, mit den Leuchtstiftakzenten könnte er gemäß Experten auf der mittleren Höhe angesiedelt werden. Für einige wirkt der Flyer durch die handschriftlichen Ergänzungen und das eigenhändige Ausmalen sogar stark affektiv, da mit dem üblichen Reproduktionsmodus gebrochen und etwas Selbstgemachtes hineingebracht werde.

Angemessenheit und Empfehlungen: Aufgrund der kontrovers wahrgenommenen Wirkungen gehen auch die Einschätzungen der Angemessenheit dieser Drucksache in diametral unterschiedliche Richtungen. Für die eine Seite klaffen die mit dem Flyerplakat vermittelte Wirkung und das beworbene Angebot weit auseinander. Da der Treff auch ernste Themen wie Verhütung oder Menstruation mit qualifizierten Fachpersonen behandelt, untergrabe die fahrige Gestaltung die Sorgfalt und Glaubwürdigkeit des Anbieters, die sich auch im Kommunikationsmittel manifestieren sollte. Die Veranstalter ließen damit sowohl Ernsthaftigkeit und Engagement als auch ein Identifikationsangebot für die Mädchen vermissen. Von anderer Seite wird gerade der Kontrast zwischen der witzigen, unverfrorenen Gestaltung und den ernsten Inhalten, die dem Ganzen «untergemischt» würden, gelobt, weil er die Niederschwelligkeit des Angebots befördere: Zwischen Aktivitäten wie Kochen, dem Anmalen der Fingernägel oder dem Knüpfen von Bändern könne die Gesundheitsberaterin wichtige Aufklärungsarbeit leisten. Im «Unterju- 
beln» ernsthafter Themen könnte diese Art der laienhaften Kommunikation also unter Umständen erfolgreicher sein als seriös gestaltete Profiarbeit. Die sorglose Gestaltung trifft aus dieser Sicht genau die Stimmung der Zielgruppe - Mädchen im frühen Teenageralter seien ebenso launisch und inkonsequent - und holt die jungen Frauen damit perfekt ab. Durch die handschriftlichen Ergänzungen und die Handkolorierung erhalte das Produkt zudem eine handgemachte Anmutung und wirke sympathisch, authentisch und dadurch auch glaubwürdig.

Die für den Haupttext verwendete technische «Monospaced〉-Schrift sei im Grunde völlig unpassend für eine junge, weibliche Zielgruppe, da sie mit Aktenordnern oder einer Informatikumgebung assoziiert werde. Auch die wuchtige Überschrift mit optischem Effekt und technoider Wirkung sagt lautExperten nichts über das damit gesetzte Wort «Moditreff〉 aus, sondern dient ganz einfach der Auszeichnung des Haupttitels. Die Icons dienen einem rein dekorativen Zweck und schaffen keinerlei inhaltliche Verbindung zu den Adressatinnen oder dem Thema der Anlässe: Damit die Information nicht zu «trocken» herüberkommt, wurde das Ganze «ein wenig verziert». Gerade durch diese Passungsfehler und Stilbrüche entsteht in den Augen der befürwortenden Experten aber etwas Ungezwungenes, da (unwissentlich) allerlei einengende Gestaltungsprinzipien einfach übergangen wurden. Letztlich gehen die Einschätzungen also von der Vermutung, dass mit der kruden Ausgestaltung des Kleinplakats die Lese- und Sehgewohnheiten der Zielgruppe komplett verfehlt wurden, bis hin zur entgegensetzten Annahme, dass die Jugendarbeitenden, die als Gestalter vermutet werden, offenbar intuitiv gewusst hätten, was ihre Zielgruppe optimal anspreche.

Eine Verbesserung der Formensprache, Verbalisierung der Inhalte und technischen Ausführung kann aus Sicht jener Experten, welche diese Art der Gestaltung ablehnen, nur mit einem totalen Neubeginn erfolgen. Für jene, welche ihr zugeneigt sind, könnte die ehrliche und authentische Wirkung sogar noch verstärkt werden, indem der gesamte Text handschriftlich abgefasst würde (jedoch idealerweise von einer Person mit einer etwas schöneren und leserlicheren Handschrift). Anstelle von «Clipart〉-Icons könnte man laut Experten richtige Sticker, z.B. Glitzersternchen oder Herzchen, aufkleben, wie sie Mädchen lieben würden. Für eine maximale Identifikation bestehe auch die Möglichkeit, die wiederkehrende Titelzeile «Moditreff〉 in Graffitischrift von den Mädchen selber gestalten zu lassen. Falls man das Ganze doch etwas weniger chaotisch ausgestalten wolle, sollten nur noch ein Schrifttyp und lediglich eine Form von Satzausrichtung verwendet werden. 


\subsubsection{Sympathische Nüchternheit: Flugblatt Freiwillige Feuerwehr Zollikofen}

Elaboration und Imperfektion: Aus Sicht der Gestaltungexperten lehnt sich das Flugblatt der Freiwilligen Feuerwehr Zollikofen (Abb. 69) gestalterisch an die offiziellen Infobroschüren von Gemeindeverwaltungen an. Der Professionalitätsgrad wird zwischen Semiprofessionalität und Polygrafenarbeit eingestuft (vgl. Grafik 15): Entweder wurde der Flyer von einem gestalterischen Autodidakten mit gewissen technischen Kenntnissen gestaltet oder von einer Druckerei gesetzt, welche das Logo telquel übernahm, weil vielleicht ein unerfahrener Lehrling am Werk war oder der Feuerwehr kein ausreichendes Budget für den Druck zur Verfügung stand. Das Layoutprogramm wurde relativ gekonnt eingesetzt. Gleichzeitig wird die gestalterische Qualität aber durch die Verwendung von sprachlichen und grafischen «Gemeinplätzen» und zahlreiche Mängel gemildert: Durch das Überlagern von Bild- und Textebenen mit abgeblendeten Hintergrundbildern, was von Experten auch als «Glacékartendesign» bezeichnet wurde, verflachen sich Stil und Wirkung des Artefakts. Beim Betrachten weiß man nicht, was man tun soll: lesen oder das Bild ansehen. Besonders auf der Rückseite wird dadurch trotz des großzügigen Schriftgrads die Lesbarkeit schlecht. Zudem hat der verantwortliche Gestalter seiner ursprünglichen Idee zu wenig vertraut: Das Spiel von Metapher und Remetapher (Rückübertragung), das durch den Slogan «Mit der Feuerwehr hoch hinaus! > und die abgebildete Person auf der Feuerwehrleiter entsteht, wird durch zu viele Bildelemente und Ebenen unabsichtlich unterlaufen. Diese Idee wird zwar nicht als besonders originell eingeschätzt, sie schafft jedoch eine Verbindung von Bild und Text - was bei nicht-professionell gestalteten Artefakten eher die Ausnahme ist.

Für die vorhandene Fläche wurden aus Sicht der Gestaltungsprofis zu viele Elemente platziert und die auf den drei Fotos abgebildeten Motive sind schwer zu erkennen: Die Abbildungen werden als zu klein erachtet für die Komplexität der gezeigten Szenen und wurden zu dunkel reproduziert. Zudem stören die kleinen Bilder das Motiv im Hintergrund (oder umgekehrt). Insgesamt wird die fehlende typografische Struktur und Hierarchisierung des Flugblatts bemängelt. Da die verwendeten Gestaltungsmittel Bild, Signet, Hintergrundbild und Text nicht gewichtet wurden, stehen sie alle gleichwertig da, was zu einer zusätzlichen Verflachung führt - das Auge kann sich nirgendwo festhalten. Hinzu kommen mikrotypografische Mängel im Satzbild, wie etwa fehlende Silbentrennungen, ein optisch zu niedriger Zeilenabstand oder zu lange Zeilen im Verhältnis zur Blockbreite. Auch der Randabstand ist relativ zur Schriftgröße zu klein.

Besonders das Signet wirkt auf die Bewertenden fehlerhaft: Es scheint nicht als digitale Datei existiert zu haben, weshalb es erst von einer Papiervorlage ausgeschnitten und reproduziert werden musste und nun noch Schneidkanten und 


\section{Mit der FEUERWEHR hoch hinaus!}

Wir suchen DICH für den aktiven Feuerwehrdienst!
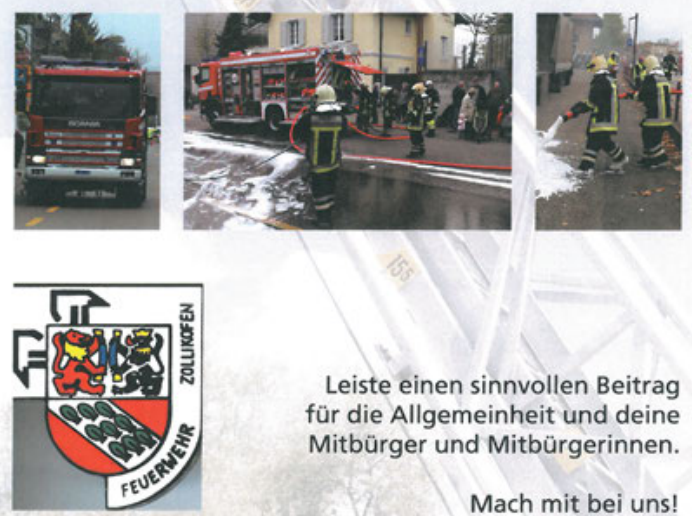

Leiste einen sinnvollen Beitrag für die Allgemeinheit und deine Mitbürger und Mitbürgerinnen.

Mach mit bei uns!

370

Wer steckt hinter der Miliz-Feuenwehr Zollikofen?

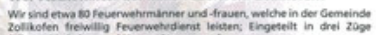

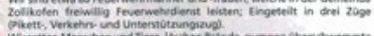

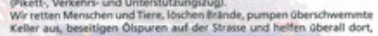
wo Menucher h Not gereten

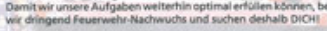

Wir bieten DIR

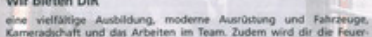

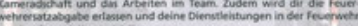
werden finanzieli entischidigt.

Unsere Enwartungen an $\mathrm{DiCH}$

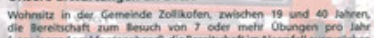

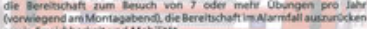

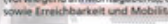

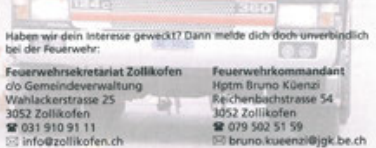

Der Flyer der Freiwilligen Feuerwehr Zollikofen ist kein perfektes, aber im Verwendungskontext angemessenes, nüchtern bis sympathisch wirkendes Produkt. Durch die auffallende Schichtung in einen Vorder- und Hintergrund sowie die fehlende Gewichtung der Bildund Textelemente verflacht sich die Wirkung des Flyers: Er wirkt austauschbar, die Lesbarkeit ist eingeschränkt und die unübliche, Bild und Text verbindende Gestaltungsidee («Hoch hinaus!») geht verloren. Positiv aufgenommen wurde die Betonung der roten Farbe als optischer Bezugspunkt zur Feuerwehr, kontrovers das selbstgebastelt daherkommende Logo.

Abb. 69: Flugblatt Freiwillige Feuerwehr Zollikofen 


\section{Flugblatt Freiwillige Feuerwehr Zollikofen}

\section{Formale Analyse}

Art und Produktion Flugblatt, Farbfotokopie oder Digitaldruck, doppelseitig, auf satiniertem, weißem Papier $90 \mathrm{~g} / \mathrm{m}^{2}$

\begin{tabular}{ll}
\hline Format & DIN A5 (148.5 mm x $210 \mathrm{~mm})$, hoch \\
\hline Grafische Mittel & $\begin{array}{l}\text { Fotografie, Bildwortmarke mit Gemeindewappen, Schrift, Kleinpikto- } \\
\text { gramme ('Wingdings): Telefon, E-Mail), Schichtung der Bildebenen: Text } \\
\text { und Bild laufen über ein aufgehelltes, teiltransparentes Hintergrundbild }\end{array}$ \\
\hline
\end{tabular}

Layout

Gesamtanmutung

\section{Typografie}

Für den Text wird eine traditionelle serifenlose Linearantiqua (evtl. (Frutiger`) verwendet, in fettem (Titel) und normalem (Textkörper) Schriftschnitt und mit überschaubarem Schriftgrößeneinsatz (18, 14, $10 \mathrm{pt})$. Die typografischen Paramater wie Zeilenabstand und Laufweite wurden vermutlich durch das Anwenderprogramm (vermutlich ‘Word)) bestimmt. Vorne findet sich eine plakative und annähernd gleichberechtigte Anordnung von Bild, zweifarbig schwarzroter Typografie und Bildwortmarke des Absenders im Stil einer Titelseite. Der Titel ist akzentuiert ausgezeichnet, wichtige Einzelworte sind durch rote Farbe, Größen- und Glyphenwechsel speziell herausgehoben. Die Schrift wird erst links-, dann rechtsbündig angeordnet, mit akzentuierten Leerräumen bzw. Absatzseparierung durch Einsatz von Leerzeilen. Dazwischen befindet sich ein symmetrisch inszeniertes Foto-Triptychon. Alle genannten Elemente laufen über ein aufgehelltes (ca. $10 \%$ ), farbiges, die Diagonale akzentuierendes, vollflächiges Hintergrundbild. Die Gesamtanordnung erfolgt ohne sichtbares Gestaltungsraster. Hinten wurden vier einfarbig schwarze Textabschnitte in Blocksatz gesetzt. Die ersten drei verlaufen mit Überschrift und mehreren Absätzen über die ganze Formatbreite. Am Formatfuß wird die Komposition mit zwei linksbündig nebeneinanderstehenden Adressblöcken geschlossen. Zwischen den einzelnen Textabschnitten finden sich ausgeprägte Zäsuren. Analog zur Vorderseite läuft der Text über ein zurückgesetztes farbiges Hintergrundbild, das als Sujet bereits klein auf der Vorderseite zu sehen war.

\begin{tabular}{ll}
\hline Bildinhalt & Fotos mit Einsatzwagen und Personal der Feuerwehr in Aktion bei einer \\
Topos & Löschschaumdemonstration und an einem Tag der offenen Tür (Kind \\
Figur & auf Feuerwehrleiter). Die Bildwahl symbolisiert Einsatzbereitschaft und \\
& Verantwortung und zeigt den modernen Ausrüstungsstand: Die Feuer- \\
& wehr als Freund und Helfer.
\end{tabular}

Art der $\quad$ Aktionsbestimmte Laienaufnahmen im Reportagestil. Zurückgestellte
Bildgestaltung Hintergrundaufnahmen.

Farbe Das Farbklima liegt insgesamt im Rot-Schwarz-Grau-Bereich. Ein hoher Rotanteil findet sich bei den Fotos und in der Typografie (Rotstich durch Kopierverfahren verstärkt). Das Rot verbindet sich mit der Thematik der Feuerwehr. 


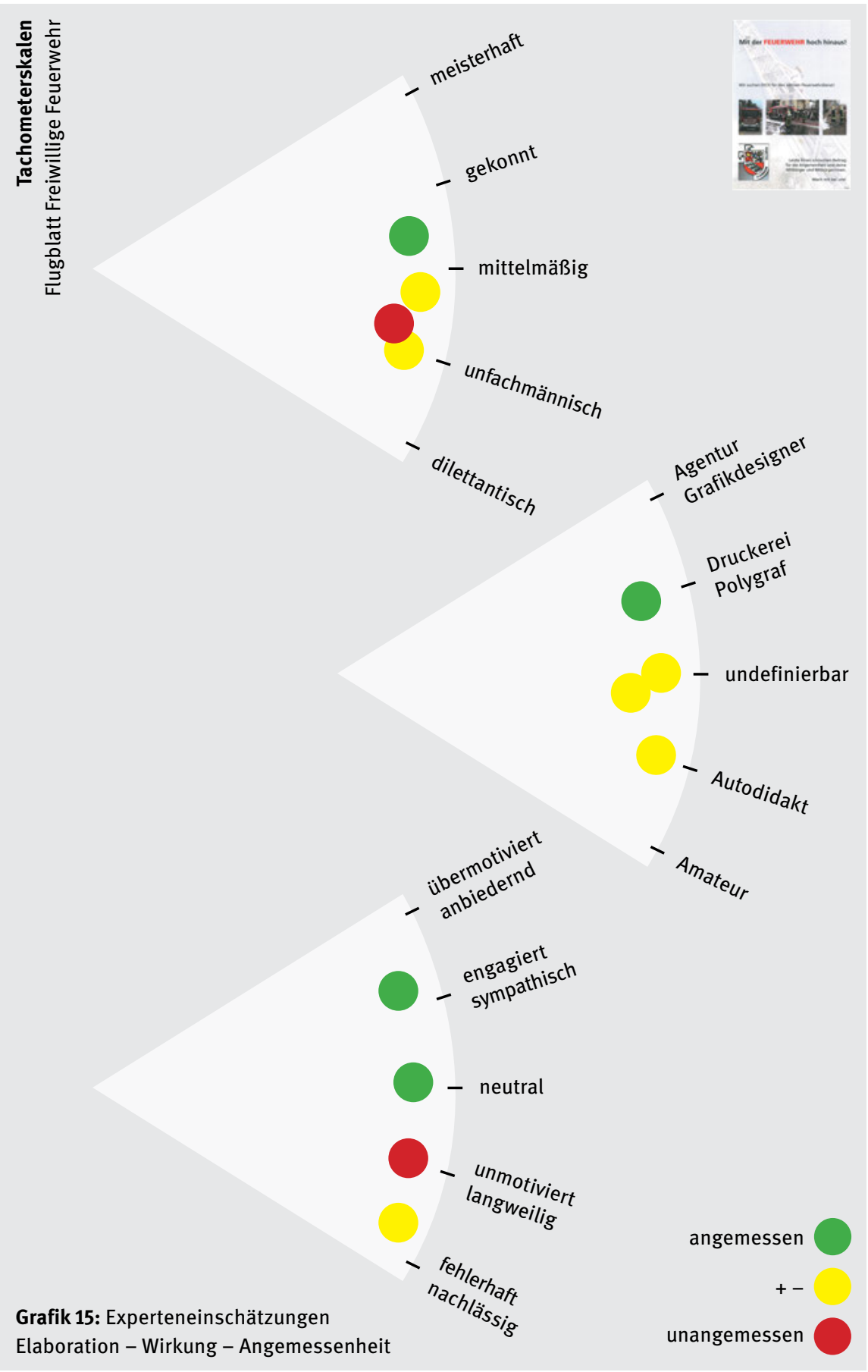


Schattenwurf sichtbar sind. Die verantwortliche Person war offenbar nicht in der Lage, das Logo korrekt freizustellen (bzw. nur als rechteckige Form), so dass es nun aussieht, als stünde es auf einer Fläche. Ob der obere schwarze Rand zum ursprünglichen Logo gehört oder erst durch die mangelhafte Reproduktion hinzukam, ist nicht erkennbar. Der Schriftzug um das Wappen herum wurde von Hand in Schablonenschrift gezogen, welche jedoch gemäß den Experten völlig ungeeignet ist, kurvig gesetzt zu werden. Da ein übergeordnetes Gestaltungsraster zu fehlen scheint, ist das Logo nicht auf das durch die Fotografien vorgegebene Raster angepasst. Im Verhältnis zum Gesamtformat A5 und zu den Abbildungen in der Mitte wird das Signet mit fünf Zentimetern Höhe als deutlich zu groß beurteilt. Das Logo wirkt dominant und selbstgebastelt. Keine der genannten Imperfektionen ist aus Sicht der Gestaltungsprofis bewusst eingesetzt worden, sondern diese sind zufällig bzw. aufgrund von fehlendem Know-how zustande gekommen. Aufgrund der genannten Mängel erscheint der Flyer trotz Vierfarbdruck, Satinierung und über dem Level von Kopierpapier liegender Papiergrammatur handgemacht und von minderwertiger Gestaltungsqualität.

Wirkungen: Der Feuerwehr-Flyer wirkt sachlich, formelhaft, uninspiriert und langweilig, jedoch einigermaßen seriös und für einige Experten auch sympathisch. Aufgrund der beschränkten Textmenge und des vorhandenen Leerraums wird der Flyer als übersichtlich, wegen der formatfüllenden Hintergründe und knappen Seitenränder jedoch als wenig luftig wahrgenommen. Die verwendete grafische Sprache erscheint austauschbar - die Gestaltungsidee «Hoch hinaus!〉 wird aufgrund konkurrierender Elemente und des blass hinterlegten Bilds kaum wirksam. Die Verwendung ganzflächiger Hintergrundbilder hat aus Sicht der Experten direkt zur Folge, dass die Drucksache stilistisch verflacht und in der Flut ähnlicher Produkte untergeht. Zudem schwächen die transparent hinterlegten Bilder den Signalkontrast der roten Textfarbe ab und steuern dem Ganzen durch ihr kühles Grau eine nüchterne Atmosphäre bei. Die Typografie wirkt auch deshalb langweilig, weil mit einer Standard-Groteskschrift gearbeitet wurde. Die persönliche Ansprache auf Textebene (‘Wir suchen DICH!〉, 〈Mach mit bei uns!〉) wird als sympathisch und jugendlich beurteilt, findet aber keine Entsprechung auf visueller Ebene. Die gezeigten Bilder nehmen die Experten als informativ und sachlich wahr, da sie die Tätigkeit der Feuerwehr dokumentarisch, aus Distanz und in Normalperspektive abbilden. Eine Ausnahme stellt die leicht dramatisierende Untersicht beim Hintergrundbild auf der Vorderseite dar. Das Signet der Feuerwehr fällt für sie komplett aus dem Rahmen, da es nicht im Raster gesetzt wurde und von völlig anderer Machart ist als der Rest. 
Wirkungsdimension: Gemäß Experteneinschätzung generiert das Kommunikationsmittel der Freiwilligen Feuerwehr unterschiedliche, einander teilweise widersprechende Wirkungen. Neben der nüchternen Wirkung der zurückhaltenden Typografie, dem relativ aufgeräumten Layout und der streng symmetrischen Platzierung und sachlichen Darstellung der Bilder (Logos) verweist das eingesetzte stilistische Repertoire - insbesondere die triviale Überlagerungstechnik in «Glacékartenoptik» - auf einen ästhetisch wenig kultivierten Geschmack des Absenders (Ethos). Auf Bildebene wird augenscheinlich versucht, das Arbeitsethos der Freiwilligen Feuerwehr zu vermitteln, doch vermag der dokumentarische Stil mit den kleinformatigen Bildern kein eigentliches Image zu konstruieren. Zurückgenommenes Pathos - Stolz und ein wenig Nervenkitzel - wird durch die appellativen Slogans und das hinterlegte Bild der Zivilperson auf der Feuerwehrleiter in Untersicht verströmt. Letztlich können die Experten jedoch kein herausragendes Wirkungselement erkennen, mit dem es dem Flyer gelingen könnte, inhaltlich oder formal Aufmerksamkeit zu erregen, Interesse zu wecken oder einen Wiedererkennungswert zu etablieren. Aufgrund des insgesamt sachlichen Stils und des sich gegenseitig abschwächenden, profillosen Bild- und Texteinsatzes entfaltet sich die Wirkung auf niedriger bis allenfalls mittlerer Stilhöhe.

Angemessenheit und Empfehlungen: Das Flugblatt richtet sich an bodenständige, gesellige, vereinsorientierte, stärker in der ruralen als urbanen Kultur verortete Agglomerationsbürgerinnen und -bürger mit Gemeinschaftssinn und verfolgt das Ziel, neue Mitglieder für die Freiwillige Feuerwehr zu akquirieren. Da tendenziell eher nicht urban orientierte und somit «designfremde» Personen angesprochen werden sollen, schätzen die Experten, dass die mit dem Produkt ausgedrückte, wenig inspirierte gestalterische Haltung hier passend sein könnte: Der Flyer verwendet eine zwar nüchterne und austauschbare, aber vermutlich angemessene visuelle Sprache, um sein Publikum anzusprechen. Auch die Tatsache, dass der Flyer auf spektakuläre Bilder verzichtet und keine unrealistischen Erwartungen an «Action» schürt, sondern durch seine optische Anlehnung an bekannte Gemeindedrucksachen den offiziellen Charakter der Arbeit unterstreicht, scheint durchaus dem Zweck der propagierten Sache angepasst zu sein. So erscheinen der ausführliche Text und die dokumentarischen Bilder dann sinnvoll, wenn das Flugblatt dem Neuzuzüglerdossier der Gemeinde Zollikofen beigelegt oder an interessierte Gemeindemitglieder verschickt wird. Falls der Flyer jedoch als Werbeflyer funktionieren müsste, der öffentlich ausgelegt wird und Interesse wecken soll, wäre er aus Sicht der Experten klar zu wenig plakativ gestaltet: Mit den kleinen Bildern und ohne eine augenfällige Kernbotschaft entfaltet er zu wenig Appellcharakter und überschreitet mit dem Text auf der Rückseite die Aufmerksamkeitsspanne des durchschnittlichen Lesers. 
Für den Fall, dass man einen Mindestanspruch an profilierte Gestaltung durchsetzen wollen würde, schlagen die Experten diverse Verbesserungsmaßnahmen vor, die selbst im Rahmen von nicht-professioneller Arbeit verwirklicht werden könnten, etwa durch einen akzentuierten Farbeinsatz. Die gewählte Farbharmonie in Schwarz-Rot-Grau wirkt zwar bereits ansprechend und angemessen sachlich, könnte aber noch konsequenter eingesetzt werden. Zudem müsste man sich auf Bildebene für ein zentrales Sujet entscheiden. So könnte beispielsweise das Leitermotiv zentral eingesetzt und mit dem Hauptslogan zu einer stimmigen Gesamtaussage verbunden werden. Die Idee selbst wäre zwar immer noch nicht innovativ, könnte aber eine gute, einfache Wirkung erzielen. $\mathrm{Zu}$ dieser Idee passt aus Expertensicht jedoch nicht ein Kind am Tag der offenen Tür, sondern ein Feuerwehrmann (oder, um das Klischee zu unterlaufen, eine Feuerwehrfrau) in Aktion. Anstatt der aktuellen, bei schlechter Witterung aufgenommen Laienfotos, welche die Arbeit der Feuerwehr langweilig und unattraktiv erscheinen lassen, könnte man mit besseren Fotos eine stärkere Wirkung erzeugen: heller, größer und in Nahaufnahme, ein wenig dramatischer inszeniert. Dynamischer wäre die Wirkung, wenn die Leiter von links unten nach rechts oben verlaufen würde; dramatischer würde das Foto durch eine stärkere Untersicht oder eine Obersicht mit «Vertigo-Effekt». Zudem könnte man auch zeigen, wie 〈hoch hinaus» man kommt, d.h. als Referenzpunkt ein Haus, einen Baum oder den Himmel zeigen. Gleichwohl wird der Verzicht auf reißerische «Action» von den Experten als sympathisch und authentisch wahrgenommen und das Bild dürfte auf keinen Fall inszeniert wirken. Die dilettantische Machart des Logos wurde als unterschiedlich störend empfunden: Einerseits wird vermutet, dass der selbstgemachte Charakter das persönliche Engagement des Absenders noch betonen könnte, andererseits aber auch befürchtet, dass sich zu viel Dilettantismus negativ auf die Wahrnehmung der Arbeitsweise und somit das Ethos der Feuerwehr auswirken könnte. Schließlich könnte die Reproduktion des Logos mit wenig Aufwand verbessert werden, wodurch sich aber auch der selbstgemachte Touch verlöre, der das persönliche Engagement des Absenders betont.

\subsubsection{Plattitüden der Freundlichkeit: Broschüre «Seniorensommer` der Stadtberner Kirchen}

Elaboration und Imperfektion: Die Experten sind sich nicht ganz einig in der Einordnung der Broschüre 〈Seniorensommer〉 (Abb. 70 und 71), die von mehreren Berner Kirchgemeinden herausgegeben wurde (vgl. Grafik 16): Ist sie das Resultat versierter Laienarbeit oder Polygrafengestaltung aus der Druckerei? Oder handelt es sich um ein professionelles Gestaltungskonzept, das jedoch auf eine einfache 
und preiswerte Produktion ausgerichtet wurde? Allenfalls könnte die Broschüre auch auf Basis einer professionell gestalteten Layoutvorlage entstanden sein, die von den Veranstaltern selbst jährlich neu mit Inhalten und Fotos gefüllt wird. Die in der Broschüre angewendeten Gestaltungsregeln folgen verschiedenen gestalterischen «Gemeinplätzen», die bei Polygrafen und Billigdruckereien verbreitet sind. Das Gesamtbild ähnelt der Standardgrafik, wie man sie auch von Menükarten her kennt. Als Erkennungsmerkmal für diese Art der Ausgestaltung nennen die Experten die Anwendung von auffallend vielen verschiedenen stilistischen Parametern: Formen, z.B. die hinterlegten Ovale, Farben, Ebenen und Textauszeichnungen. Der großzügige Einsatz von Weißraum lässt eine gestalterische Vorbildung vermuten, das allzu regelmäßige Layout und der dilettantische Umgang mit Bildern durchbricht jedoch den professionellen Eindruck. Die verwendeten Fotos scheinen aus verschiedenen privaten Archiven zu stammen und wirken unprofessionell aufgenommen, die Bildinhalte und -ästhetiken wurden nicht aufeinander abgestimmt. Viele Bilder weisen einen Rotstich oder ein starkes Rauschen (störende Pixel) auf. Auch das Hauptbild wurde mehr schlecht als recht bearbeitet: Wegen der Blendung durch die Sonne wurden die Mitteltöne stark aufgehellt, so dass nun nicht mehr ersichtlich ist, wie das Wetter war. Das Gruppenbild auf Seite eins wurde lediglich grob freigestellt. Beim Übergang der schwarzen Balken zu den Bildern ergeben sich weiße Blitzer, was ebenfalls unsauber gelöst erscheint. Etliche kleinere Imperfektionen finden sich in der Detailtypografie: falsche Zeichen und Abstände, ein unschöner Zeilenumbruch, Aufzählungszeichen aus einer fremden Schriftfamilie. Die Titeltypografie wird als ein paar Punkte zu groß beurteilt und wirkt wie «eingequetscht» zwischen dem Oval und den Köpfen. Die Schrift tritt optisch aus dem Hintergrund heraus, weil sie den Hut der Dame überschneidet, und zwischen rotem Text und blauem Grund entsteht ein Flimmerkontrast - allesamt unintendierte Effekte. Auch fällt den Experten die schlechte Druckqualität auf. Zusammen mit der lediglich mittig gesetzten Heftklammer deutet sie auf einen allzu hohen Sparwillen hin.

Eine Besonderheit bildet die Montage des Texts 〈Aktiv im Alter〉 auf dem Hut des Seniors auf der Titelseite: Die hierfür verwendete Pseudoschreibschrift zeugt von einem amateurhaften Versuch, spontan und persönlich zu wirken. Die Montage wurde unbeholfen und unprofessionell umgesetzt und ist auch formal nicht wirklich gelungen.

Wirkungen: Von einigen Experten wird die erwähnte Montage gerade aufgrund ihrer dilettantischen bzw. nicht um Perfektion bemühten Form als kreativ, überraschend, keck, erfrischend und sympathisch wahrgenommen. Die Imperfektion verleihe dem Produkt das «gewisse Etwas», einen «subversiven Kick» - mit der im Hut versteckten Botschaft werde den Senioren «sanft aufs Auge gedrückt», 


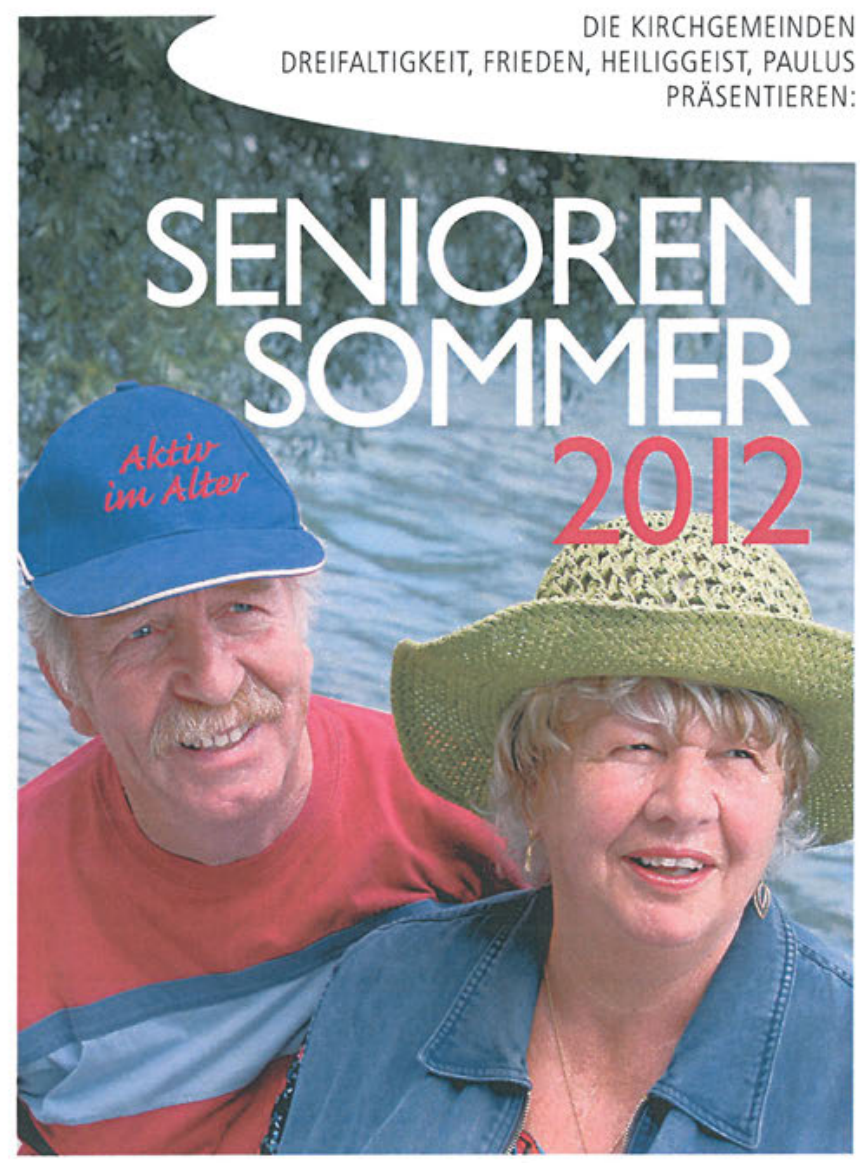

23.-28. Juli und 30. Juli-3. August Pfarrei Dreifaltigkeit, Sulgeneckstr. 13, Bern

Abb. 70: Broschüre «Seniorensommer〉 der Berner Kirchgemeinden Dreifaltigkeit, Frieden, Heiliggeist, Paulus 


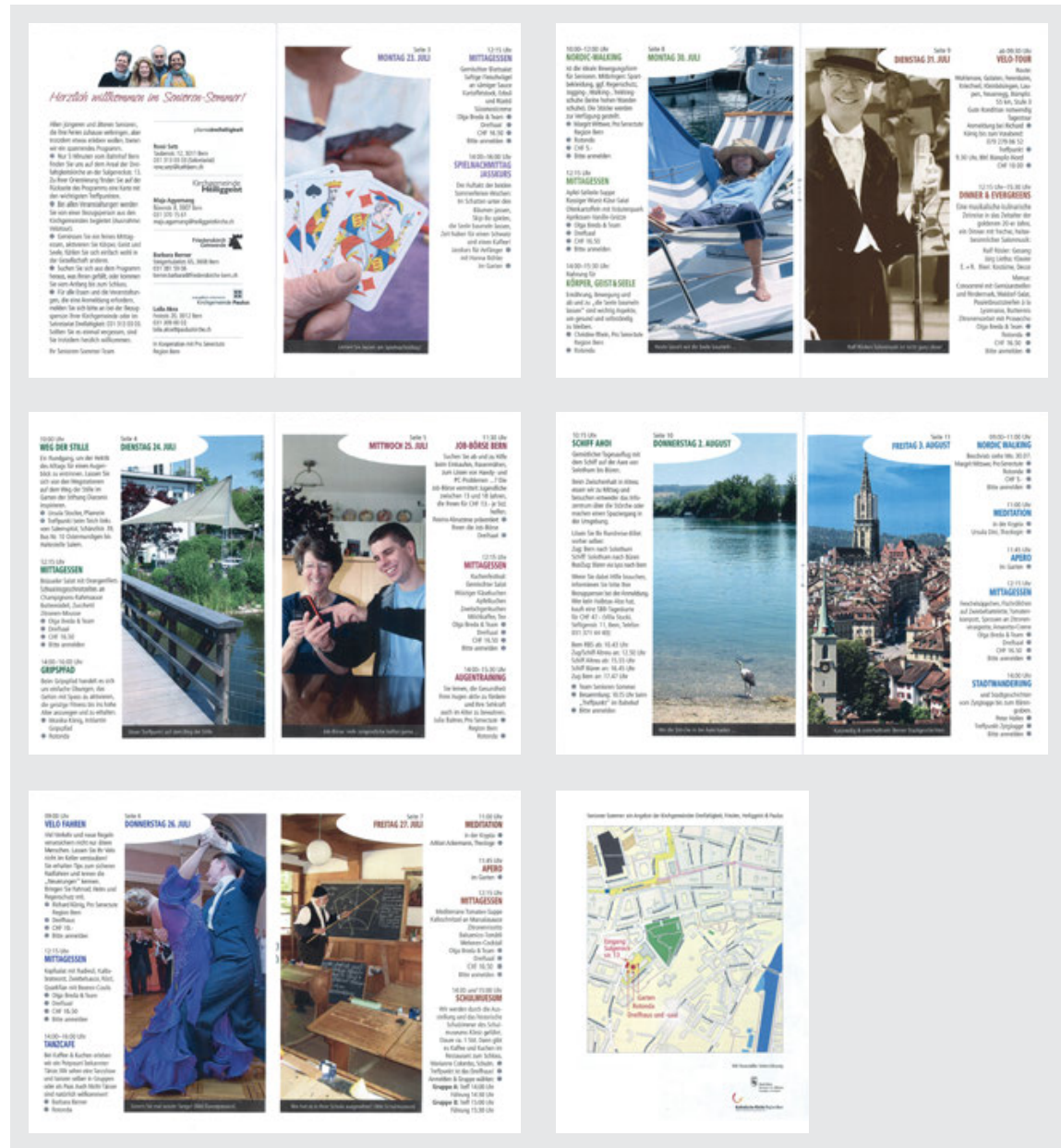

Die Broschüre zu einer Serie von Seniorenanlässen verschiedener Stadtberner Kirchgemeinden ist informativ und übersichtlich. Obschon sie stark nach gestalterischen Gemeinplätzen gestaltet ist und die Fotos unprofessionell aufgenommen und eingesetzt wurden, verströmt sie eine freundliche und sympathische Atmosphäre.

Abb. 71: Innenseiten und Rückseite Broschüre «Seniorensommer` 


\section{Broschüre «Seniorensommer» der Stadtberner Kirchen}

\section{Formale Analyse}

\begin{tabular}{|c|c|}
\hline Art und Produktion & $\begin{array}{l}\text { Klammer-geheftete Falzbroschur, Farbfotokopie, zweiseitig auf hoch- } \\
\text { weißem, satiniertem Kopierpapier } 100 \mathrm{~g} / \mathrm{m}^{2}\end{array}$ \\
\hline Format & DIN A5 (148.5 mm x $210 \mathrm{~mm}$ ), hoch (gefaltet), 12 Seiten \\
\hline Grafische Mittel & $\begin{array}{l}\text { Schrift, Fotografie, Fotomontage, Grafik (Kartenausschnitt), Wortbild- } \\
\text { marken }\end{array}$ \\
\hline $\begin{array}{l}\text { Typografie } \\
\text { Layout } \\
\text { Gesamtanmutung }\end{array}$ & 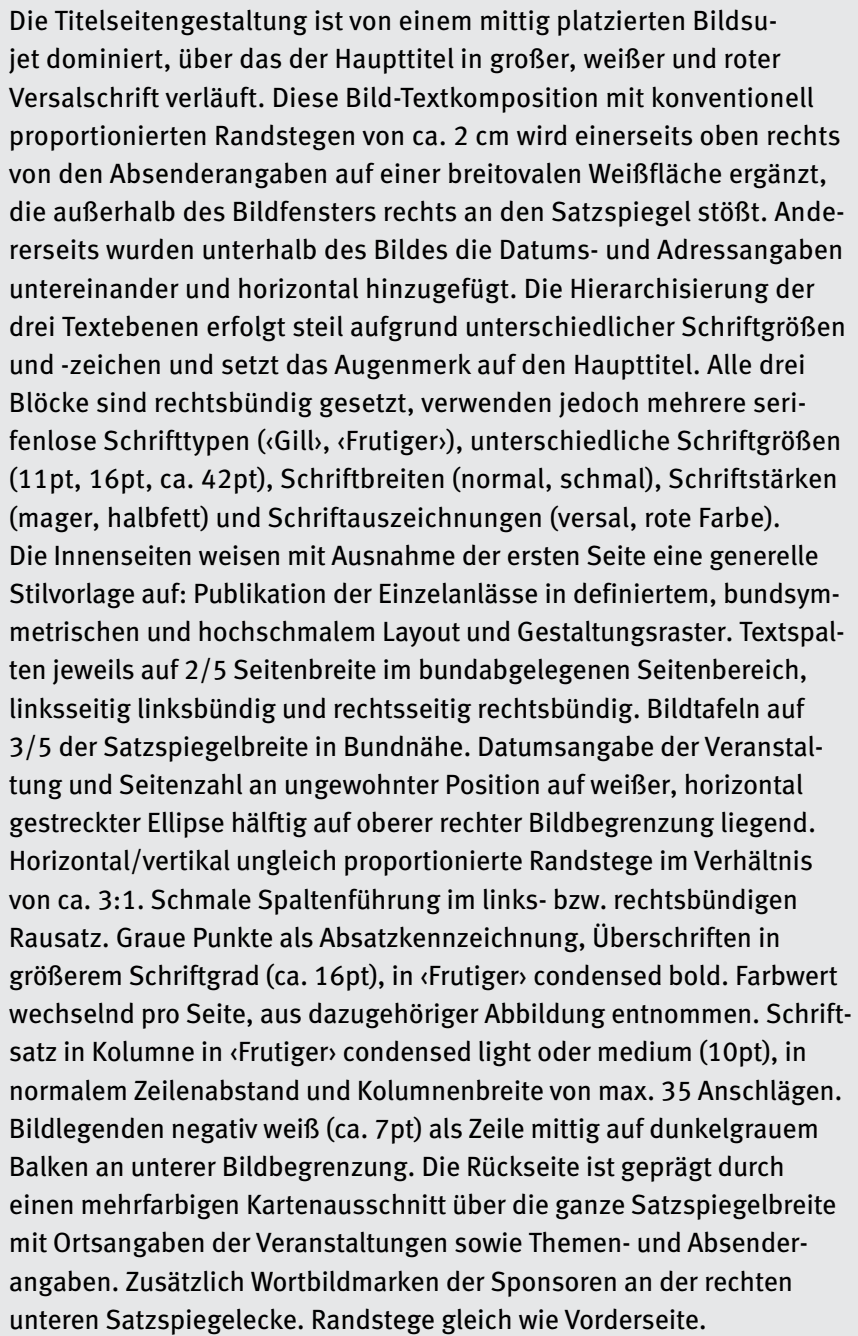 \\
\hline
\end{tabular}




\begin{tabular}{|ll}
\hline $\begin{array}{l}\text { Bildinhalt } \\
\text { Topos }\end{array}$ & $\begin{array}{l}\text { Titelseite: Seniorenpaar in Freizeitkleidung (rüstiger, sportiver, } \\
\text { aufmerksamer Habitus) vor einem Fluss (der Fluss des Lebens?) nach } \\
\text { rechts oben in die Sonne (zu Gott, in die Zukunft?) blickend. } \\
\text { Innenseiten: Bildtafeln repräsentieren mit Stellvertretersujet den } \\
\text { angekündeten Anlass. Aktive Senioren und Örtlichkeiten stehen im } \\
\text { Zentrum. }\end{array}$ \\
\hline $\begin{array}{l}\text { Art der } \\
\text { Bildgestaltung }\end{array}$ & $\begin{array}{l}\text { Titelseite: Porträtfoto von oben aus leicht erhöhter Perspektive vor } \\
\text { Naturkulisse. Verhalten eingesetzte und klar als solche erkennbare }\end{array}$ \\
& $\begin{array}{l}\text { Fotomontage auf Kopfbedeckung des Mannes mit Schriftzug ‘Aktiv } \\
\text { im Alters. Innenseiten: Verschiedene farbige Sujets und Beleuch- } \\
\text { tungssituationen, Ausschnitte, Größenverhältnisse, Perspektiven, }\end{array}$ \\
& $\begin{array}{l}\text { Aufnahmewinkel, Bildaufbereitungen, Außen- und Innenaufnahmen. } \\
\text { Freigestellte Gruppenfotografie des Veranstalterteams auf Seite 1. }\end{array}$ \\
& $\begin{array}{l}\text { Auffallend ist die breitovale Weißfläche, die jeweils oben rechts das } \\
\text { hochformatige Foto anschneidet und die ansonsten strenge Orthogo- } \\
\text { nalität auflöst. }\end{array}$ \\
\hline Farbe & $\begin{array}{l}\text { Rotdominanz auf Titelseite. Innenseiten haben keine Farbpriorität, } \\
\text { jedoch Tendenz ins kühle Spektrum. Einzelbilder gehen teilweise in } \\
\text { bestimmtes Farbspektrum (z.B. Blautöne, Sepia), pro Seite wech- } \\
\text { selnde Titelfarben. Druckträger hochweiß. }\end{array}$ \\
\hline
\end{tabular}



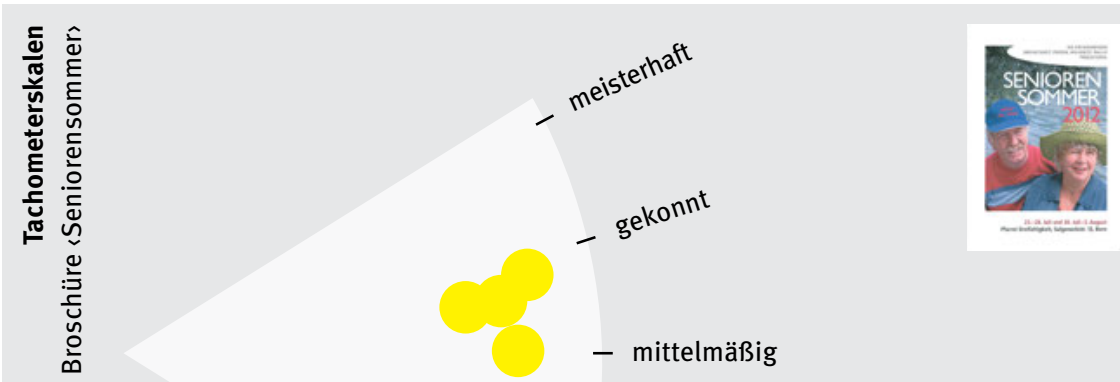

:气
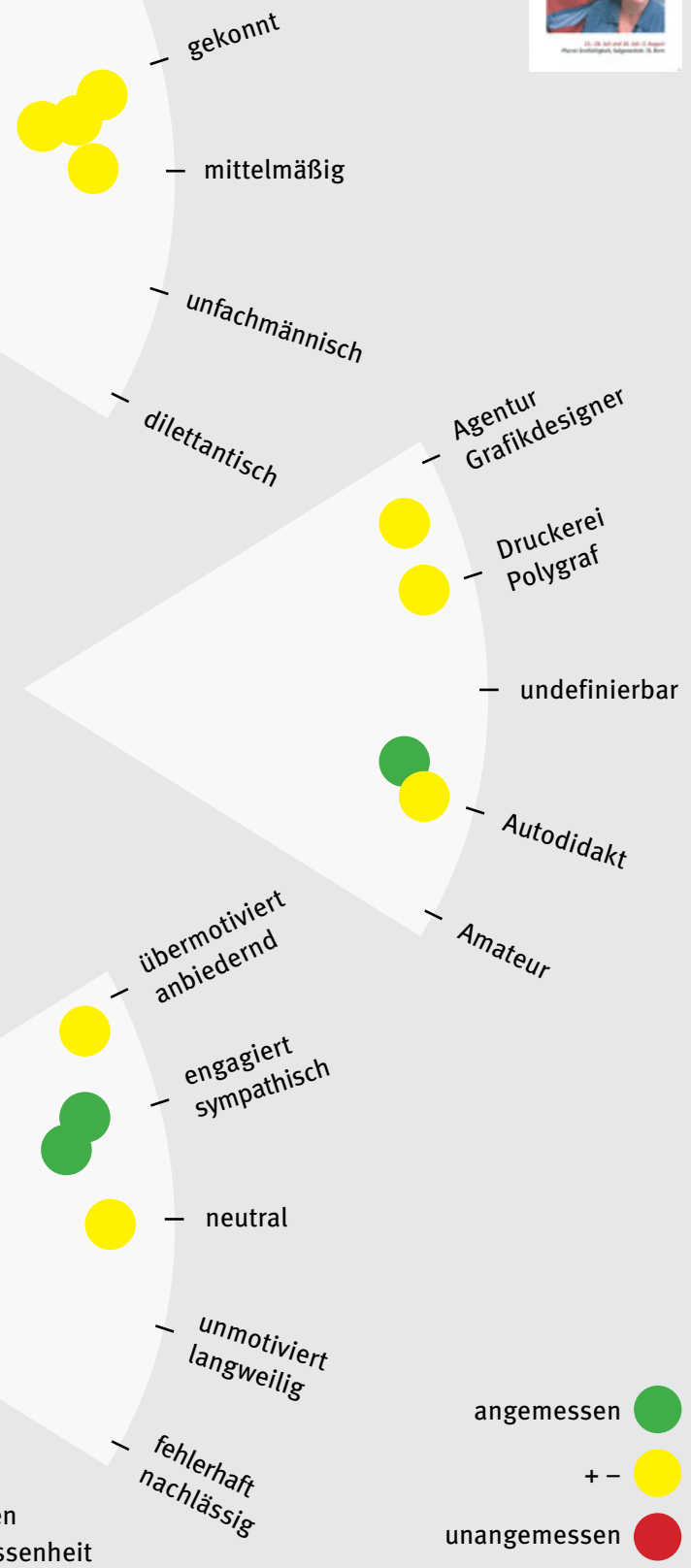

Grafik 16: Experteneinschätzungen Elaboration - Wirkung - Angemessenheit
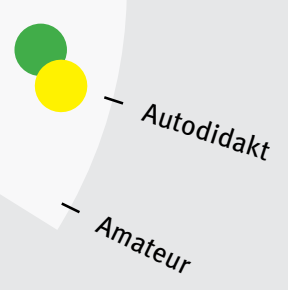

angemessen

unangemessen 
dass man sie mit dem propagierten Angebot aktivieren möchte. In dieser Montage gelinge die löbliche Ausnahme im Prospekt, Bild- und Textebene zusammenzuführen. Die genannten Zusammenhänge könnten nach Einschätzung der Experten auch ohne Absicht, aus purem Dilettantismus bewirkt worden sein.

Insgesamt kommt die Broschüre schlicht, sachlich und informativ daher. Vielfach wird sie als sympathisch und freundlich wahrgenommen - vereinzelt hinterlässt sie jedoch auch den Eindruck, etwas bemüht zu sein. Als attraktiv wird die Gestaltung mit ihrem durchmischten Bildfundus, den verwendeten Plattitüden im Bereich von Typografie und Layout und den stilistischen Patzern nicht gerade beurteilt, doch erscheint sie den Experten übersichtlich sowie typografisch und konzeptionell einigermaßen durchgestaltet. Da die Informationsebenen gut differenziert und hierarchisiert sind, kann der Inhalt einfach rezipiert werden. Die freundliche Anmutung wird auf die helle Stimmung der Fotografien und den ausreichendem Weißraum rund um die Fotografien zurückgeführt, unterstützt durch die weichen ovalen Formen, die über die Bilder gelegt wurden. Diese Ovale sorgen aber auch für eine gewisse Unruhe und Inkonsequenz im ansonsten rechtwinklig angeordneten Ensemble.

Wirkungsdimension und Stilhöhe: Mit den vielen Fotos ist aus Expertensicht vor allem versucht worden, die Pathos-Ebene ins Spiel zu bringen: Die lächelnden Senioren sollen den Betrachtenden ein positives Gefühl von Glück, Gesundheit und Aktivität im Alter vermitteln. Die Textebene dagegen bedient vorwiegend den Logos. Sie dient primär der Information - abgesehen von wenigen Pathos-orientierten Akzenten wie dem in Schreibschrift gesetzten Willkommensgruß und den fröhlich-bunt eingefärbten Titelschriften. Ein eigentliches Absenderimage (Ethos) wird nicht kreiert. Die verwendete Stilhöhe lässt sich in der Mitte ansiedeln: Die verwendeten populärgrafischen Stilmittel wirken eher bescheiden und gleichzeitig angenehm. Die Bildebene wird als gelöst und unaufgeregt wahrgenommen: Gepflegte Ausflugsatmosphäre jenseits von «Rosamunde Pilcher-Alterskitsch». Einzig den ellipsenförmigen Aussparungen wird ein etwas dominanter Effekt zugeschrieben.

Angemessenheit und Empfehlungen: Die Broschüre soll Seniorinnen und Senioren aus verschiedenen Berner Kirchgemeinden ansprechen, die ihre Zeit mit gleichaltrigen Menschen aktiv verbringen möchten. Sie bietet einen Überblick der Angebote und versucht zur Teilnahme zu motivieren. Der Broschüre dürfte es nach Meinung der Experten durchaus gelingen, die angesprochene Klientel $\mathrm{zu}$ den propagierten Aktivitäten zu motivieren. In ihrer freundlichen, gestalterisch unverfänglichen Art könnte sie im Grundsatz den richtigen Tonfall für die Ansprechgruppe treffen und ist stimmig zum kommunizierten Inhalt: Ein 
adäquates Produkt, nicht atemberaubend, aber auch nicht altmodisch. Etwas bedauert wird, dass die Broschüre keine eigene visuelle Identität entwickelt. Hierzu reichen die auffallenden ovalen Aussparungen nicht aus, ja diese werden sogar eher als störend empfunden, da sie die ansonsten klare und aufgeräumte Struktur brechen und eine fast schon bemühte Lockerheit suggerieren. Ob die heterogene Bildwelt zusätzliche Motivationsanreize schafft, wird ebenfalls in Frage gestellt - vielleicht hilft sie einfach nur dabei, sich innerhalb des Veranstaltungsprogramms zu orientieren und eine freundliche Atmosphäre zu kreieren. Die gewählte Typografie wird für sehschwache Menschen nicht als ideal beurteilt. Besonders der enge Schriftschnitt und der zu kleine Zeilenabstand sind ungünstig gewählt und die Seitenzahlen wurden an einer unüblichen Stelle «versteckt». Ansonsten wurden die Inhalte für die Altersgruppe schlüssig und übersichtlich aufbereitet und strukturiert.

Vor allem auf Ebene der Fotografie sehen die Experten Verbesserungsmöglichkeiten in Form eines klaren Bildkonzepts und einer einheitlichen Bildsprache: Durch eine gezielte und konsequente Auswahl aus dem vermutlich umfangreichen Fundus und eine gekonnte Nachbearbeitung könnten die Bilder einander optisch angenähert werden. Um die Inhalte besser darzustellen, wäre zudem eine horizontale anstelle einer vertikalen Bildformat- und Textausrichtung zu empfehlen. Schließlich würde es der Broschüre aus Sicht der Experten guttun, von stilistischen Allgemeinplätzen wegzukommen und sich stattdessen visuell stärker an der Zielgruppe auszurichten und beispielsweise auf Momente der Interaktion zu fokussieren.

\subsubsection{Semiprofessioneller Gestaltungsüberschwang: Plakat Jugendgottesdienst reformierte Kirchgemeinde Schüpfen}

Elaboration und Imperfektion: Über die Herstellungsweise dieses ungewohnt üppig ausgestalteten Kleinplakats für einen Jugendgottesdienst der reformierten Kirche Schüpfen (Abb. 72) sind sich die Experten uneinig. Für die einen handelt es sich um typische, wenn auch «überreizte» Laiengestaltung, für die anderen deutet das klar umrissene Textfeld auf die Verwendung eines professionell vorgefertigten 〈Templates〉 hin, in das sich verschiedene Inhalte einfüllen lassen und das von Laien zum Bewerben unterschiedlichster Veranstaltungen verwendet werden kann (vgl. Grafik 17). In Hinblick auf die Wahl und Anordnung der Bildund Textelemente wird kein Konzept erkennbar, weshalb das Plakat der Veranstaltung keinerlei visuelle Identität verschafft. Auch die Schriftgestaltung deutet für die Experten nicht auf eine gestalterische Ausbildung hin. Immerhin wird 


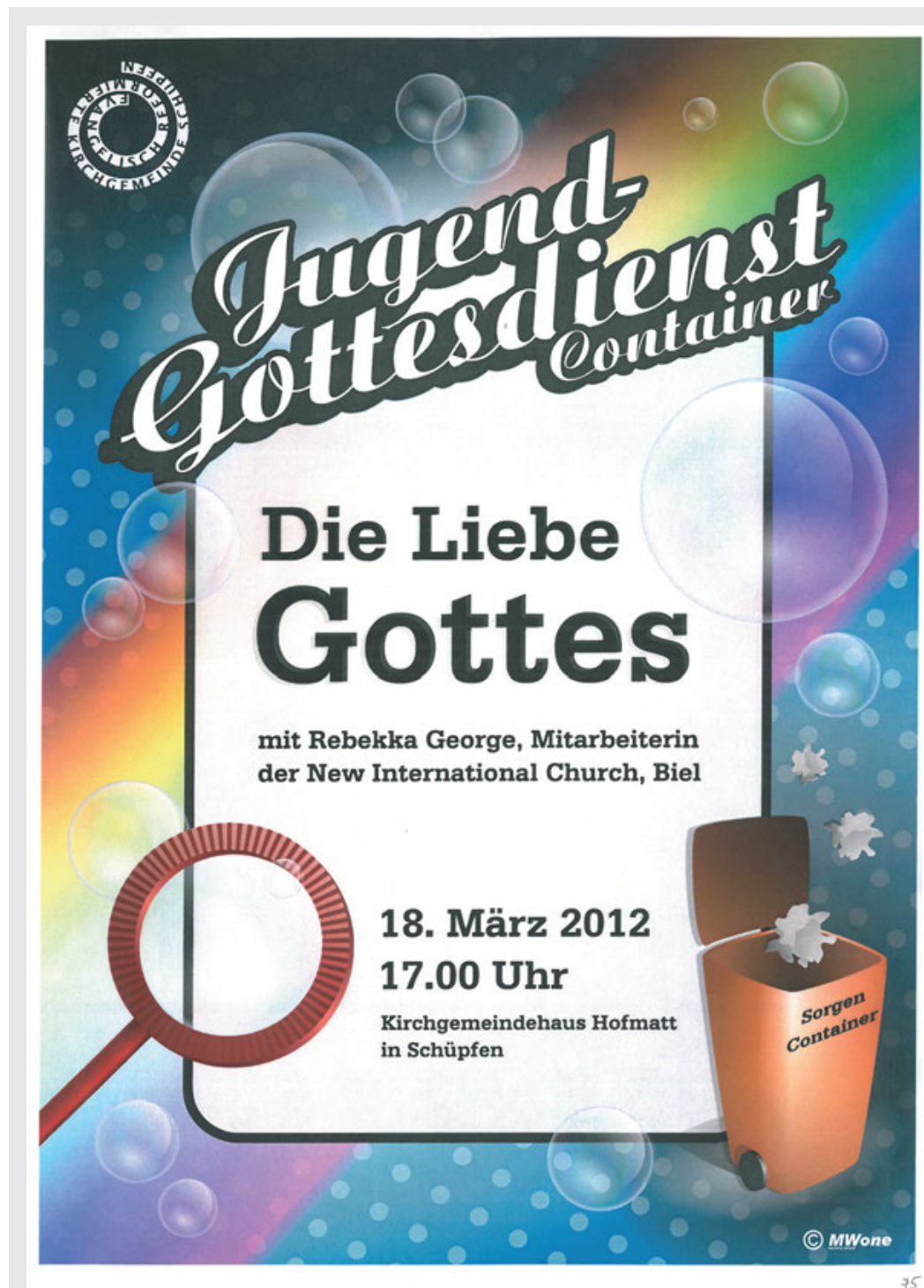

Das Kleinplakat für einen Jugendgottesdienst der reformierten Kirchgemeinde Schüpfen sticht durch seine auffallend opulente, effektreiche Hintergrundillustration in digitaler Optik aus der Masse der Kommunikationsmittel der Gemeinwesenarbeit heraus. Aufgrund der überinstrumentierten, aber zugleich konzeptlosen Machart wird das Produkt als nicht angemessen sowohl in Bezug auf die Zielgruppe als auch den Absender bewertet.

Abb. 72: Kleinplakat Jugendgottesdienst reformierte Kirchgemeinde Schüpfen 


\section{Kleinplakat Jugendgottesdienst Reformierte Kirchgemeinde Schüpfen}

\section{Formale Analyse}

\begin{tabular}{|c|c|}
\hline Art und Produktion & $\begin{array}{l}\text { Kleinplakat, Farbfotokopie einseitig, nicht randabfallend (bedingt } \\
\text { durch Reproduktionstechnik), auf Kopierpapier weiß } 80 \mathrm{~g} / \mathrm{m}^{2}\end{array}$ \\
\hline Format & DIN A4 (210 mm x $297 \mathrm{~mm})$, hoch \\
\hline Grafische Mittel & $\begin{array}{l}\text { Farbige, computergenerierte Illustration, Schrift, Textfeld mit } \\
\text { Rahmen, Wortbildmarke, Titel/Wortmarke, Signatur }\end{array}$ \\
\hline $\begin{array}{l}\text { Typografie } \\
\text { Layout } \\
\text { Gesamtanmutung }\end{array}$ & $\begin{array}{l}\text { Die stilistisch heterogene Komposition besteht zum einen aus einem } \\
\text { kursiven Script-Schriftzug mit fettem Schriftschnitt, Schattenlegung, } \\
\text { Outline und 3D-Effekt, in ca. } 25^{\circ} \text { Winkelung (Titel), einer serifenbetonten } \\
\text { Schrift (vermutlich ‘Serifa`) in fettem Schriftschnitt (Haupttext) und einer } \\
\text { Groteskschrift, die versal und spiralig gesetzt ist (Veranstalterlogo). Zum } \\
\text { anderen wird das zentral platzierte, schwarz umrahmte Textfeld von } \\
\text { einer digitalen Illustration, welche die Diagonale betont, umschlossen } \\
\text { und teilweise überlagert. In und um die Formatmitte dominiert Schrift } \\
\text { auf weißem Grund, insgesamt verhältnisgleiche Gewichtung von Bild- } \\
\text { und Textelementen. Textaussagen hierarchisch steil strukturiert und in } \\
\text { verschiedenen Schriftgrößen zu zwei linksbündigen Informationsblö- } \\
\text { cken gruppiert, der untere aufgrund der in das Textfeld hineinragenden } \\
\text { Illustration nach rechts versetzt. Anordnung ohne erkennbares Gestal- } \\
\text { tungsraster. Formatzentrierte Platzierung des Wortes ¿Gott`. Ansonsten } \\
\text { rhythmisch und proportional undifferenzierte typografische Gestaltung, } \\
\text { inkonsequenter Umgang mit Leerzeilen und Weißraum. }\end{array}$ \\
\hline
\end{tabular}

Bildinhalt Regenbogen, diverse Seifenblasen mit dazugehörigem Produktionswerk-

Topos

Figur zeug, Abfallcontainer, drei Papierknäuel. Regenbogen kann als Symbol für positive Gefühle, Harmonie, Ganzheit, Frieden, Pazifismus interpretiert werden («Peace`-Bewegung, «Greenpeace)). Seifenblasen stehen für Sorglosigkeit und Leichtigkeit. Pustet da Gott? Der Container übernimmt in metaphorischer Umkehrung die Rolle als Auffangbehälter für Sorgen. Das Punktemuster ist rein dekorativ, nimmt die runde Form und helle Farbe der Seifenblasen auf. Das Textfeld erinnert an ein Handydisplay.
Art der Bildgestaltung

Illustration mit digitalen Mitteln erstellt und stark von der eingesetzten Software beeinflusst, hohe Dichte an digitalen visuellen Effekten: weichgezeichnete Farbverläufe/Fading, Licht/Schatten, teiltransparente Flächen, überlagernde Ebenen, die Räumlichkeit suggerieren. Transparenz der Seifenblasen aufwändig modelliert, andere Elemente schematischer und z.T. missverständlich ausgearbeitet (zerknülltes Papier sieht wie Popcorn aus, Seifenblasenring platziert wie Lupe). Blaues Punktraster ergibt tapetenartigen Hintergrund, der wie ein Himmel erscheint.

Farbe
Satte Farbigkeit. Kontrast zwischen reicher, bunter Farbpalette der Illustration (Regenbogenfarben, hoher Blauanteil) und schwarzweiBem Textfeld, das in sich eine hohe Kontrastwirkung aufweist. 


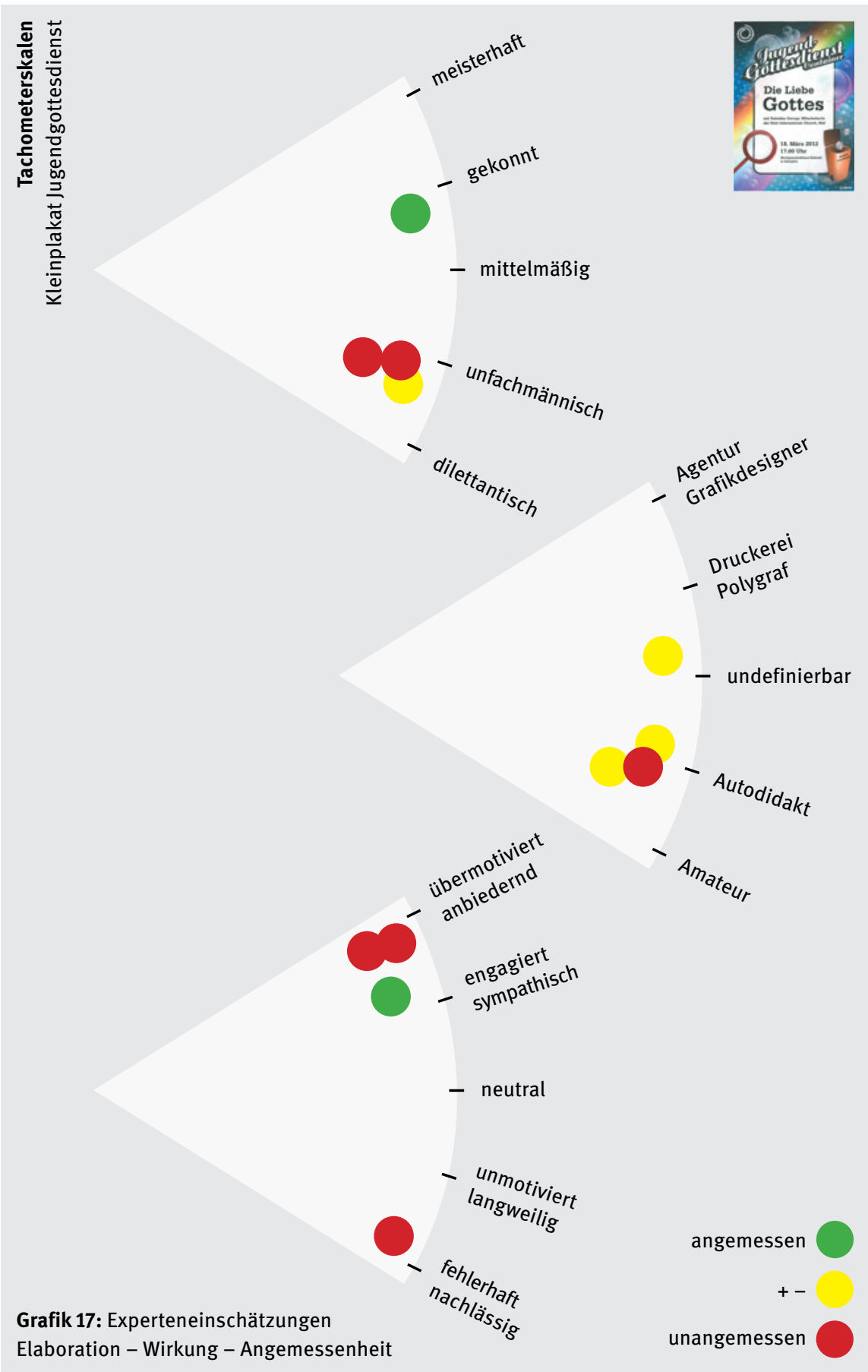


die Lesbarkeit der Information als gut eingeschätzt, da das Textfeld vom bunten Hintergrund freigestellt ist und sich kontrastreich abhebt. Mit seinen allzu großzügig eingesetzten visuellen Stilmitteln schießt das gestaltete Produkt in der Einschätzung der Gestaltungsprofis über das Ziel hinaus und lässt die eigentliche Botschaft hohl werden. Definitiv übertrieben erscheint ihnen die effektreiche Ausgestaltung der Titel. Das Veranstaltungsthema «Die Liebe Gottes〉 wird sogar vom eigenen Schatten überlagert, was aus gestalterischer Sicht überflüssig ist und unnatürlich («übernatürlich»?) wirkt. Das Produkt offenbart mehr die technischen Möglichkeiten der Software als eine eigentliche gestalterische Haltung der Designverantwortlichen. Der suboptimale Schriftenmix, der unausgewogene Umgang mit Textproportionen und das Fehlen eines Konzepts lassen vermuten, dass ein Amateur am Werk gewesen ist. Andererseits zeigt sich die Gestalterin bzw. der Gestalter offensichtlich bewandert im Generieren von Formen und Bildern wie auch im Setzen von Schwerpunkten. Die Illustrationen sprechen jedoch keine einheitliche Sprache, da sie unterschiedliche Elaborations-, Abstraktions- und Karikierungsgrade aufweisen.

Wirkungen: Das Kleinplakat mit seinen zusammengewürfelten, computergenerierten Motiven und Standardeffekten wirkt auffällig, effekthascherisch, überinstrumentiert und zugleich austauschbar, krud, nichtssagend und lieblos. Es vermittelt eine unverbindlich friedvolle bis «freikirchlerische» Atmosphäre. Die Bildaussage selbst bleibt uneindeutig und diffus. Bei den Experten führt das Plakat zu einem Abwehrreflex mit stark negativen Geschmacksurteilen: von kitschig und geschmacklos bis zu hässlich.

Wirkungsdimension und Stilhöhe: Der Versuch, Effekt zu erzeugen, wird bei diesem Plakat offensichtlich. Für die Experten stimuliert die Gestaltung «laut», in hohem Stil und affektstark die Wirkungsachse von Pathos und Ethos. Besonders auf der illustrativen Ebene beschwören die diversen opulent orchestrierten, visuell intensiven und symbolträchtigen Stilmittel eine Stimmungslage von Glück, Gemeinsamkeit und Zufriedenheit - «ähnlich der Duftorgel in Aldous Huxleys «Brave New World»». Hier soll aus Expertensicht nicht einfach nur Information vermittelt werden (Logos), ja die Art und Weise der Veranstaltung wird inhaltlich nicht einmal genauer beschrieben, sondern der Charakter von Veranstalter und Veranstaltung soll durch die Gestaltung fühlbar werden. Bezüglich konkreter Werte bleibt das Plakat auf Ethos-Ebene dennoch seltsam unbestimmt.

Angemessenheit und Empfehlungen: Mit der verwendeten Bildsprache und dem eingesetzten Farbspektrum möchte sich das Kleinplakat an ein junges Publikum richten: Junge Menschen - vor allem sorgenvolle und liebesbedürftige - sollen 
motiviert werden, den beworbenen Jugendgottesdienst $\mathrm{zu}$ besuchen. Entsprechend erkennen die Experten im Plakat die durchaus legitime Absicht, jung, frisch und auffallend zu wirken und die Kirche als "poppige» und zeitgemäße Institution zu präsentieren. Die Art und Weise, wie dies getan wird, rückt den Auftritt aus Sicht der Experten jedoch in Richtung der evangelikalen Freikirchen. Damit entspricht die Gestaltungssprache nicht dem landeskirchlichen Absender und Zielpublikum und vermutlich auch nicht dem beworbenen Anlass. In seiner Überdrehtheit spricht das Produkt weder eine jugendliche Sprache, noch behält es die nötige Distanz, um den von einer Landeskirche durchgeführten Anlass hinreichend sachlich und ernsthaft $\mathrm{zu}$ vermitteln. Letztlich sind sich die Experten jedoch uneinig, ob sich hier jemand gestalterisch über Gebühr ausgelebt hat oder ob die gewählte Gestaltungsweise die anvisierte Zielgruppe tatsächlich anspricht und somit angemessen sein könnte.

Was die Symbolik betrifft, sehen die Experten Seifenblasen eher als Symbole für die Vergänglichkeit von Hoffnungen oder gar des Lebens (etwa in VanitasBildern), was sich nur schwer mit dem Absender und dem Thema in Verbindung bringen lässt: Sollen sie Sorglosigkeit oder gar die Liebe Gottes symbolisieren? Signalisiert der Regenbogen Offenheit für Friedensliebende oder Homosexuelle? Oder dienen die Regenbogenfarben als Stilmittel, um Aufmerksamkeit zu erregen - oder wurden sie gänzlich unreflektiert und rein dekorativ eingesetzt? Sieht man von der symbolischen Besetzung der Motive ab, erachten die Experten die Bildwelt von Seifenblasen, Regenbogen und Pünktchen eher zur Ansprache von Kindern als von Jugendlichen geeignet. Auffallend ist schließlich der außerhalb dieser «ätherisch-leichten» Welt stehende 〈Sorgencontainer»: Hier wird eine Sprachmetapher in metaphorischer Umkehrung bildhaft umgesetzt.

Das Bild-Sprachspiel des Sorgencontainers wirkt zwar ein wenig gesucht und nicht besonders kreativ, hätte aus Sicht der Experten aber der Ursprung eines übergeordneten Konzepts werden können. Zumindest deutet sich hier ein Ziel der Veranstaltung an: Teilnehmende des Jugendgottesdienstes können sich von ihren Sorgen befreien. Für eine stilistische Verbesserung böte sich an, anstelle der sterilen digitalen Formen einen karikierenden oder comichaften Stil anzuwenden, um den Container witzig statt pathetisch in Szene zu setzen. Laut Experten müsse man sich bei der Bewerbung eines Jugendgottesdienstes zwischen zwei Gestaltungsoptionen entscheiden: Entweder präzise auf die Sprache der Zielgruppe eingehen oder aber ein ernstzunehmendes, seriös wirkendes Angebot machen. 


\subsubsection{Professionelle Verfehlungen: Informationskarte Kindertagesstätte «Crescendo» Bern}

Elaboration und Imperfektion: Die Informationskarte der Berner Kindertagesstätte «Crescendo〉 (Abb. 73) wurde aus technischer Sicht, sowohl fotografisch als auch gestalterisch, solide und professionell erarbeitet (vgl. Grafik 18). Dennoch lässt die auffallend sterile und unbelebte Wirkung der Infokarte, welche sich kaum mit dem Alltag einer Kita in Einklang bringen lässt, die Experten auf begrenzte konzeptuelle Fähigkeiten des Gestalters - oder auf ein mangelhaft durchgeführtes Briefing - schließen. Auch kleinere Kritikpunkte in der technischen Ausarbeitung werden angemerkt: Die Anordnung und der Beschnitt der Bilder wirkt etwas unausgereift und beliebig, weil nicht auf die Aussagen der Bildsujets geachtet wurde. Der Schrifttypeneinsatz auf der Rückseite wird für eine professionelle Gestaltungsarbeit als zu heterogen und die Druckqualität als mangelhaft beurteilt. Die Lesbarkeit der Wortmarke liegt im Grenzbereich und ihre typografische Qualität ist zweifelhaft, da sie $\mathrm{zu}$ viele Stilmittel verwendet und etwas altmodisch erscheint.

Wirkungen: Die Karte wirkt professionell, in sich stimmig, sachlich, sauber, ruhig und - insbesondere durch das starke Papier - wertig. Die schlechte Druckqualität des später hinzugefügten Texts auf der Rückseite bricht jedoch mit dieser Materialität. Die Bildwelt wird als frisch, hell, freundlich, ordentlich und aufgeräumt, die Farbstimmung als ansprechend wahrgenommen. Insgesamt kommt das Produkt mit seinen offensichtlich inszenierten Innenraumaufnahmen und sauber arrangierten Bildfeldern harmonisch, aber auch langweilig, unoriginell bis nichtssagend daher. Besonders im Kontext einer Kindertagesstätte wirke die Karte kühl, unbelebt, anonym, fast schon traurig. Das Logo fällt aufgrund typografischer Effekte besonders auf: Es enthält verschiedene Schriften, Schriftschnitte und exzentrische Einzelbuchstaben, z.B. wurde der Stamm des 〈d〉 stark nach oben verlängert und läuft rückwärts geneigt aus. Die Optik des Logos verweist laut Experten in den Bereich Soziales, könnte aber auch das Logo für ein offenes Seniorenheim oder ein musikalisches Beschäftigungsprogramm für Menschen mit Beeinträchtigung sein.

Wirkungsdimension und Stilhöhe: Mit der Vorderseite möchte die Karte offenbar die Ebenen Ethos und Pathos ansprechen, um dem Zielpublikum einen Eindruck des Charakters und der Stimmung der beworbenen Institution zu vermitteln, um dann auf der Rückseite nüchtern die entsprechenden Informationen anzugeben (Logos). Auf Ethos-Ebene gelingt es dem Absender, Werte wie Seriosität und Sauberkeit zu vermitteln. Die auf emotionaler Ebene erreichte Wirkung erscheint 


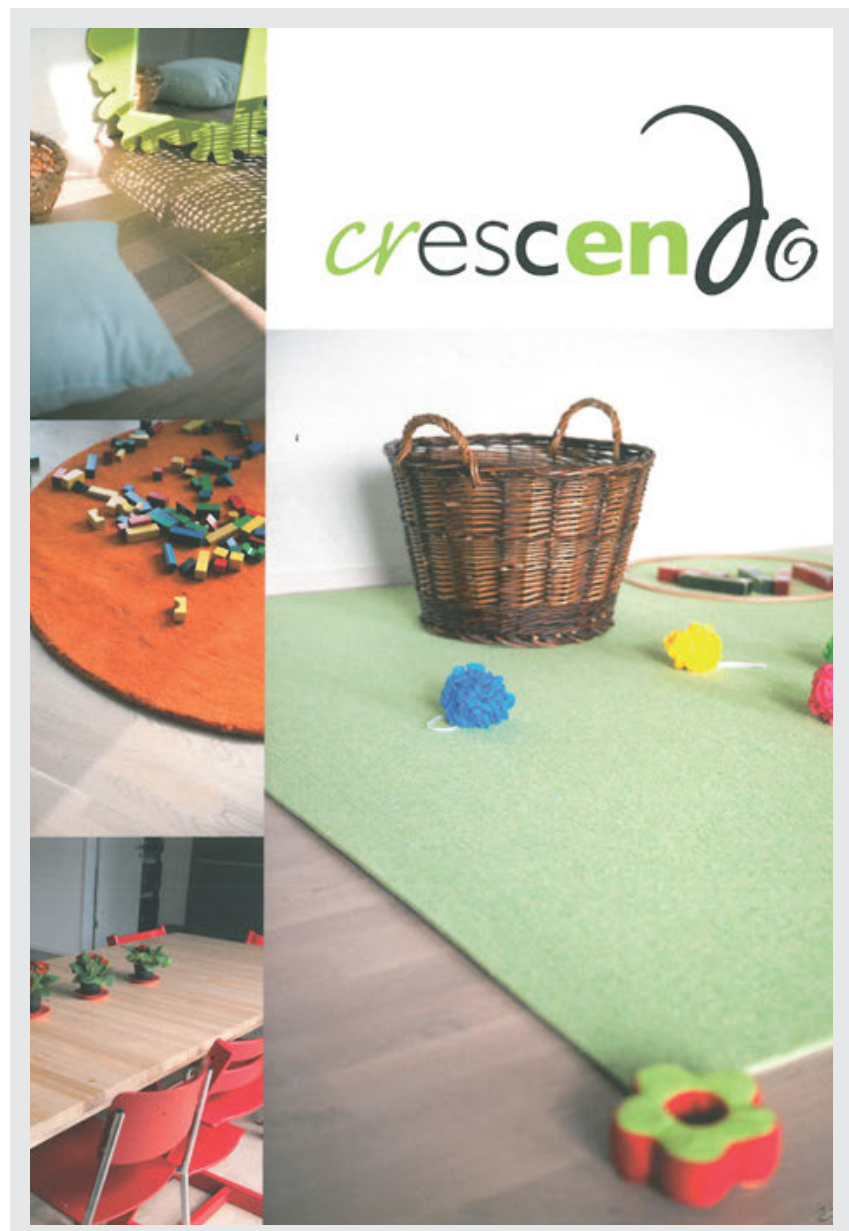

Obschon die Informationskarte einer Berner Kindertagesstätte technisch solide und professionell ausgestaltet wurde und eine harmonische, lichte Bildwelt zeigt, wird sie von den Experten als nicht angemessen bewertet. Die allzu saubere und aufgeräumte Erscheinung, die durch den ausschließlichen Fokus auf Gegenstände statt Kinder, offensichtlich inszenierte Aufnahmen und ein statisches Layout zustande kommt, führt zu einer unbelebten, sterilen Wirkung, die im Widerspruch zur lebendigen Realität einer Kita steht.

Abb. 73: Informationskarte Kita «Crescendo» Bern 


\section{Informationskarte Kindertagesstätte «Crescendo〉 Bern}

Formale Analyse

\begin{tabular}{|c|c|}
\hline Art und Produktion & $\begin{array}{l}\text { Infokarte, Offsetdruck vollflächig, doppelseitig, vierfarbig, auf } \\
\text { einseitig gestrichenem Papier/Karton } 240 \mathrm{~g} / \mathrm{m}^{2}\end{array}$ \\
\hline Format & DIN A5 (148.5 mm x $210 \mathrm{~mm})$, hoch \\
\hline Grafische Mittel & Fotografie, Wortmarke, Schrift \\
\hline $\begin{array}{l}\text { Typografie } \\
\text { Layout } \\
\text { Gesamtanmutung }\end{array}$ & $\begin{array}{l}\text { Die Vorderseite besteht aus einer hochformatigen, asymmetrischen } \\
\text { Aufteilung der Formatfläche in strengem, gut sichtbarem Gestal- } \\
\text { tungsraster mit mehreren proportional zusammenspielenden Bildflä- } \\
\text { chen und dem Absenderlogo der Kita: Im linken Drittel befinden sich } \\
\text { drei hochformatige, randabfallende, übereinanderliegende, gleich- } \\
\text { große Bildfenster, die zusammen ein vertikales Band bilden. Rechts } \\
\text { daran anstoßend bzw. steglos gesetzt ein hochformatiges, die rest- } \\
\text { liche Kartenbreite einnehmendes, unten und rechts randabfallendes } \\
\text { und vertikal über drei Viertel der Formathöhe laufendes Bildfenster. } \\
\text { Auf weißem Grund nimmt die Wortmarke in der verbleibenden quer- } \\
\text { formatigen Fläche oben rechts den übrigen Raum ein. Die Rückseite } \\
\text { besteht nur aus Text und Wortmarke: Unterhalb des Logos, das in der } \\
\text { oberen, linken Kartenecke platziert ist, kommen zwei links ausge- } \\
\text { richtete Textblöcke mit Adressangaben und Öffnungszeiten schwarz } \\
\text { auf weißem Grund zu stehen: einmal linksbündig und einmal in } \\
\text { tabellarischem Blocksatz in zwei Schriftgraden («Frutiger`normal } \\
\text { 8pt und } 12 \text { pt). Die Textinhalte sind mit Leerzeilen und Leerräumen } \\
\text { getrennt. Drei Viertel der Kartenfläche werden für handschriftliche } \\
\text { Mitteilungen oder Notizen leer gehalten. Die Wortmarke selbst fällt } \\
\text { auf durch einen zweifarbigen Schriftzug (grasgrün, schwarz) in } \\
\text { wilder Schriftenmischung, bestehend aus mehreren Schrifttypen } \\
\text { und -schnitten: «Gillı leicht bis fett, zwei verschiedene Script-Schrif- } \\
\text { ten, davon eine mit Pinseleffekt und exzentrischer Formgebung. Das } \\
\text { Logo auf der Rückseite enthält einen Markenzusatz in «Frutiger`, fett. }\end{array}$ \\
\hline $\begin{array}{l}\text { Bildinhalt } \\
\text { Topos } \\
\text { Figur }\end{array}$ & $\begin{array}{l}\text { Lichte, atmosphärische Fotografien aus verschiedenen Zonen der } \\
\text { Kita-Räumlichkeiten (Schlafen, Spielen, Essen). Gezeigt werden } \\
\text { keine Kinder, sondern Mobiliar und Spielzeug. Verschiedene Natur- } \\
\text { materialien und -farben (Körbe, Wollteppiche, Holzboden, -tisch } \\
\text { und -spielsachen) verbunden mit leuchtenden Farben und moder- } \\
\text { nen Elementen stehen für Reinlichkeit, Ordentlichkeit, Stilbewusst- } \\
\text { sein: «Hier werden Kinder zu ordentlichen Erwachsenen erzogen». }\end{array}$ \\
\hline $\begin{array}{l}\text { Art der } \\
\text { Bildgestaltung }\end{array}$ & $\begin{array}{l}\text { Sorgfältig arrangierte, inszenierte und sonnenlichtdurchflutete } \\
\text { Aufnahmen ausgewählter räumlicher Teilansichten aus Erwachse- } \\
\text { nen- und Kinderperspektive. Auffällige Wortmarke. }\end{array}$ \\
\hline Farbe & $\begin{array}{l}\text { Auf den Bildern dominieren warme Farben (Orange, Rot, Lindgrün, } \\
\text { Beige- und Brauntöne). }\end{array}$ \\
\hline
\end{tabular}




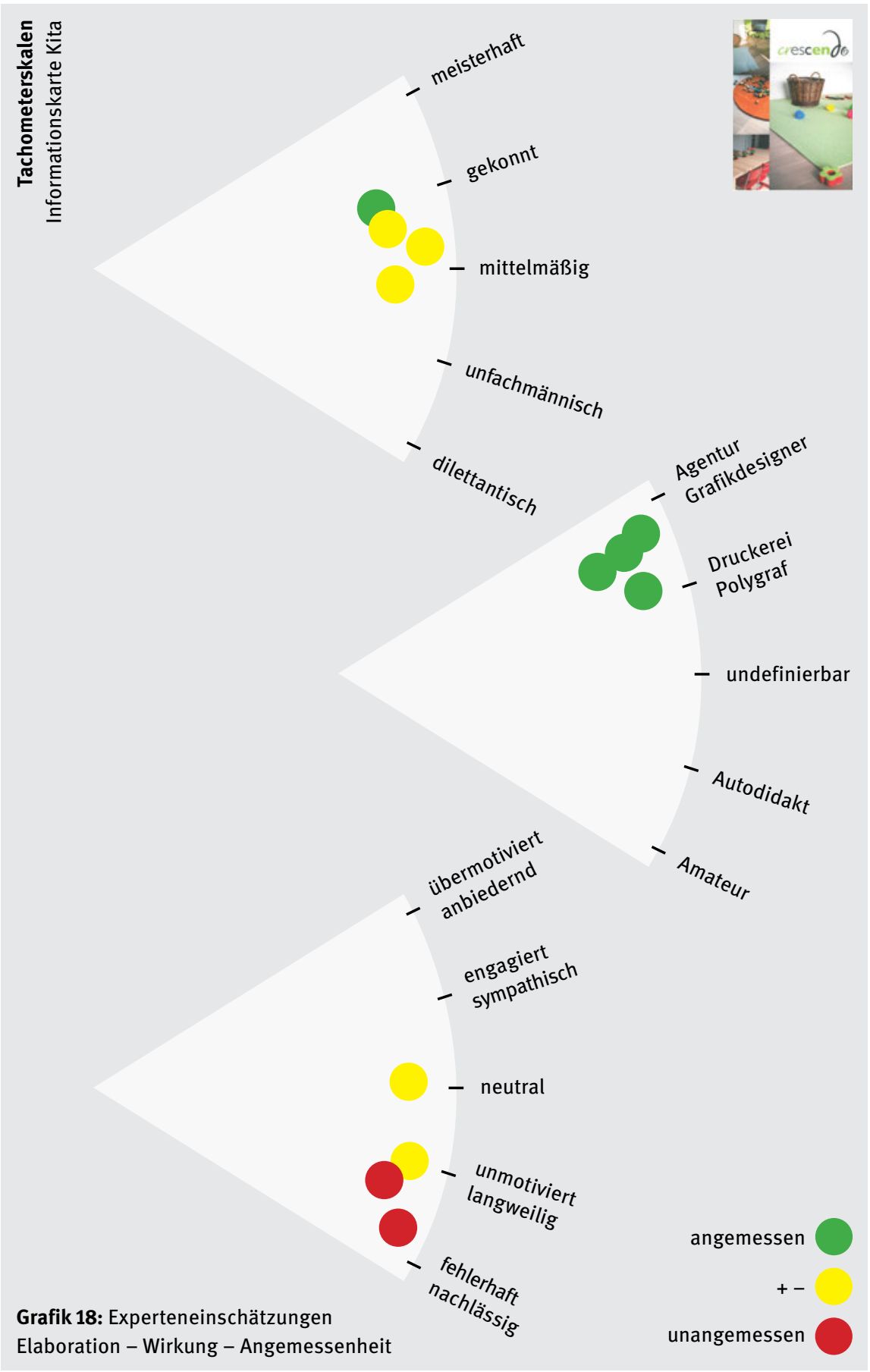


den Experten jedoch konträr zur verfolgten Absicht: Die kinderfreie, unbelebte Stimmung wirkt viel zu unterkühlt für eine Kita. Insgesamt wird die Wirkung auf der mittleren Stilhöhe verortet: Während das strenge Layout eher niedrig, sachlich und unprätentiös wirkt, zielen die abgebildeten Materialien, die Papierhaptik und die Farbharmonie auf die affektive Ebene und wirken somit etwas stärker.

Angemessenheit und Empfehlungen: Die Infokarte richtet sich an junge Eltern, die ihre Kleinkinder in einer städtischen Kindertagesstätte betreuen lassen möchten. Sie soll die Kita «Crescendo〉 im Umfeld bekannt machen und als freundliche, ordentliche und seriöse Institution herausstellen. Das Produkt spiegelt nach Einschätzung der Experten den Anspruch einer professionell agierenden Organisation, die über Einnahmen und Werbemittel verfügt. Dadurch hebt sie sich von der Mehrzahl der Kommunikationsmittel aus der Gemeinwesenarbeit ab, die auf Arbeiten von Freiwilligen und sozialem Engagement aufbauen. Die angestrebte Professionalität wird zwar technisch erreicht, doch die künstlich arrangierte, aufgeräumte Bildsprache und die strenge Anordnung in einem Raster verhindert die Vermittlung von Lebendigkeit und Geborgenheit, die man von einer Kindertagesstätte erwarten würde. Die Hauptakteure einer Kita, die Kinder, werden auf der Karte nicht gezeigt - ja nicht einmal eine Spur ihrer Anwesenheit oder tatsächlichen Aktivitäten wird sichtbar. Trotz der gezeigten Materialien mit stark taktiler Wirkung, der gelungenen Farbharmonie und des freundlichen Lichts wirkt das Resultat steril und lässt sich kaum mit einer Kita in Übereinstimmung bringen. Eher könnte man als Absender ein Inneneinrichtungsgeschäft vermuten, allenfalls ein Heim für Senioren oder Menschen mit Beeinträchtigung. Der Versuch, durch den Schriftenmix die «anarchische Kreativität» der Kinder zu repräsentieren, scheitert daran, dass sämtliche Schriftzeichen «brav» auf gleicher Schriftlinie und mit angeglichenen Größen abgebildet wurden. Der musikalisch geprägte Begriff «Crescendo〉 lockt ebenfalls auf eine falsche Fährte. Trotz ihrer professionellen technischen Ausarbeitung muss die Werbekarte folglich als gescheitert und unangemessen betrachtet werden. Selbst wenn es die Absicht der Absenderinstitution wäre, Eltern mit bürgerlichem Niveau anzusprechen, die ihre Kinder ohne Umwege zu verantwortungsbewussten Erwachsenen erziehen lassen wollen, dürfte sich die Kundschaft nach Meinung der Experten ein emotionaleres und lebendigeres Produkt wünschen.

Um die Gestaltung adäquater umzusetzen, wird deshalb unbedingt empfohlen, mehr Individualität, Lebendigkeit und Authentizität in die Bildwelt hineinzubringen, um Sympathie und Glaubwürdigkeit für die Absenderinstitution zu erlangen. Dies wäre etwa durch Fotos spielender Kinder erreichbar. Auch könnten Bilder von Kinderzeichnungen an den Wänden, gefüllten Gläsern auf dem Tisch und echten Spielzeugkonstellationen gezeigt werden, die von der Präsenz der 
Kinder zeugen. Das rigide Festhalten an den formalen Regeln des klassischen Modernismus bzw. seine Überführung in eine zeitgenössische Ästhetik (humanistische Grotesk statt Akzidenz Grotesk, stegloses Layout statt Quadratraster) erscheint den Experten in diesem Kontext unnötig oder gar kontraproduktiv.

\subsection{Gestaltungsspielraum Elaboration und Imperfektion}

Zum Abschluss der Designanalyse soll versucht werden, aus den 'Tachometerskalen`, die für jedes der zwölf Artefakte der Detailanalyse erstellt wurden, das Spektrum der Angemessenheit für Kommunikationsmittel in den Bereichen Lokalpolitik und Gemeinwesenarbeit abzuleiten. Durch die Überlagerung der Experteneinschätzungen zu den Artefakten lässt sich der Gestaltungsspielraum für die Elaborationsgrade (Professionalität, technische Ausarbeitung und Sorgfalt) ablesen, die in diesen Bereichen als angemessen angesehen werden können. Das Gesamtbild, das sich auf diese Weise ergibt, ist auf den nachfolgenden Grafiken zu sehen (Grafiken 19 bis 22). Vier wesentliche Befunde der Designanalyse werden durch die grafische Darstellung besonders gut erkennbar:

- Die Toleranz für wenig gekonnte bis dilettantische, nicht professionelle oder wenig engagierte grafische Gestaltung ist im Bereich der Gemeinwesenarbeit deutlich größer als in der lokalpolitischen Kommunikation.

- Lokalpolitische Kommunikationsmittel müssen nicht zwingend hochprofessionell oder engagiert gestaltet sein: Es existiert ein Spielraum für mittelmäßige, wenig inspirierte Arbeit.

- In der Gemeinwesenarbeit besteht selbst unter Gestaltungsexperten eine Ambivalenz in der Beurteilung offensichtlich «schlecht» gestalteter Entwürfe. Sie sind sich uneinig, ob bestimmte gestalterische Dilettantismen als zielgruppennah oder als unseriös einzuschätzen sind.

- Nicht nur in der Lokalpolitik, sondern auch in der Gemeinwesenarbeit werden allzu unsorgfältige und fehlerhafte sowie übermotivierte Arbeiten klar als unangemessen beurteilt. 



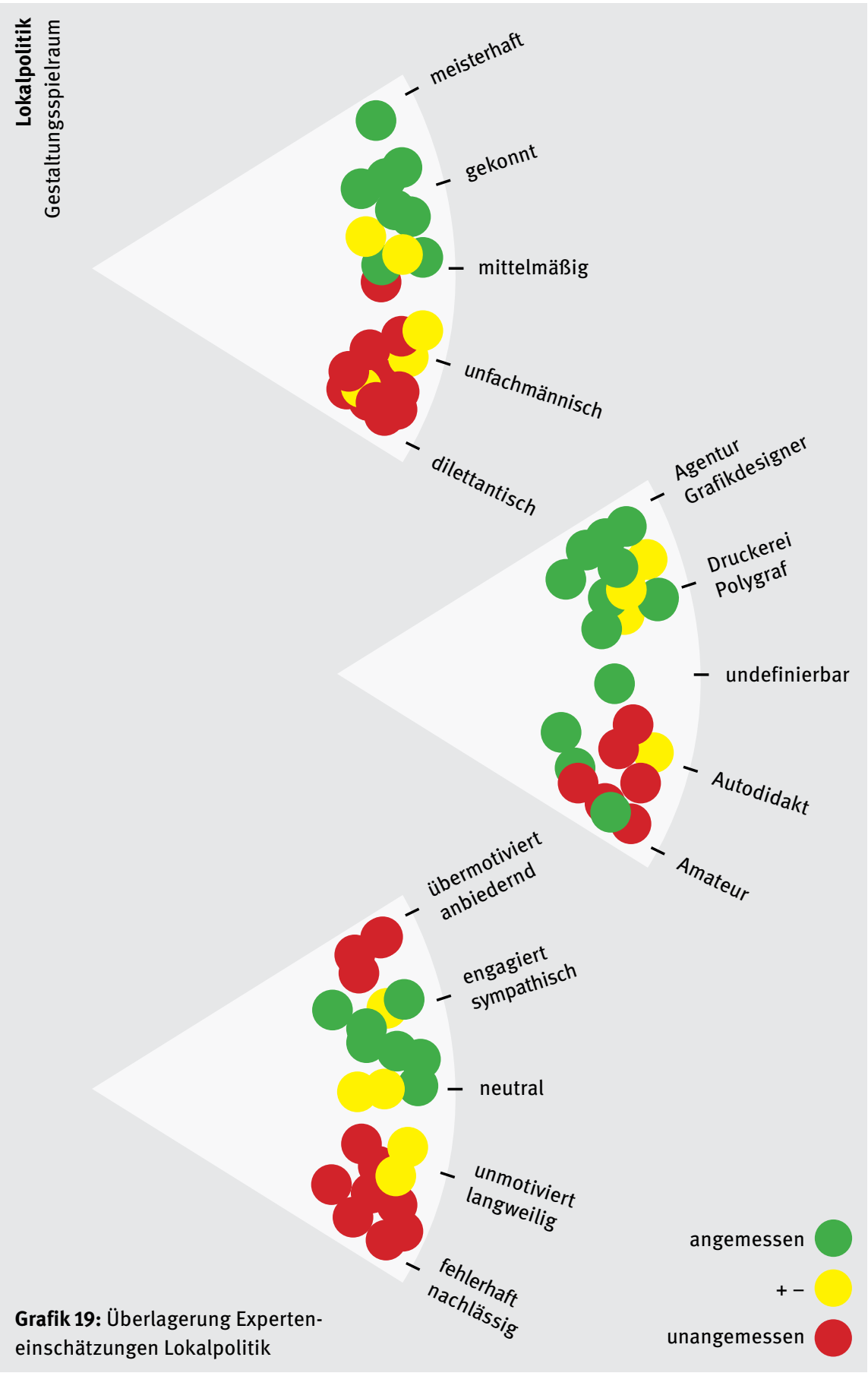




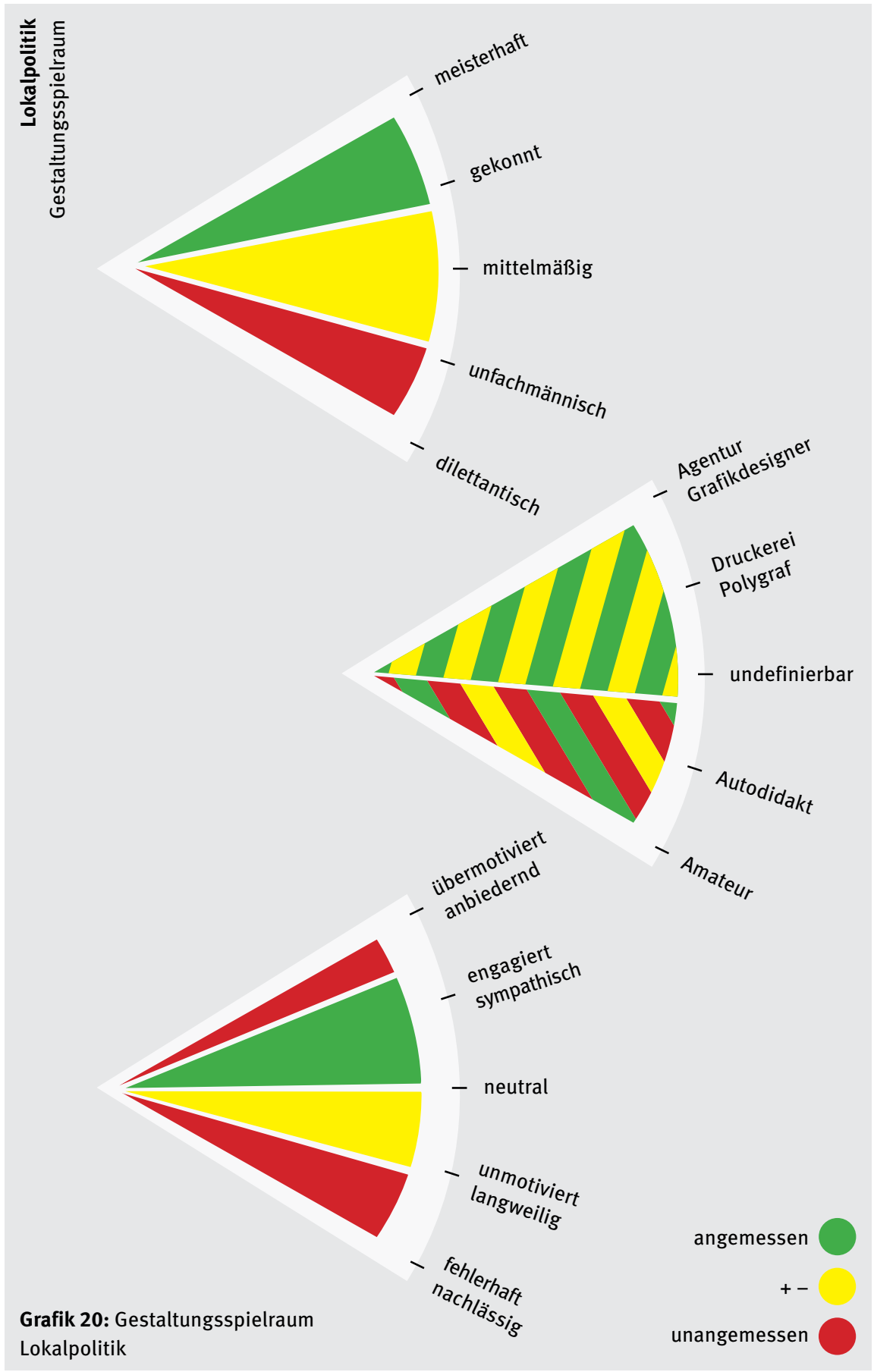




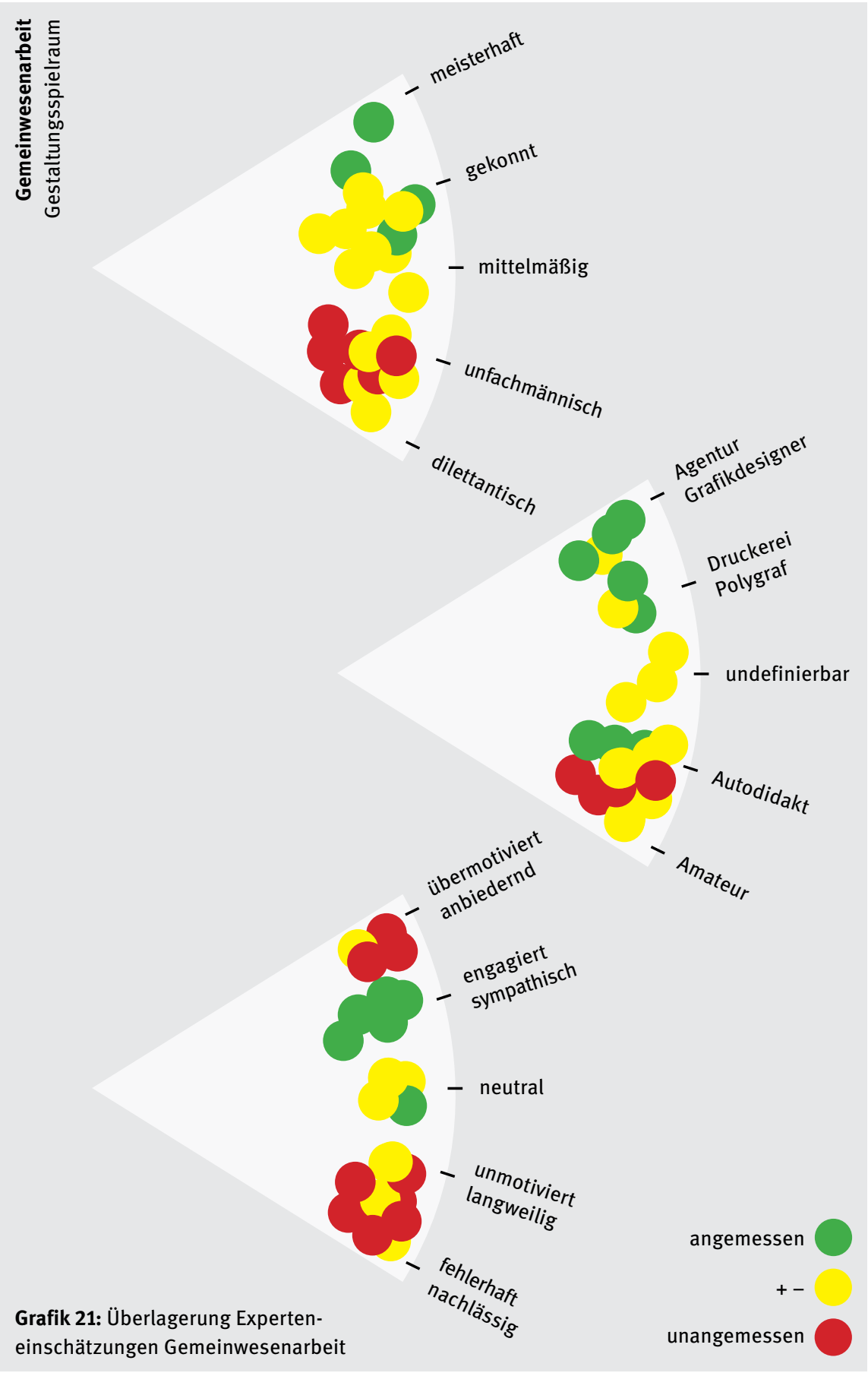




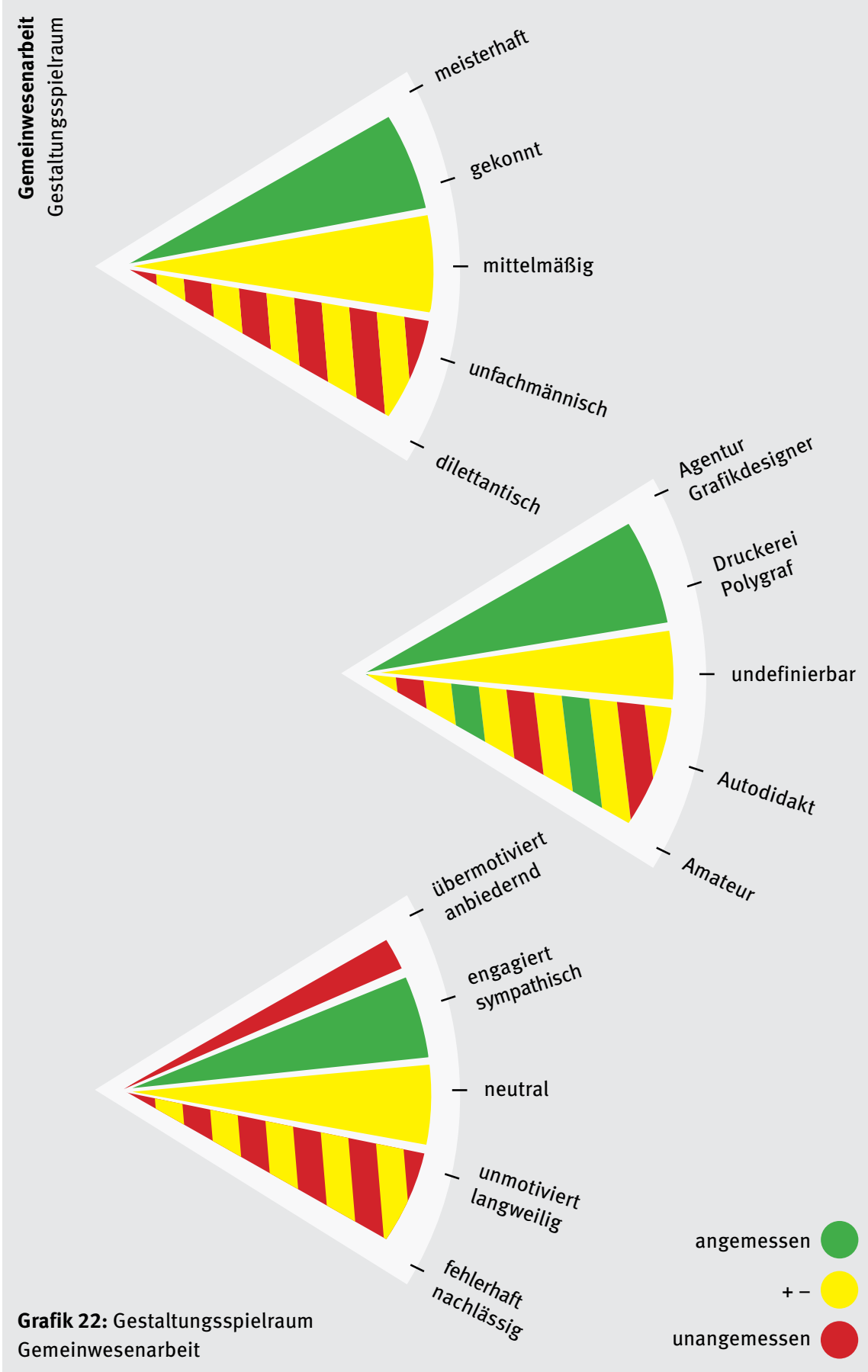


